Report No. 37820

\title{
Crime, Violence, and Development: Trends, Costs, and Policy Options in the Caribbean
}

March 2007

A Joint Report by the United Nations Office on Drugs and Crime and the Latin America and the Caribbean Region of the World Bank

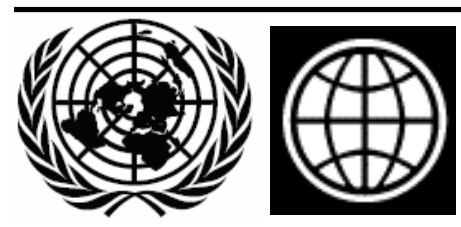




\section{ACRONYMS AND ABBREVIATIONS}

$\begin{array}{ll}\text { ADR } & \text { Alternative Dispute Resolution } \\ \text { CEM } & \text { Country Economic Memorandum } \\ \text { CFATF } & \text { Caribbean Financial Action Task Force } \\ \text { CGNAA } & \text { COSAT Guard for the Netherlands Antilles and Aruba } \\ \text { CONANI } & \text { Consejo Nacional de la Niñez } \\ \text { CPI } & \text { Corruption Perceptions Index } \\ \text { CPTED } & \text { Crime Prevention Through Environmental Design } \\ \text { CTS } & \text { Crime Trends Surveys - United Nations } \\ \text { DALYs } & \text { Disability-Adjusted Life Years } \\ \text { DHS } & \text { Department of Homeland Security } \\ \text { EBA } & \text { Educación Básica para Adultos y Jóvenes } \\ \text { ECLAC } & \text { Economic Commission for Latin America and the Caribbean } \\ \text { ENHOGAR } & \text { Encuesta Nacional de Hogares de Propósitos Múltiples } \\ \text { EU/LAC } & \text { European Union/Latin American and the Caribbean } \\ \text { FARC } & \text { Fuerzas Armadas Revolucionarias de Colombia } \\ \text { GDP } & \text { Gross Domestic Product } \\ \text { ICS } & \text { Investment Climate Survey } \\ \text { ICVS } & \text { International Crime Victims Survey } \\ \text { LAC } & \text { Latin America and Caribbean } \\ \text { OECS } & \text { Organization of Eastern Caribbean States } \\ \text { PATH } & \text { Program for Appropriate Technology in Health } \\ \text { RNN } & \text { Royal Navy of the Netherlands } \\ \text { RSS } & \text { Regional Security System } \\ \text { RTFCS } & \text { Regional Task Force on Crime and Security } \\ \text { UNODC } & \text { United Nations Office on Drugs and Crime } \\ \text { WDR } & \text { World Development Report } \\ \text { WHO } & \text { World Health Organization } \\ & \end{array}$

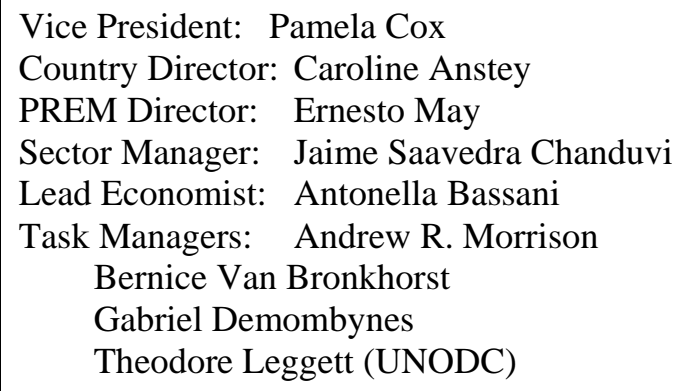




\section{TABLE OF CONTENTS}

Preface

\section{Acknowledgments}

Executive Summary

Chapter 1. Conventional Crime: an Overview___ 1

The Diversity of the Caribbean___ 2

How to Measure Crime? __ 4

Homicide and Assault _ 7

Violence Against Women _ 12

Property Crime__ 13

Chapter 2. Organized Crime __ 15

Drug Trafficking _ 15

Other Forms of Organized Crime: Kidnapping, Money Laundering, Corruption___ 21

Chapter 3. Risk Factors for Crime and Violence___ 26

Conceptual Foundations of Risk Factors for Crime and Violence __ 26

Macro Analysis of Risk Factors for Crime in the World and the Caribbean___ 27

Risk Factors for Crime at the Household Level: Evidence from

Three Caribbean Countries___ 34

Policy Implications _

Chapter 4. Socioeconomic Costs of Crime

Approaches to Measuring the Costs of Crime and Violence __ 42

Specific Costs of Crime__ 43

Total Costs: Estimates Using an Accounting Approach ___ $\mathbf{5 0}$

Disability-Adjusted Life Years Lost to Violence ___ 53

The Impact of Victimization on Self-Reported Life Satisfaction__ $\mathbf{5 6}$

The Impact of Violent Crime on Economic Growth _ 57

Policy Implications _ 59

Chapter 5. Youth Violence in the Caribbean: A Case Study of the Dominican Republic___ 61

Scope of Youth Crime and Violence _ 62

Factors Contributing to Youth Violence __ 67

Policy Recommendations for Strengthening the Response to Youth Violence____ 73

Conclusions — 79

Chapter 6. Case Study: Criminal Deportations and Jamaica __ 81

The Scale of the Expatriate Population _ 83

Criminal Deportation__ 84

Policy Implications _ 91

Chapter 7. Case Study: Drug Trafficking and the Netherlands Antilles___ 93

Drug Trafficking on Commercial Air Flights: an Innovative Policy Response ___ 96

Maritime Trafficking 101

Policy Implications _ 102 
Chapter 8. The Contributions of Criminal Justice Systems to the Control of Crime and

Violence: A Case Study of Jamaica and the Dominican Republic

Introduction: Criminal Justice Reform in Civil and Common Law System __ 105

Country Cases: Two Approaches to Criminal Justice Reform __ 108

A Quantitative Evaluation of System Performance: Performance Statistics

and Indicators

112

Measuring the System's Workload: Reported Offenses ___ 113

Institutional Performance Measures _ 114

Impact Indicators: Using Crime and Arrest Data for Crime Prevention___ 122

Conclusion: From Organizational Reform and Performance Measurement to

Interagency Governance __ 126

Chapter 9. Guns and Crime: A Case Study of Trinidad and Tobago __ 128

Sources 130

Registration of Firearms and Seizures of Illegal Weapons ___ 131

Demand__ 132

Victims, Perpetrators and their Environment__ 132

Drug Trafficking and Gun-Related Criminality _ـ 133

Policy Implications _ 136

Chapter 10. Public Policy of Crime and Violence Prevention: Regional and

National Approaches _ 141

Sectoral and Cross-Sectoral Approaches

Regional Initiatives to Address Crime and Violence _ 145

Priority Steps to Achieve Reductions in Crime and Violence in the Caribbean ___ 149

References _ 141

Annexes

\section{FIGURES}

Figure 1.1: Ranking of Caribbean Countries in the Human Development Index ------------------------------- 3

Figure 1.2: Population Distribution of the Independent Caribbean ---------------------------------------- 3

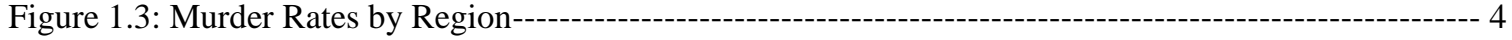

Figure 1.4: Murders per 100,000 Population by Year, Anguilla ---------------------------------------------------- 6

Figure 1.5: Number of Murders in Guyana, Police and Public Health Sources ------------------------------ 7

Figure 1.6: Deaths Rates from Violence in Caribbean and Comparison Countries ------------------------------ 9

Figure 1.7: Homicides per 100,000 in Guyana and Jamaica----------------------------------------------------10

Figure 1.8: Homicides Rates in the Dominican Republic, St. Lucia and Trinidad and Tobago: 1999-2005 11

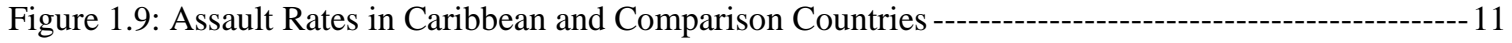

Figure 1.10: Rape Rates in Caribbean and Comparison Countries -----------------------------------------------12

Figure 2.1: Cannabis Eradication in Jamaica -----------------------------------------------------------------------17

Figure 2.2: Shares of Cocaine Flowing to the United States by Transport Corridors -------------------------17

Figure 2.3: Origin of Heroin Seized in the United States -----------------------------------------------------19

Figure 2.4: Kidnappings per 100,000 Population in Trinidad and Tobago ---------------------------------------23

Figure 3.1: Ecological Model for Understanding Crime and Violence ---------------------------------------27

Figure 3.2: Cross-Country Correlates of Crime -------------------------------------------------------------29

Figure 3.3: Robbery Rates vs. Mean Consumption by Neighborhood --------------------------------------------36

Figure 3.4: Distribution of Victimization by Crime and Quintile in Haiti ----------------------------------------37 
Figure 4.1: Responses to Fear of Crime in Dominican Republic -What Do People Stop Doing

Due to Fear? ------- 44

Figure 4.2: Responses to Fear of Crime in Haiti: Where Do People Stop Going Due to Fear? ----------------45

Figure 4.3: Impact of Crime on Various Business Practices in Jamaica ------------------------------------47

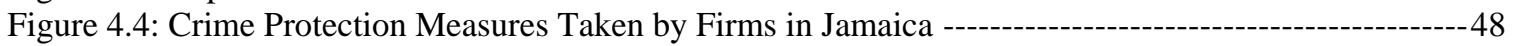

Figure 4.5: Private Security Costs for Firms by Size of Enterprise as Percentage of Firm Revenue

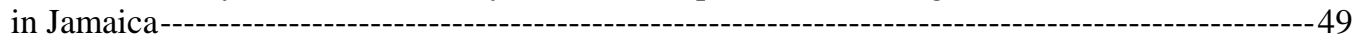

Figure 4.6: Crime Protection Measures Taken by Firms in the Dominican Republic ------------------------49

Figure 4.7: Impact of Higher Crime on Businesses in the Dominican Republic ---------------------------50

Figure 4.8: How Reliable is WHO Homicide Information for the Caribbean? Homicide Rates

According to WHO vs. Official Sources Homicide Deaths per 100,000 Population -------------54

Figure 4.9: Disability-Adjusted Life Years Lost to Violence in the Caribbean, 2002-------------------------55

Figure 4.10: Disability-Adjusted Life Years Lost to Violence vs. Other Causes Caribbean 2002 -----------55

Figure 4.11 Potential Boost to Annual Economic Growth Rate from Reducing Homicide Rate to

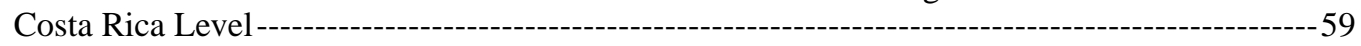

Figure 5.1: Homicide Deaths by Age (10-29) in the Dominican Republic (2000-2005)-------------------65

Figure 5.2: Trends of Minor Arrest over Past Decade in the Dominican Republic--------------------------66

Figure 6.1: Number of Deportees and Number of Murders in Jamaica --------------------------------82

Figure 6.2: Caribbean-Born Populations in the United States-------------------------------------84

Figure 6.3: Total Criminal Deportations from the U.S. to the Caribbean-----------------------------------85

Figure 6.4: Criminal Deportees from the U.S. per 100,000 Population of Home Country -------------------86

Figure 6.5: Total Criminal Deportations to Jamaica: 1998-2004 ---------on

Figure 6.6: Drug Deportations to Jamaica from the United States and the United Kingdom -----------------87

Figure 6.7: Breakdown of Criminal Deportees by Crime Type, All Three Source Countries, 2001-2004 --88

Figure 6.8: Age on Arrival in the U.S. of Jamaican Criminal Deportees (Percent of Headley's Sample) - 889

Figure 6.9: Age on Deportation from the U.S. of Jamaican Criminal Deportees (Percent of Headley's

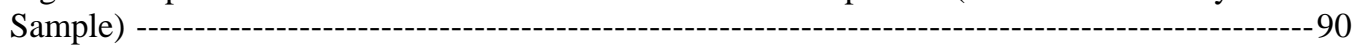

Figure 7.1: Kilograms of Cocaine Seized in Caribbean Territories in 2004 -------------------------------------95

Figure 7.2: Kilos of Cocaine Seized in the Netherlands Antilles, 1980-2004 ----------------------------------96

Figure 7.3: Couriers Detected arriving at Schiphol from Curacao, by quarter ---------------------------------99

Figure 7.4: Cocaine Seizures in Trinidad and Tobago ---------------------------------------------- 103

Figure 8.1: Sentenced and Unsentenced Prison Inmates, Dominican Republic, May 2003 to May 2006 - 119

Figure 8.2: Prison Deaths, Escapes, and Recaptures, Dominican Republic ----ons 120

Figure 8.3: Unnatural Deaths and Violent Incidents in Jamaican Prisons, 2000-2005------------------- 121

Figure 9.1: Distribution of Injury Deaths by Type of Injury: Trinidad and Tobago, 1999-2003 ---------- 129

Figure 9.2: Police Reports of Narcotics Possession and Murders, and Certified Firearm Homicides:

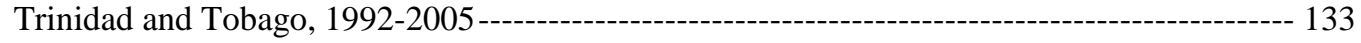

\section{BOXES}

Box 1.1 Crime Definitions ------------------------------------------------------------------------------------ 5

Box 2.1: Financial Fraud in the Dominican Republic - The Baninter Case ----------------------------------25

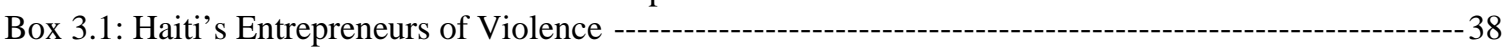

Box 5.1: The Sophisticated Extortion of Santo Domingo Gangs and Drug Lords-------------------------67

Box 8.1: Using Crime Data and Analysis to Formulate a Multi-Sectoral Crime Prevention Strategy:

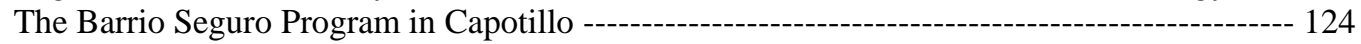

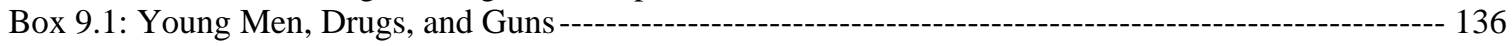

Box 9.2: UN Resolution and Plan of Action on Small Arms and Light Weapons------------------------- 139

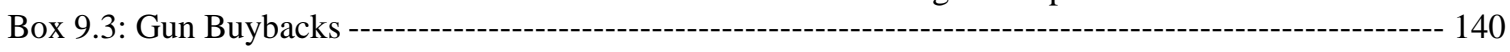

Box 10.1. Crime and Violence Prevention Components in Bank-Financed Integrated Slum Upgrading Operations - Jamaica Inner Cities Basic Services for the Poor Project----------------------- 146

Box 10.2. The Pride in Gonzales Initiative, Port of Spain, Trinidad and Tobago: A Community-Driven

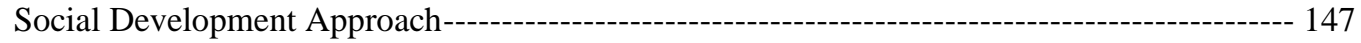

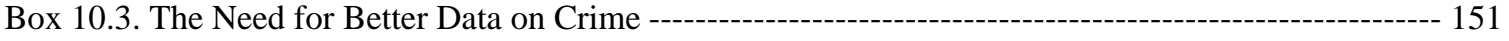




\section{TABLES}

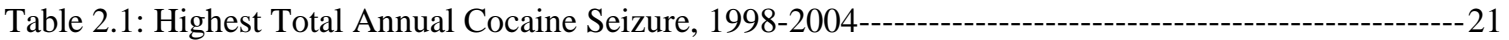

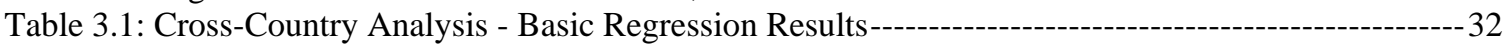

Table 3.2: Summary of Micro-Analysis of Risk Factors for Criminal Victimization -------------------------35

Table 4.1: Effects of Lifetime Physical Violence by Intimate Partner in Haiti ------------------------------46

Table 4.2: The Costs of Crime in Jamaica: an Accounting Exercise -------------------------------52

Table 4.3: Cross-Country Regression Estimate of the Effect of Violent Crime on Economic Growth ------58

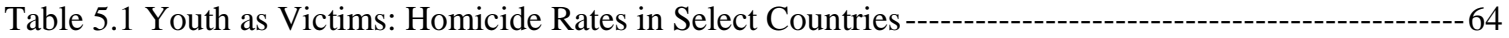

Table 5.2: Highlights of Youth in Numbers in Latin America and the Caribbean--------------------------69

Table 5.3: Violence Prevention Strategies by Developmental Stage and Ecological Context ---------------- 76

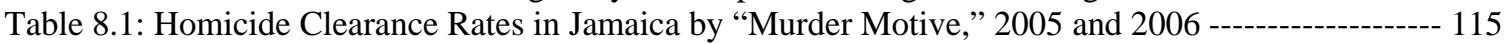

Table 9.1: Murders Committed in Trinidad and Tobago Using a Firearm, 2001-2006 --------------------- 129

Table 9.2: Woundings Committed in Trinidad and Tobago Utilizing a Firearm, 2000-2005 --------------- 130

Table 9.3: Firearm Seizures in Trinidad and Tobago------------------------------------------ 132

Table 9.4: Modified Haddon Matrix Applied to the Analysis of Gun-Related Criminality (GRC) -------- 135

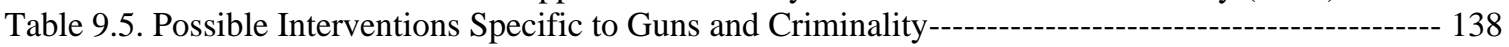

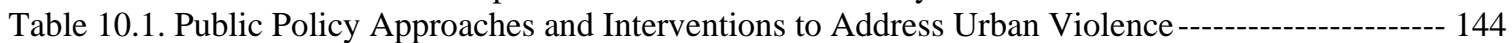

\section{ANNEXES}

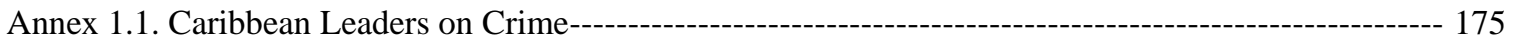

Annex 1.2. Tourism and the Caribbean Economy --------------------------------------------------------------- 175

Annex 1.3. Emigration and Crime --------------------------------------------------------------------- 175

Annex 1.4. Caribbean Police Forces and Prison Populations------------------------------------------------ 176

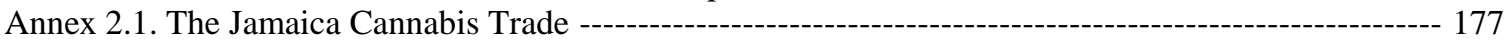

Annex 2.2. Patterns of Drug Transshipment by Organized Criminal Groups ---------------------------- 177

Annex 2.3. Dates of large Seizures of Cocaine Entering Canada from Caribbean Countries 2004 -----o-- 178

Annex 2.4. Organized Crime in Jamaica and the Dominican Republic ---o---on 178

Annex 2.5. Jamaat-al-Muslimeen in Trinidad and Tobago ----------------------------------------- 179

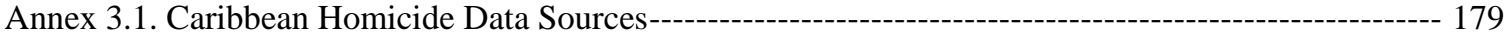

Annex 4.1. Impact of Crime Victimization on Satisfaction with Life------------------------------------ 184

Annex 5.1. Risk Factors and Policy Responses to Youth Violence in the Dominican Republic----------- 185

Annex 5.2. Inventory of Governmental Initiatives for Youth Violence Prevention in the Dominican Republic --------------------------------------------------------------- 188

Annex 5.3. Inventory of Civil Society Initiatives for Youth Violence Prevention in the Dominican Republic -------------------------------------------------------------- 193

Annex 6.1. Criminal Deportations to Jamaica by Year, Offence, and Sending Country--------------------- 199 


\section{PREFACE}

This report is the result of a fruitful collaboration between the United Nations Office on Drugs and Crime (UNODC) and the World Bank. It addresses the issue of crime and violence in the Caribbean, a complex problem that prejudices both the social and economic development of the region.

The Governments of the Caribbean countries recognize the seriousness of the problem and are exploring innovative policy responses at both the national and regional levels. Civil society organizations are doing their part as well by designing and implementing violence prevention programs targeting youth violence, violence against women, and other important forms of violence.

Much, however, remains to be done. Some of the factors that make the Caribbean most vulnerable to crime and violence-the drug trade and trafficking of weapons are two important examples-require a response that transcends national and even regional boundaries. Also, promising initiatives at the national level must be evaluated for effectiveness so that scarce resources can be efficiently invested.

This report is offered as a contribution to the ongoing dialogue in the region on approaches to address crime and violence. It is not intended to provide a definitive blueprint for action, but rather is offered as a tool to engage stakeholders-governments, civil society organizations, citizens, and international partners-in a serious dialogue on crime and violence, based on evidence and good practices from inside and outside the region.

Francis Maertens

Director, Division for Policy

Analysis and Public Affairs

UNODC
Caroline Anstey

Country Director for the Caribbean

World Bank 


\section{ACKNOWLEDGMENTS}

This report is a joint product of the United National Office of Drugs and Crime (UNODC) and the World Bank. The multisectoral team was led by Theodore Leggett (UNODC), Bernice van Bronkhorst (LCSFU), Gabriel Demombynes (LCSPP), and Andrew Morrison (PRMGE). Individual chapters were prepared by Mr. Leggett (overview chapters, criminal deportees in Jamaica, narcotics trafficking in the Netherlands Antilles), Mr. Demombynes (risk factors and costs), Linda McGinnis and Peter Holland (HDNCY: youth in the Dominican Republic), and Ms. van Bronkhorst and Mr. Morrison (public policy). The criminal justice chapter was written by Linn Hammergren (LCSPS) and Stephanie Ann Kuttner (SDV), based on a background paper on criminal justice prepared by Todd Foglesong (Vera Institute of Justice) and Christopher Stone (Harvard University). The firearms chapter was written by Bernice van Bronkhorst, Andrew Morrison, and Theodore Leggett, based on a background paper prepared by Yvette Holder (independent consultant) and Folade Mutota (Women's Institute for Alternative Development, Trinidad and Tobago). The team benefited from significant contributions from Ana Maria Diaz (LCSPP) and Mariel Fiat (LCCDO), as well as the excellent assistance of Ane Perez Orsi de Castro (LCSPP) in the preparation of the final report. The team would also like to thank the following individuals for their contributions: Lisa Bhansali, Teresa Genta-Fons, Lillian Mallet Crawford Abbensetts, Willy Egset, Dorte Verner, and Christina Malmberg Calvo.

The team is very grateful for the work and insightful comments of its External Advisory Committee, chaired by Professor Anthony Harriott (Professor, University of the West Indies-Mona, Jamaica) and comprised of Dr. Franklin Almeyda (Minister of the Interior and Police, Dominican Republic), Mr. George de Peana (General Secretary, Caribbean Congress of Labor, Barbados), Professor Ramesh Deosaran (Director, Center for Criminology and Criminal Justice, University of the West Indies-St. Augustine, Trinidad and Tobago), Dr. Len Ishmael (Director General, OECS Secretariat, St. Lucia), Colonel Trevor MacMillan (Chairman, Standing Committee on National Security of the Private Sector Organization of Jamaica), the Honorable Dale D. Marshall (Attorney General, Barbados), and the Honorable Gail Teixeira (Special Advisor to the President and Director, Governance Unit, Office of the Presidency, Guyana).

This task was guided and supervised by Jaime Saavedra (Sector Manager, LCSPR) and Antonella Bassani (Lead Economist, LCSPR). The peer reviewers were Pablo Fajnzylber (LCSFR), Wendy Cunningham (LCSHS), and Anthony Harriott (University of the West Indies, Mona Campus). 


\section{EXECUTIVE SUMMARY}

In his 2006 New Year's address as then prime minister of Jamaica, P.J. Patterson said, "Without a doubt, the high level of violent crime remains our most troubling and pressing problem." In opening the Parliament of Trinidad and Tobago in September 2005, President George Maxwell Richards said the country was in crisis due to the escalating crime rate. Through multiple channels, crime and violence threaten the welfare of Caribbean citizens. Beyond the direct effect on victims, crime and violence inflict widespread costs, generating a climate of fear for all citizens and diminishing economic growth. Crime and violence present one of the paramount challenges to development in the Caribbean.

Several factors which cut across the diverse countries of the region heighten their vulnerability to crime and violence. Primary among these is the region's vulnerability to drug trafficking. Wedged between the world's source of cocaine to the south and its primary consumer markets to the north, the Caribbean is the transit point for a torrent of narcotics, with a street value that exceeds the value of the entire legal economy. Compounding their difficulties, Caribbean countries have large coastlines and territorial waters and many have weak criminal justice systems that are easily overwhelmed.

Key messages and recommendations from the report include the following:

1) Crime and violence are a development issue. The high rates of crime and violence in the region have both direct effects on human welfare in the short-run and longer run effects on economic growth and social development. Estimates suggest that were Jamaica and Haiti to reduce their rates of homicide to the level of Costa Rica, each country would see an increase in its growth rate of 5.4 percent annually.

2) While levels of crime and associated circumstances vary by country, the strongest explanation for the relatively high rates of crime and violence rates in the region-and their apparent rise in recent years-is narcotics trafficking. The drug trade drives crime in a number of ways: through violence tied to trafficking, by normalizing illegal behavior, by diverting criminal justice resources from other activities, by provoking property crime related to addiction, by contributing to the widespread availability of firearms, and by undermining and corrupting societal institutions. At the same time, it should be recognized that there is a trade-off between resources spent on combating drug trafficking and those spent on other forms of crime and violence prevention.

3) In general, there has been an over-reliance on the criminal justice approach to crime reduction in the region, to the detriment of other complementary approaches which can be effective in reducing certain types of crime and violence. Over the last few years, however, several countries such as Jamaica and the Dominican Republic are increasingly investing in different approaches. Crime prevention through environmental design (CPTED), the study and design of environments to encourage desirable behavior and discourage antisocial behavior, has significant potential to generate rapid decreases in property crime and some 
forms of inter-personal violence. Integrated citizen security approaches have seen initial success in the Dominican Republic and should be explored elsewhere. These programs, by combining modern methods of policing with prevention interventions undertaken by both government and non-governmental organizations, are extremely promising. The public health approach, which focuses on modifying risk factors for violent conduct, is especially promising for addressing violence against women and youth violence.

4) At the same time, it is also crucial to note that certain types of crime and violence - in particular, organized crime and drug trafficking-are largely impervious to prevention approaches; a criminal justice-focused approach is essential in dealing with them. Within the criminal justice approach, there is much room for improvement. An especially urgent priority is the development of management information systems and performance indicators for better problem diagnosis, tracking of system outputs, monitoring reform programs and providing increased accountability to citizens.

5) These different approaches mean that there are multiple possible entry points to engage in violence and crime prevention. In one instance, the most promising approach may be in the context of a slum-upgrading project; in another, in the context of a reform of the health service; in a third, in the context of a reform of the criminal justice system. There is no one "ideal" approach. The common denominator is that successful interventions are evidence-based, starting with a clear diagnostic about types of violence and risk factors, and ending with a careful evaluation of the intervention's impact which will inform future actions.

6) Evidence from Jamaica and other countries shows that the average deportee is not involved in criminal activity, but a minority may be causing serious problems, both by direct involvement in crime and by providing a perverse role model for youth. More services should be offered to reintegrate deportees, along the lines of those provided by the Office for the Resettlement of Deportees in St. Kitts and Nevis. Options should be explored for deporting countries to shoulder a significant portion of the costs of these programs, in exchange for serious monitoring and evaluation of program impacts.

7) Given that Caribbean countries are transit and not producer countries of cocaine, interdiction needs to be complemented by other strategies outside the region (principally demand reduction in consumer countries and eradication and/or alternative development in producer countries). Within the region, policies should focus on limiting the availability of firearms and on providing meaningful alternatives to youth. Since the Caribbean nations have limited resources to effectively fight the drug trade, significant assistance should come from the destination countries in support of interdiction efforts. The case study of the Netherlands Antilles shows this to be both effective and in the self-interest of developed countries.

8) Gun ownership is an outgrowth of the drug trade and, in some countries, of politics and associated garrison communities. Within these environments, which 
promote the demand for weapons, reducing gun ownership is a difficult undertaking. Better gun registries, marking and tracking can help, as can improved gun interdiction in ports. Long run and sustained reduction in the demand for guns, however, will hinge on progress in combating drugs.

9) To address issues of youth violence, policy makers in the short run should borrow from the toolkit of evidence-based programs from other regions, such as early childhood development and mentoring programs, interventions to increase retention of high-risk youth in secondary schools, and opening schools after-hours and on weekends to offer youth attractive activities to occupy their free time. While there are a multitude of programs in the region that address youth violence, few if any have been subject to rigorous impact evaluation. In the medium and long run, impact evaluations should systematically document what works in youth violence prevention in the Caribbean.

10) This report has culled many different sources of data to present as comprehensive a picture as possible of crime and violence in the Caribbean. Yet it is clear that there are major data gaps that hinder policy making. Chief among them is the lack of regular, periodic victimization surveys that permit comparison of crime levels both across countries and over time.

\section{ROAD MAP OF THE REPORT}

The report is organized as follows. It begins with an overview of crime in the region, separately considering conventional and organized crime. Two subsequent chapters examine risk factors and the costs of crime for the region as a whole. Next, a series of chapters presents case studies designed to highlight particular issues in specific countries. These case studies were chosen in order to provide a detailed analysis of the most pressing issues that are amenable to policy making at the regional and national levels. The specific issues were chosen in consultation with stakeholders in the region to ensure that the report was responding to their demands and needs. The report ends with a chapter on public policy responses to crime in the region. ${ }^{1}$

\section{Overview of Crime Trends}

Murder rates in the Caribbean —at 30 per 100,000 population annually—are higher than for any other region of the world and have risen in recent years for many of the region's countries. Assault rates, at least based on assaults reported to police, are also significantly above the world average. These reported rates are highly sensitive to the level of trust in the local police in general and the willingness to report domestic violence, in particular. Victimization surveys are needed to even approximate true levels of assault, yet standardized victimization surveys have rarely been undertaken in the Caribbean.

\footnotetext{
${ }^{1}$ Note that this report does not contain an in-depth analysis of political violence in the Caribbean.
} 


\section{Murder Rates in Selected Caribbean Countries: 1999-2005}

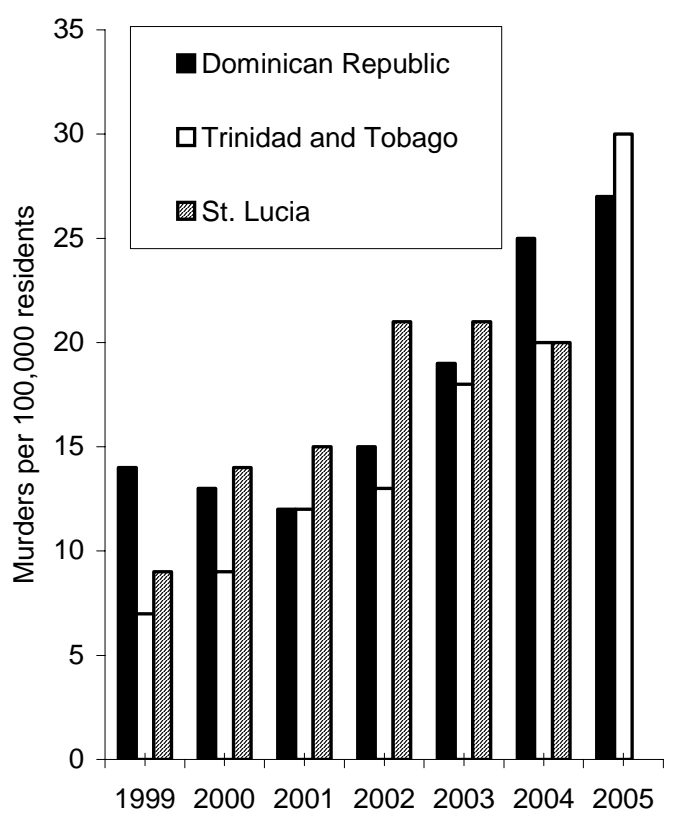

Murder Rates by Region of the World

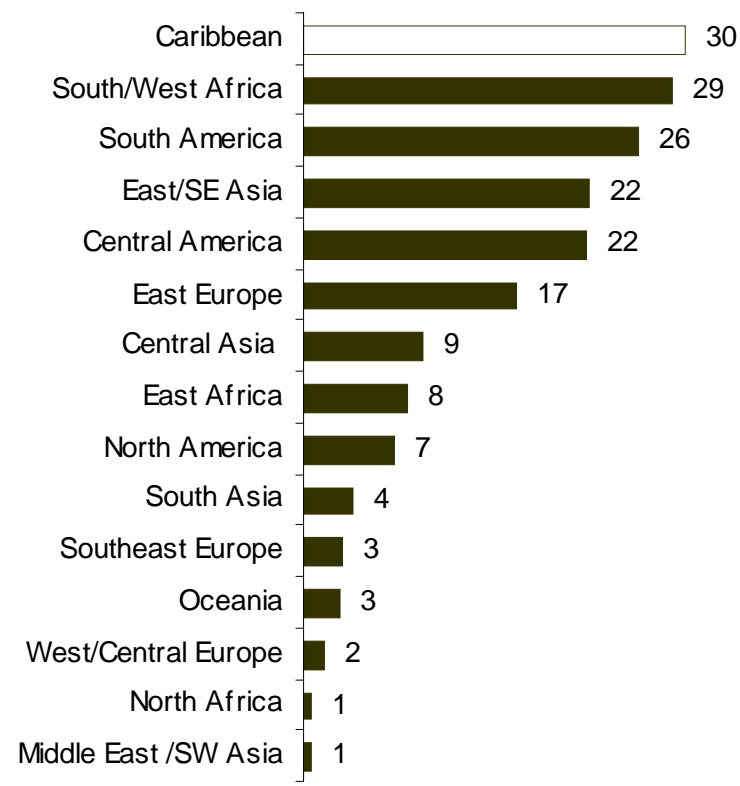

Sources: (left figure) Procuraduría General of the Dominican Republic; Central Statistical Office of Trinidad and Tobago; Central Statistical Office of St. Lucia.

Sources: (right figure) UN Crime Trends Survey and Interpol, 2002 or most recent year.

Note: Figures shown are annual murder rates per 100,000 population.

Violence against women affects a significant percentage of women and girls in the Caribbean. Police statistics offer only a very imperfect picture of violence against women, since the majority of these incidents are not reported to police and increased trust in police will increase reporting. To get a more precise idea of prevalence rates, one must use victimization surveys that focus on violence against women. One such regional victimization survey revealed that 48 percent of adolescent girls' sexual initiation was "forced” or "somewhat forced” in nine Caribbean countries (Halcon et al., 2003).

According to the latest available data from the UNODC's Crime Trends Survey (CTS), which is based on police statistics, three of the top ten recorded rape rates in the world occur in the Caribbean. All countries in the Caribbean for which comparable data are available (Bahamas, St. Vincent and the Grenadines, Jamaica, St. Kitts and Nevis, Dominica, Barbados, and Trinidad and Tobago) experienced a rate of rape above the unweighted average of the 102 countries in the CTS.

Despite their diversity, one thing all Caribbean countries have in common is that they have long been caught in the crossfire of international drug trafficking. The good news is that the flow of drugs through the region may be decreasing. The transshipment of cocaine to the United States, the most significant flow in economic terms, appears to be in decline. Cannabis production for export from Jamaica, the largest cannabis producer in the region, appears to be in a slump. 
Despite these recent shifts, large quantities of drugs continue to transit the Caribbean. In 2005, it is estimated that about 10 tons of cocaine transited through Jamaica, and 20 tons through Haiti and the Dominican Republic.

In addition to drug trafficking, kidnapping and corruption are other forms of organized crime which affect the region. Two countries-Haiti and Trinidad and Tobago-have seen recent and rapid increases in kidnappings. The kidnapping rate nearly doubled in Trinidad and Tobago between 1999 and 2005 (Central Statistics Office of Trinidad and Tobago, 2006).

Corruption is a difficult crime to measure. While there are methodological concerns about Transparency International's Corruption Perceptions Index (CPI), it remains the standard for international corruption comparisons and boasts one of the few datasets with near-global coverage. In the $2006 \mathrm{CPI}$, ten Caribbean countries were included in the world rankings. Haiti was ranked as the most corrupt country in the world, while Barbados was ranked as the $24^{\text {th }}$ least corrupt country, ahead of many European countries.

\section{Risk Factors for Crime and Violence}

Potential risk factors for crime victimization encompass conditions at the individual, relationship, community, and societal levels. As a whole, Caribbean countries exhibit crime patterns similar to those in other countries. Both murder and robbery rates are higher in countries with low economic growth while murder rates are highest in countries and communities that are poor and have large populations of young men. But these factors alone cannot explain the high rates of crime in the Caribbean. In Caribbean countries overall, homicide rates are 34 percent higher and robbery rates are 26 percent higher than in countries with comparable macroeconomic conditions.

Household-level victimization data from Jamaica, Haiti, and the Dominican Republic were analyzed to generate a profile of key risk factors. Poorer households in poor communities face higher risk of violent crime, while property crime more often strikes the wealthy. The presence of a large population of young men in the community is associated with higher levels of both types of crime in both Jamaica and the Dominican Republic. In all three countries, crime is highly concentrated in urban areas and in most cases in areas with high population density.

While these risk factors provide a profile of who is most likely to be victimized, observable variables have low predictive power in a statistical sense because victims vary widely in their characteristics. In other words, crime victimization is a general phenomenon which strikes citizens of all stripes, and few if any are immune from the threat. This can be seen in part for Haiti by the fact that while property crimes most often strike those in the richest quintile, and those in the poorest quintile most often suffer injury due to crime, victims are spread across all five quintiles of the income distribution. 
Murder Rates for Countries of the World vs. GDP per Capita, Late 1990s

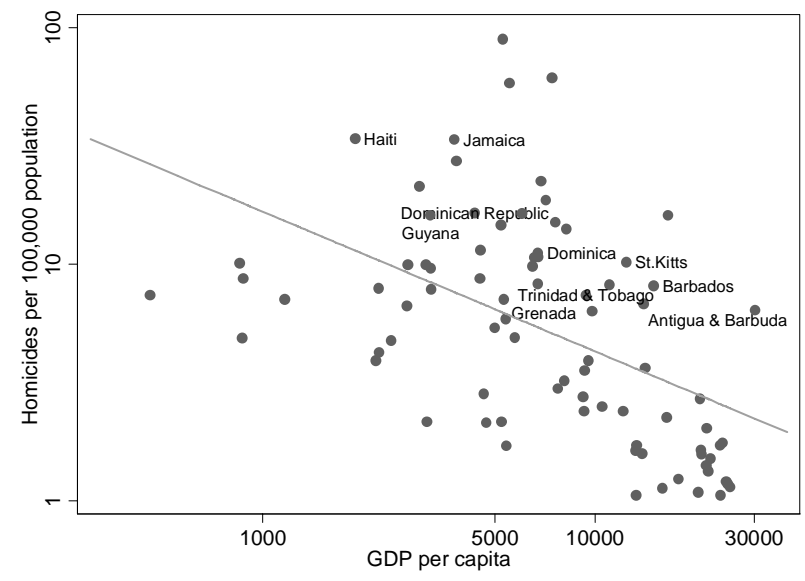

Sources: Own analysis. UNODC data and other (see Annex 3.1) for crime rates, Penn World Tables for GDP per capita.
An important finding of this study is that in Jamaica a lower percentage of crimes are reported to the police in areas with higher crime rates. The reporting rate can plausibly be interpreted as a measure of confidence in the police, as people will be more likely to report when they trust the police and believe they will respond. Lack of trust and confidence in the police is then lower in areas with higher local crime rates. This suggests also that official police data distort the true geographic profile of crime, because official data are biased downwards for higher crime areas.

\section{Socioeconomic Costs of Crime and Violence}

This report reviews the literature on the effects of crime in the region and presents new analysis of the costs of crime in terms of loss of quality of life for victims, responses to fear of crime, and economic growth.

Few studies in the region have examined socioeconomic costs of gender-based violence and its effects. Morrison and Orlando (2005) find that women victimized by physical violence in Haiti are: i) less likely to receive antenatal care; ii) more likely to suffer from genital sores and ulcers; and iii) more likely to be anemic (as are their children).

Due to the high levels of violence in parts of urban Jamaica, residents are afraid to leave the homes and interact less often with friends and family who live elsewhere. Similarly, survey data from the Dominican Republic and Haiti show that people avoid activities and locations that are perceived to expose them to a high risk of criminal victimization.

Another channel through which crime exacts costs is through its effects on businesses, which can be particularly damaging because they can involve both short-run costs and long-run consequences for development, by diverting resources to crime prevention measures and otherwise discouraging investment. In Jamaica, 39 percent of business managers in a World Bank survey responded that they were less likely to expand their business because of crime, and 37 percent reported that crime discourages investments that would improve productivity. Because of the key role that tourism plays in many Caribbean countries, the effects of crime on tourism are of particular concern. Alleyne and Boxil (2003) examined the relationship over time between tourist arrivals and crime in Jamaica and concluded that crime has discouraged tourists. 
It is possible to add up the total costs of crime through the accounting method. A study by Francis et al. (2003) found that the total costs of crime in Jamaica in 2001 came to $\mathrm{J} \$ 12.4$ billion, which was 3.7 percent of GDP. Security costs dominate the total costs of crime as calculated by the accounting method.

Potential Boost to Annual Economic Growth Rate from Reducing Homicide Rate to Costa Rica Level

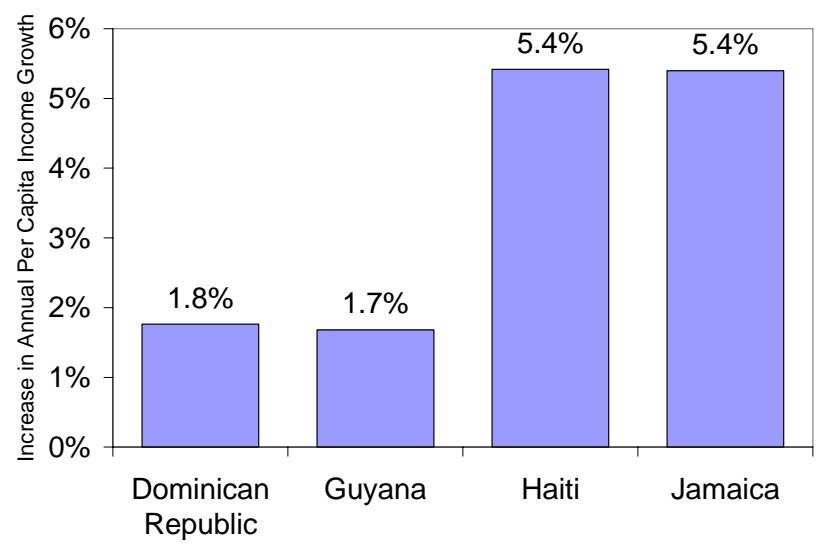

Source: Own analysis.
The impact of crime on overall economic growth can also be estimated using cross-country panel data. Results from this kind of analysis suggest very large potential gains from reduction in violence for Haiti and Jamaica. Both countries could boost annual economic growth per capita by 5.4 percent if they were to bring their homicide rates down to the levels of Costa Rica. Guyana and the Dominican Republic would also benefit substantially, with potential growth rate increases of 1.7 percent and 1.8 percent, respectively.

\section{Criminal Deportees in Jamaica}

Each year, the United States, the United Kingdom, and Canada deport thousands of people convicted of various crimes to their countries of citizenship in the Caribbean. There is a widely held belief in the Caribbean that recent crime troubles can be tied directly to the activities of deportees who have learned criminal behavior in the developed countries. This report examines the situation in Jamaica, which is proportionately most affected by criminal deportations, and where officials have worried that the country's rising murder rate may be linked to the growing stock of deported convicts. The figure below shows both the number of murders and the number and source of deportee arrivals over the 1998-2004 period. Whether these two variables are related cannot be determined from this figure. 


\section{Deportees and Murders in Jamaica by Year}

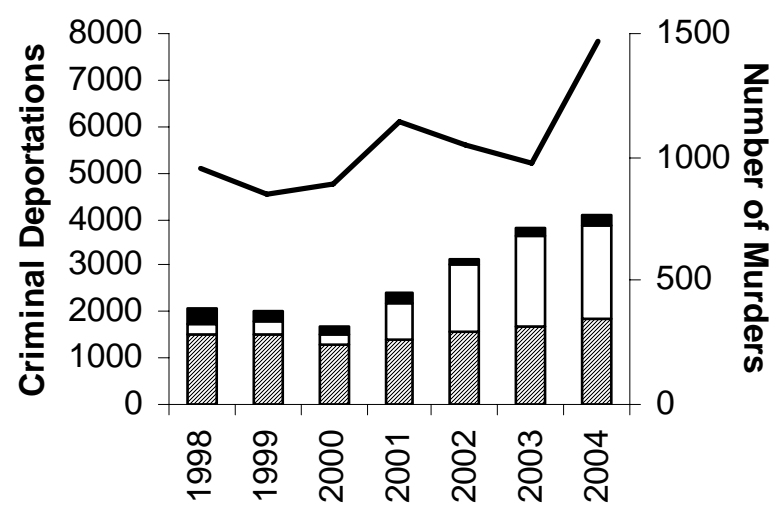

Canada deportees (left axis)

$\square$ UK deportees (left axis)

USA deportees (left axis)

Murders (right axis)

Source: Social and Economic Survey of Jamaica; Jamaica Constabulary Force.

committing violent crime in Jamaica. At the same time, although the majority of the criminal deportees were deported for non-violent offenses, 224 convicted murderers were included in the flow between 2001 and 2004. Relative to the Jamaican population, this is not a small number, and it does not take a large number of offenders to have a potentially large impact.

Are deportees contributing significantly to crime in other countries of the region? Of 332 criminal deportees returned to Barbados between 1994 and 2000, only 13 percent were subsequently charged with a criminal offense. Similarly, in Trinidad and Tobago, of the 565 deportees received between 1999 and 2001, only 15 percent were subsequently charged with a crime. This recidivism rate is low compared to the reoffense rate of prisoners released from local prisons.

Developed countries provide a variety of forms of aid to the Caribbean to support development. Subsidizing reintegration for deported offenders would be a very costeffective way of achieving similar ends. It would save Caribbean societies the cost and trauma of recidivism; reduce criminal justice costs involved in processing and incarcerating repeat offenders; and promote the stability essential to attracting investment, promoting tourism, and reducing emigration. Another result might be weakened international crime networks, which also will benefit developed countries.

\section{Guns in Trinidad and Tobago}

The data for several countries shows that not only have levels of crime and violence increased, but so too has the use of weapons in criminal acts. The profile of these 
incidents has also changed, with increased use of more powerful weapons resulting in higher mortality levels.

The CARICOM Regional Task Force on Crime and Security recently commissioned a report on the proliferation of small arms and light weapons (SALW) in the Caribbean (CARICOM, 2002). The resulting report identified three levels of SALW proliferation in the region: countries with established high levels and patterns of armed crime (Jamaica), countries with emerging high levels of armed and organized criminality (Guyana, Trinidad and Tobago), and countries with indications of increased use and availability of small arms (Antigua and Barbuda, Barbados, Dominica, Grenada, St. Kitts and Nevis, Saint Lucia, St. Vincent and the Grenadines).

At that time, it was determined that, among CARICOM nations, only Jamaica fell in the first category, with indications that military type weapons were available and that paramilitary units were operating (Burrows and Matthias, 2003). If such an evaluation were done today, Trinidad and Tobago might also be included in this tier, as the murder rate doubled between 2002 and 2005. In 2004, the country experienced 160 firearm murders, more than 450 firearm woundings, and 1,500 firearm incidents that did not result in injury (Trinidad and Tobago Police Service, $\mathrm{n} / \mathrm{d}$ ).

A major factor contributing to the surge of guns-related criminality in the region is the trafficking of narcotics, which has facilitated the availability of firearms. More specifically, the firearms required for protection of contraband during transportation are smuggled in along with drugs. Within these environments that promote the demand for weapons, reducing gun ownership is a difficult undertaking. Better gun registries, marking, and tracking can help, as can improved gun interdiction in ports. In the long term progress will hinge on changes in the drug trade, changes in the "gun-culture," and progress in the implementation of international treaties and agreements on small arms and light weapons, such as the Protocol against the Illicit Manufacturing of and Trafficking in Firearms, their Parts and Components and Ammunition, supplementing the United Nations Convention against Transnational Organized Crime.

\section{Drug Trafficking and the Netherlands Antilles}

The drug trade is a prime driver of crime across the Caribbean. This report examines unusual interdiction efforts in the Netherlands Antilles, where authorities estimate that 75 percent of crime is drug-related. Some 60 percent of all the cocaine seized in the Caribbean in 2004 was seized in the Netherlands Antilles, and cocaine seizures increased dramatically between 2001 and 2004.

Confronted with large numbers of people attempting to smuggle drugs by plane, authorities implemented a "100\% Control" strategy, by which passengers landing in Schiphol Airport in Amsterdam and originating from the Dutch Caribbean, Suriname, and Venezuela are subject to extensive searches. Persons found with drugs on their person had the drugs confiscated and were immediately deported to their country of origin but were not arrested. Rather than attempting to scare off potential smugglers with 
the threat of incarceration, the Dutch approach was based on increasing the rate of interdiction to the point that smuggling became unprofitable. In other words, the focus was on the drugs, rather than the couriers.

The authorities estimate that between 80 and 100 couriers per day were passing through the airport in 2003. This was cut to an estimated 10 a month by October 2005. While displacement effects would need to be tallied to properly evaluate the impact of this intervention, the $100 \%$ Control strategy has apparently disrupted what was once a major trafficking route.

Commercial air flights are only one of the vectors through which cocaine transits the Netherlands Antilles and not necessarily the most significant one. The $100 \%$ Control approach has seized 7.5 tons of cocaine in 2.5 years, but multi-ton seizures can be made in a single instance of maritime interdiction. Detecting maritime trafficking requires intelligence work and a dedicated interdiction force.

Even eliminating the Netherlands Antilles as a drug transit area altogether would not stop the flow of drugs, and displacement effects are inevitable. Nonetheless, focusing on the drugs rather than the couriers is a powerful approach because it defeats the "shotgun" technique, where traffickers are willing to sacrifice an endless stream of gullible couriers as long as sufficient quantities of drugs arrive for them to make a profit. It has proven itself to work in the case of the Netherlands Antilles, and could be tested in other contexts, including other Caribbean countries suffering from drug transshipment. The Antillean example also highlights the need for cooperation between Caribbean transshipment countries and destination countries in maritime interdiction.

\section{Youth Violence in the Dominican Republic}

Deaths and injuries from youth violence constitute a major public health, social and economic problem across the Caribbean, where youth are disproportionately represented in the ranks of both victims and perpetrators of crime and violence. Moreover, in many Caribbean countries violent crimes are being committed at younger ages. The Dominican Republic is one of the countries in which this pattern has become more stark over time, as rates of crime and violence overall have increased. In 2005, homicides of those aged 1130 accounted for approximately 46 percent of total homicide deaths.

A wide variety of risk factors contribute to the prevalence of youth violence, including poverty, youth unemployment, large-scale migration to urban areas, drug trafficking, a weak education system, ineffective policing, the widespread availability of weapons, drug and alcohol use, and the presence of organized gangs.

Nonetheless, youth violence is preventable. A broad range of strategies for preventing and reducing youth violence have been implemented in the Dominican Republic and elsewhere. Evidence from evaluations (unfortunately, almost exclusively in developed countries) documents that most highly effective programs combine components that address both individual risks and environmental conditions, by building individual skills 
and competencies, supporting parental effectiveness, improving chances for youth to access and complete their secondary education, improving the social climate of schools, providing second chances, and promoting changes in involvement with peer groups.

The best youth violence interventions target specific populations of young people associated with risk factors, such as school leavers, those involved with delinquent peers, gang members, and those exposed to family violence or substance abuse. Targeting highviolence communities with a holistic approach to address violence and emphasizing violence prevention directed at children and youth, as exemplified by the Barrios Seguros program in the Dominican Republic, is a very promising-albeit not yet formally evaluated-approach.

Homicide Deaths by Age in the Dominican Republic, 2000-2005

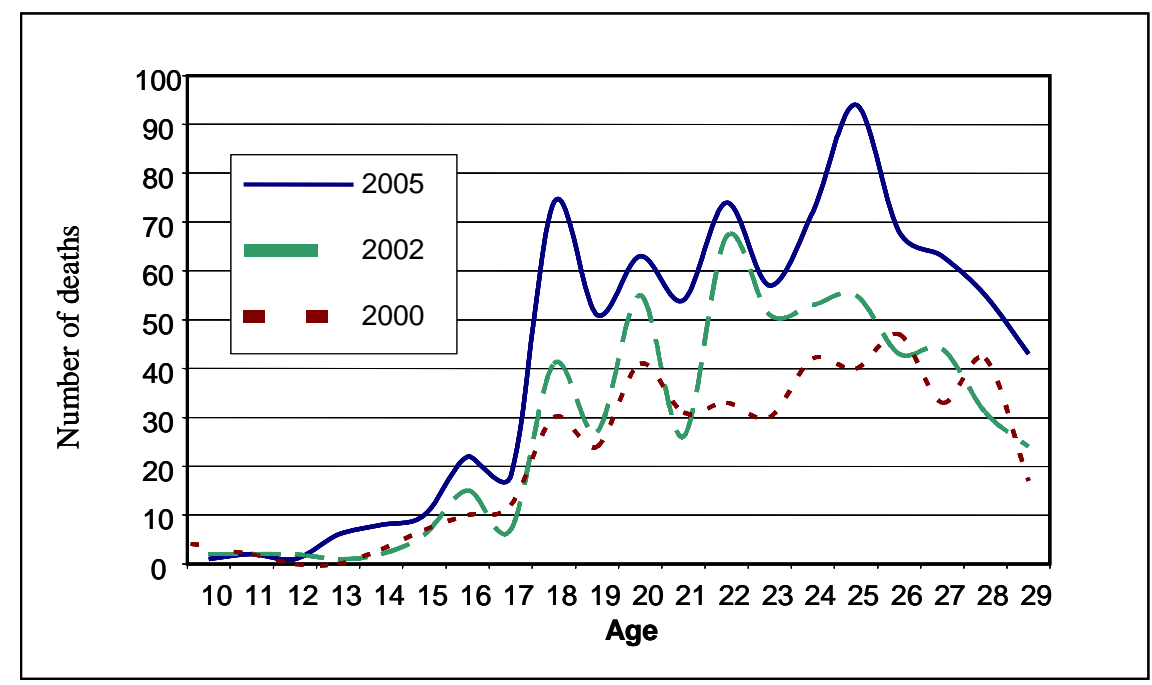

Source: Dominican Republic National Police, unpublished data.

Early child development interventions and effective parenting training for poor and atrisk children and their families are some of the most cost-effective investments in reducing youth violence and delinquency over time. Incentives for youths to complete their secondary education have also proven to be effective.

Overall, reducing "mano dura” or repressive programs in favor of expanding prevention strategies (including prevention-focused law enforcement) would represent an effective and potentially cost-saving strategy. Finally, promoting interventions that reduce gun and alcohol availability — and their social acceptance-among youth can play a crucial role in countries like the Dominican Republic, where the use of both is widespread at young ages and the links to violence are significant. 


\section{Criminal Justice Systems}

Many countries in the Caribbean have experimented with reform of their criminal justice systems, and the experience is mixed. This chapter focuses on the criminal justice reform experience of two countries: the Dominican Republic and Jamaica. Two important lessons emerge: (i) the need to pursue better coordination among institutions, including the introduction of information systems capable of tracking systemic performance and generating a set of performance indicators, and (ii) the desirability of linking criminal justice reforms to a broader, multi-sector strategy of crime and violence prevention.

Performance indicators should not be the product of ad hoc efforts to measure outputs currently of interest. Instead, basic data on work processes should be routinely gathered and transferred to centralized databases, where it can be reviewed and analyzed for its broader implications. Once in place, such systems provide a very potent tool for reviewing organizational performance and identifying and diagnosing problems. They also facilitate the creation of new indicators as they are needed.

A key performance indicator for the police is the "clearance" rate at which dockets leave the authority of the police and become the primary responsibility of the prosecuting authority. Another important indicator is the number and nature of complaints against the police. The most common indicators for measuring prosecutorial performance are the rate of convictions and the percentage or number of prisoners awaiting trial. Prison performance can be measured at a basic level by the rate of escape and amount of violence in prisons. The performance of the prison system in rehabilitating inmates can be measured by the re-arrest rate within a specified time period.

Governments also need inter-agency governance mechanisms and incentives to help individual agencies in the justice sector align their work with system-wide goals. If sector-wide governance mechanisms are to succeed, their authority must go beyond performance measurement to include real executive powers (see Vera Institute of Justice, $2004)^{2}$. The recent history of justice reforms in both Jamaica and the Dominican Republic illustrates the need for such interagency mechanisms and effective performance evaluation systems.

\section{Public Policy of Crime and Violence Prevention: National and Regional Approaches}

In the Caribbean and most other regions, efforts to prevent violence have fallen into two categories: sector-specific approaches_such as criminal justice, public health, and conflict transformation and human rights — and cross-sectoral approaches — such as crime prevention through environmental design and citizen security. These approaches are complementary. For example, criminal justice reform initiatives (e.g. improved policing and better rehabilitation in prisons) can be pursued simultaneously with citizen security

\footnotetext{
${ }^{2}$ An example of sector-wide coordination currently limited to performance measurement is the role played by National Commission for the Coordination of the Reforms in Chile.
} 
programs that employ social prevention interventions and crime prevention through environmental design. In other words, there is no one "magic bullet" or single approach that can address all the risk and protective factors for crime and violence.

It is important to note that many of the issues facing the Caribbean transcend national boundaries and require a coordinated regional response. Demand for drugs emanates from Europe and the United States; deportees are sent back to the region from the United States, the United Kingdom, and Canada; and many weapons that are trafficked are sourced from the United States.

CARICOM has undertaken several important steps to deal with emerging regional security issues. Perhaps the most important regional initiative in the area of crime and violence reduction was the Regional Task Force on Crime and Security (RTFCS). The Task Force identified the following principal security threats to the region: illegal drugs, illegal firearms, corruption, rising crime against persons and property, criminal deportees, growing lawlessness, poverty and inequity, and terrorism. For the areas of illegal drugs, illegal firearms, terrorism, and deportees, the report included a short discussion of key issues and challenges and a long list of detailed recommendations at both national and regional levels (CARICOM, 2002). ${ }^{3}$ The Task Force presented its report to a meeting of Heads of Government in July 2002 and the recommendations of the Task Force were endorsed by this meeting.

Caribbean heads of government endorsed a new Management Framework for Crime and Security in July 2005. This framework establishes a Council of Ministers responsible for security and law enforcement, a Policy Advisory Committee, and an Implementation Agency to implement CARICOM policy initiatives in this area.

Yet no regional strategy in these areas can hope to succeed without significant support from OECD countries. This support has so far been limited predominantly to security sector reforms initiatives and drug interdiction, but has been lacking in the areas of weapons control and deportees.

Nor does good policy making to reduce crime and violence happen by accident. The Regional Task Force on Crime and Security (CARICOM, 2002) called for the development of national crime control master plans and the establishment of national crime commissions to ensure multi-sectoral collaboration. National plans allow for crosssectoral collaboration and serious discussions about the priorities in resource allocation. Equally importantly, they offer a vehicle for the involvement of civil society organizations, where much of the expertise in violence prevention resides. While the Task Force recommendations have been heeded in some countries, in some they have not. Preparation of a national plan should be a priority in these countries.

Crime and violence are not immutable. While the Caribbean faces serious challenges, especially in the areas of drugs, guns and youth violence, intelligent policy making at the national and regional levels can make a difference. Given the high social and economic

\footnotetext{
${ }^{3}$ The key findings from these sections have been incorporated into the relevant sections of this report.
} 
costs associated with crime and violence, the development of sound policies and programs is a key development priority for the region.

The table below summarizes the key policy recommendations of the report.

\section{Summary of Policy Recommendations}

\begin{tabular}{|c|c|c|}
\hline & Priority Recommended Policy Actions & Medium-Term Policy Actions \\
\hline $\begin{array}{l}\text { Data/evidence } \\
\text { based policy- } \\
\text { making }\end{array}$ & $\begin{array}{l}\text { - Conduct regular, periodic and } \\
\text { standardized victimization surveys } \\
\text { that permit comparison of crime } \\
\text { levels both across countries and over } \\
\text { time } \\
\text { - Use data and analysis to identify } \\
\text { geographical and demographic foci } \\
\text { for interventions: } \\
\text { o Employ geographical } \\
\text { information systems (GIS) to } \\
\text { analyze crime trends and } \\
\text { allocation prevention and } \\
\text { control resources in large cities } \\
\text { Pilot “integrated citizen } \\
\text { security" approaches to rapidly } \\
\text { reduce crime in violent areas }\end{array}$ & $\begin{array}{l}\text { - Create Injury Surveillance } \\
\text { Systems } \\
\text { Conduct impact evaluations } \\
\text { of all types of crime and } \\
\text { violence prevention/ } \\
\text { reduction programs in the } \\
\text { Caribbean region }\end{array}$ \\
\hline $\begin{array}{l}\text { Criminal } \\
\text { Justice Reform }\end{array}$ & $\begin{array}{l}\text { - Develop information systems and } \\
\text { performance measurement indicators } \\
\text { to promote institutional efficiency } \\
\text { and accountability }\end{array}$ & $\begin{array}{l}\text { - Undertake institutional } \\
\text { reform to promote systemic } \\
\text { alignment and crime } \\
\text { reduction } \\
\text { - Modernize policing through } \\
\text { the use of information } \\
\text { systems and problem- } \\
\text { oriented policing }\end{array}$ \\
\hline $\begin{array}{l}\text { Social and } \\
\text { Situational } \\
\text { Prevention }\end{array}$ & $\begin{array}{l}\text { Integrate crime and violence } \\
\text { prevention into sectoral programs } \\
\text { such as slum-upgrading, education, } \\
\text { and health }\end{array}$ & $\begin{array}{l}\text { - Conduct impact evaluations } \\
\text { of social and situational } \\
\text { crime prevention initiatives } \\
\text { - Scale up successful civil } \\
\text { society crime and violence } \\
\text { prevention programs }\end{array}$ \\
\hline
\end{tabular}




\begin{tabular}{|c|c|c|}
\hline Youth Violence & 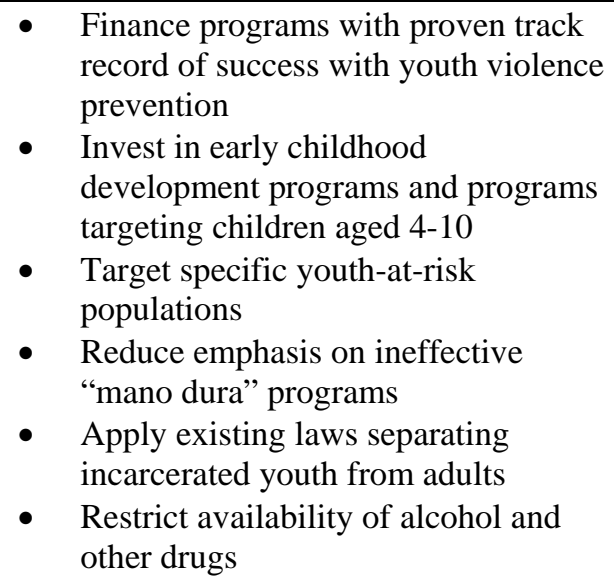 & $\begin{array}{l}\text { - Undertake impact } \\
\text { evaluations that } \\
\text { systematically document } \\
\text { what works in youth } \\
\text { violence prevention in the } \\
\text { Caribbean } \\
\text { - Provide skills training and } \\
\text { internships for at-risk youth }\end{array}$ \\
\hline Deportees & $\begin{array}{l}\text { - Improve coordination with sending } \\
\text { countries (who, when, share criminal } \\
\text { records, etc.) } \\
\text { - Undertake robust research on } \\
\text { contribution of deportees to crime } \\
\text { - Finance deportee reintegration, } \\
\text { targeting deportees most likely to re- } \\
\text { offend }\end{array}$ & $\begin{array}{l}\text { Enlist sending countries to } \\
\text { finance programs for } \\
\text { reintegration of criminal } \\
\text { deportees }\end{array}$ \\
\hline $\begin{array}{l}\text { Drug } \\
\text { Trafficking }\end{array}$ & $\begin{array}{l}\text { Improve both commercial air and } \\
\text { maritime interdiction by building on } \\
\text { regional successes such as drug- } \\
\text { focused interdiction } \\
\text { - Implement/expand drug abuse } \\
\text { treatment programs }\end{array}$ & $\begin{array}{l}\text { - Enlist consuming countries } \\
\text { to provide financial and } \\
\text { technical assistance for } \\
\text { improved interdiction. } \\
\text { - Create alternative } \\
\text { opportunities for youth. } \\
\text { - Reduce demand in } \\
\text { consuming countries }\end{array}$ \\
\hline Guns & $\begin{array}{l}\text { - } \quad \text { Create/improve marking and tracking } \\
\text { systems } \\
\text { - } \quad \text { Create/improve national gun } \\
\text { registries } \\
\text { - Enforce gun laws and regulations for } \\
\text { - } \quad \text { Iicensing, selling, import/export } \\
\text { Improve illegal gun interdiction }\end{array}$ & $\begin{array}{l}\text { - } \quad \text { Change gun culture } \\
\text { - Implement and enforce } \\
\text { international and regional } \\
\text { agreements on the } \\
\text { proliferation of Small Arms } \\
\text { and Light Weapons } \\
\text { (SALW) }\end{array}$ \\
\hline
\end{tabular}




\begin{tabular}{|c|c|c|}
\hline $\begin{array}{l}\text { Regional and } \\
\text { international } \\
\text { cooperation }\end{array}$ & $\begin{array}{l}\text { Follow-up and finance } \\
\text { recommendations of the Regional } \\
\text { Task Force on Crime and Security } \\
\text { - Create/strengthen national crime } \\
\text { prevention plans and commissions } \\
\text { Ratify the relevant international } \\
\text { conventions on drug trafficking and } \\
\text { organized crime, including in } \\
\text { particular the United Nations } \\
\text { Convention on Transnational } \\
\text { Organized Crime and its protocols.. }\end{array}$ & $\begin{array}{l}\text { Create regional facilities for } \\
\text { police training } \\
\text { - Create regional } \\
\text { forensics/ballistic laboratory } \\
\text { and technical capacity } \\
\text { - Improve intelligence sharing }\end{array}$ \\
\hline
\end{tabular}




\section{CONVENTIONAL CRIME: AN OVERVIEW}

The Caribbean countries are highly diverse in terms of their political structure, population size, and level of development. They share the experience of a colonial past and a geography which places them in the path of the international drug trade. According to figures from the United Nations Office of Drugs and Crime (UNODC) and Interpol, the overall Caribbean murder rate of 30 per 100,000 is higher than for any other region of the world. The region also has high levels of other violent crime, and violence against women is widespread.

1.1 Crime is arguably the number one social issue for much of the Caribbean, with its only serious rival being economic development (see World Bank, 2005a). ${ }^{4}$ Leaders are coming to realize, however, that the two issues are strongly related. ${ }^{5}$ Crime drives away investment, both foreign and domestic, and consequently slows growth. The Caribbean has been described as the most tourism-dependent area in the world, and crime is anathema for this industry. ${ }^{6}$ A second key industry-the financial services sector-is threatened by white collar crime and money laundering. ${ }^{7}$ The region is also one of the areas of the world most affected by brain drain, and there is evidence that crime is feeding this exodus in some areas. ${ }^{8}$ In these and many other ways, it is clear that crime is impeding the development of the Caribbean.

1.2 The Caribbean is especially vulnerable to crime for several reasons. It suffers from the disadvantage of being situated between the world's source of cocaine (the Andean region of South America) and its primary consumer markets (the United States and Europe) (UNODC, 2006). ${ }^{9}$ As small islands, Caribbean countries and territories have large coastlines and territorial waters to control relative to their ability to fund law enforcement coverage. Small criminal justice systems are easily overwhelmed in terms of police, courts, and prisons. Police must deal with seasonal tourist inflows, and, in some countries, the number of annual visitors actually exceeds the size of the local population. The Caribbean has some of the highest prisoner to population ratios in the world, and overcrowding interferes with the rehabilitation process. ${ }^{10}$ Finally, a number of countries

\footnotetext{
${ }^{4}$ The open-ended question "What would you say is the single most serious challenge facing our country today?" was asked to a representative sample of the population of the islands of St Kitts and Nevis, St Lucia, St. Vincent and the Grenadines, and Antigua and Barbuda in Spring 2005. "The crime rate" was the most popular response, with 45 percent of respondents mentioning it as a first or second priority. The next most common response was "the rising cost of living", mentioned by 26 percent as a first or second priority.

${ }^{5}$ See Annex 1.1 for quotations from Caribbean leaders on the threat posed by crime.

${ }^{6}$ See Annex 1.2 for a discussion of the importance of tourism in Caribbean economy.

${ }^{7}$ See Box 2.1 for discussion of an example of white collar crime in the Dominican Republic.

${ }^{8}$ See Annex 1.3 for a discussion of the links between emigration and crime.

${ }^{9}$ In 2005, nearly all the world's cocaine came from Colombia (54 percent), Peru (30 percent), and Bolivia (16 percent). Most of this cocaine was used in North America (about half) and West/Central Europe (about a quarter). Cocaine prices in these countries were also generally higher than in other markets.

${ }^{10}$ See Annex 1.4 for discussions of Caribbean police forces and prison populations.
} 
have experienced periods of political instability, which may have a long-term impact on crime. $^{11}$

1.3 Discussions of crime typically distinguish between "organized crime" and "conventional crime." Organized crime typically refers to criminal enterprises (crime organizations that operate in similar fashion to businesses), while conventional crime includes all the common law offenses of murder, rape, assault, robbery, burglary, theft, fraud, and the like. This chapter discusses conventional crime, while the following chapter provides an overview of organized crime in the Caribbean.

\section{THE DIVERSITY OF THE CARIBBEAN}

1.4 To those unfamiliar with the area, "the Caribbean" conjures rather uniform images of picture-postcard islands. The truth is that, on the contrary, it would be difficult to imagine a region that displays more diversity than the Caribbean.

- The area was colonized by Denmark, France, the Netherlands, Spain, the United Kingdom, and the United States, and each power left its mark on the language, culture, and politics of the areas it held. Some countries retain varying degrees of dependence on these powers.

- Some countries are highly developed, such as Barbados, which appears $31^{\text {st }}$ in the world in the United Nations 2006 Human Development Index rankings, just above the Czech Republic. Others are extremely poor, such as Haiti, which ranks $154^{\text {th }}$, below both Kenya and Zimbabwe (see Figure 1.1) (UNDP, 2006).

- Populations vary from about 4,000 (Montserrat) to over 11 million (Cuba).

1.5 This final factor, the uneven distribution of the region's population among countries, considerably complicates crime analysis. While there are 20 to 30 countries and territories in the Caribbean (depending on how they are counted) some 88 percent of the population is found in just five countries (see Figure 1.2). Since many islands are actually parts of larger countries (for example, the Netherlands Antilles and Aruba are part of the Kingdom of the Netherlands while Martinique, Guadeloupe, and French Guiana are French départments), they are often excluded from discussions of regional issues. If only fully independent countries are included in the analysis, Cuba comprises a third and the Dominican Republic and Haiti together half of the regional population.

\footnotetext{
${ }^{11}$ Key among these areas are Jamaica, which has experienced political violence since the 1940s, and Haiti, which has had repeated periods of instability since independence in 1804.
} 


\section{Figure 1.1: Ranking of Caribbean Countries in the Human Development Index}

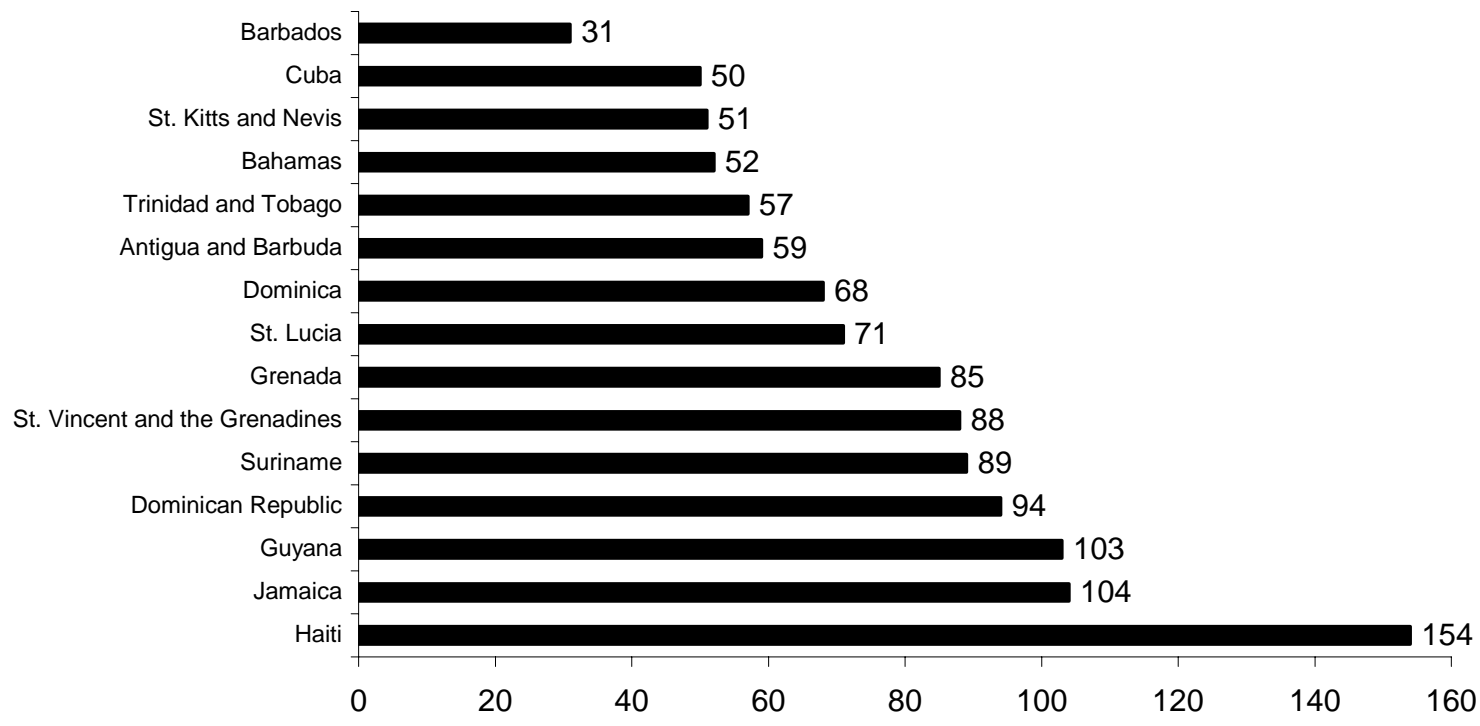

Ranking Among All Countries of the Word in HDI

Source: Human Development Report 2006.

1.6 Thus, the Caribbean is highly diverse, but the population of the Caribbean is concentrated in a few countries that may not represent the experiences of the smaller islands. For example, while the majority of the countries and territories are Englishspeaking, the bulk of the population is Spanish-speaking. Cuba comprises over a quarter of the total regional population (a third of the independent Caribbean), and its society and politics are unlike those of the other islands. Haiti makes up a fifth but is a unique case due its extreme poverty and history of political instability and violence. Often both Cuba and Haiti are excluded from analysis due to data availability, but this also presents problems: it is difficult to speak of "the Caribbean" while excluding almost half the region's population, and doing so gives disproportionate weight to the experiences of the Dominican Republic and Jamaica.

1.7 For this reason, it is difficult to compare the Caribbean as a region to other regions in the world in terms of crime. Does the Caribbean have a serious crime problem?

\section{Figure 1.2: Population Distribution of the Independent Caribbean}

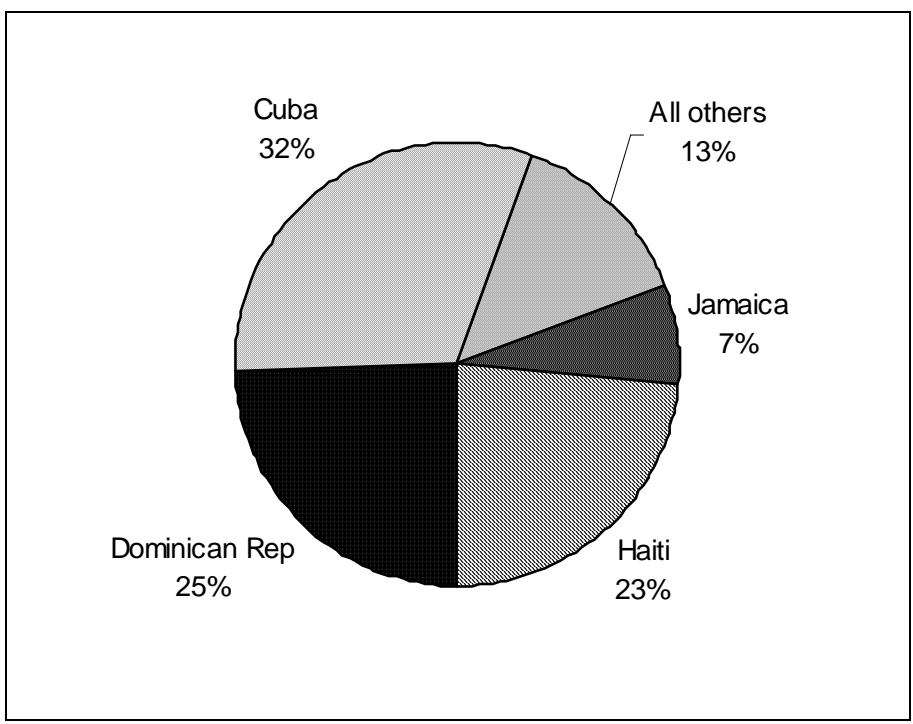

Source: UN Population Division. 
It depends on which countries are included in the sample, and any generalization will gloss over a tremendous variety of experiences. But at least one international comparison, done by the UNODC based on standardized data sources, suggested that the Caribbean suffers from more murder per capita than any other region of the world (see Figure 1.3) (UNODC, 2005).

Figure 1.3: Murder Rates by Region

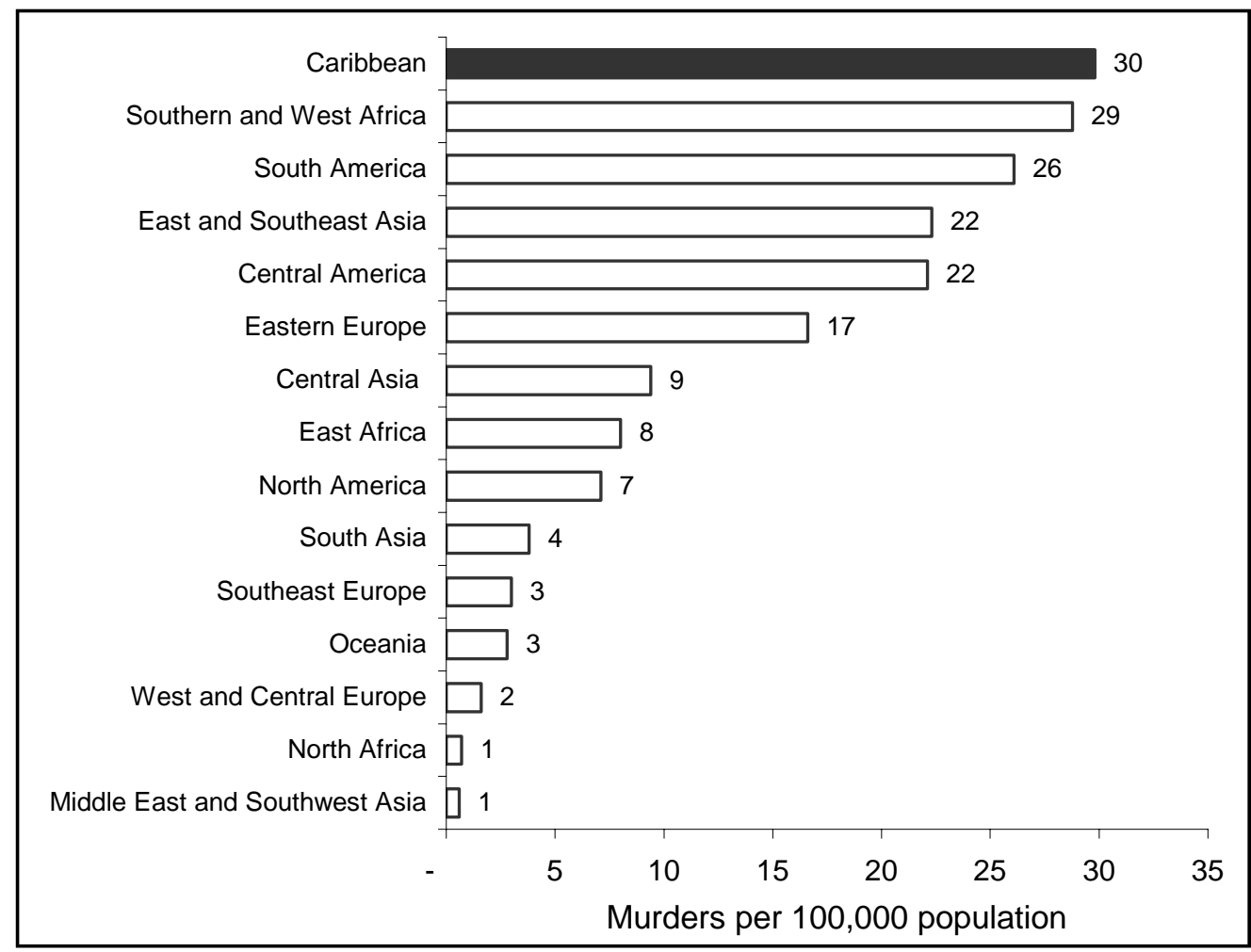

Source: UNODC Crime Trends Surveys and Interpol, 2002 or most recent year.

\section{HOW TO MEASURE CRIME?}

1.8 In general, crime data are extremely problematic, and the Caribbean region provides an excellent case study of just how deceptive they can be. The best source of information on crime comes from household surveys, such as the standardized crime surveys conducted under the aegis of the International Crime Victims Surveys (ICVS). Unfortunately, only one country in the Caribbean has participated in the ICVS: Barbados. Information from other survey sources can be interesting, but rarely approaches the degree of precision needed for sound analysis of the crime situation. For example, the Latinobarómetro poll covers 18 countries in Latin America but only asks the most general questions about crime.

1.9 The official crime figures published by national governments are much more problematic. They are generally based on police statistics, and the police figures are 
largely based on cases that are reported to the police by the public. Unreported cases cannot be recorded, and there is good reason to believe a great deal of crime is not reported in the region. Making comparisons across jurisdictions is even more complicated, because the precise rate of under-reporting varies between countries, and countries where the criminal justice system enjoys a good deal of public confidence tend to have higher rates of reporting. On the other hand, as Chapter 3 shows, it is precisely in the most crime ridden-areas that reporting rates are the lowest.

1.10 In addition, definitions of crime vary greatly between countries. Even for what seems like an easily defined offense such as murder, definitions vary widely, and crimes like burglary, robbery, and sexual offenses are defined very differently across jurisdictions. These differences are strongest when comparisons are made between entirely different legal traditions, and there are many in the Caribbean. In addition, the point in the criminal justice process when an alleged offense is recorded as a crime differs greatly between countries. This complicates comparison between civil law jurisdictions (such as in Spanish-speaking Caribbean countries) and common-law jurisdictions (such as the Anglophone states of the Caribbean).

\section{Box 1.1 Crime Definitions}

The following definitions of crime types are used by the United Nations Office on Drugs and Crime in the biennial Survey of Crime Trends and Operations of Criminal Justice Systems:

- Intentional homicide is death deliberately inflicted on a person by another person, including infanticide.

- Assault is physical attack against the body of another person, including battery but excluding indecent assault.

- Rape is sexual intercourse without valid consent.

- Robbery is the theft of property from a person, overcoming resistance by force or threat of force.

- Theft is the removal of property without the property owner's consent.

- Automobile theft is the removal of a motor vehicle without the consent of the owner of the vehicle.

- Burglary is unlawful entry into someone else's premises with the intention to commit a crime.

- Kidnapping is unlawfully detaining a person or persons against their will (or national equivalent, e.g. using force, threat, fraud or enticement) for the purpose of demanding for their liberation an illicit gain or any other economic gain or other material benefit, or in order to oblige someone to do or not to do something.

1.11 Another issue is the usefulness of crime rates in very small countries. Small countries typically stand out in the global rankings of a number of variables when these figures are calculated as a rate per 100,000 citizens, because a relatively small number of incidents can result in high rates. Many countries and territories in the Caribbean have populations of less than 100,000. Low populations also make interpretation of rates over time difficult, since trends tend to be erratic. The figure below showing murder rates in Anguilla (population 10,000-16,000, depending on source) illustrates this point. Since 1995 Anguilla has experienced either zero, one, or two murders per year-yet the 
difference between zero and two murders is enough to move Anguilla from a low to a high murder rate (see Figure 1.4).

Figure 1.4: Murders per 100,000 Population by Year, Anguilla

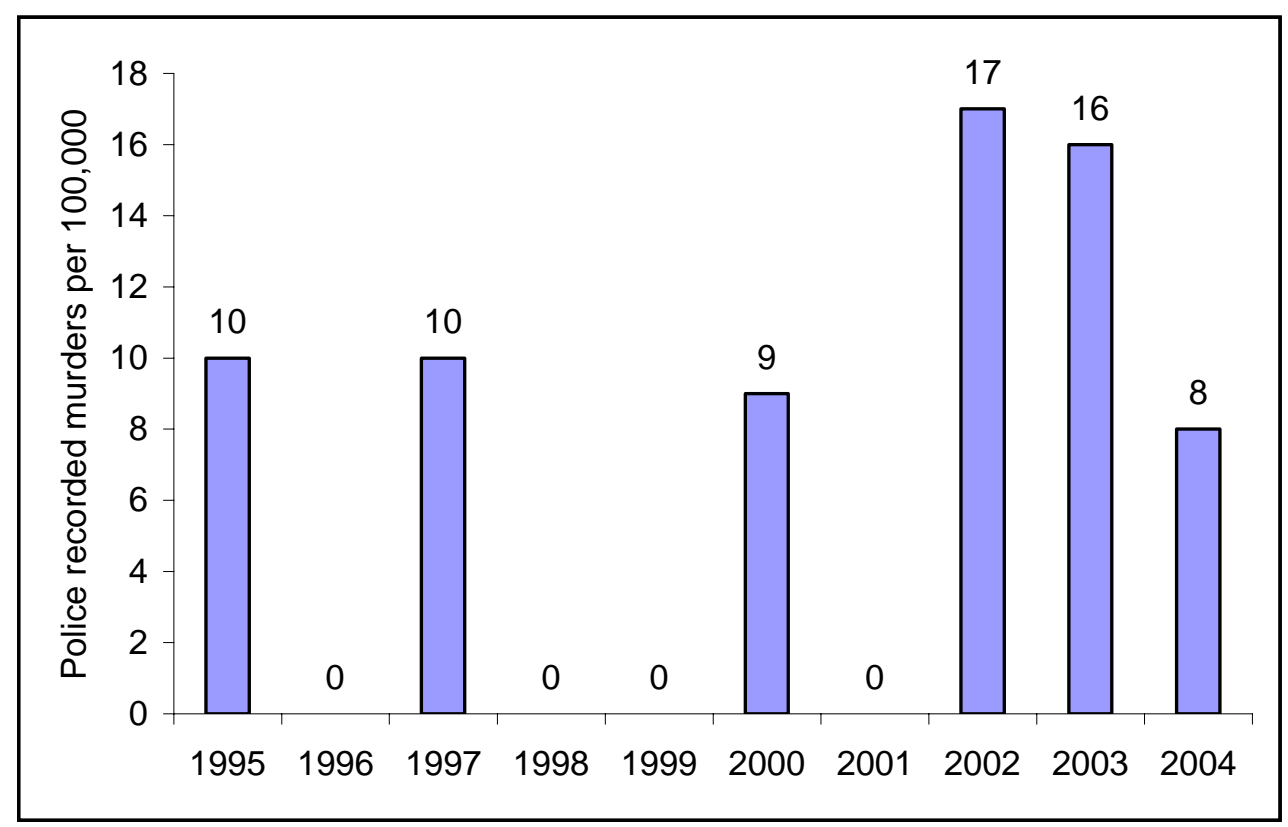

Source: Anguilla Statistics Unit.

1.12 Crime rates are based on the ratio of crimes to full-time residents, but the actual population of small countries with large tourist industries can swell considerably during peak tourism periods. For example, the Bahamas, with a resident population of about 321,000, received nearly 1.5 million stay-over tourist arrivals in 2003 (World Travel and Tourism Council, 2004). Any of these people could have become a crime victim or perpetrator during their stay, so the ratio of crimes to the resident population can be deceptive.

1.13 To complicate matters further, there are frequently significant discrepancies in crime rates within a country depending on the source of the data. In the case of homicide rates, police and public health data sometimes differ substantially. The case of Guyana is instructive: two different murder counts are published in the same statistical bulletinone from the police and one from the ministry of health. This difference is not surprising since public health definitions differ from those used in the criminal justice system, but the ratio between the two varies also considerably over time. The public health figures show a clear increasing trend, while the police figures do not (see Figure 1.5). 
Figure 1.5: Number of Murders in Guyana, Police and Public Health Sources

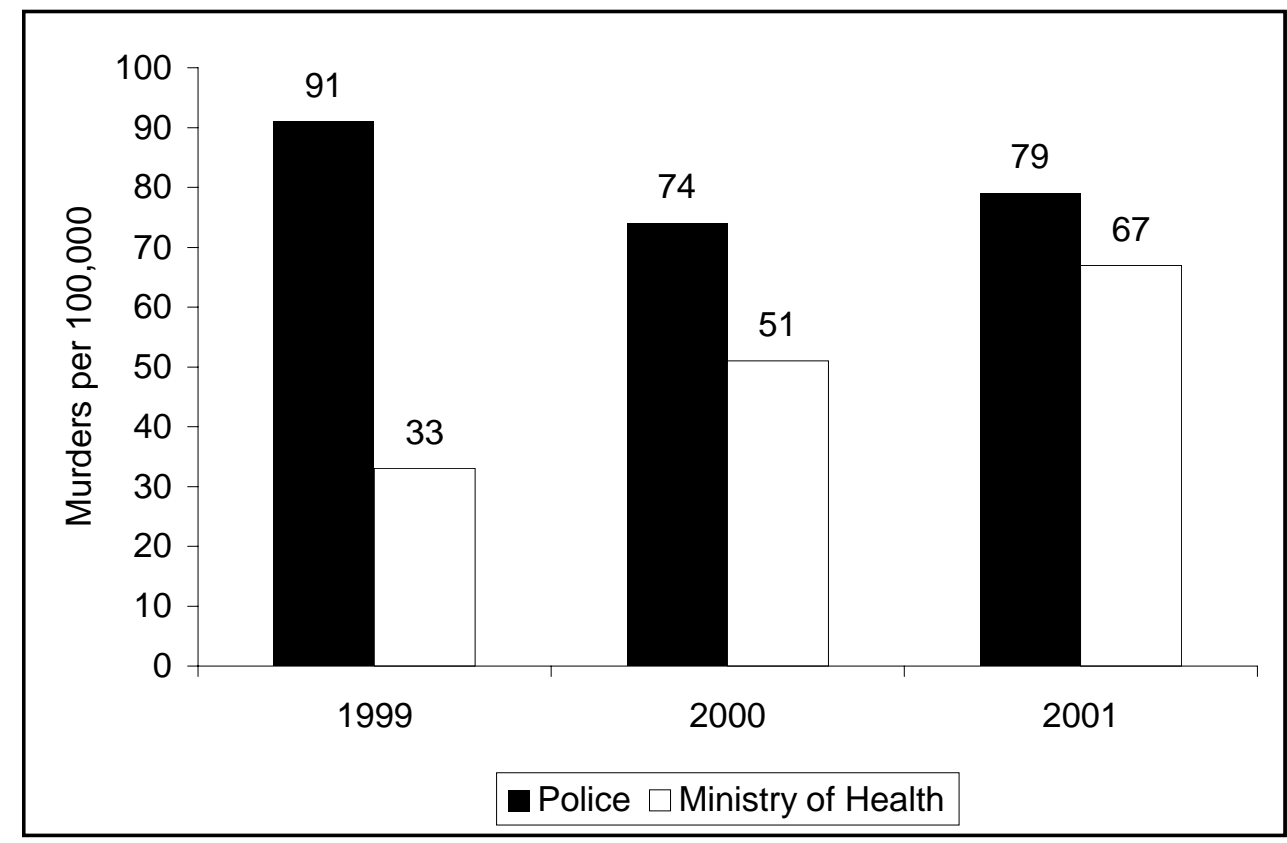

Source: Guyana Bureau of Statistics, 2005.

1.14 UNODC attempts to overcome some of these difficulties through its biannual Survey on Crime Trends and the Operations of Criminal Justice Systems, or CTS. A questionnaire is sent to all United Nations Member States giving standardized definitions of each crime type and asking the respondents to fit their crime figures into the appropriate categories. Of course, this is a difficult exercise, and it is not clear how carefully each respondent complies, but it does provide a better basis for comparison than the figures published by the national police forces. ${ }^{12}$ In the discussion that follows, the CTS data is used, but this data must be treated with caution for all the reasons described above.

\section{HOMICIDE AND ASSAULT}

1.15 Murder figures are generally considered the most reliable indicator of the violent crime situation in a country, since most murders come to the attention of the police, which is not the case with crimes like robbery and domestic violence. But definitions of murder still vary widely. In some countries, attempted murder is included, since legally this is deemed equivalent to the completed act, while in others "culpable" homicides (the killing of another through reckless behavior) are included.

\footnotetext{
${ }^{12}$ Unfortunately, not all Member States supply this information, or they do so erratically, and so global coverage is far from complete. Obviously, countries with extreme stability problems are not able to provide reliable statistics, and it is precisely in these areas that the problems are likely to be worst. For example, little police data are available for Haiti, a country which is probably one of the more dangerous in the region.
} 
1.16 For these reasons, it is best to use standardized data (such as those gathered by CTS or Interpol) for comparative analysis. Unfortunately, the data from both CTS and Interpol are far from complete in this region. Time series CTS figures for the Caribbean are limited to four countries and Interpol figures to two, and even these two data sets differ in many respects.

1.17 Aside from the police statistics, public health authorities maintain records of the numbers of murders in many countries, which are collected by the World Health Organization (WHO) and their regional affiliates. These public health data are available for a wider range of countries than are CTS data, including very small countries. Public health definitions of murder are generally more expansive than those of criminal law, so these figures will be greater than those reported to the UNODC and Interpol.

1.18 According to figures published by the WHO from 2002, a number of Caribbean countries record a rate of death due to violence ${ }^{13}$ in excess of the unweighted average of the 191 countries reporting worldwide, but far below the rates of countries like Colombia, Sierra Leone, or El Salvador (see Figure 1.6). These countries include countries with acknowledged violence issues, such as the Dominican Republic and Haiti, as well as some surprises, such as St. Kitts and Nevis and St. Vincent and the Grenadines. WHO data for Jamaica are clearly in error. According to WHO data Jamaica has one of the lowest rates of intentional violence in the world. According to the police statistics, however, the homicide rate was 56 per 100,000 residents in 2005- one of the highest rates in the world (Jamaican Constabulary Force, 2006).

1.19 Where no standardized data are available, national police statistics can give us a sense of trends within a country over time. The Jamaican Constabulary Force makes long-term comprehensive statistics available to the public, and the trend for Jamaica is quite remarkable (see Figure 1.7). After a peak during the politically-driven violence of the 1980 election, murder rates dropped to pre-election levels and were relatively stable throughout the 1980s. It was during this period of time that many Jamaican criminal groups ("posses") were active in the crack cocaine markets of the United States (Gunst, 1995). Ironically, as the crack trade declined, Jamaican murder rates went up. This may be due to former traffickers turning to income sources more directly rooted in violence, such as extortion. It may also be a symptom of the declining political control of the "area dons" in the "garrison" communities and the proliferation of a larger number of "corner dons," more likely to victimize their own constituencies (Mogensen, 2005), or it may also be related to the deportation of some Jamaican criminals that had been preying on the United States, the United Kingdom, and Canada (see Chapter 6).

1.20 Between 1982 and 1997, the homicide rate more than doubled in Jamaica; from 2003 to 2005 alone, the homicide rate rose from 36 to 58 per 100,000, before falling to 49 per 100,000 in 2006. Jamaica authorities attribute the $15 \%$ decline in the homicide rate in 2006 to law enforcement action. While the recent decline is encouraging, murder rates in Jamaica remain among the highest in the world, and similar rapid reductions in the past

\footnotetext{
${ }^{13}$ Violence in this context is defined as intentional violence minus suicides and war deaths.
} 
have not abated a long-term upward trend. Still, more than 200 people are alive today that would not have been had the murder rate remained at 2005 levels.

\section{Figure 1.6: Deaths Rates from Violence in Caribbean and Comparison Countries}

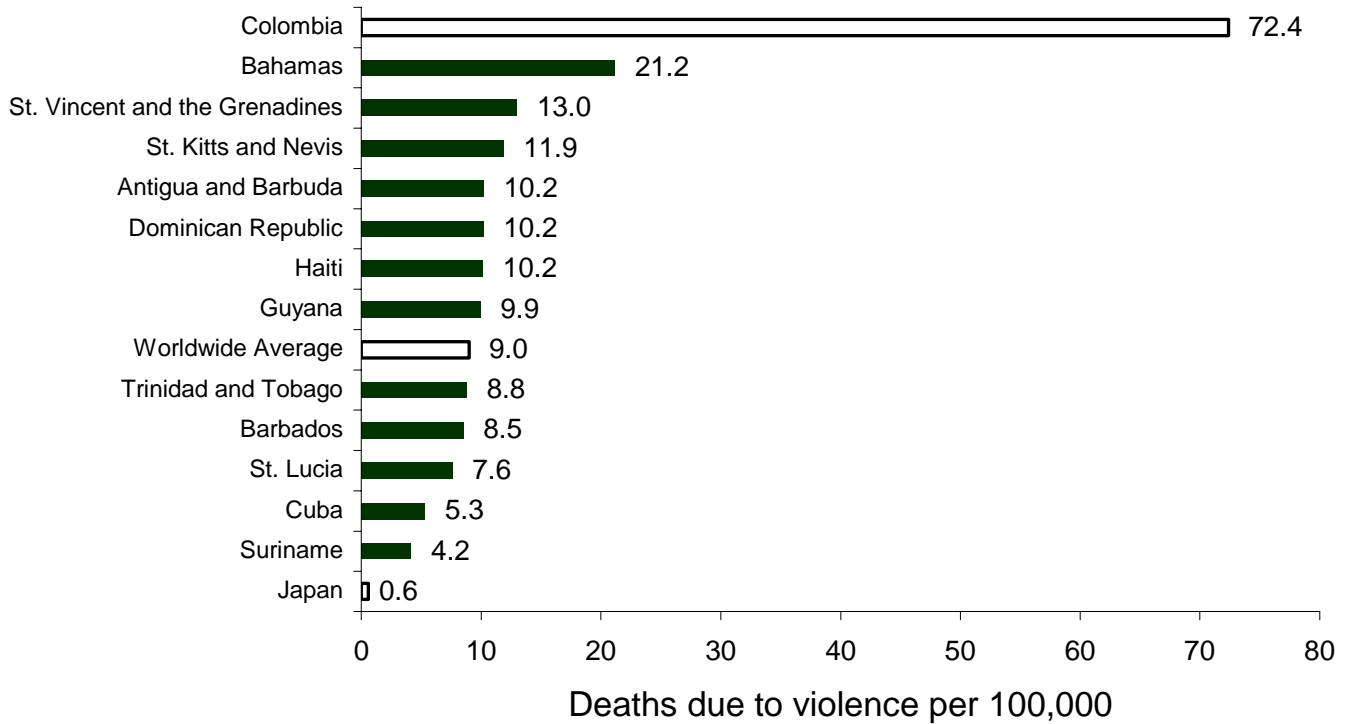

Source: WHO 2002.

1.21 The murder rate in Guyana (see Figure 1.7) has been a subject of frequent alarm in the country, but it displays no clear trend. An average of about 75 to 125 murders occurred annually since 1978, aside from brief peaks in 1991 and 2002-2003. The most recent increase has been attributed to gang warfare in the Buxton area (Guyana Government Information Agency, 2004). Given the small population (about three quarters of a million people), the murder rate is quite volatile and has varied from a low of about 10 per 100,000 in 1986 and 2000 to a high of 27 per 100,000 in 2003. As noted above, the police figures differ considerably from Ministry of Health figures, which were higher to varying degrees in 1999 (33 murders per 100,000 versus 12), 2000 (51 versus 10) and 2001 (67 versus 19).

1.22 Shorter time series on homicide rates are available for the Dominican Republic, St. Lucia, and Trinidad and Tobago (see Figure 1.8). All three countries show rapidly rising rates over the 1999-2005 period. In the Dominican Republic, the homicide rate almost doubled, from 14 to 27 per 100,000. In St. Lucia, the rate more than doubled, from 9 to 20, and in Trinidad and Tobago the rate more than quadrupled, from 7 to 30 per 100,000 . 
Figure 1.7: Homicides per 100,000 in Guyana and Jamaica

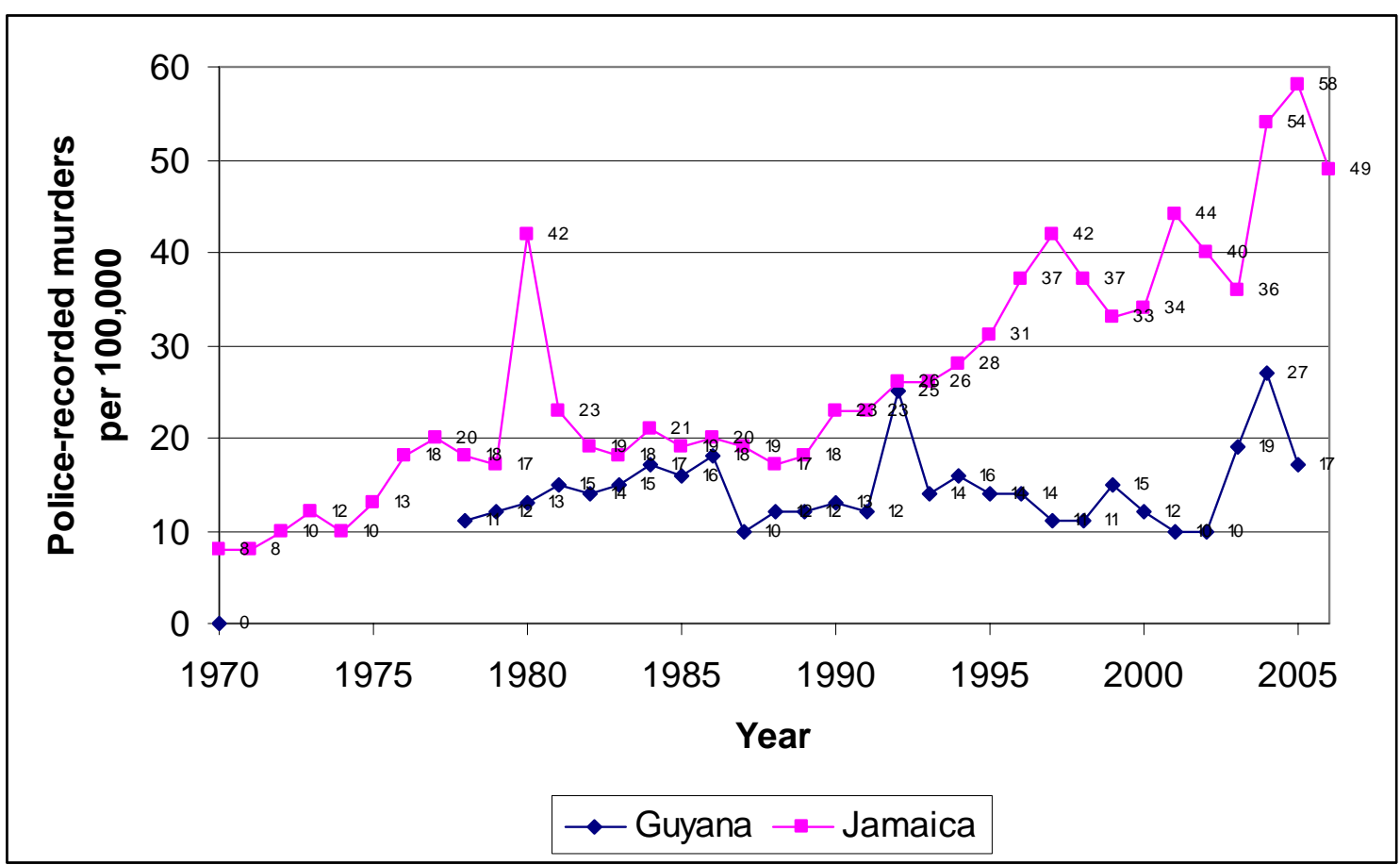

Sources: Jamaica Constabulary Force, 2006; Guyana Bureau of Statistics, 2005.

1.23 According to the police statistics, the French départements (provinces) in the Caribbean also show remarkably high murder rates, despite their relative affluence. Out of 100 French départements, Guiana ranks first in terms of homicide, suffering a total of 94 murders in 2004, for a police recorded murder rate 51 murders 100,000. ${ }^{14}$ Guadeloupe and Martinique ranked third and fourth of 100, with 11 and 10 murders per 100,000 respectively (Direction Centrale de la Police Judiciaire, 2005).

1.24 In sum, homicide rates in the Caribbean are quite high by world standards. For the majority of countries for which time series data are available, homicide rates seem to be rising quite rapidly. Guyana is a notable exception to this trend.

1.25 While most murders make it to the attention of the police, lesser assaults are clearly highly reliant on reporting. The country's attitude toward domestic violence is pivotal, as is the level of trust in the local police. Figure 1.9 reports assault rates for countries with available CTS data. Even Dominica, with its 93 assaults annually per 100,000 citizens, is far in excess of the unweighted average of 10 for the 89 countries for which comparable data are available. The Bahamas reports the highest rate in the CTS dataset: 1,697 per 100,000, twice as high as the second highest rate recorded: 754 per 100,000 in Swaziland, a world leader in murder. This high rate is probably attributable to genuinely high levels of violence, possibly affected by the tourist influx, combined with high rates of reporting to a trusted police force. Victimization surveys are needed to even

\footnotetext{
14 This is much higher than its closest rival, Southern Corsica, which registered 21 murders per 100,000.
} 
approximate true levels of assault, yet standardized victimization surveys have rarely been undertaken in the Caribbean.

Figure 1.8: Homicides Rates in the Dominican Republic, St. Lucia and Trinidad and Tobago: 1999-2005

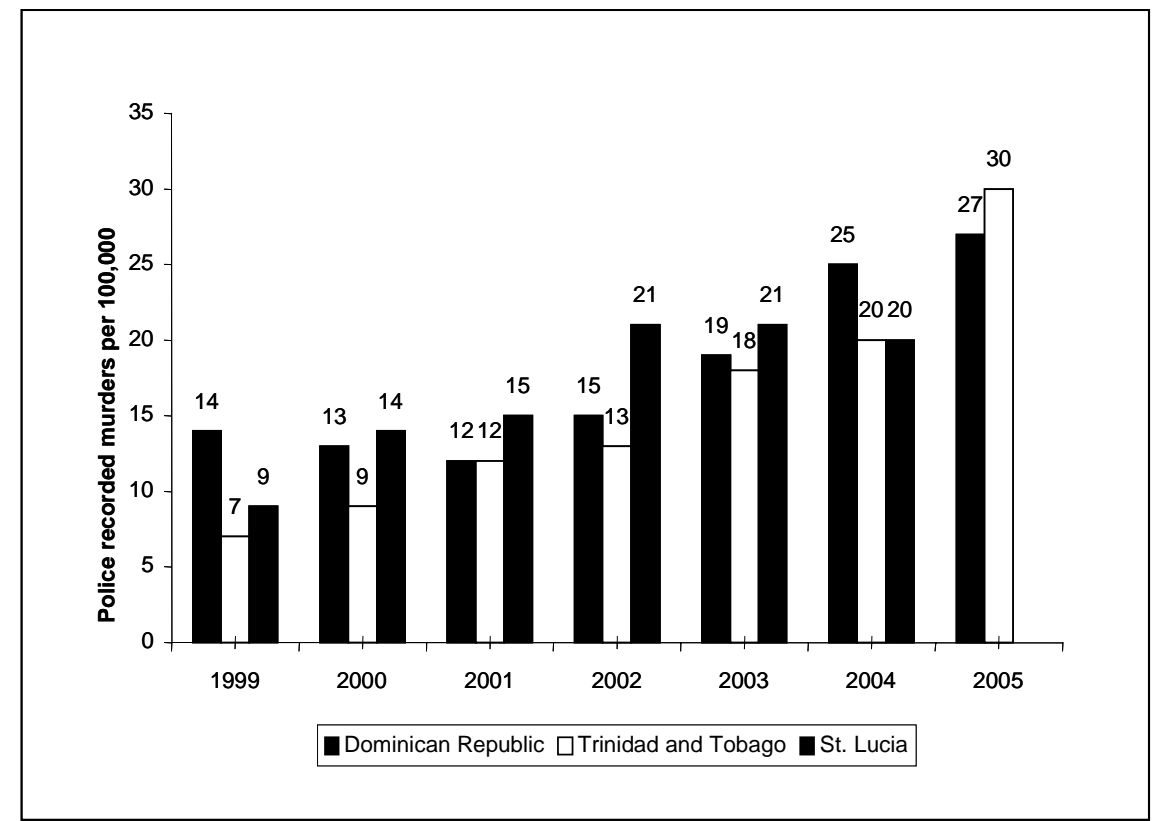

Sources: Procuraduría General de la República Dominicana; Central Statistical Office of Trinidad and Tobago; Central Statistical Office of St. Lucia.

Figure 1.9: Assault Rates in Caribbean and Comparison Countries

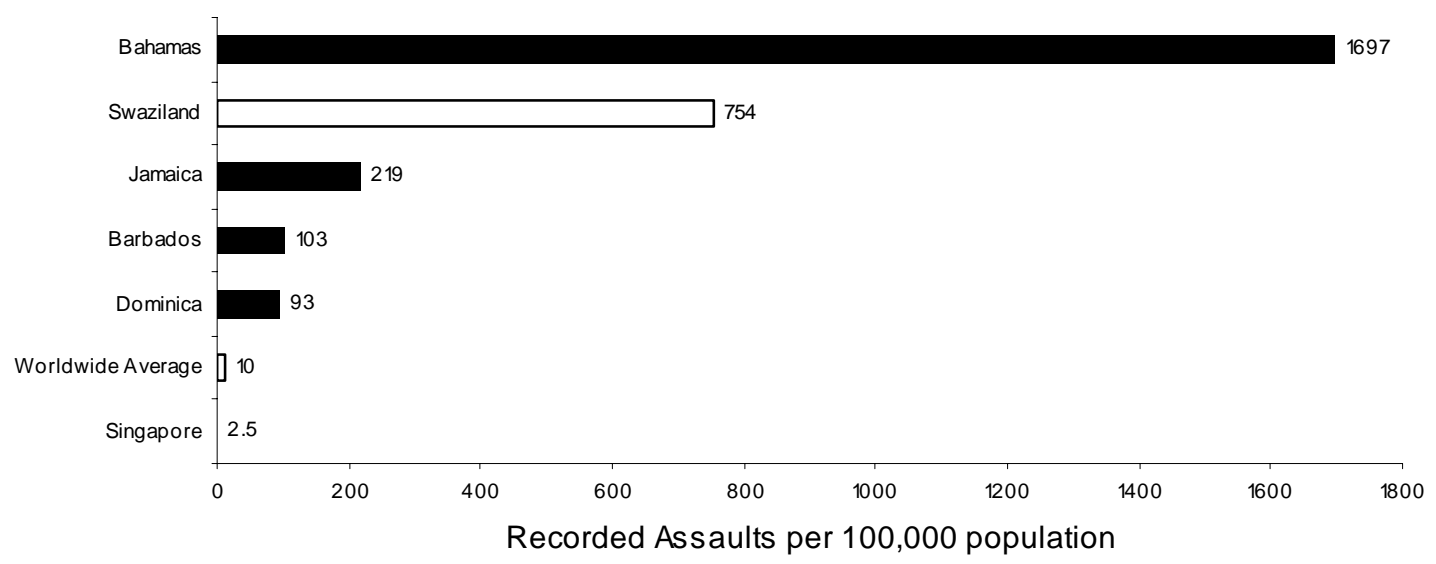

Source: Crime Trends Surveys - United Nations (various years). 


\section{VIOLENCE AGAINST WOMEN}

1.26 Violence against women affects a significant percentage of women and girls in the Caribbean. ${ }^{15}$ Rape is greatly under-reported everywhere in the world, and relatively high recorded rape rates can actually be due to high levels of trust that reporting will result in positive outcomes for the victim. But given the fact that most of the rapes reported did occur, high rape rates do reflect a serious problem. According to the latest available CTS data, three of the top ten recorded rape rates occur in the Caribbean, including the top rated: the Bahamas. All countries in the Caribbean for which comparable data are available experienced a higher rate of rape than the unweighted average of 102 countries responding to the CTS: 15 rapes per 100,000.

Figure 1.10: Rape Rates in Caribbean and Comparison Countries

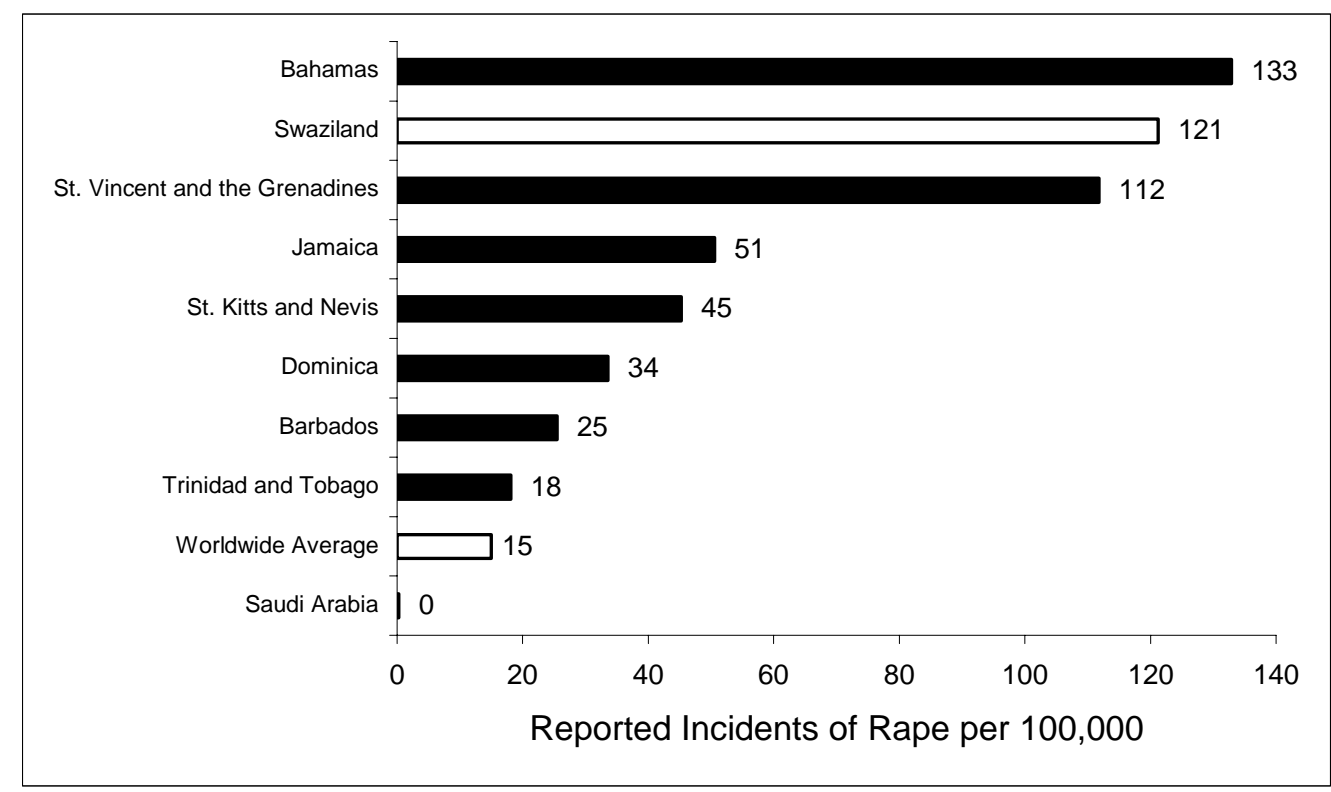

Source: Crime Trends Surveys - United Nations (various years).

1.27 According to police records in the Dominican Republic, women between the ages of 15 and 34 account for nearly two-thirds of all violent deaths among women, despite only representing 36 percent of the female population (ALEPH, 2006.) Those at highest risk are young women working as domestic laborers and those having recently ended an intimate relationship. In approximately 63 percent of cases, the perpetrator is the victim's husband (boyfriend) or ex-husband (ex-boyfriend), followed by mothers (14 percent) and fathers (10 percent) (Caceres, F. and G. Estevez, 2004).

1.28 Police statistics offer only a very imperfect picture of violence against women, since the majority of these incidents are not reported to police. To get a more precise idea

\footnotetext{
${ }^{15}$ Violence against women was defined by a declaration of the General Assembly of the United Nations (Declaration on the Elimination of Violence against Women, 1993) as "any act of gender-based violence that results in, or is likely to result in, physical, sexual or mental harm or suffering to women, including threats of such acts, coercion or arbitrary deprivation of liberty, whether occurring in public or in private life."
} 
of prevalence rates, one must use victimization surveys that focus on violence against women. Unfortunately, as is the case with other crimes, there are no victimization surveys using a common methodology that have been widely used across the Caribbean to document levels of violence against women (see Ellsberg and Heise, 2005). ${ }^{16}$ Consequently, we are left with isolated, country-specific data on prevalence rates; while this is undoubtedly better than relying on country-specific official crime reports, it does not allow cross-country comparisons.

1.29 One notable exception is a regional study carried out in nine Caribbean countries in 1997 and 1998 on adolescent health. According to this study, 48 percent of adolescent girls' sexual initiation was "forced" or "somewhat forced" in these nine countries (see Halcon et al, 2003). ${ }^{17}$ In Kingston, Jamaica in the early 1990s, 17 percent of 13 and 14 year-olds had been raped or been victims of attempted rape, and 33 percent had experienced unwanted physical contact or verbal enticements to have sex (Walker et al., 1994).

1.30 While there has been no comparable methodology used in a large number of Caribbean countries on domestic violence, national level prevalence studies generate surprisingly similar victimization rates. In Haiti, a recent DHS survey found that 28.8 percent of ever-married women had been beaten by a spouse. Older data from nationally representative surveys undertaken in Antigua and Barbuda and Barbados in 1990 indicated that 30 percent of all women in each country had been victimized by physical violence at the hands of an intimate partner at some point in their lives (see Heise et al, 1999). ${ }^{18}$ These lifetime prevalence rates are within the range of those found outside the region in a study recently undertaken by the World Health Organization. Rates of lifetime physical violence ranged from a low of 12.9 percent in urban Japan to a high of 61 percent in rural Peru, with a non-population weighted average prevalence rate of 36.3 percent over the 15 study sites in the ten countries (García-Moreno, C. et al., 2006).

1.31 In sum, violence against women seems to be endemic in Caribbean countriesas it is in most countries around the world.

\section{PROPERTY CRIME}

1.32 As the preceding sections have shown, the rate of murders is the single best crime statistic for comparative analysis. Data on property crime are far less reliable, since the rates of reporting the various offenses vary so greatly between jurisdictions and across time. In wealthier countries, a greater share of the population may have insurance and thus strong incentives for reporting victimization. These countries may appear to have much higher rates of property crime than poorer areas. Similarly, in some countries

\footnotetext{
${ }^{16}$ Standard victimization surveys do not do a good job of capturing violence against women. Special protocols are needed, both to protect the safety of interviewers and respondents, and to elicit accurate answers.

${ }^{17} 32$ percent of male adolescents' first intercourse was forced. The nine countries and territories were: Antigua and Barbuda, Bahamas, Barbados, British Virgin Islands, Dominica, Grenada, Guyana, Jamaica, and St. Lucia.

${ }^{18}$ In Antigua and Barbuda, the sample was of women ages 29-45, while in Barbados it was women 20-45.
} 
reporting minor crimes is seen as a civic duty, even if the prospects for a positive outcome are poor. If there were good victim survey data indicating the level of underreporting, the police figures could be interpreted in this light. Unfortunately, only Barbados has participated in the ICVS surveys.

1.33 Generally speaking, the best reported property crime is vehicular theft, and it is often used as an indicator of overall property crime levels. There are two problems with doing this in the Caribbean. First, the opportunities to successfully steal a car are limited on small islands, so vehicular theft rates may not be indicative of overall property crime levels. Second, since not everyone owns a car, the rate of property theft should properly be calculated as the number of incidents per motor vehicle in the country, not per 100,000 population. However, recent and reliable information on the number of vehicles in the Caribbean is not available.

1.34 The fact that reporting rates are key determinants in the levels of recorded crime is demonstrated by the available statistics on other forms of property crime. Australia leads the world in reported burglary rates, with Dominica scoring third, after Denmark (United Nations Crime Trends Survey, various years). While it is possible that some of the most developed countries, with low levels of inequality, suffer from extreme levels of burglary, it is more likely that this offense is simply under-reported in countries where it actually occurs more often.

1.35 Theft rates are subject to even higher levels of under-reporting. It is highly unlikely, for example, that Demark has an incidence of major theft 7,000 times higher than in Poland (3,449 episodes per 100,000 persons in Demark, versus 0.5 per 100,000 in Poland). Dominica has the second highest rate of recorded major theft among the 65 countries reporting this figure in the Crime Trends Survey, but the meaning of this distinction is highly dubious.

1.36 Given what is known about other aspects of crime in the region, it is highly unlikely that Dominica, which bills itself as "the nature island of the Caribbean" has 20 times the burglary rate and 30 times the theft rate of Jamaica, an island with acknowledged crime problems. 


\section{ORGANIZED CRIME}

Organized crime in the Caribbean is involved in a variety of activities, among which the most widespread is drug trafficking. In 2005, it is estimated that about 10 tons of cocaine transited through Jamaica, and 20 tons went through Haiti or the Dominican Republic. However, the flow of drugs through the region has decreased with the shift of trafficking to the Central American corridor. Cannabis production for export from Jamaica, the largest producer in the region, also appears to be in a slump. But demand from Europe may be increasing, and much of this traffic transits the Caribbean. Kidnapping and corruption also affect the region. Haiti and Trinidad and Tobago have seen recent and rapid increases in kidnappings. There appears to be wide variation in levels of corruption in the region. According to Transparency International's 2006 Corruption Perceptions Index, Haiti is perceived to be the country in the world with the highest levels of corruption, while Barbados was ranked among the least corrupt.

2.1 Violence in the Caribbean is aggravated by the presence of organized crime. There are no internationally comparable statistics on organized crime generally, but its activities can be detected in conventional crime statistics, as well as in seizures of contraband, particularly drugs. This information is supplemented by details emerging from criminal cases, as well as criminal intelligence, largely from developed countries. ${ }^{19}$

\section{DRUG TRAFFICKING}

2.2 Despite their diversity, one thing all Caribbean countries have in common is that they have long been caught in the crossfire of international drug trafficking. The Caribbean suffers greatly from the supply from the south and the demand in the north. Drug flows through a country can aggravate crime in a range of ways:

- They produce local drug use problems, as couriers are often paid in product rather than cash and are compelled to sell on local markets. This has secondary effects on domestic crime problems, including youth gangs, prostitution, and marketrelated violent and property crime.

- $\quad$ Drug transactions involve firearms, and firearms are often traded for drugs.

- Movement of drugs inevitably involves corruption of local law enforcement officials, as well as other civil servants.

- Laundering the proceeds of drug sales undermines legitimate economic activity.

\footnotetext{
${ }^{19}$ Since the United States is the main source of drug demand affecting the Caribbean, U.S. information sources are used extensively in this chapter.
} 
2.3 The good news is that the flow of drugs through the region may be decreasing:

- The transshipment of cocaine to the United States, the most significant flow in economic terms, has declined, as cocaine consumption in the United States dropped from its high levels in the 1980s (see National Institute on Drug Abuse, 2005). ${ }^{20}$

- Cannabis production for export from Jamaica, the largest cannabis producer in the region, appears to be in a slump (see Royal Canadian Mounted Police Criminal Intelligence Directorate, 2005). ${ }^{21}$ On the high end of the market, Jamaican cannabis faces competition from the growing popularity of indoor-produced sinsemilla in consumer countries in North America and Europe. ${ }^{22}$ Partly as a result, cannabis eradication rates dropped sharply after 1999, though they have recovered somewhat since then (see Figure 2.1). ${ }^{23}$

- The Caribbean has traditionally been the preferred drug transshipment corridor of Colombian organized crime groups, often working with wholesalers and retailers from the Dominican Republic. For a number of reasons (including effective law enforcement in the Caribbean, the break-up of the major Colombian cartels, and growing stability in Colombia), Mexican organized crime groups have supplanted the Colombian organizations throughout much of the United States. Mexican groups prefer to transship along the Central American coast and then across the U.S./Mexico border. They also prefer to market Mexican-produced cannabis on the low end of the market ${ }^{24}$ (see Figure 2.2 for the most commonly used transport corridors for the shipment of cocaine to the U.S.).

\footnotetext{
${ }^{20}$ While changes in the methodology of the national household surveys in the United States make longterm national comparisons problematic, cocaine use among U.S. high school $12^{\text {th }}$ graders plummeted from 13.1 percent annual prevalence in 1985 to 5.1 percent in 2005.

${ }^{21}$ The one area where the Caribbean continues to dominate is hash oil, a product Central and Atlantic Canada have long imported from Jamaica. Jamaican traffickers in Ontario are responsible for smuggling hash oil directly from the Caribbean and also manufacturing it within Canada.

${ }^{22}$ The share of sinsemilla in cannabis samples submitted to the Marijuana Potency Monitoring Project, which tests every seizure in which federal agents are involved, grew from 5 percent in 1985 to 31 percent in 2003. This sinsemilla averaged 14 percent THC in 2003, much higher than most field-grown cannabis.

${ }^{23}$ See Annex 2.1 for a discussion of the Jamaican cannabis trade.

${ }^{24}$ See Annex 2.2 for a discussion of patterns of drug transhipment by organized crime.
} 
Figure 2.1: Cannabis Eradication in Jamaica

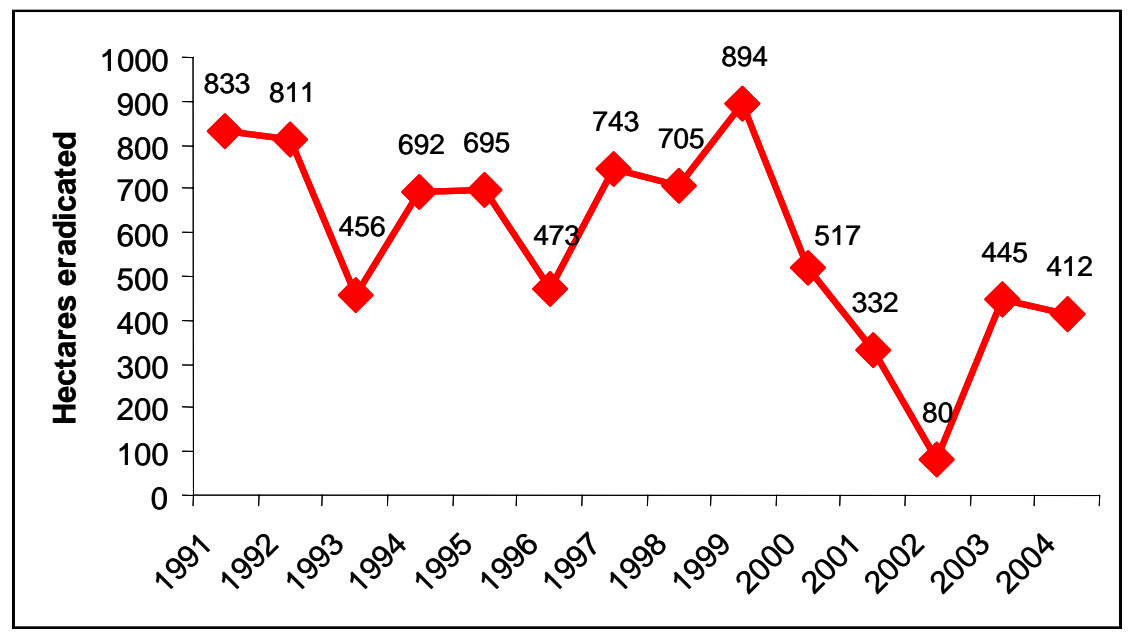

Source: International Narcotics Control Strategy Report, various years.

Figure 2.2: Shares of Cocaine Flowing to the United States by Transport Corridors

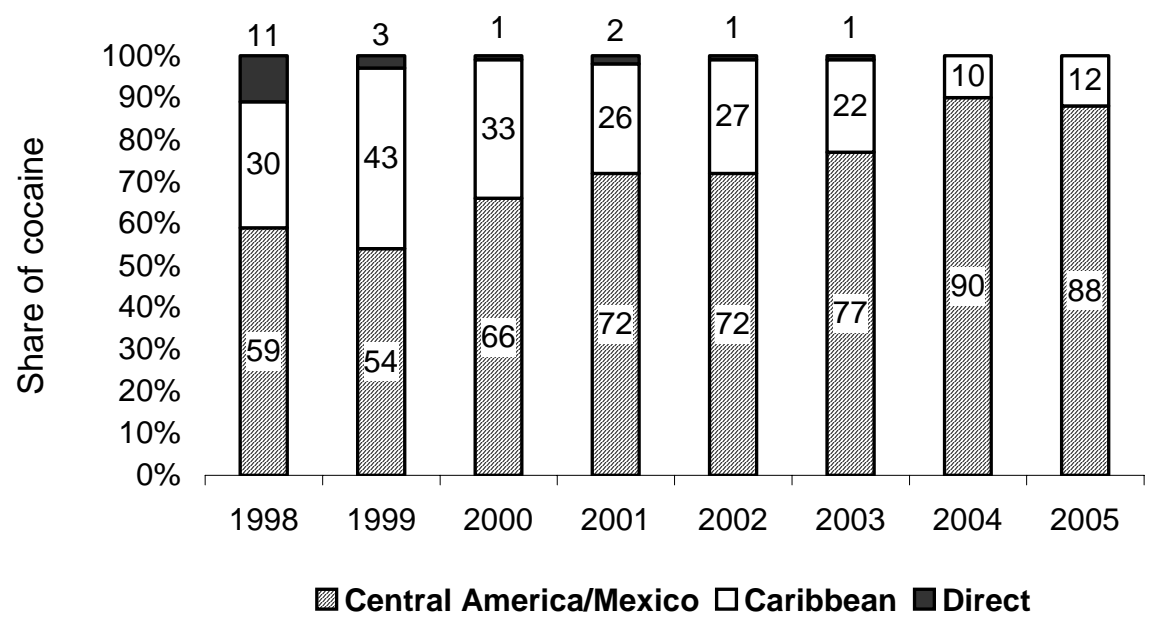

Source: U.S. National Drug Intelligence Center, various years.

2.4 There are, however, several contrary developments:

- While cocaine use in the United States has declined, it is increasing in Europe. For example, cocaine use rates in Spain and England today are close to United States rates (see World Drug Report, 2006). ${ }^{25}$ Europol reports that 40 percent of the cocaine entering Europe transits the Caribbean. ${ }^{26}$

\footnotetext{
${ }^{25}$ In 2003, adult annual cocaine usage stood at 2.7 percent in Spain and 2.4 percent in England and Wales. In the USA, it stood at 2.8 percent in 2004.

${ }^{26}$ Europol, statements made at the Horizontal Drug Group (HDG) of the European Union, 10 January 2006. See Annex 2.3 for a discussion of cocaine transhipment patterns.
} 
- Canada also poses an alternative market, with a high level of cocaine use. ${ }^{27}$ In 2004, large (in excess of 100 g) seizures of cocaine were made entering into Canada from a number of countries in the Caribbean, including Jamaica, Trinidad and Tobago, the Netherlands Antilles, Guyana, St. Vincent and the Grenadines, Haiti, St. Lucia, Grenada, Barbados, Suriname, and Dominica.

- Since 1993, the United States has become increasingly dependent on Colombian heroin (see Figure 2.3). In terms of value per unit volume, heroin is worth more than cocaine, and thus it is still most commonly trafficked using couriers on commercial air flights. However, many large volume shipments have also been detected.

- Synthetic drugs seem to be increasingly transiting or originating in the Caribbean. For example, on 28 November 2005, 259,338 ecstasy tablets were found when three abandoned bags were seized at the airport in Puerto Playa, believed to have originated in the Netherlands and to be destined for the United States. ${ }^{28}$ In 2005, an LSD lab was discovered on the Dutch side of St. Maarten, (U.S. Department of State, 2006) a relatively rare find for law enforcement anywhere in the world due to the difficulty of synthesizing this drug.

2.5 Thus, despite recent shifts and as indicated above, large quantities of drugs continue to transit the Caribbean. There are many reasons to expect that the Caribbean will continue to be a key drug transshipment area:

- Colombia remains the source of most of the United States' cocaine and heroin, so the Caribbean will remain an attractive transshipment route.

- The Caribbean has language, historical, commercial, and legal ties to some of the major consumer countries, including the massive tourism industry. These ties include daily direct air flights and container traffic.

- The Caribbean diaspora, particularly nationals of Jamaica and the Dominican Republic, are key in domestic drug distribution in parts of North America and Europe. ${ }^{29}$ Expatriates from Europe and the United States living in the Caribbean further enhance this network. ${ }^{30}$

- The torrent of remittances from expatriate populations, as well as a large financial services industry, provides cover for money laundering.

\footnotetext{
${ }^{27}$ Annual use prevalence of 2.3 percent in 2004. See World Drug Report 2006 Volume 2 page 385.

${ }^{28}$ Personal communication, Col. Radhames Antigua Sanchez, Director CICC, Direccion Nacional del Control de Drogas, 1 February 2006.

${ }^{29}$ See Annex 2.4 for a discussion of organized crime in Jamaica and the Dominican Republic.

${ }^{30}$ Some arrest data reported to the UNODC in response to the Annual Reports Questionnaire gives an interesting perspective into the role citizens of the former colonial powers play in drug trafficking in this region. In Jamaica in 2004, for example, there were nearly as many foreigners arrested for drug offenses (221) as Jamaicans (234). The single largest group were British (although some may have been British of Caribbean ancestry). There were 68 British citizens arrested for cocaine offenses, compared to 79 Jamaicans. Overall, there were more foreigners arrested for cocaine offenses (124) than Jamaicans (79). Similarly, in Suriname in 2004, 269 Surinamese were arrested for drug offenses, compared to 174 Dutch nationals.
} 
Figure 2.3: Origin of Heroin Seized in the United States

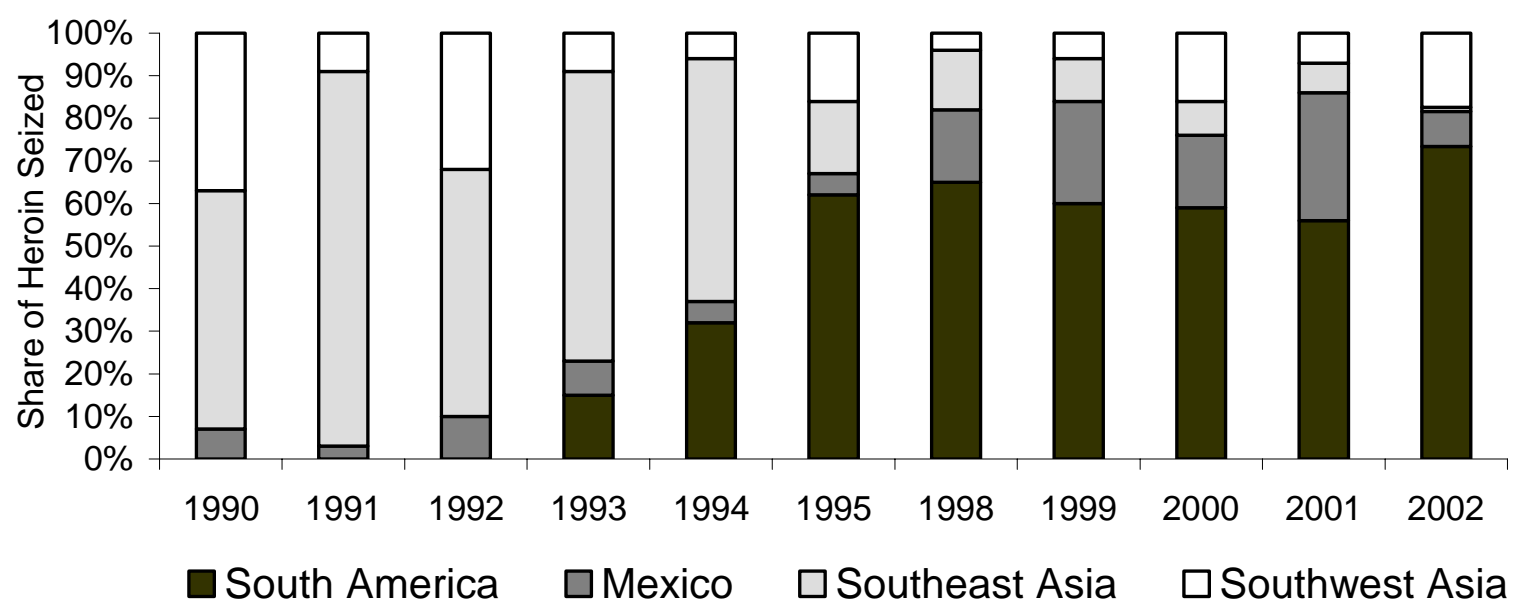

Source: U.S. Drug Enforcement Administration Heroin Signature Program (National Drug Intelligence Center, 2002, 2003 and 2004; Drug Enforcement Administration, 1996)

2.6 It is not surprising, then, that of the 20 countries identified as major drug transit or major drug producing countries by the United States government in 2006, four are in the Caribbean: the Bahamas, the Dominican Republic, Haiti, and Jamaica. ${ }^{31}$ In commenting on this list, however, the United States government has noted the interdiction successes of the Bahamas and the Dominican Republic. ${ }^{32}$ In contrast, Haiti has received less praise for their cooperation with the United States, and has even faced being designated as a non-cooperating country. ${ }^{33}$

2.7 On the other side of Hispaniola, Dominican authorities estimate that, in 2004, most (67 percent) of the cocaine entering their country came by land, which means it came from Haiti. This is actually a substantial decrease from 2003, when the figure was 90 percent (UNODC, 2004). The Dominican Republic is seen as a "command, control, and communications" center for drug operations in the Caribbean. It is also used to store drugs, before onward shipment to Puerto Rico or the United States. ${ }^{34}$

\footnotetext{
${ }^{31}$ United States Presidential Determination No 2006-24, September 18, 2006.

${ }^{32}$ Statement of Acting Assistant Secretary of State for International Narcotics and Law Enforcement Affairs, Ambassador Nancy Powell, Briefing on Ongoing Diplomatic Activities at the UN and Other Current U.S. Foreign Policy Issues, Foreign Press Center, New York City September 15, 2005.

${ }^{33}$ The U.S. Drug Enforcement Agency has been involved in the arrest of many individuals linked to former-President Artistide's Lavalas party, including former senators and senior police officials, such as the former chief of presidential palace security and former chief of the anti-drug police. The fact that Haiti does not seize as much cocaine as many of her neighbours is more reflective of law enforcement capacity then drug flows: the Haitian anti-drug police has only about 40 members. See International Crisis Group, "Spoiling security in Haiti." Latin America/Caribbean Report No 13. Brussels: International Crisis Group, 2005.

${ }^{34}$ Statement of Rogelio E. Guevara, Chief of Operations of the U.S. Drug Enforcement Administration, before the House of Representatives Committee on International Relations, 10 October 2002.
} 
2.8 The U.S. list does not include Puerto Rico, a U.S. territory. Puerto Rico has the third busiest port in North America, and its commonwealth status with the United States means that any shipments leaving Puerto Rico are not subject to search in the United States. In 2001, the head of the United States Drug Enforcement Administration described Puerto Rico as "an excellent gateway for drugs destined for East Coast [U.S.] cities. ${ }^{35}$ It has been the traditional transit area used by Dominican groups to bring cocaine into the United States. ${ }^{36}$

2.9 Cuba's relatively low ranking in terms of seizures has been attributed to recent enforcement efforts. According to the Nicaraguan police, seaborne cocaine has abandoned the routes along the Cuban coast due to increased patrolling, and now hugs the coastline of Nicaragua and Honduras. ${ }^{37}$

2.10 But there are few islands that cannot claim annual seizures of over half a ton of cocaine at some point in the recent past (Table 2.1). In addition, substantial amounts of heroin have been seized in the Dominican Republic, Aruba, the Netherlands Antilles, Bermuda, Puerto Rico, and, most recently, Trinidad and Tobago. ${ }^{38}$ The Dominican Republic in particular seems to be seeing an increasing flow of heroin, with seizures growing from seven kilos in 1998 to 122 in 2005. This is not surprising given the role Dominican expatriates have played in drug distribution in the United States.

\footnotetext{
${ }^{35}$ Statement of R. Marshall, head of the U.S. Drug Enforcement Administration, before the Senate Caucus on International Narcotics Control, 15 May 2001. Marshall also noted that while "Mexican trafficking groups normally charge Colombian traffickers 50 percent of each shipment to transport their product through Mexico, ...Dominican and Puerto Rican groups offer the same service for as low as 20 percent.”

${ }^{36}$ Statement of Micheal T. Horn, chief of International Operations, U.S. Drug Enforcement Administration, before Senate Foreign Relations Committee, Subcommittee on the Western Hemisphere, Peace Corps, Narcotics, and Terrorism, 16 July 1997.

${ }^{37}$ Lt Col. Miguel Guilarte, head of the Nicaraguan anti-drugs unit of the border police, in LatinNews.com, "Cuba: Antinarcotics drive becomes a 'national security issue."” Latin American Regional Report: Caribbean and Central America, March 2005.

${ }^{38}$ Fifteenth Meeting of the Heads of National Drug Law Enforcement Agencies, Latin America and the Caribbean, Santa Marta, Colombia, 18- 21 October 2005
} 
Table 2.1: Highest Total Annual Cocaine Seizure, 1998-2004

\begin{tabular}{|l|c|c|}
\hline \multicolumn{1}{|c|}{ Country/territory } & Year & $\begin{array}{c}\text { Highest annual seizure } \\
\text { total (kilograms of } \\
\text { cocaine) 1998-2004 }\end{array}$ \\
\hline Puerto Rico & 1998 & 10344 \\
\hline Netherlands Antilles & 2003 & 9025 \\
\hline Bahamas & 2003 & 4361 \\
\hline Jamaica & 2002 & 3725 \\
\hline Guadeloupe & 1998 & 3222 \\
\hline Cuba & 1999 & 2444 \\
\hline Dominican Republic & 1998 & 2342 \\
\hline British Virgin Islands & 2001 & 2159 \\
\hline Turks and Caicos & 1998 & 2075 \\
\hline Cayman Islands & 1999 & 1926 \\
\hline Haiti & 1998 & 1272 \\
\hline Martinique & 2003 & 1138 \\
\hline Anguilla & 2001 & 926 \\
\hline Trinidad and Tobago & 2001 & 821 \\
\hline Aruba & 1998 & 794 \\
\hline Antigua and Barbuda & 2001 & 767 \\
\hline Bermuda & 2001 & 667 \\
\hline
\end{tabular}

Source: UNODC Data database

2.11 One possible side effect of drug transshipment is the development of local use problems, as have started to manifest themselves with heroin and ecstasy in the Dominican Republic. ${ }^{39}$ This is particularly true if the drug is moved through a diffuse network of couriers (as is typical with heroin) rather than through a small number of large shipments orchestrated by a few central players. For the most part, drug use levels in the Caribbean are lower than in the destination markets, suggesting that high levels of organization have typified the market in the past. Today, however, in a number of countries, drugs are dealt on the street by loosely organized groups of young people.

\section{OTHER FORMS OF ORGANIZED CRIME: KIDNAPPING, MONEY LAUNDERING, CORRUPTION}

2.12 Other forms of organized crime affect the region as well. Three forms of important organized crime are kidnapping, money laundering and corruption. ${ }^{40}$

\footnotetext{
39 Unfortunately, the survey data on drug use in the Dominican Republic are rather dated. In 2001, heroin users comprised about 4 percent of the treatment population in the country, the highest share in Latin America except Mexico, where the drug is produced (5 percent). Authorities estimate that half of the ecstasy trafficked through the country is for local use.

${ }^{40}$ While there is some evidence that forms of human trafficking occur in the Caribbean, there is little data on the scale of this problem. There were only 56 convictions in the entire Western Hemisphere for human trafficking in 2004, up from 27 in 2003. Compare this to Europe and South Asia, both of which lodged over 1,200 convictions in 2004. See Office to Monitor and Combat Trafficking in Persons, 2005.
} 
2.13 Official statistics on kidnapping are not reflective of the extent of a kidnapping problem in a country. There are several reasons for this. Definitions of kidnapping vary greatly, from the very specific offense of abducting a child for the purpose of extorting money out of parents to more generic laws proscribing moving people against their will. Most kidnapping laws do not distinguish between the unlawful removal of a person for non-financial motives (such as often occurs during a custody dispute over a child) and organized kidnapping for ransom. In some jurisdictions, kidnapping is often a supplemental charge brought in to strengthen a case that was really about something else, such as cases of abduction for the purposes of sexual assault. Perhaps most importantly, many kidnappings go unreported to the police, as this is often a demand made by the kidnappers as a condition for the safe return of the person. In fact, it is precisely in countries where kidnappings are common that reporting often declines, as professional negotiators enter the picture and supplant the role of official law enforcement.

2.14 Thus, it is more useful to look at trends within a country than to compare rates across countries. Using this metric, two countries in the Caribbean have seen rapid increases in their kidnapping rates in recent years. The kidnapping rate nearly doubled in Trinidad and Tobago between 1999 and 2005. ${ }^{41}$ And in Haiti, the acceleration between September and December 2005 was meteoric: according to 2005 figures compiled by MINUSTAH, 56 individuals were kidnapped in September, 63 in October, 74 in November and 241 in December-almost all in urban areas (United Nations, 2006).

2.15 Kidnapping is a relatively new problem for Trinidad and Tobago, possibly fuelled by wealth disparities, ethnic divisions, and the proximity of the country to Colombia. While suspicion typically falls on the Muslim extremist group Jamaat-alMuslimeen, ${ }^{42}$ there is evidence that less organized criminals are tapping into this lucrative activity. The ransoms can be considerable: more than seven million U.S. dollars was paid out for the release of six members of the Greater Chaguanas Chamber of Industry after they were kidnapped in 2004 (Maharaj, 2004). The situation in Haiti may be even more dire, which is remarkable given that the crime really only emerged in the past two years.

2.16 Historically, the Caribbean has been susceptible to money laundering for a number of reasons. It has long focused on providing offshore financial services to the United States and European markets, but due to the small state capacity, did not have sufficient oversight resources. It is physically located along one of the world's premiere drug and cash thoroughfares. The tourism sector generates numerous cash-based businesses through which dirty money can flow undetected. The Dominican Republic provides an example of both of these techniques, as transport of bulk cash remains one of the primary means of transporting drug proceeds from the United States to

\footnotetext{
${ }^{41}$ These figures are based on information provided by the Central Statistical Office of Trinidad and Tobago.

${ }^{42}$ See Annex 2.5 for a description of Jammat-al-Muslimeen’s activities in Trinidad and Tobago.
} 
Figure 2.4: Kidnappings per 100,000 Population in Trinidad and Tobago

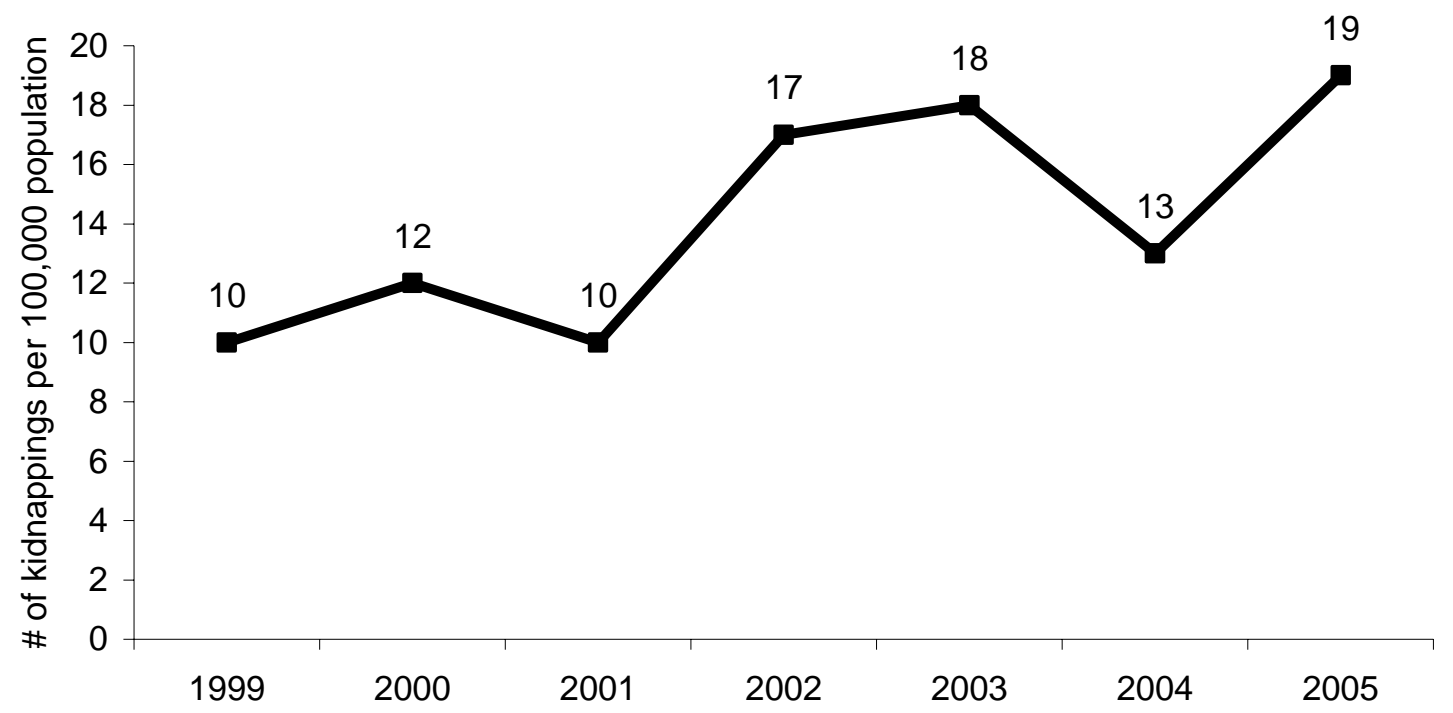

Source: Elaborated from Central Statistical Office of Trinidad and Tobago

the country. Local casinos and currency exchange houses are also said to be a major channel. ${ }^{43}$ Finally, the region is the recipient of a huge number of small cash remittances from the United States and Europe, constituting up to 30 percent of the GDPs of some Caribbean countries (ECLAC, 2005). ${ }^{44}$

2.17 Considerable progress has been made in combating money laundering in recent years, in part due to measures to block terrorist financing. The Financial Action Task Force (FATF) on Money Laundering, a Caribbean inter-governmental body, has published a list of "non-cooperative" countries and territories since 2000. Four Caribbean countries and one territory (Bahamas, Cayman Islands, Dominica, St. Kitts and Nevis and St. Vincent and the Grenadines) were placed on this list in 2000, and Grenada was added in 2001. By 2003, actions in all these countries and in the Cayman Islands led them to be removed from the non-cooperative list. ${ }^{45}$ The FATF has been a major factor in Caribbean countries improving their policies to combat money laundering (Sullivan, 2006).

2.18 The United States government also publishes a list of countries where money laundering is believed to be taking place. A number of Caribbean nations are currently listed as "jurisdictions of primary concern" for money laundering by the U.S, State Department: Antigua and Barbuda, the Bahamas, Belize, Cayman Islands, the Dominican

\footnotetext{
${ }^{43}$ Statement of Rogelio E. Guevara, Chief of Operations of the U.S. Drug Enforcement Administration, before the House of Representatives Committee on International Relations, 10 October 2002.

${ }^{44}$ It is estimated that Haiti's remittances are around US\$1 billion, while its GDP is only about US\$3 billion. After the collapse of its coffee and offshore assembly sectors, Haiti's top sources of foreign exchange are said to be remittances, foreign aid, and the drug trade.

${ }^{45}$ Bahamas and the Cayman Islands were removed in June 2001; St. Kitts and Nevis in June 2002; Dominica in October 2002; Grenada in February 2003; and St Vincent and the Grenadines in June 2003 (Sullivan, 2006).
} 
Republic, Haiti, and St. Kitts and Nevis. It is important to note, however, that many major financial centers are also on the list, including the United States itself, the United Kingdom, Canada, France, Germany, Italy, and the Netherlands, as well as many other countries.

2.19 "Corruption" is a broad heading for a variety of activities related to the misuse of public office, including the extortion of bribes, procurement fraud and related kickback schemes, and the direct embezzlement of public funds. Not all of these activities are "organized" in the sense that large networks of individuals are concerned, but official corruption is extremely valuable to organized crime groups, and these groups play a strong role in promoting it, especially among law enforcement and border control officials. A case of corruption that had serious impacts on the economy of the Dominican Republic is described in Box 2.1.

2.20 The Caribbean may be vulnerable to corruption for a variety of reasons. In small states, the educated elite may be widely connected by blood, marriage, or social ties, and so it is difficult to distinguish nepotism from simple market necessity. Areas with a history of authoritarian government may also be susceptible, as the lack of transparency during these regimes can create a culture of corruption that endures even after the coming of democracy.

2.21 While there are serious methodological concerns about Transparency International's Corruption Perceptions Index (CPI), it remains the standard for international corruption comparisons, and boasts one of the few datasets with near-global coverage. In the $2006 \mathrm{CPI}$, Haiti ranked as the country perceived as most corrupt in the world (163 ${ }^{\text {rd }}$ out of 163 countries). Ranking for some other Caribbean countries were as follows: Guyana (121), Dominican Republic (99), Suriname (90), Trinidad and Tobago (79), Grenada (66), Jamaica (61), Dominica (53), and Barbados (24).

2.22 While Jamaica scores near the worldwide average in cross-country surveys of corruption, bribery and lack of transparency in government contracts are considered by Jamaicans to be important problems. Jamaica ranks poorly in perceptions of favoritism shown by government officials towards well-connected firms and individuals when deciding on policies and contracts. This is closely linked with the pressure exerted on businesses by protection rackets, and reflected in the high perceived costs imposed on businesses by organized crime (World Bank, 2004).

2.23 The best quantified information on corruption in the region comes from the Dominican Republic, a country that is included in the various cross-national surveys of Spanish-speaking countries, as well as Transparency International's Corruption Barometer; it was, in fact, the only Caribbean country to be included in the 2005 Corruption Barometer report. According to the Corruption Barometer 2005, some 16 percent of the Dominicans surveyed had paid a bribe in the previous year, the average amount being equivalent to US\$274 when adjusted for purchasing power parity. More than half complained that they had to pay a bribe in order to access a public service to which they were entitled and to avoid problems with authorities (Transparency International, 2005). The World Bank's Investment Climate Survey showed that 72 
percent of firms operating in the Dominican Republic reported "being affected" by corruption, and 21 percent of firms reported paying bribes in order to gain government contracts (World Bank, 2006a).

2.24 In the 2005 Latinobarómetro survey, 72 percent of Dominicans said that corruption had increased "a lot" in the previous three years, and 34 percent said they expected it to increase "a lot" in the next three years. Corruption among the police and political parties was emphasized. At the same time, 30 percent said that some progress had been made against corruption in the last year, but only 39 percent said that corruption would ever be solved (Latinobarómetro, 2005).

\section{Box 2.1: Financial Fraud in the Dominican Republic - The Baninter Case}

The Banco Intercontinental, S.A., better known as Baninter, began to experience liquidity problems late in 2002, due primarily to the alleged appropriation of funds by the bank's owners, and to a lesser extent because of an increase in deposit withdrawals. The bank had maintained a parallel bank with off-book operations through a system called "Interbanco." This off-book portfolio was of very low quality, consisting of related party lending and inadequate due diligence: some 82 percent of all outstanding loans did not meet the minimum required approval procedures, the necessary collateral, or appropriate documentation indicating a commitment or intention to repay obligations. Registered losses accumulated from 1989 to December 2002 in the Interbanco amounted to US\$1.2 billion, and by March 2003, Baninter's overdraft amounted to US\$2.1 billion (Procuraduría General de la República Dominicana, 2006). In effect, this double accounting system hid overdrafts, representing not only a failure in banking supervision but also fraudulent practices by the bank's managers.

The Central Bank provided substantial liquidity support during the 2002-2003 period, leading to a severe decapitalization that was remedied through issuing Central Bank debt at high interest rates. Subsequent audits of the use of these bail-out funds to Baninter revealed further instances of fraud, such as increased lending to related parties and high-ranking bank employees, continued misreporting of liabilities, and repayment of related party deposits and obligations including those in offshore affiliates, all in violation of the Monetary and Financial Law (e.g., banks receiving liquidity support are prohibited from issuing new debt).

The total direct cost of the bank bail-out to three failed commercial banks in 2003 amounted to 21 percent of GDP, and Baninter accounted for the lion's share-approximately 15-16 percent of GDP. The social and economic costs went beyond the direct cost of the bailouts: a rapid depreciation of the peso (due to a loss of confidence) led to very high inflation and a serious erosion of real incomes. Approximately 1.5 million Dominicans (about 16 percent of the population) fell below the poverty line in the aftermath of the banking crisis, 670,000 of whom fell into extreme poverty (World Bank and IDB, 2006). Although Dominican GDP growth has rebounded since 2004, the government and Central Bank continue to struggle to service the resulting higher debt stock.

As of the end of December 2006, while the legal process continues, no one has been convicted of any crime related to the Baninter fraud. 


\section{RISK FACTORS FOR CRIME AND VIOLENCE}

Potential risk factors for crime victimization encompass conditions at the individual, relationship, community, and societal levels. As a whole Caribbean countries exhibit crime patterns similar to those in other countries. Both murder and robbery rates are higher in countries with low economic growth. Murder rates are also higher in poor countries and in communities that are poor and have large populations of young men. In Caribbean countries overall, homicide rates are 34 percent higher and robbery rates are 26 percent higher than in countries with comparable macroeconomic conditions. In general, the analysis implies that policies to reduce crime should focus on improving economic conditions, providing opportunities to young men, and improving trust in law enforcement.

3.1 This chapter assesses the risk factors for crime and violence in the Caribbean. Some studies characterize this type of analysis as one of determinants or correlates. The term "risk factors," which comes from the public health literature, is used here to emphasize that while it may be possible to cautiously infer causal relationships between crime and other variables, such relationships are not deterministic - the presence of a single risk factor does not guarantee that violence or crime will occur. In addition, the use of the risk factors terminology emphasizes that well-designed interventions may succeed in counteracting those risk factors.

3.2 An analysis of risk factors is potentially useful in a number of ways. First, a profile of the primary risk factors offers an understanding of who is at risk for criminal victimization. This may be useful in targeting interventions. Second, a profile of risk factors, when combined with theories of crime, can lend insights into the social process behind criminal activity, allowing for a better understanding of the nature of crime and ultimately leading to more effective anti-crime policy.

\section{CONCEPTUAL FOUNDATIONS OF RISK FACTORS FOR CRIME AND VIOLENCE}

3.3 Economists have traditionally conceptualized criminal behavior as a rational decision made taking into account the expected benefits compared to the expected costs. ${ }^{46}$ The economic approach tends to lead to a focus on factors which directly affect the costs and benefits of participating in criminal activity: the relative returns of crime versus legal activities, the probability of being apprehended and convicted, and punishments for those convicted.

3.4 The analysis in this chapter seeks a wider perspective. A useful approach to conceptualize the various influences on crime and violence is the so-called ecological model (see Figure 3.1), which is broad enough to encompass a wide variety of theories from economics, sociology, and public health. The ecological model identifies four levels of influence on criminal and violent behavior. Individual factors include characteristics such as education level, marital status, and biological endowments. Relationship factors cover relations with peers, partners, and family. At a higher level, community factors

${ }^{46}$ A long line of research in this framework begins with Becker (1968). 
include the broader context of social relationships in environments such as schools and neighborhoods. Finally, at the broadest level, there are societal factors such as cultural norms and economic conditions that also influence violence (WHO, 2002).

Figure 3.1: Ecological Model for Understanding Crime and Violence

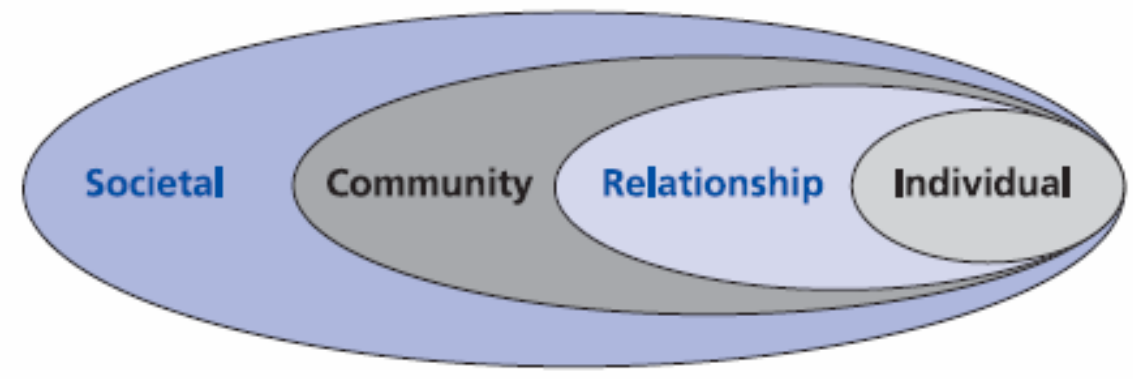

Source: World Health Organization (2002).

3.5 This chapter presents two types of analysis. First, it shows results from a macroanalysis of risk factors for crime, using country-level data from around the world. Second, it provides insights from an analysis of household-level crime data in three Caribbean countries: Jamaica, the Dominican Republic, and Haiti.

\section{MACRO ANALYSIS OF RISK FACTORS FOR CRIME IN THE WORLD AND THE CARIBBEAN}

3.6 Macro-level analyses can reveal how risk factors are associated with crime at the national level. These types of studies fall into two categories. Some studies examine trends over time in national crime rates in a single country and note how they are associated with changes in country-level variables. Others look at variation in crime rates across countries to determine how various factors may influence crime, sometimes drawing on panel data with multiple observations over time for particular countries.

3.7 The different approaches have various advantages and disadvantages. While a study of time trends in a single country can be tailored to take into account the particular circumstances of that country, in most circumstances it is difficult to infer a causal relationship between other variables and crime with national data from just one country. Studies across countries can exploit the large variation in crime rates and other conditions across the world. Cross-country studies suffer from several weaknesses, however. Crosscountry crime data is often of questionable comparability; differences in official crime rates may reflect differences in definitions and reporting. Additionally, at best crosscountry studies produce estimates of average relationships, which may be of limited relevance to individual countries. In principle, cross-country studies based on panel data should be of greatest interest. Only a few countries, however, produce long time series of crime data.

3.8 A few single-country studies have been conducted in the Caribbean. Ellis (1991) examines annual crime rates in Jamaica for the period 1950-84 and finds that high crime in the country is associated with periods of low economic growth, high unemployment, 
and a large cohort in the 14-24 age group. He concludes that increases in crime in Jamaica can largely be explained as the consequence of economic decline, aggravated by changes in the population's age structure. Albuquerque and McElroy (1999) look at the case of Barbados and conclude that increased levels of property and violent crime there have been associated with worsening economic conditions and increased levels of visitor density.

3.9 This section presents a series of graphical bivariate comparisons of crime rates across countries with various risk factors and then proceeds to multivariate regression analysis. All the analysis is based on crime data collected from national police authorities by the United Nations Office of Drugs and Crime (UNODC) through its Crime Trends Surveys. The UNODC dataset used for the regression analysis includes three Caribbean countries-Barbados, Jamaica, and Trinidad and Tobago-along with 58 other countries. For the bivariate comparisons, the UNODC data is supplemented by additional data from other sources for some Caribbean countries (see data source description in Annex 3.1).

3.10 The analysis here is carried out using both homicide and robbery data. Many cross-country studies use only homicide data, because differences in reporting rates and definitions are thought to be minimal for this crime. Robbery is included as well to add a perspective on how risk factors for violent crime and property crime may differ. ${ }^{47}$

3.11 Figure 3.2 shows a collection of scatter plots for murder and robbery rates against various variables. For all the plots, each point corresponds to a country, and points corresponding to Caribbean countries are labeled. The number of points in each plot varies because some variables are only available for a selection of countries. In particular, the number of Caribbean countries for which robbery data is available is limited.

3.12 One pattern that is clear from the scatter plots is that both homicide and robbery rates exhibit strong inertia over time. In other words, countries that experience high crime rates in one period are very likely to have high crime rates in the following period. This can be seen in panels (a) and (b) of Figure 3.2, which show homicide rates in the period 1995-99 compared to those during the period 1990-94. There are several reasons why crime may show such persistence. First, criminal activity may become more attractive to individual criminals both as they become more experienced and as their legal labor market opportunities diminish with the accumulation of criminal records. Second, a society may fall into a high crime trap if, with a rise in criminal activity, increased social interactions with criminals reduce the social cost of criminal behavior. Likewise, if the legal system fails to respond to a spike in the incidence of criminal behavior, so that the perceived likelihood of arrest and conviction decreases, future criminal activity may rise as well. The inertia of crime rates also may reflect a link between crime and other variables which are persistent over time. Finally, the inertia pattern may reflect correlation over time in the errors in the data for individual countries. ${ }^{48}$

\footnotetext{
${ }^{47}$ Robbery involves violence as well but can be considered a property crime with a violence component.

${ }^{48}$ For discussion of some of the reasons for crime inertia, see Glaeser, Sacerdote, and Scheinkman (1996), Leung (1995), Sah (1991), Posada (1994), and Mocan, Billups, and Overland (2005).
} 
Figure 3.2: Cross-Country Correlates of Crime

\section{CRIME Is PERsistent Over TIME}

a) Murder Rate: Late 90s vs. Early 90s

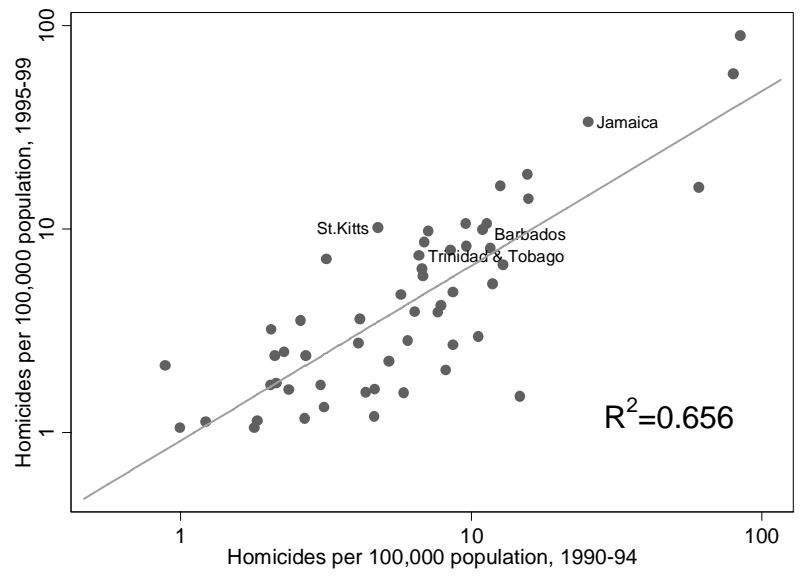

b) Robbery Rate Late 90 s vs. Early $90 \mathrm{~s}$

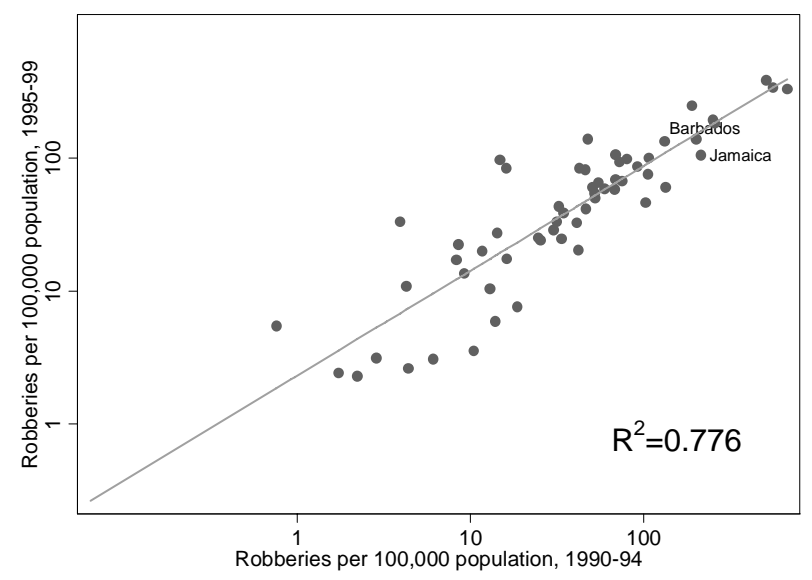

COUNTRIES WITH HighER GROWTH RATES HAVE LOWER CRIME RATES

c) Murder Rate vs. Growth Rate

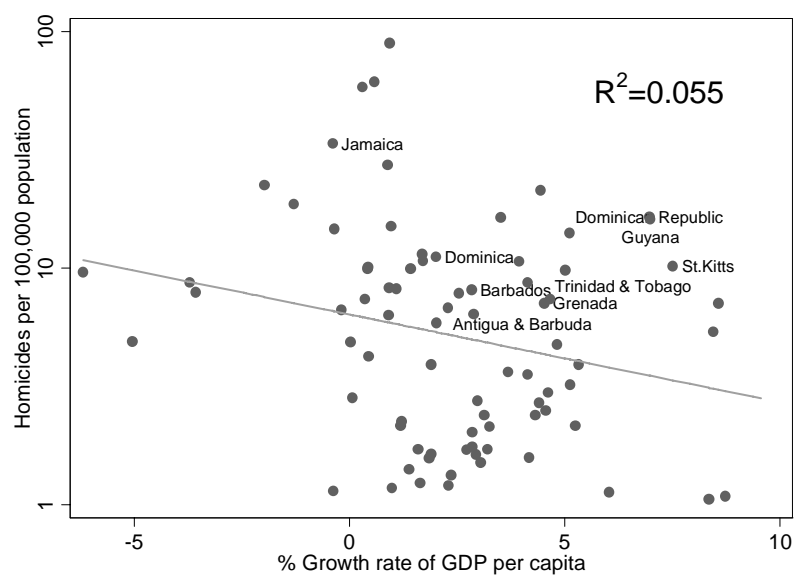

d) Robbery Rate vs. Growth Rate

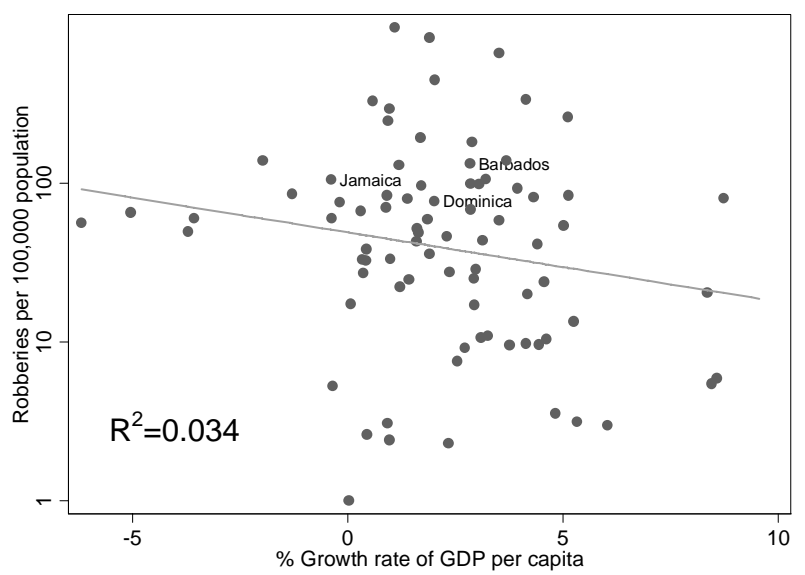

WEALTHIER COUNTRIES HAVE FEWER Murders AND MORE ROBBERIES

e) Murder Rate vs. GDP per Capita

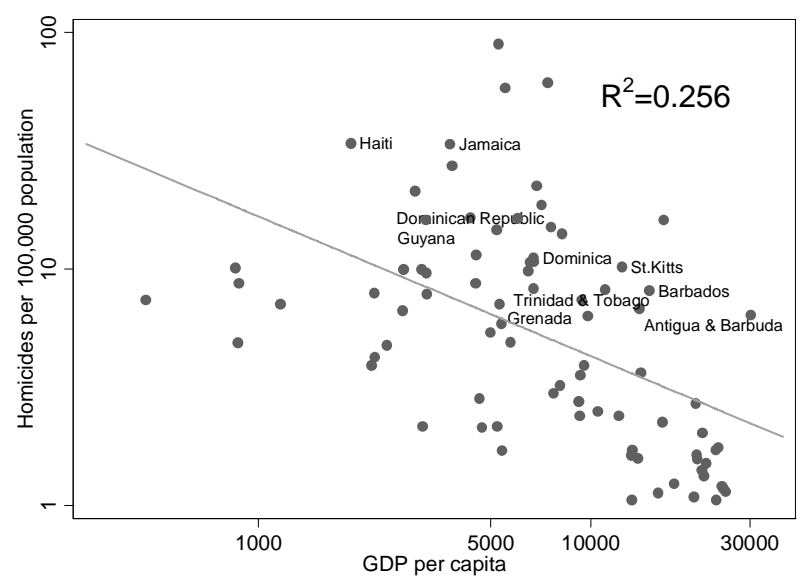

f) Robbery Rate vs. GDP per Capita

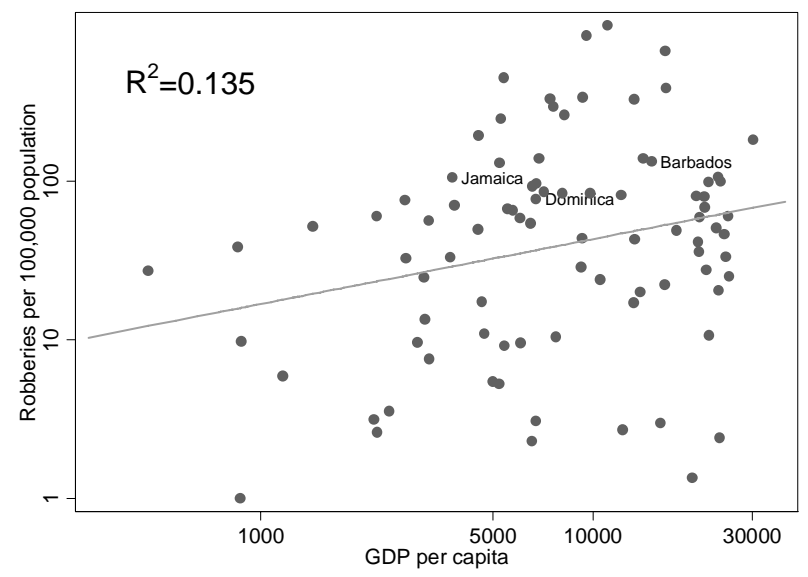




\section{(continued) Figure 3.2: Cross-Country Correlates of Crime}

\section{Countries With Higher Inequality Have Higher Murder And RobBery Rates}

g) Murder Rate vs. Gini Coefficient

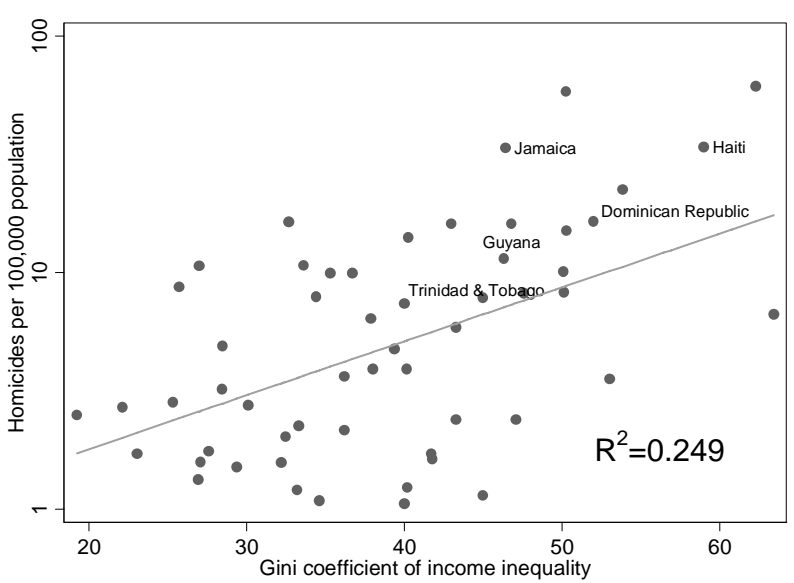

h) Robbery Rate vs. Gini Coefficient

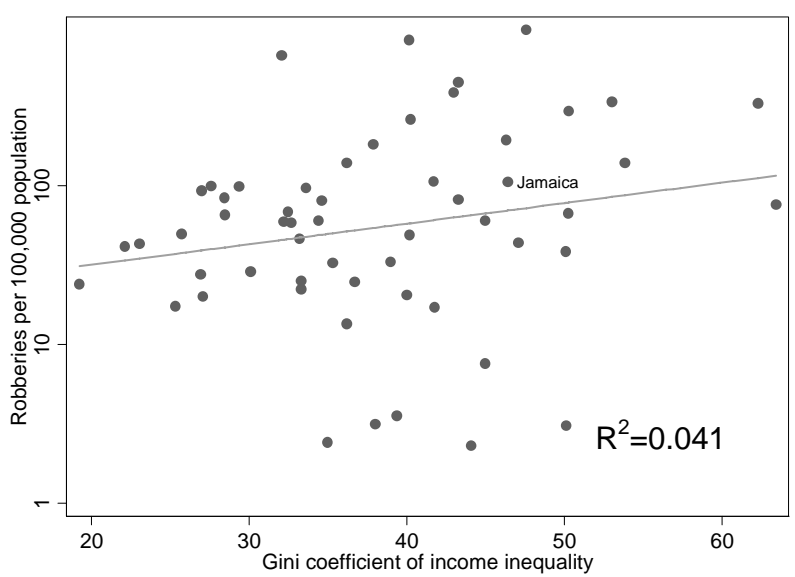

Countries With More Young Men Have Higher Murder Rates

i) Murder Rate vs. Young Men in Population

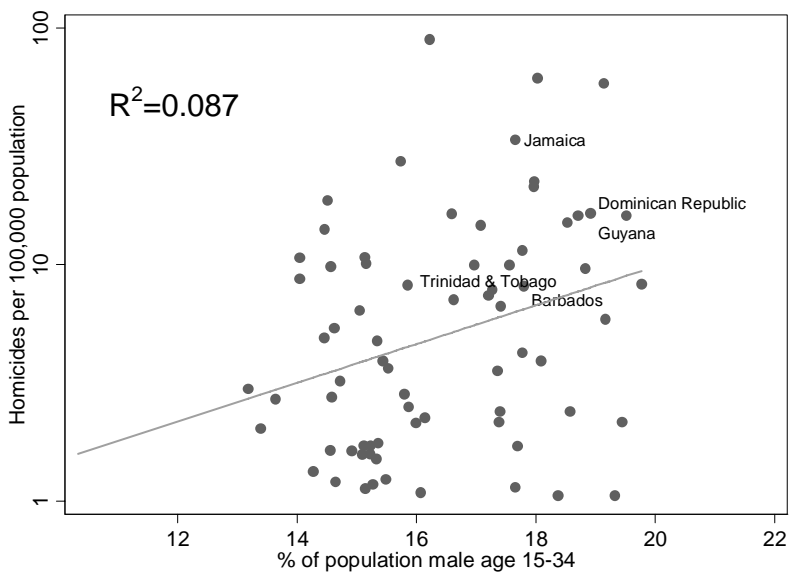

j) Robbery Rate vs. Young Men in Population

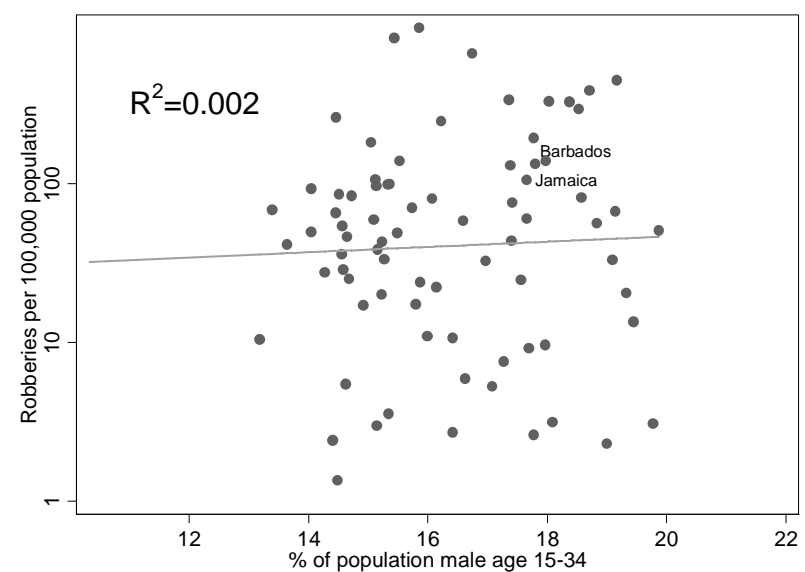

More Educated COUNTRIES HAVE LOWER MURDER RATES

k) Murder Rate vs. Average Adult Education

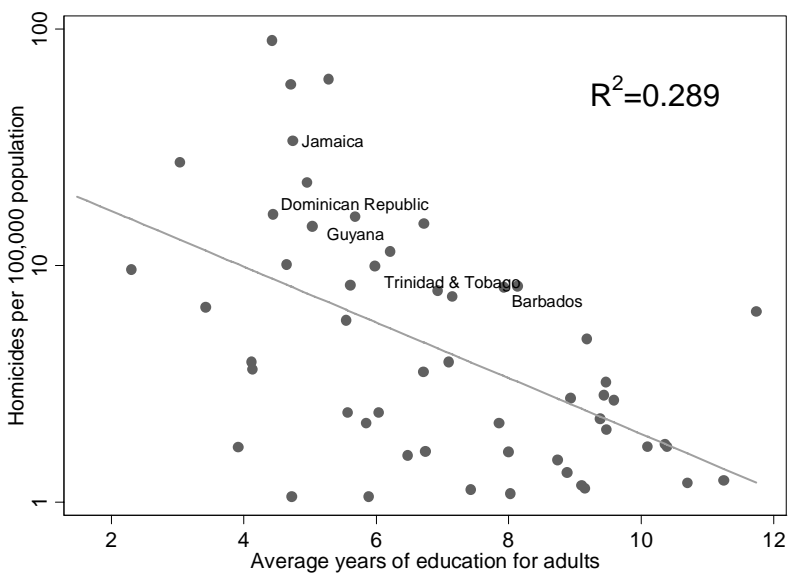

l) Robbery Rate vs. Average Adult Education

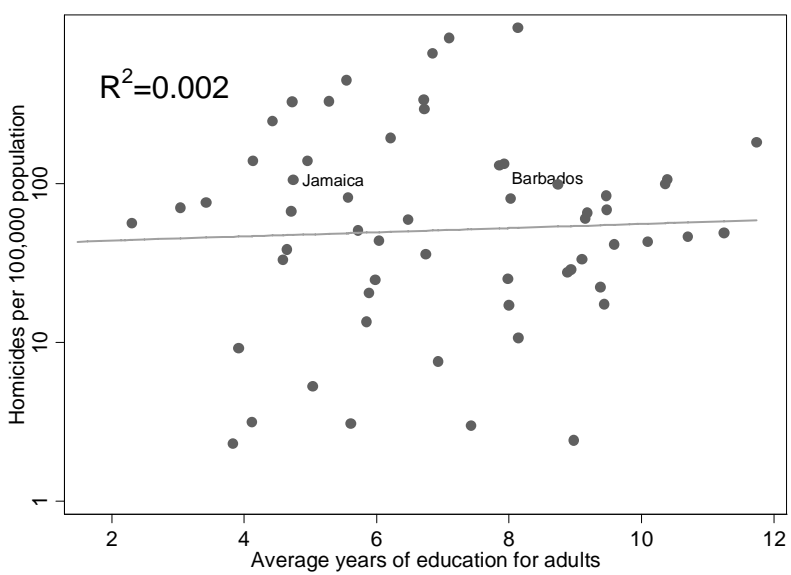

Sources: Own analysis. UNODC data and other (see Annex 3.1 for discussion of homicide data source), Penn World Figures for growth rate in GDP per capita, Penn World Tables for GDP per capita in 1996 \$US, Barro and Lee (1996) for education; World Development Indicators for population data by age group. 
3.13 Countries with higher growth rates have on average lower rates of both homicides and burglaries (see panels (c) and (d) of Figure 3.2). This may indicate that higher growth reduces crime, by increasing opportunities in the legal labor market for those who might otherwise choose to engage in criminal behavior. The Caribbean countries in the sample have crime rates that are in all cases above the line showing the international tendency by GDP growth rate. In other words, on average countries in the Caribbean have higher crime rates than countries with comparable growth rates.

3.14 Countries with higher average incomes tend to have lower murder rates and higher robbery rates (see panels (e) and (f) of Figure 3.2). As with the growth rate plots, these figures show that each of the Caribbean countries for which data is available has a murder or robbery rate above the line showing the international tendency by GDP per capita. Higher inequality, on the other hand, is correlated with both higher murder and burglary rates.

3.15 The remaining panels of Figure 3.2 show overall correlations between homicide and two other factors that are often linked to high level of violence. Higher murder rates are found in countries with larger populations of young men and those with lower average adult education levels. Robbery rates, however, show no correlation with education levels or youth populations.

3.16 To attempt to isolate which variables may be driving crime rates, multivariate regression analysis is applied to the data. This work draws upon similar analysis conducted by Fajnzylber, Lederman, and Loayza (2000) (referred to as FLL in subsequent references) for the 1970-1995 period. Like FLL, this analysis is a based on an unbalanced panel dataset from all countries of the world with available data. Each observation is the average of values over a five-year period for a particular country.

3.17 The regression analysis presented here differs from the FLL analysis in several ways. First, it incorporates the updated United Nations crime data from the period 199599. (The second half of the 1990s is the last five-year period for which the U.N. data is available for a large number of countries.) Second, it uses the simpler OLS regression approach, rather than more elaborate regression techniques. ${ }^{49}$ Table 3.1 presents results from the basic country-analysis. The explanatory variables used are the lagged value of the dependent variable, the growth rate of GDP per capita, average income per capita (in logs), and the Gini coefficient of income inequality.

\footnotetext{
${ }^{49}$ FLL employ the Arrellano and Bond generalized method of moments (GMM) estimator which attempts to control for endogeneity of crime determinants by instrumenting the explanatory variables with lagged values of the explanatory variables.
} 
Table 3.1: Cross-Country Analysis - Basic Regression Results

\begin{tabular}{lcccc}
\hline Variable & $\begin{array}{c}(1) \\
\text { Homicide } \\
\text { rate }\end{array}$ & $\begin{array}{c}(2) \\
\text { Robbery } \\
\text { rate }\end{array}$ & $\begin{array}{c}(3) \\
\text { Homicide } \\
\text { rate }\end{array}$ & $\begin{array}{c}(4) \\
\text { Robbery } \\
\text { rate }\end{array}$ \\
\hline Constant & $0.914 * *$ & $-1.107 * *$ & $0.998 * *$ & $-1.108 * *$ \\
& $(0.458)$ & $(0.531)$ & $(0.453)$ & $(0.527)$ \\
Lagged dependent variable & $0.833 * *$ & $0.902 * *$ & $0.808 * *$ & 0.891 \\
& $(0.038)$ & $(0.031)$ & $(0.039)$ & $(0.032)$ \\
Growth rate & $-0.017 *$ & $-0.026 * *$ & $-0.017 *$ & -0.026 \\
& $(0.010)$ & $(0.012)$ & $(0.010)$ & $(0.011)$ \\
Average income (log) & $-0.089 * *$ & $0.174 * *$ & $-0.094 * *$ & 0.178 \\
& $(0.040)$ & $(0.050)$ & $(0.039)$ & $(0.050)$ \\
Income inequality & 0.003 & 0.003 & 0.002 & 0.002 \\
& $(0.005)$ & $(0.005)$ & $(0.005)$ & $(0.005)$ \\
Caribbean dummy & & & $0.343 * *$ & 0.264 \\
& & & $(0.139)$ & $(0.148)$ \\
Number of countries & 61 & 54 & 61 & 54 \\
Number of observations & 182 & 179 & 182 & 179 \\
R-squared & 0.746 & 0.878 & 0.754 & 0.880 \\
\hline
\end{tabular}

Source: Own analysis. UNODC for homicide and robbery rates; Penn World Figures for growth rate in GDP per capita and average income (per capita GDP); Deininger and Squire (1996) and World Development Indicators 2005 for Gini coefficient of income inequality. Notes: All regressions are OLS.

3.18 Like the bivariate comparisons, the regression results show that there is a strong element of inertia to crime rates and that higher crime rates are associated with lower growth rates. The regressions also show the same result as the scatter plot for average income: wealthier countries have lower homicide rates and higher robbery rates. In particular, the results from the simplest specifications show that a 10 percent increase in average income is associated with a decline of 0.89 percent in the murder rate and a 1.74 percent increase in the robbery rate. The effect of inequality on crime implied by the regression results, however, is not statistically significant after controlling for past crime, growth, and GDP per capita.

3.19 Columns (3) and (4) of Table 3.1 display results using the basic specification plus a Caribbean dummy. Those results show that for Caribbean countries in the panel sample (Barbados, Jamaica, and Trinidad and Tobago), homicide rates have been 34 percent higher and robbery rates have been 26 percent higher than in countries with comparable income per capita, growth rates, inequality, and past crime rates. Table A3.2 (in the Appendix) shows results from specifications which also include the average level of adult education and the percentage of the population made up of young men (age 1534). Neither shows a statistically significant effect on crime rates. The correlation of higher crime rates with lower education levels and large number of young men, apparent in the scatter plots, does not hold after controlling for past crime rates, the growth rate, and average income. 
- There are strong inertia effects to crime, which means that once crime rates are high, it may be difficult to reduce them. At the same time, crime-reduction efforts in the short-term are likely to have huge long-term gains.

- As countries develop, violent crime tends to decrease, while property crime increases.

- Inequality is associated with both violent crime and property crime, but the relationship does not hold after controlling for other variables.

- Caribbean countries show similar patterns to the world as a whole, but have higher crime rates overall.

3.21 Why do Caribbean countries have higher crime rates on average? The obvious candidate reason is drug trafficking. Although the countries of the Caribbean are very diverse along many lines, one thing they have in common is that nearly all are used as points for drug transshipment. De Albuquerque and McElroy (1999), among others, have noted that the rise of crime in the Caribbean over time coincides with the expansion of the narcotics trade. The U.S. Government's most recent annual report on the international drug trade, Department of State (2006), lists nearly every country in the Caribbean as a "transshipment point." ${ }^{, 0}$ Large quantities of drugs are regularly seized by law enforcement in most Caribbean countries; of the top 20 countries in the world in terms of drugs seizures per capita, half are in the Caribbean. ${ }^{51}$ The Dominican Republic, Haiti, Jamaica and the Bahamas are all identified by the U.S. report as "major" drug transit countries. While the drug trade clearly does not explain all variation in crime rates across countries, it is undoubtedly an important contributing factor to crime and violence in the region.

3.22 It is very important to recognize the limitations of regression analysis. First, regression analysis provides estimates of average relationships between variables. In the case of cross-country regressions, the relationships are averages across countries of the world. There are inevitably exceptions which do not fit the average pattern. To take just one example, while the regression results show that higher growth rates are associated with lower crime rates, some countries experience both rapid growth and high crime rates, as has been the case for Trinidad and Tobago in recent years. But the regressions do control for other factors, which helps clarify the relationship between crime and growth.

3.23 It should also be noted that with all the relationships presented here there are multiple possible relationships between the variables. It may be the case that causality runs not from growth rates to crime but in the other direction, so that a higher rate of violence tends to decrease growth. Viewed from this perspective, the growth rates of

\footnotetext{
${ }^{50}$ Specifically, the report lists the following countries as transshipment points: Antigua and Barbuda, Aruba, the Bahamas, Barbados, Cuba, Dominica, the Dominican Republic, Grenada, Guyana, Haiti, Jamaica, the Netherlands Antilles, St. Kitts and Nevis, St. Lucia, St. Vincent and the Grenadines, and Trinidad and Tobago. Given that such a large number of Caribbean countries are classified as transhipment points, it is not possible to introduce a "drug transhipment" dummy variable in the cross-country regressions; such a dummy would be highly collinear with Caribbean region dummy.

51 This statement is based on analysis of the UNODC's drug seizure database.
} 
Caribbean countries are higher than would be predicted based on their crime rates alone. It is also possible that the negative correlation between growth rates and crime rates is due to a third factor which affects both growth and crime.

3.24 Econometrics offers a variety of strategies for attempting to distinguish causal relationships from mere correlations. Unfortunately, convincing applications face a number of hurdles, foremost among them being data requirements that are difficult to fulfill for cross-country crime regressions. The analysis in this chapter does not apply such techniques but instead uses the simplest form of regression analysis, ordinary least squares. Rather than making hard claims of causality, the analysis in this chapter is presented in the spirit of providing suggestive evidence on possible relationships between crime and other variables. Note that the primary finding from the cross-country analysis - the fact that the crime rates of Caribbean countries are above the rates predicted by purely economic variables - does not rely on any causal story, but rather it suggests that given its economic performance, the Caribbean's crime rates are on average higher than what would be expected.

3.25 In Chapter 4 of this report, cross-country analysis is presented on the possible effects of growth on crime. In that case, the focus is necessarily on identifying a causal relationship, but the obstacles to doing so are no less daunting..$^{52}$ Also, the identification of any "causal" effect of crime on growth depends on the assumption that past levels of crime are significantly different from current levels of crime, and in any case, this technique relies on technical statistical properties of the data rather than on an intuitive or conceptual identification of the causal effect of crime on growth. Consequently, readers should be modest in drawing strong causal conclusions from this analysis as well.

\section{RISK FACTORS FOR CRIME AT THE HOUSEHOLD LEVEL: EVIDENCE FROM THREE CARIBBEAN COUNTRIES}

3.26 While macro-level estimates are useful for providing a sense of average relationships between crime and other variables, country-specific studies based on microdata are useful for examining the circumstances in individual countries. Micro-level studies also allow for a more detailed examination of risk factors at the community, relationship, and individual level. This section considers risk factors for crime victimization, using victimization data collected at the household level in three countries: Jamaica, the Dominican Republic, and Haiti. The victimization data for Jamaica comes from the national population census conducted in 2001. The Dominican Republic data is from a household survey in 2005, matched with information from the national census at the province level. Finally, the Haiti analysis is based on more limited crime victimization questions from a 2001 survey.

3.27 For all three countries, the micro-level risk factor analysis uses probit regressions, with crime victimization as an outcome variable and household characteristics as explanatory variables. The set of explanatory variables varies by

\footnotetext{
${ }^{52}$ The growth-on-crime analysis employs the Arellano-Bond estimator that is sometimes used, particularly in the cross-country literature, to identify a causal relationship. When measurement error in the data is likely to be substantial, as is typically the case for crime data, the estimator is less reliable.
} 
country but includes both household and community-level characteristics. Complete regression results from each country can be found in Annexes 3.2, 3.3, and 3.4. Results from the regression analysis are summarized in Table 3.2 and described below.

Table 3.2: Summary of Micro-Analysis of Risk Factors for Criminal Victimization

\begin{tabular}{|c|c|c|c|c|}
\hline & \multicolumn{2}{|c|}{ Jamaica } & \multirow{2}{*}{$\begin{array}{c}\text { Dominican } \\
\text { Republic } \\
\text { Property } \\
\text { Crime } \\
\text { (Burglary/ } \\
\text { Mugging) }\end{array}$} & \multirow{2}{*}{$\begin{array}{c}\text { Haiti } \\
\text { Property } \\
\text { Crime } \\
\text { (Burglary/ } \\
\text { Mugging) }\end{array}$} \\
\hline & $\begin{array}{l}\text { Violent } \\
\text { Crime } \\
\text { (Murder) }\end{array}$ & $\begin{array}{l}\text { Property } \\
\text { Crime } \\
\text { (Robbery) }\end{array}$ & & \\
\hline \multicolumn{5}{|l|}{ Household-level } \\
\hline Consumption/income & - & + & + & + \\
\hline Female-headed & + & - & not sig. & not sig. \\
\hline Young men & + & - & not sig. & not sig. \\
\hline Education level & + & - & + & not sig. \\
\hline \multicolumn{5}{|c|}{ Community/province-level } \\
\hline Consumption/income & - & + & not sig. & $\mathrm{n} / \mathrm{a}$ \\
\hline Inequality & not sig. & not sig. & - & $\mathrm{n} / \mathrm{a}$ \\
\hline Female-headed & + & + & - & $\mathrm{n} / \mathrm{a}$ \\
\hline Young men & + & + & + & $\mathrm{n} / \mathrm{a}$ \\
\hline Education level & - & - & + & $\mathrm{n} / \mathrm{a}$ \\
\hline Population density & + & - & + & $\mathrm{n} / \mathrm{a}$ \\
\hline Urban & + & + & + & + \\
\hline Reporting rate & - & - & not sig. & $\mathrm{n} / \mathrm{a}$ \\
\hline
\end{tabular}

Source: Own analysis.

Notes: Table entries indicate results from multivariate regression results for each variable, for analyses from different countries and crimes. A plus sign indicates a positive relationship, a negative sign indicates a negative relationship, "not sig." indicates that results for the variable in question were not significant at the 10 percent level, and "n/a" indicates that the variable was not available for a particular country. See Annex 3.2, 3.3 and 3.4 for detailed results. For Jamaica, results shown for violent crime are for murder and those shown for property crime are for robbery.

\section{Economic Factors}

3.28 For Jamaica, the patterns of crime victimization by consumption level —of both households and communities-mirror the trends in the cross-national data: increases in wealth are associated with lower levels of violent crime and higher levels of property crime. In Jamaica, wealthier household are much more likely to experience property crime (robbery and the theft of agricultural goods), while poorer households are more at risk to be victims of all violent crime. Additionally, households in poorer areas, even after controlling for the household-level consumption, suffer higher risk of murder and wounding. On the other hand, households in wealthier areas are more likely to be victims of property crime. This last relationship can be seen in Figure 3.3, which shows a scatter plot of robbery rates versus mean consumption by neighborhood (census enumeration district.) 
3.29 In the Dominican Republic, better off households are more likely to suffer from all forms of theft. Even after controlling for household-level welfare, all types of theft occur more frequently in wealthier provinces. Provincial-level unemployment is also associated with higher levels of personal theft.

\section{Figure 3.3: Robbery Rates vs. Mean Consumption by Neighborhood}

Property Crime is More Prevalent in Wealthier Areas in Jamaica

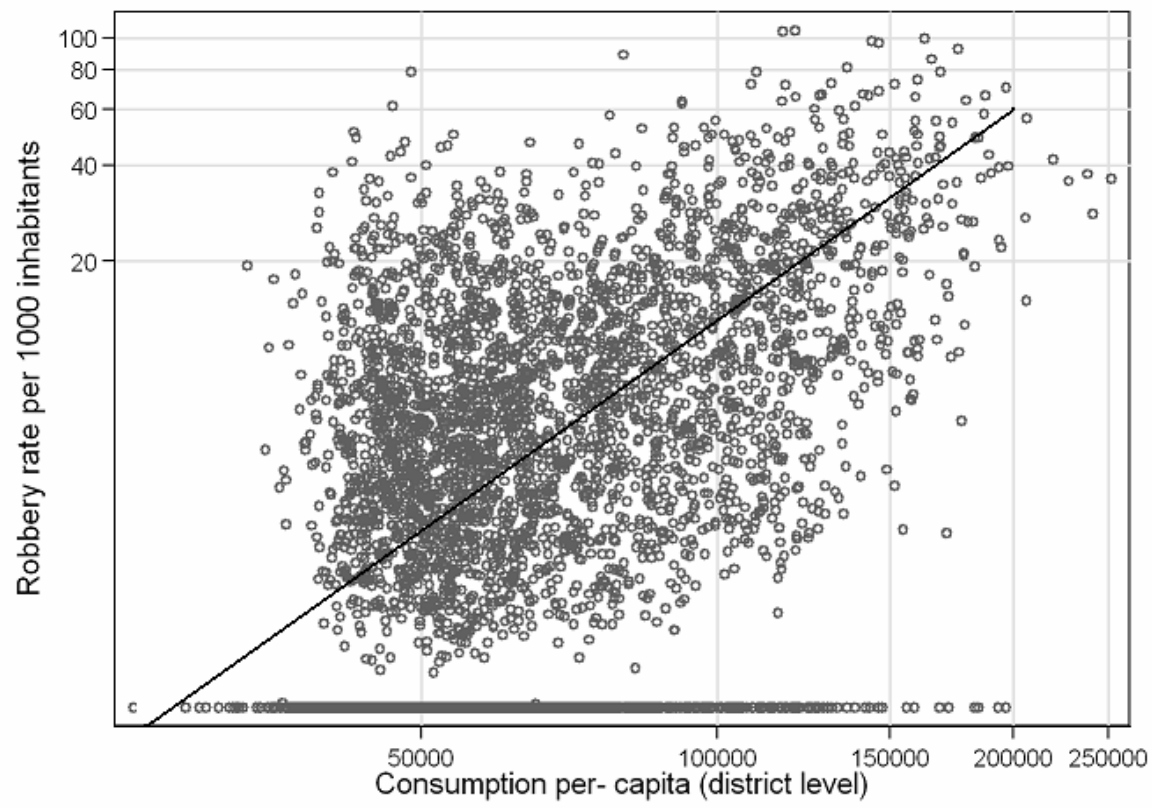

Source: Analysis of 2001 Population and Housing Census.

Notes: For the purposes of the figure, observations with values of zero for robberies were replaced with the smallest value in the sample.

3.30 In Haiti, wealthier households are more likely to be victims of both burglary and mugging. The distribution of victimization by quintile is shown in Figure 3.4. Robberies, burglaries, and muggings disproportionately strike Haitians in the top two quintiles, who are most likely to have property of value. Personal injury victims, however, are concentrated in both the top and bottom quintiles.

3.31 The analysis does not find a consistent relationship between crime and inequality. In the multivariate regressions, all but one of the crimes show no relationship to community inequality levels; only the theft of agricultural products from farms is found to be more prevalent in higher inequality areas. Counter to expectations, in the Dominican Republic vehicle theft and burglary occur less often in provinces with higher inequality. These findings differ from those from a similar study in South Africa (Demombynes and Özler, 2005) which found local inequality to be correlated with both violent and property crime, after controlling for plausible proxies for the returns from crime and non-crime activities. 
Figure 3.4: Distribution of Victimization by Crime and Quintile in Haiti

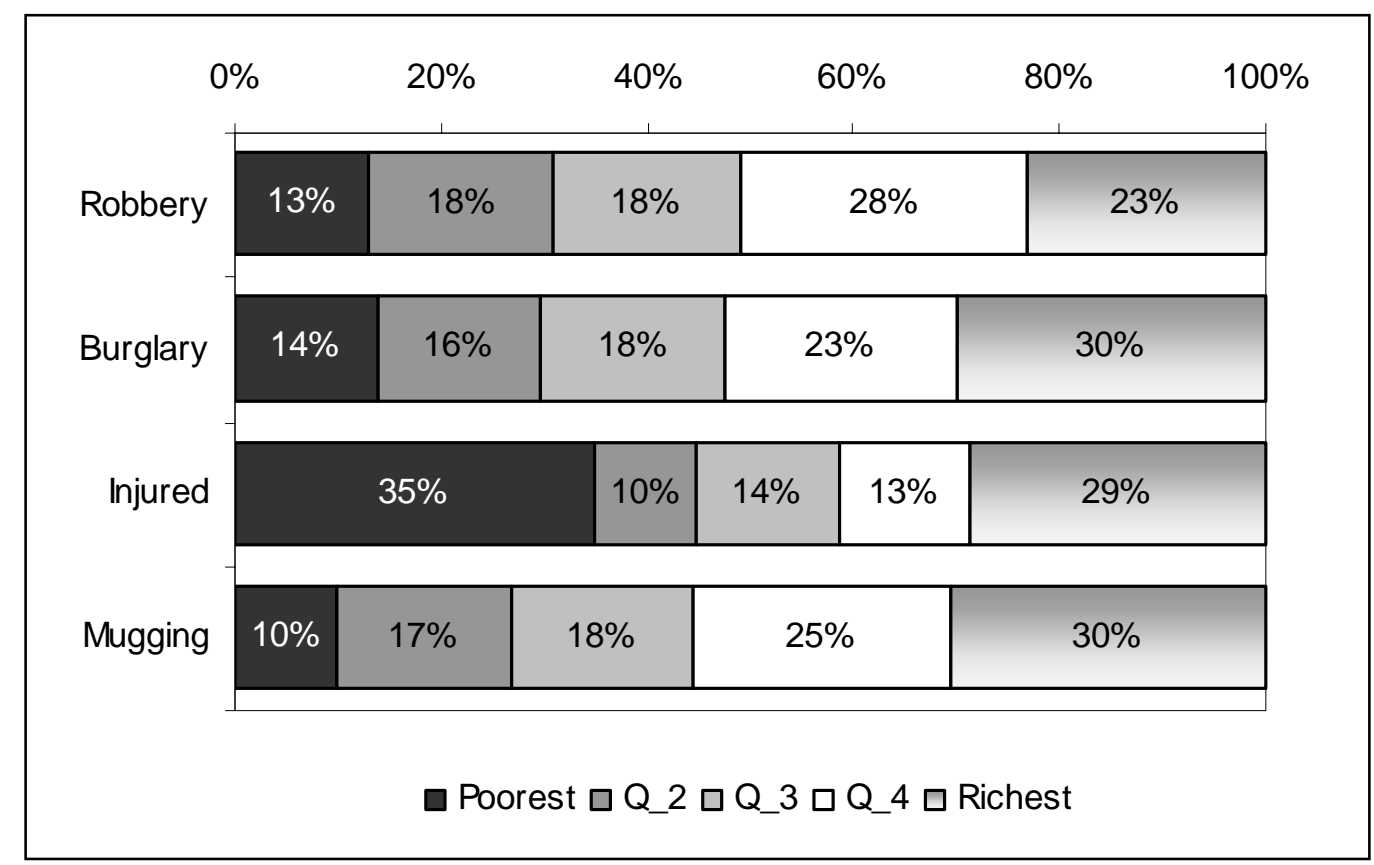

Source: Own analysis of ECVH 2001.

Note: The figure shows the percentage of victims of each crime who are in each income quintile.

\section{Demographic Factors}

3.32 In Jamaica, households in communities in which female-headed households make up a larger share of the population are more likely to suffer from murder, shooting, and robbery. This finding is compatible with sociological theories that predict that female-headed households are more prevalent in areas with breakdowns of social ties, which may lead to more violent crime. The opposite relationship holds, however, for mugging in the Dominican Republic, and across all three countries there is no consistent relationship at the household level between victimization and female headship.

3.33 The presence of young males in Jamaican households is associated with higher rates of violent crime victimization, and the presence of more young males in the district is associated with higher homicide rates. More males in the household, however, are also associated with lower rates of property crime, which suggests that they may serve a protection function for the household, even though they are highly likely to be victims themselves.

3.34 In the Dominican Republic, the presence of young males in the household is not significantly associated with crime victimization, but the presence of more young men in the province is strongly associated with all forms of property crime captured in the survey. In Haiti, however, there is no clear relationship between age structure and the likelihood of criminal victimization. 


\section{Box 3.1: Haiti's Entrepreneurs of Violence}

Political violence is not a novelty in Haiti's history, and it neither started nor ended with the Duvalier regime, although this regime's violent record was unprecedented. "Papa Doc” Duvalier (1957-71) began to institutionalize political violence soon after he was elected in 1957, by establishing a force of cagoulards ("hooded men") charged with silencing supporters of rival candidates (who challenged the election results), as well as other dissidents, which gradually developed into a more extensive network of spies for the Duvalier regime.

More recently, Haiti's democratic experience has failed to provide capable and stable governance. Initially, democracy was brutally repressed by the army and their supporters, using armed paramilitary groups that have been a feature of Haitian politics since Duvalier's macoutes. From Aristide's return in 1994, democracy was undermined by deep conflicts among erstwhile democratic allies, resulting in a political stalemate that lasted almost from Aristide's return in 1994 until his departure in 2004, and which undermined economic growth and state building alike. Moreover, it transformed important parts of the democratic movement, the urban popular organizations, into agents for the Lavalas party, using brutal violence in struggles over territorial control and state favors. With Aristide's departure, some of these groups are bent on undermining the political process, in collusion with some former political leaders. Their area of operation and influence is in the slums and "popular areas" that provide a rich reservoir of potential recruits. Violence and insecurity in these areas is pervasive and these "entrepreneurs of violence" are capable and willing to engineer violence for political or other purposes, as the line between political and criminal violence has become increasingly blurred.

Source: "Urban Violence in Haiti: A rapid assessment of socio-economic, political, and institutional causes of urban violence in Haiti." (World Bank, 2005)

\section{Education}

3.35 Jamaican households in less educated areas are more likely to be victims of all crimes. This may reflect the fact that the less educated have worse legitimate wageearning opportunities and hence the supply of potential criminals in such areas is larger. Patterns are less consistent for the education level of the household itself. Households with more educated adults suffer slightly more shootings and woundings but fewer robberies relative to the less educated.

3.36 The Dominican Republic analysis shows somewhat different results. Households living in more educated provinces are at greater risk of muggings, while more educated households are slightly more likely to be victims of burglary and mugging. The Haiti results show no pattern by education level of household members.

\section{Urban vs. Rural and Population Density}

3.37 In all three countries, crime is chiefly an urban phenomenon. In both Jamaica and the Dominican Republic, rates of victimization are highest in urban areas for nearly all crimes, (an exception is crop and livestock theft in Jamaica, which is necessarily more likely to occur in rural areas). These results hold even after controlling for population density. In Haiti, robbery, burglary, and mugging rates are highest in urban areas. All the crimes captured in the victimization survey in the Dominican Republic are more 
prevalent in areas with higher population density. In Jamaica, however, population density is positively associated with violent crime but negatively associated with property crime.

\section{Crime Reporting Prevalence}

3.38 An important finding of this study is that in Jamaica, the reporting prevalence is negatively associated with crime rates. In other words, crime rates (as measured by victimization data) are higher where a lower percentage of crimes are reported to the police. This has multiple implications. First, this suggests that official police data distort the true geographic profile of crime, because official data are biased downwards for higher crime areas. Second, the reporting rate can reasonably be plausibly be interpreted as a measure of confidence in the police, as people will be more likely to report when they trust the police and believe they will respond. If this interpretation is correct, lack of trust and confidence in the police is lower in areas with higher local crime rates.

3.39 This correlation could be explained by a number of different causal relationships. One possibility is that lower trust in the police leads to higher crime, because the police are less effective when they cannot count on the support and assistance of the population they serve. But causality could well be in the reverse direction, with higher crime leading to lower levels of trust in police. This could be the case if people form their levels of trust based on their observations of local crime levels. Finally, both distrust and high crime rates could be correlated with a third factor not controlled for in the regression analysis. An unobserved variable, like a high level of social exclusion, could both drive high crime rates and inspire lower confidence in the police. ${ }^{53}$

\section{Summary of Micro-Analysis}

3.40 Overall, several key points emerge. Although the precise relationship varies by country, local economic conditions are associated with crime. In particular, wealthier areas are consistently more likely to be the targets of property crime. In Jamaica, where information on both violent crime victimization and local conditions are available, violent crime strikes poor more than rich neighborhoods. Local inequality and crime victimization do not, however, have a clear relationship across countries.

3.41 The results related to demographic characteristics are mixed. Everywhere, crime is concentrated in urban areas, and crime rates are higher where there is a larger population of young males in the Dominican Republic and Jamaica (for violent crime). Areas with large number of female-headed households in Jamaica suffer higher crime rates, but that relationship does not hold for the Dominican Republic.

3.42 In Jamaica, community levels of trust in the police, as proxied by reporting rates, are related to crime rates. This suggests that measures that increase the trust in police, or address the root causes for the lack of trust in the police, may help reduce crime.

\footnotetext{
${ }^{53}$ Soares (2004) examines crime reporting rates at the national level, finding that reporting rates are highest in countries with longer periods of institutional stability, more police per capita, and lower levels of corruption as measured by subjective indices.
} 
3.43 It is important to note that the explanatory power of these regressions is fairly low. ${ }^{54}$ While many risk factors are strongly correlated with crime victimization, it is still largely a random process from the perspective of potential victims. Consequently, the costs of the threat of crime are universal.

\section{Policy Implications}

3.44 The analysis in this chapter points to a number of potential policy conclusions. First, the persistence of crime over time shown by the cross-country regressions suggests that efforts to reduce crime in the short run may have very large long-term effects. Second, while the direction of causality between economic conditions and crime is subject to debate, the weight of evidence suggests that increasing levels and growth rates of per capita income reduce violent crime. At the same time, rates of property crime are higher in both countries and communities with higher incomes.

3.45 Additionally, the presence of large populations of young men is associated with higher crime rates in communities. This suggests strongly that crime prevention interventions should be targeted at young men.

3.46 Finally, the fact that crime rates are higher in areas in Jamaica where trust in the police is lower suggests that policies that improve trust in the police, or address the underlying causes of a lack of trust in the police, can help reduce crime. Policies which improve the transparency of the police, reduce corruption, and make the police more accountable and accessible to citizens may be effective routes to bringing down criminal activity.

\footnotetext{
${ }^{54}$ The highest pseudo R-squared values are 0.077 in Jamaica (for crop and livestock theft), 0.084 in the Dominican Republic (for mugging), and 0.068 in Haiti (for mugging). $\mathrm{R}^{2}$ values refer to the percentage of variation in the dependent variable which can be explained by the independent variables in the regression. In other words, the higher the value of the $\mathrm{R}^{2}$, the better job the explanatory variables do in explaining the dependent variable.
} 


\section{SOCIOECONOMIC COSTS OF CRIME}

There are a wide variety of approaches that have been used to catalog and measure the costs of crime and violence. Analyses for the Caribbean have found that fear of crime causes individuals in Jamaica, the Dominican Republic, and Haiti to avoid activities and locations that are perceived as exposing them to risk of being victimized by crime. People whose families have suffered from crime report substantially lower levels of life satisfaction, and this effect is much greater in the Dominican Republic than in nonCaribbean countries. Crime also reduces tourist arrivals in the region, discourages business investment, and stifles economic growth. Cross-country panel data suggests that Haiti and Jamaica could boost economic growth per capita by 5.4 percent per year if they were to bring their homicide rates down to the levels of Costa Rica. Guyana and the Dominican Republic would also benefit substantially, with potential growth rate increases of 1.7 percent and 1.8 percent respectively.

4.1 The literature on crime and violence covers a wide ground, and there are multiple typologies for the possible sorts of costs that could be contemplated. The World Health Organization (2004) draws a distinction between direct costs (medical, legal, policing, prisons, foster care and private security) and indirect costs (lost earnings and time, lower human capital, lower productivity, lower investment, psychological costs and other non-monetary costs). Buvinic and Morrison (1999) use a more complex typology and distinguish between the following:

- Direct costs: the value of all goods and services used to prevent violence or offer treatment to its victims or perpetrators. This has been the most commonly estimated category of costs and includes health costs, police, justice and prison costs, as well as resources spent on private security measures. While the most frequently measured, this category may not be the most important.

- Non-monetary costs: higher mortality and morbidity rates that result in pain, suffering and death, but not necessarily result in either expenditures on health care or in easily quantifiable economic losses.

- Economic multiplier effects: impacts on human capital, labor force participation, lower wages and incomes, savings and macroeconomic growth.

- Social multiplier effects: erosion of social capital, inter-generational transmission of violence and lower quality of life.

4.2 One also might distinguish between short-run costs of all sorts and the long-run effects on growth. An earlier report on youth in the Caribbean by the World Bank (2003a) lists the following costs: 1) arrest, prosecution, and detention of criminals; 2) property loss and damage; 3 ) medical costs, public programs for victims, and lost income of the victim; 4) intangible costs (pain, suffering, and quality of life); 5) security costs; 6) lower tourist receipts; 7) lost income due to incarceration; and 8) lost social capital. 


\section{APPROACHES TO MEASURING THE COSTS OF CRIME AND VIOLENCE}

4.3 There are a number of different methodologies that have been employed to assess the costs of crime and violence. These include: 1) assessing specific costs; 2) adding up total costs using an "accounting approach"; 3) estimating total cost (more accurately, willingness to pay) using econometric methodologies; 4) calculating the Disability-Adjusted Life Years (DALYs) lost due to violence; and 5) estimating effects on economic growth through cross-country regressions. ${ }^{55}$

4.4 Each of the methodologies has its relative strengths and weaknesses. Studies which look at specific costs analyze the effects of crime on particular sectors or population groups without attempting to be comprehensive-i.e., without attempting to calculate the total cost of crime to society.

4.5 Among economists, the more popular approach has been to summarize the various costs of crime and violence in a single monetary figure that purports to represent the total cost associated with crime for a particular country. This is frequently done using an accounting approach, which collects data on the costs of crime in disaggregated categories and then sums up over categories (Buvinic and Morrison, 1999). This generally involves adding up all the assorted public and private expenditures associated with crime.

4.6 The accounting approach has both advantages and disadvantages. On the one hand, a single number may be useful for summarizing the myriad costs, for providing a comparison point to assess the cost-effectiveness of interventions, and for communicating to economists and business interests used to thinking in monetary terms. It is also attractive in data-poor environments; if information is missing for some categories of costs, estimates can be generated using categories for which data are available (Buvinic and Morrison, 1999b; World Bank, 2006b). On the other hand, no single measure can capture all imaginable costs and any specification of categories is necessarily arbitrary.

4.7 Another approach-which does attempt to measure the marginal benefit of crime reduction-is to estimate individual willingness-to-pay for marginal reductions in crime rates. This has been done in the case of Brazil, for example, by using hedonic housing models to estimate a relationship between housing prices and crime rates (Hermann and Haddad, 2003). It also could be done using contingent valuation methodology, which uses surveys to measure individuals' willingness to pay for reductions in crime.

4.8 A fourth approach is to estimate disability-adjusted life years (DALYs) lost to violence. The World Health Organization (2002) has estimates of violence-related DALYs lost for a large number of countries; DALYs are a widely-accepted measure of the health costs of violence.

\footnotetext{
${ }^{55}$ There are also studies which attempt to measure the marginal willingness-to-pay for reductions in crime. No such study has been conducted in the Caribbean.
} 
4.9 A fifth method is to estimate the effect of crime on growth using dynamic panel regressions. The growth effects approach has the advantage that is a summary measure which in principle captures the ultimate long-run effects of crime through many channels.

4.10 Rather than choose a single methodology to measure the costs of crime and violence, this chapter reviews a variety of work on its costs in the Caribbean, including several studies that estimate specific costs of crime, an accounting approach to measuring total costs, and estimates of DALYs lost due to violence. Also presented are new estimates of the effects of crime victimization on a self-reported measure of life satisfaction. Finally, the chapter builds on recent (2006) World Bank estimates of the impact of violent crime on growth to calculate the "growth dividend" that could be produced by reducing the homicide rate in several Caribbean countries.

\section{SPECIFIC Costs OF CRIME}

4.11 Several studies in the Caribbean examine specific costs of crime. These necessarily cover a wide variety of types of costs. Considered here are those that address the effects of crime on tourism, the non-monetary effects of violence in poor urban neighborhoods in Jamaica, gender-based violence in Haiti, and private sector responses to crime.

\section{Tourism}

4.12 Because of the key role that tourism plays in many Caribbean countries, the effects of crime on tourism are of particular concern. In 2004, the Jamaican tourism minister said that Jamaica's unprecedented crime level was threatening to derail the tourism industry by scaring away visitors and hurting investment (Associated Press, 2004). A study of popular perceptions of those working in the tourism industry found that crime and violence were perceived as the main problem afflicting the tourism industry (Dunn and Dunn, 2002).

4.13 A few studies consider the relationship between crime and tourism for the Caribbean. Albuquerque and Elroy (1999) showed that property crime tends to be disproportionately directed at tourists. Nonetheless, King (2003) showed that the odds of being victimized as a tourist in the Caribbean are low. He suggested that perceptions of the danger of crime do affect tourism but that such perceptions are driven much more by mass media coverage in the sending country than by actual dangers.

4.14 Alleyne and Boxil (2003) examined the relationship over time between tourist arrivals and crime in Jamaica and concluded that crime has discouraged tourists, particularly from European countries, but that the negative effect of crime has been mitigated by increased advertising and promotion and the growth of all-inclusive hotels. All-inclusive hotels, however, are incapable of fostering significant backward linkages to the rest of the local economy. A new business model for tourism that goes beyond airlines, cruise lines and hotels to span the entire "destination experience"-restaurants, taxis, tour operators, cultural and heritage sites and scenic locations-is necessary to 
generate backward linkages (World Bank, 2006a). This new model, however, cannot succeed if tourists are unwilling to leave all-inclusive resorts because of fear of crime.

\section{Non-Monetary Effects in Jamaica and the Dominican Republic}

4.15 Other qualitative work has examined the non-monetary effects of violence. A participatory study in poor urban Jamaican neighborhoods (Moser and Holland 1997) considers the effects of violence. The study notes that residents of inner-city neighborhoods in Jamaica suffer from "area stigma." They are judged to be associated with criminals based on where they live, which makes it difficult for them to find employment. The study also considers the intangible effects of violence on social capital, noting that "violence erodes social relationships, not only through death, but by restricting physical mobility and increasing levels of tension." Due to the high levels of violence in parts of urban Jamaica, residents are afraid to leave their homes and interact less often with friends and family who live elsewhere.

4.16 A similar phenomenon is evident in responses to the Encuesta Nacional de Hogares de Propósitos Múltiples (ENHOGAR) survey conducted in the Dominican Republic in 2005. Surprisingly large numbers of respondents report that they have stopped doing many activities due to fear of crime. As can be seen in Figure 4.1, due to the high levels of delinquency, Dominicans have reduced their recreational activities outside the house.

\section{Figure 4.1: Responses to Fear of Crime in Dominican Republic -What Do People Stop Doing Due to Fear?}

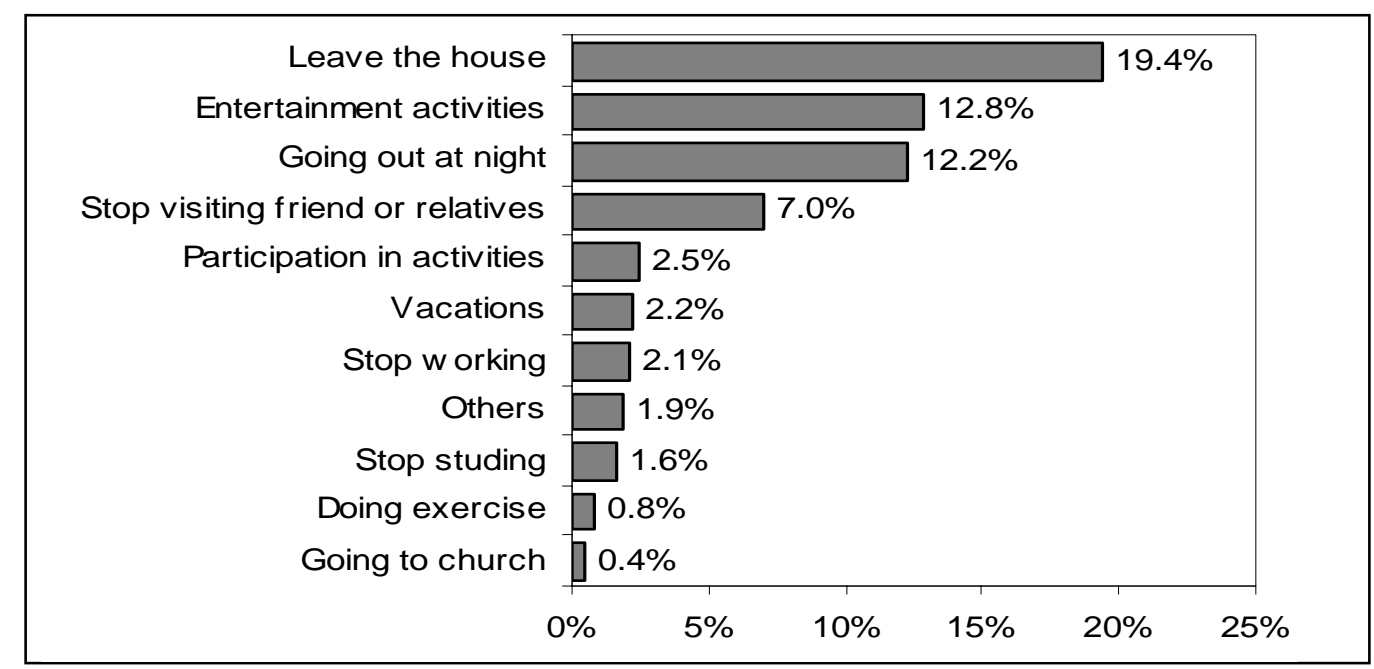

Source: Own analysis of ENHOGAR 2005. Note: Shown are the percentages responding in the affirmative to "Which of the following activities have you stopped due to fear to crime?"

4.17 Similarly, survey data from Haiti show that a high percentage of respondents are afraid of going to specific places due to fear of being mugged, attacked or having money or other belongings stolen. Figure 4.2 depicts that Haitians are more likely to avoid places like Port-au-Prince or the nearest larger town. 


\section{Figure 4.2: Responses to Fear of Crime in Haiti: Where Do People Stop Going Due to Fear?}

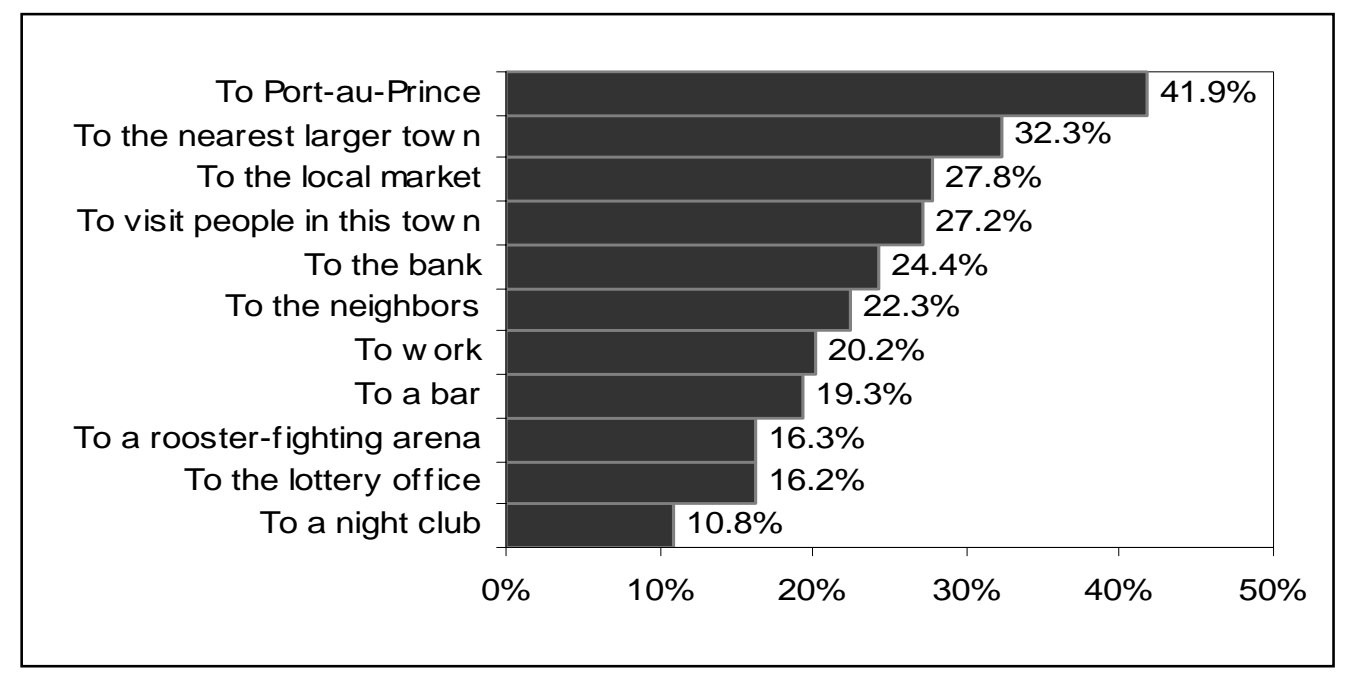

Source: ECVH 2001.

Note: Shown is the percentage responding in the affirmative to "Are you ever afraid of going to any one of the following places out of fear of being mugged, attacked or having money or things stolen from you?”

\section{Gender-Based Violence in Haiti}

4.18 Morrison and Orlando (2005) examine the impact of gender-based violence in Haiti on women's health and employment and children's health, using propensity-score matching techniques. Results from this analysis for lifetime physical violence by an intimate partner are shown in Table 4.1. ${ }^{56}$ Key results are that suffering from physical violence is strongly associated with an increased likelihood that: i) women do not receive antenatal care; ii) women suffer from genital sores and ulcers; and iii) both women and their children suffer from anemia.

\footnotetext{
${ }^{56}$ Lifetime physical violence is physical violence suffered at any point in an individual's life.
} 


\section{Table 4.1: Effects of Lifetime Physical Violence by Intimate Partner in Haiti}

\begin{tabular}{|c|c|}
\hline OUTCOME VARIABLE & $\begin{array}{l}\text { Average net effect of lifetime physical } \\
\text { violence by intimate partner (\% increase } \\
\text { or decrease compared to non-victims) }\end{array}$ \\
\hline \multicolumn{2}{|l|}{ WOMEN'S HEALTH } \\
\hline Weight for Height (centimeters x kilograms) & $-1,99 \%$ \\
\hline $\begin{array}{l}\text { Anemia (severity degree } 0-3 ; 0=\text { no anemia; } 3=\text { severe } \\
\text { anemia) }\end{array}$ & $27,63 \% *$ \\
\hline Number of Children & $-5,46 \%$ \\
\hline \% of Women who Ever had a Terminated Pregnancy & $33,18 \%$ \\
\hline $\begin{array}{l}\text { Last Child Wanted } \\
\text { (index } 1 \text { =wanted -3=did not want more children) }\end{array}$ & $5,53 \%$ \\
\hline Sexually Transmitted Disease (\%) & $55,12 \%$ \\
\hline Genital Sore /Ulcers (\%) & $116,22 \% *$ \\
\hline \multicolumn{2}{|l|}{ WOMEN'S USE OF HEALTH SERVICES } \\
\hline Visited Health Facility (\%) & $19,68 \%$ \\
\hline Antenatal Care (\%) & $-17,88 \% * *$ \\
\hline Births Assisted by Health Care Professional (\%) & $1,88 \%$ \\
\hline Unmet Family Planning Needs (\%) & $8,57 \%$ \\
\hline Contraceptive Use (\%) & $22,16 \%$ \\
\hline \multicolumn{2}{|l|}{ WOMEN'S EMPLOYMENT } \\
\hline Employed and Earning Cash (probability) & $2,27 \% *$ \\
\hline \multicolumn{2}{|l|}{ CHILDREN'S HEALTH (AGES 0-5) } \\
\hline Diarrhea $(\%)$ & $25,19 \%$ \\
\hline Coughing (\%) & $13,83 \%$ \\
\hline Anemia (\%) & $31,81 \% *$ \\
\hline Height for Age (centimeters $\mathrm{x}$ age in months) & $-5,79 \%$ \\
\hline Weight for Height (centimeters x kilograms) & $-3,41 \%$ \\
\hline Immunization (\%) & $-13,73 \%$ \\
\hline Under 5 mortality (per 1000 births) $^{\#}$ & $17,43 \%$ \\
\hline \multicolumn{2}{|l|}{ CHILDREN'S EDUCATIONAL ACHIEVEMENT (AGES 7+) } \\
\hline Education Years & $-12,21 \%$ \\
\hline Education Gap & $7,95 \%$ \\
\hline School Attendance (\%) & $-3,96 \%$ \\
\hline
\end{tabular}

Source: Propensity score matching estimates from Morrison and Orlando (2005), based on analysis of Haiti Demographic and Health Survey Data.

* significant at $10 \% * *$ significant at $5 \% * * *$ significant at $1 \%$

\# This is not a population child mortality rate. This variable is the sample average of the number of children under 5 who died divided by each woman's total number of births per 1000. In this case both rates are similar since there is no significant difference in the total number of children between the victims group and the control group. 


\section{Costs of Crime to Business}

4.19 The effects of crime on businesses can be particularly damaging because they can involve both short-run costs and long-run consequences for development by diverting resources to crime prevention measures and otherwise discouraging investment. This section reviews key findings from surveys of businesses on the costs of crime in Jamaica and the Dominican Republic. The survey in Jamaica was carried out by Francis et al. (2003) as part of the background work for the 2003 World Bank Country Economic Memorandum (CEM). The results from the crime module of the 2005 Investment Climate Survey (ICS) in the Dominican Republic are presented in the country's most recent CEM, World Bank (2006a).

Figure 4.3: Impact of Crime on Various Business Practices in Jamaica

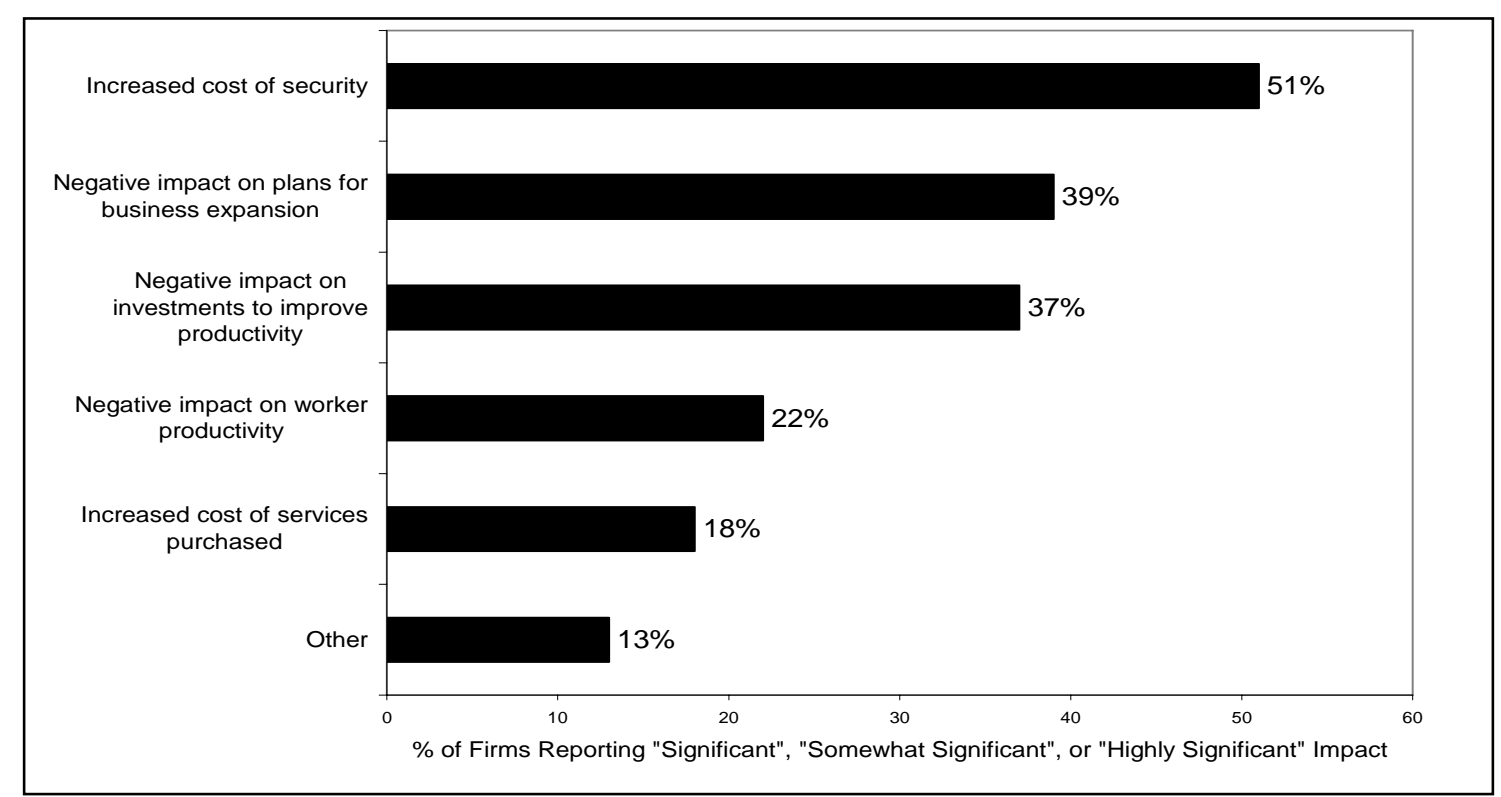

Source: 2001 Firm Victimization Survey, described in Francis et al. (2003).

4.20 Managers interviewed for the Jamaica study described how crime affected their business practices. Figure 4.3 shows the percentages of managers indicating that crime had either a significant, somewhat significant, or highly significant impact on particular business practices. Unsurprisingly, security clearly dominates the impact of crime, with more than half of firms reporting that crime increased security costs. Managers also indicated, however, that crime affects business decisions in ways that are likely to affect output in the long run. Thirty-nine percent responded that they were less likely to expand their business because of crime, and 37 percent reported that crime discourages investments that would improve productivity. 
Figure 4.4: Crime Protection Measures Taken by Firms in Jamaica

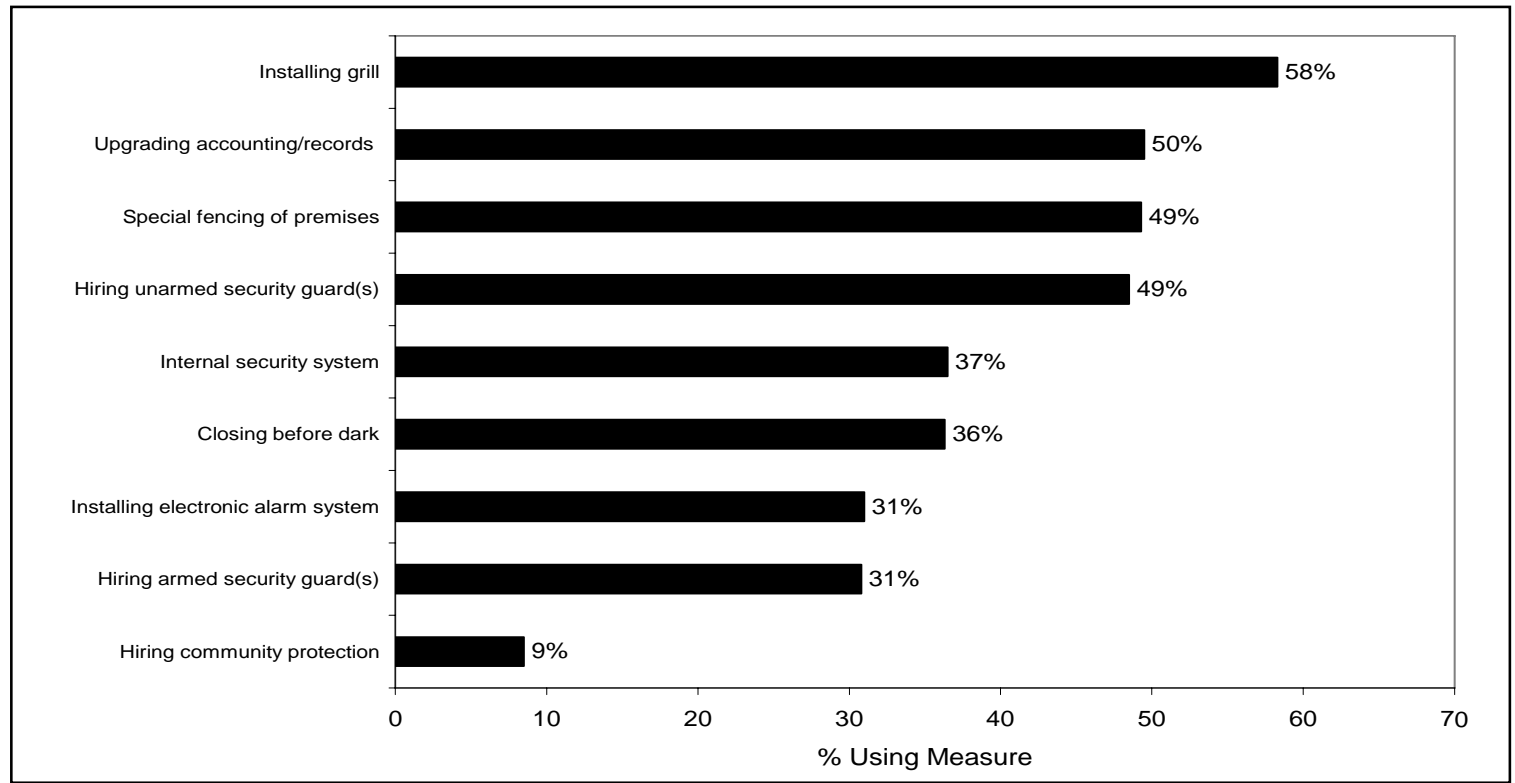

Source: 2001 Firm Victimization Survey, described in Francis et al. (2003).

4.21 The steps taken by businesses to protect themselves from crime are varied and not limited to security measures narrowly defined. A summary of these responses is shown in Figure 4.4. Physical security measures are the most common: 58.3 percent have installed protective grills on buildings, 49.3 percent have special fencing, and 31 percent have installed alarm systems. Nearly half have unarmed guards, and a remarkable 30.8 percent of firms have armed guards. Many firms (36 percent) have opted to close before dark; this practice has especially high costs in the manufacturing sector, where second shifts are not used and productive capacity consequently sits idle.

4.22 Among the more troubling costs to business are extortion and protection costs. Extortion occurs when a firm pays an extortionist in order to avoid victimization threatened by the extortionist. A protection racket, though similar, is distinguished in that the payment is in exchange for protection from criminal behavior from all other sources. To capture both types of coerced payments, the survey inquires about both. Notably, 8.5 percent of managers in Jamaica list paying for protection as being among their crime prevention measures, and 5 percent reported that they were force to pay extortionists.

4.23 Data from the firm victimization survey shows that security costs pose the largest burden for small firms. As shown in Figure 4.5, small firms pay security costs equal to 17 percent of their revenue on average, as compared to just 2 percent of revenue for firms overall.

4.24 Findings regarding crime from the ICS in the Dominican Republic were broadly similar to those from the Jamaica study. Seventy-two percent of firms surveyed took at least one action to prevent crime. As in Jamaica, substantial numbers of firms reported that they installed security equipment or software, hired security personnel, and closed before dark in response to the threat of crime (see Figure 4.6). 
Figure 4.5: Private Security Costs for Firms by Size of Enterprise as Percentage of Firm Revenue in Jamaica

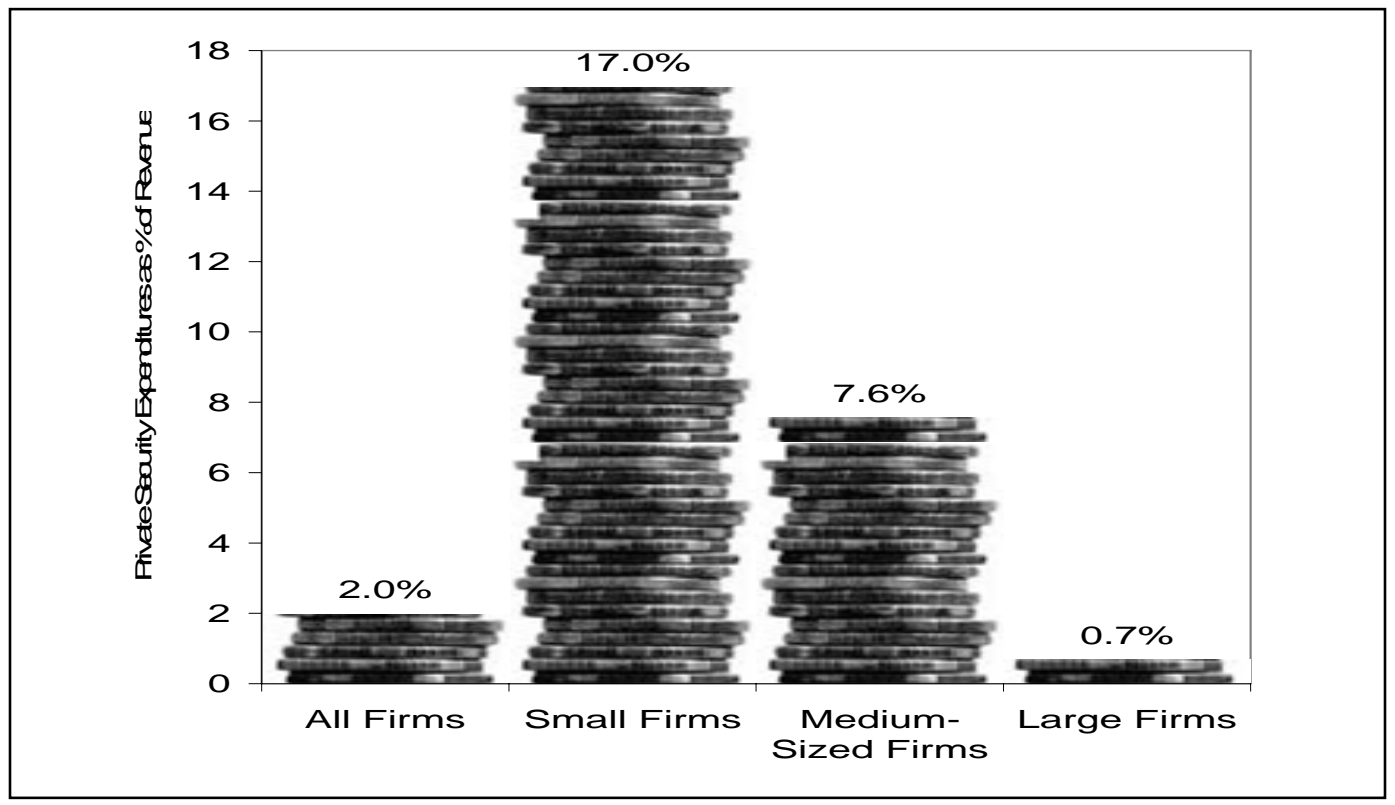

Source: 2001 Firm Victimization Survey, described in Francis et al. (2003).

Figure 4.6: Crime Protection Measures Taken by Firms in the Dominican Republic

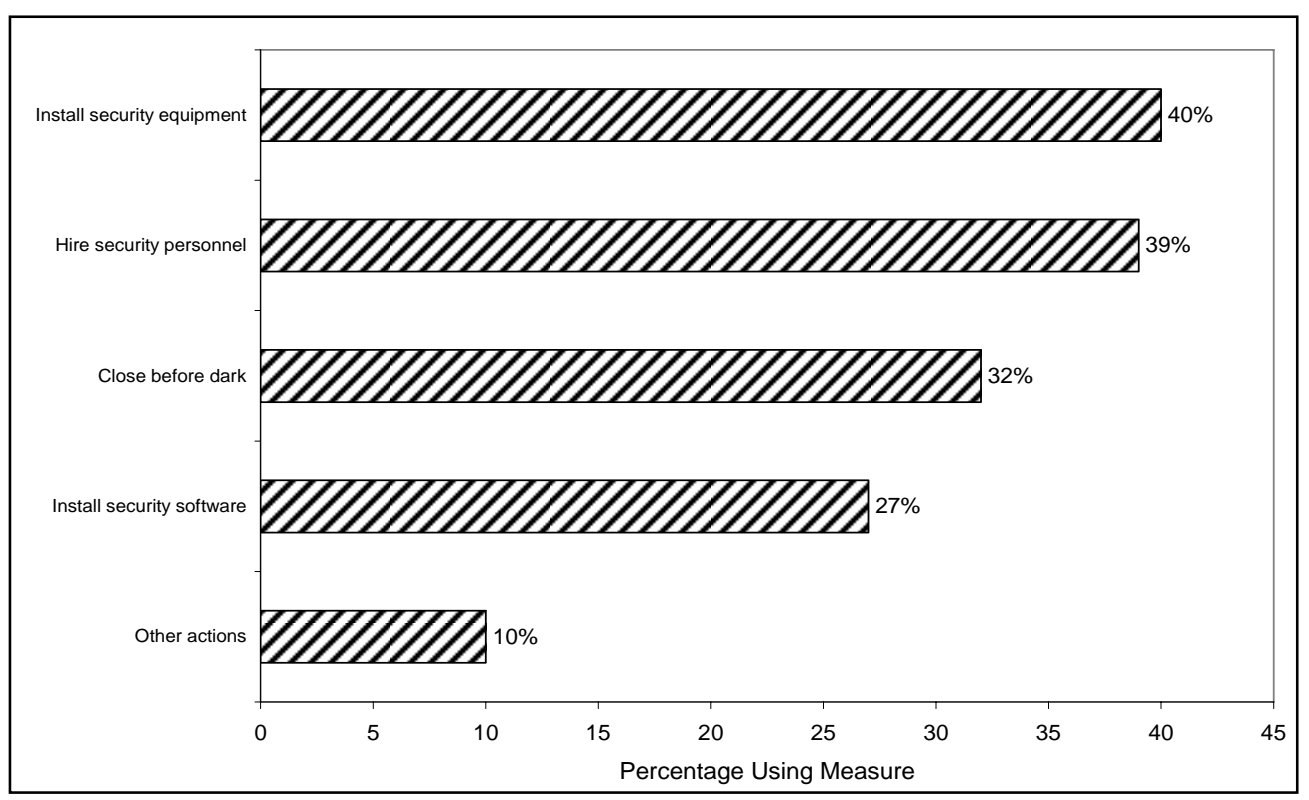

Source: World Bank (2006a), based on 2005 Investment Climate Survey.

4.25 Firms in the Dominican Republic also report other impacts of crime. Sixty-three percent cite crime as a major obstacle to investment. Similarly, 57 percent indicated that their access to financing had declined as result of crime, although only 10 percent of the firms were actually victims of crime, illustrating the fact that the effects extend far beyond the direct effects on victims. Other impacts of increased crime mentioned by 
respondents to the ICS include increases in spending on formal and informal security measures and declines in worker productivity (see Figure 4.7).

Figure 4.7: Impact of Higher Crime on Businesses in the Dominican Republic

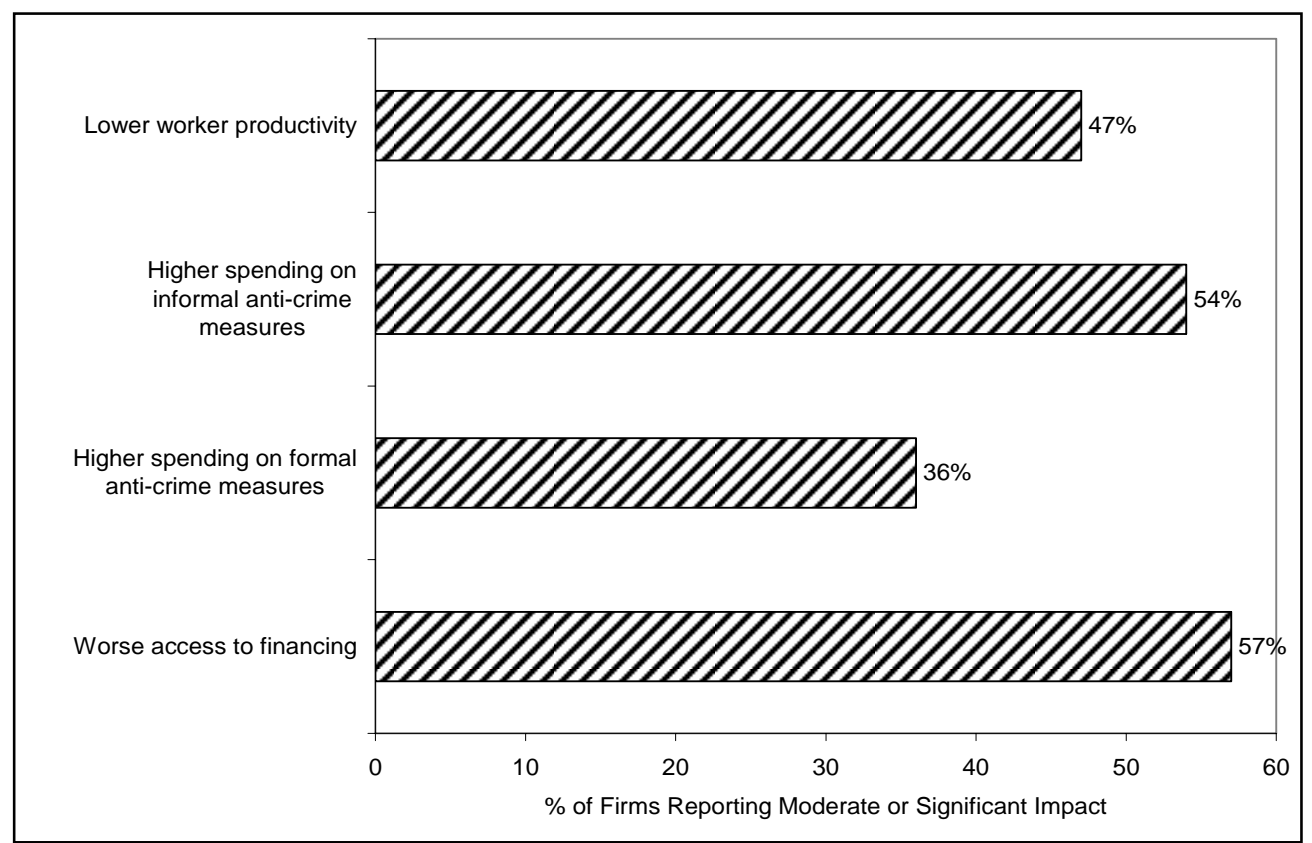

Source: World Bank (2006a), based on 2005 Investment Climate Survey.

\section{Total Costs: Estimates Using an Accounting ApProach}

4.26 Estimates using the accounting approach for measuring costs vary in terms of the extent of costs they measure. As part as the background work for this report, Holder and Mutota (2006) estimated that the costs of crime in Trinidad and Tobago in 2003 amounted to TT\$1.098 billion (US\$160 million), 1.6 percent of 2003 GDP. This estimate includes the value of lost productive years due to both fatal and non-fatal injuries, the value of the lost productivity of ex-criminals who have reduced earnings capability after serving jail time, funeral costs, and business security costs. It does not include the costs of public security and other elements of the criminal justice system.

4.27 An attempt at a comprehensive study of the costs of crime in Jamaica was conducted by Francis et al. (2003). They included both private and public costs in their summary measure. The study considered health costs-both those borne by the public health system and those paid by private citizens - along with the value of lost production due to mortality and injury related to crime, public expenditures on security, and private expenditures on security.

4.28 Health costs are among the most important costs of crime and violence in Jamaica. Violence has reached such high levels that it puts a substantial strain on medical services. A study of hospital-based data suggested that violence is the chief source of injuries in Jamaica. Data collected at three hospitals in 1999 and 2000 showed that 51 
percent of injuries were violence-related, with the remainder classified as unintentional (33 percent) and motor vehicle-related (15 percent) (Sharon Arscott Mills, 2002). Other studies in Jamaica show similar figures. ${ }^{57}$

4.29 The Francis et al. study estimated the public health costs of violence by calculating the share of emergency room admissions that are due to violence-related injuries and then multiplying that share by the total cost of the public health system. Using this method, they find that the total annual cost to the public health system is J\$996 million or about 0.3 percent of GDP in 2001.

4.30 Private health costs for those hospitalized due to injury are estimated based on data from the 1998 Jamaica Survey of Living Conditions. Using data on the average cost of hospital stays, treatment, and medication for those hospitalized for violence-related injuries, along with the number hospitalized for such injuries, the total private costs from violence-related hospitalization are found to be J\$254 million, just under 0.1 percent of GDP in 2001. ${ }^{58}$ This estimate does not include the private costs of treatment to those not hospitalized.

4.31 Apart from direct private health costs, some victims of violence are incapacitated and unable to carry out normal activities during periods of convalescence. Survey data suggest that the average length of hospital stay for violence victims was nine days. Using information on the average wage and number of people hospitalized for violence, and assuming that a hospitalized victim is out of the workforce for two weeks, the value of time lost due to violence-related morbidity is estimated to be J\$337 million, about 0.1 percent of GDP. ${ }^{59}$

4.32 Another part of the cost of violence is the funeral costs for murder victims. Based on a poll of funeral service providers, the study estimates funeral costs to be $\mathrm{J} \$ 66,000$ per person average, for a total cost of J\$64 million. The study also counts the time required for funeral preparations, which are found to have a value of approximately J\$41 million.

4.33 Additionally, the study considers the output lost due to the loss of what the individual would have produced during the year of his or her death. ${ }^{60}$ They calculate this

\footnotetext{
${ }^{57}$ Intentional violence cases accounted for 39.4 percent of cases at emergency rooms at the University Hospital of the West Indies in 1996 and 43 percent of emergency room visits at public hospitals in 2001. (McDonald et al., 1999) and Francis et al. (2003).

${ }^{58}$ An earlier study, Mansigh and Ramphal (1993) examined the costs of treating interpersonal violence in Kingston Public Hospital and estimated them at a value equivalent to \$709 in 2001 U.S. dollars.

${ }^{59}$ The study values the time of injury victims using the average weekly wage estimated in the study for murder victims of $\mathbf{J} \$ 8423$. While it is not clear in the study, presumably this average is among those who are employed. Because unemployment is high in Jamaica, this is likely to be an over-estimate of the value of victims' time in terms of wages. If not incapacitated by injury, some victims would be unemployed or out of the labor force rather than working.

${ }^{60}$ Note that it would be preferable to calculate the net present value of a discounted lifetime stream of wages, rather than take the wages in one year. The use of just one year's wages gives an underestimate of the future value of the individual's production. Calculations like this of the value of a person's life are controversial because they essentially assume that the life of a person with low-earning power is worth less than that of someone who earns more.
} 
by examining the occupational distribution of a random sample of murder cases in the previous three years and constructing a corresponding average wage. Multiplying this wage (on an annual basis) by the number of murder victims, they find a total lost output of J\$194 million.

4.34 Security costs dominate the total costs of crime as calculated by the accounting method. In the year examined in the study, the Government's budget for security services, including defense, justice, correctional services, and the police, totaled J\$10.5 billion or about 3.1 percent of GDP. Government expenditures on the justice system and the police are oriented chiefly towards criminal cases; of all cases filed with the Resident Magistrate courts in 2001, just 10 percent were civil cases. For the purposes of the costs exercise the full value of public security forces is counted as a cost of crime.

Table 4.2: The Costs of Crime in Jamaica: an Accounting Exercise

\begin{tabular}{|lc|}
\hline 1) Health Costs & 1.3 bn (0.4\% of GDP) \\
Public Health System & 995.7 \\
Private Citizens & 254.5 \\
2) Lost Production & 0.5 bn (0.2\% of GDP) \\
$\quad$ Mortality & 194.1 \\
$\quad$ Injury Due to Crime & 337.2 \\
3) Public Expenditure on Security & 10.5 bn (3.1\%of GDP) \\
& \\
& \\
Total (1) + (2) + (3) & $\mathbf{1 2 . 4}$ bn (3.7\% of GDP) \\
\hline
\end{tabular}

Source: Francis et al. (2003).

4.35 Table 4.2 above summarizes the costs of crime as calculated by Francis et al. (2003). They find that the total costs of crime in 2001 came to $\mathrm{J} \$ 12.4$ billion, which was 3.7 percent of GDP.

4.36 It is important to note what costs are not included in the 3.7 percent of GDP figure. First, this does not include the private security costs to firms shown in Figure 4.7, which average 2.0 percent of firm revenue across all firms. ${ }^{61}$ The Francis et al. study makes no attempt to quantify non-monetary costs like the pain and suffering of victims and their families and the psychological effects of living in fear of being victimized. The estimate of crime's effect on GDP also does not take into account the long-run economic or social effects of violence, such as the impact of violence on capital accumulation and future growth rates. In particular, there is a risk of a vicious circle, where violenceplagued neighborhoods receive little productive investment and hence offer few productive employment opportunities. The lack of opportunities, in turn, could lead youth to engage in violent and criminal activities. Nor does the cost estimate capture the fact that children who grow up in violent environments are themselves more likely to be violent as adults. This last effect-sometimes called "the inter-generational transmission of violence"-means that violence has significant inertia.

\footnotetext{
${ }^{61}$ Because the firm survey is not representative of the population of Jamaican firms and because security costs as a percentage of revenue vary greatly with firm size, it is not possible to reliably convert the 2.0 percent of revenue figure into a percentage of GDP.
} 


\section{DisABILITY-AdJUSTED LifE YeARS LOST TO ViOLENCE}

4.37 Another way to summarize the costs of violence is by examining the DisabilityAdjusted Life Years (DALYs) lost to violence. DALYs are the standard international health measure of the burden of disease. DALYs express years of healthy life lost, summarizing both the years of life lost to mortality and the suffering or incapacity associated with morbidity (Mathers et al., 2003). An important strength of analysis based on DALYs is that it provides a clear basis to compare the impact of violence on health with impacts from other threats to health.

4.38 The World Health Organization (2002) publishes estimates of cause-specific deaths and Disability-Adjusted Life Years (DALYs) lost, and violence is among the listed causes. ${ }^{62}$ One weakness of the WHO figures is that they measure only the direct effects of violence on those who are killed or injured and do not capture indirect effects on other individuals (such as increased stress levels or other reductions in the quality of life due to the fear of violence) or on society more broadly (such as lowered saving, investment and growth).

4.39 The DALYs lost to violence are calculated based on two estimated components: age-specific rates of death (mortality) due to violence, and age-specific rates of suffering and incapacity (morbidity) due to violence. The WHO publishes the overall deaths due to each cause, including violence.

4.40 The quality of the WHO data varies enormously by country. The reliability of the WHO data can be considered by examining the WHO figures on deaths due to violence with official homicide rates for each country. Figure 4.8 shows a scatter plot of the WHO data for 2002 vs. data from official sources for the closest available comparison period. The official source figures for Jamaica, the Dominican Republic, and Guyana are the respective governments' published figures for 2002. The Haiti figure is calculated from responses to a 2001 household survey. Figures for other countries are from government reports for various periods during the 1990s.

4.41 The figure shows that for particular countries the WHO data are substantially in error. In the case of Jamaica, in particular, the WHO data appear to be significantly flawed: the WHO data for 2002 show a murder rate of 0.5 murders per 100,000 Jamaicans, compared to the rate of 40 per 100,000 reported by the police for that year. Likewise, the WHO's figure (10.2) for Haiti is less than a third of the estimate based on 2001 household survey data (33.9). ${ }^{63}$ For Guyana and the Dominican Republic - the two other large countries in the region for which both official and WHO data are availablethe WHO figures are also substantially below official homicide rates. Nonetheless, excluding the two cases where the data are clearly deeply flawed-Jamaica and Haitithe WHO figures do not appear to show any systematic bias with respect to the official figures. For the remaining eight countries, the WHO estimate is above the official figure

\footnotetext{
${ }^{62}$ Jamaica homicide figures from multiple sources are examined in detail in the World Bank's forthcoming Jamaica Poverty Assessment (2006).

${ }^{63}$ Note that the household survey-based estimate for Haiti has a wide confidence interval and is not as reliable as the estimates from official reports.
} 
in half the cases and below it the other half. These can be seen in the figure as the points that fall above and below the 45 degree line. This suggests that although there are problems with the data, for countries other than Jamaica and Haiti, the DALY figures are not necessarily over- or under-stated and may be cautiously interpreted as a measure of violence's cost in terms of health.

\section{Figure 4.8: How Reliable is WHO Homicide Information for the Caribbean? Homicide Rates According to WHO vs. Official Sources Homicide Deaths per 100,000 Population}

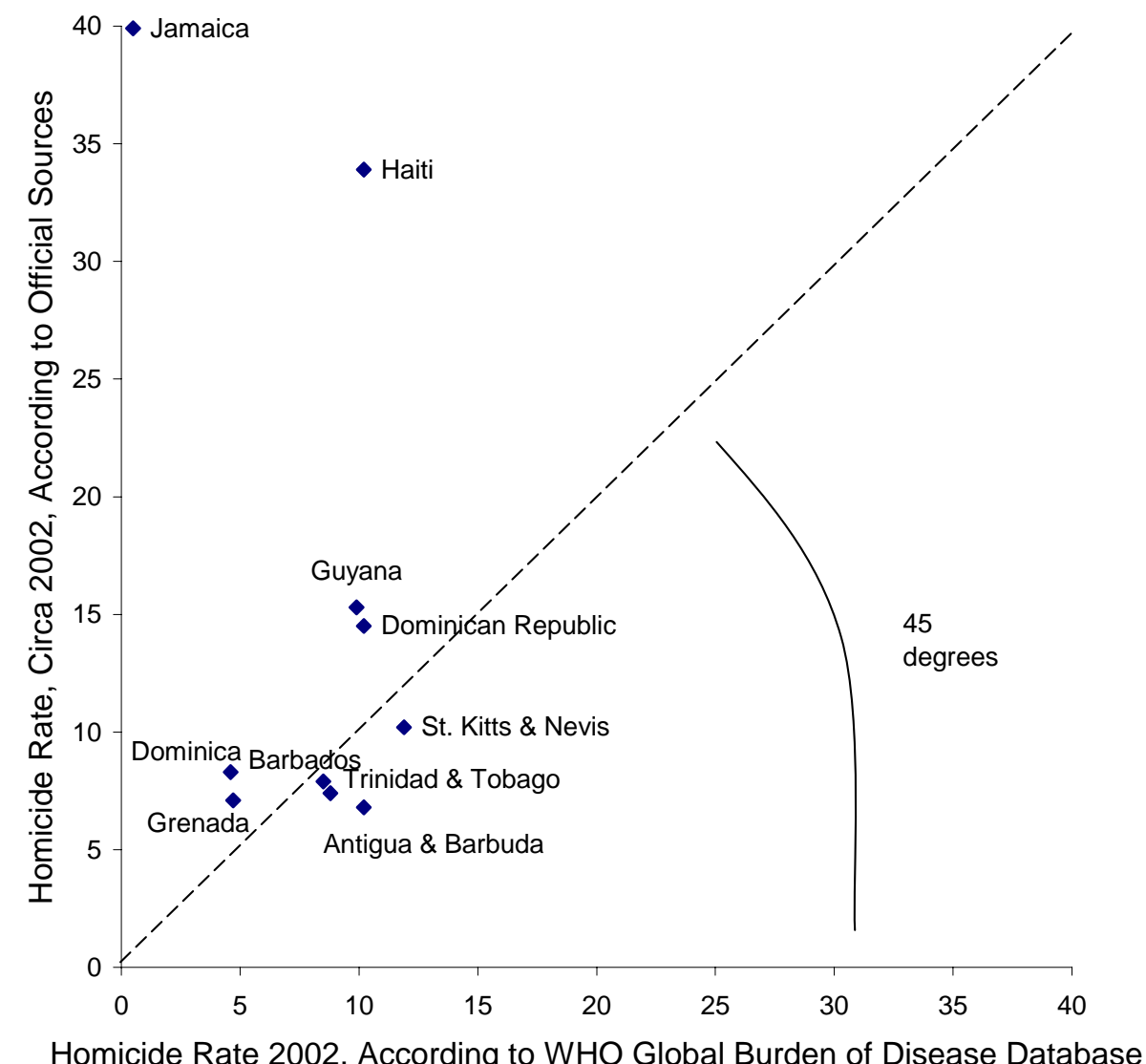

Source: WHO and various national sources.

4.42 Figure 4.9 shows the DALYs lost to violence by country in the Caribbean, according to WHO figures, both in raw totals and per 100,000 residents. The largest numbers of DALYs lost to violence are in the region's largest countries: Cuba, the Dominican Republic, Haiti, and Guyana. In terms of population-standardized rates of DALYs lost, Guyana ranks at the top in the WHO figures, followed by St. Vincent and the Grenadines and Saint Kitts and Nevis. It should be noted, however, that because the populations of the OECS countries are small, the population-standardized rates are sensitive to small errors in the DALY figures. 
4.43 The rate of DALYs lost to violence in almost all Caribbean countries is above the worldwide average. The exceptions are Dominica, and the two countries for which the data is evidently in error: Haiti and Jamaica.

Figure 4.9: Disability-Adjusted Life Years Lost to Violence in the Caribbean, 2002

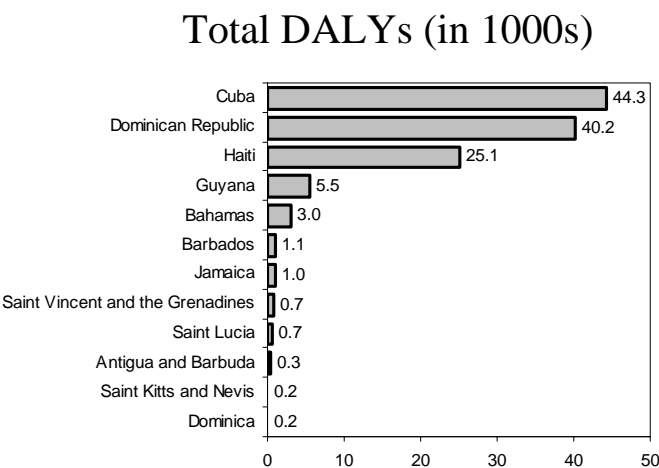

DALYs per 100,000 population

Source: WHO (2002).

Note: The world average DALYs per 100,000 population is calculated across all countries, weighted by population.

Figure 4.10: Disability-Adjusted Life Years Lost to Violence

vs. Other Causes Caribbean, 2002
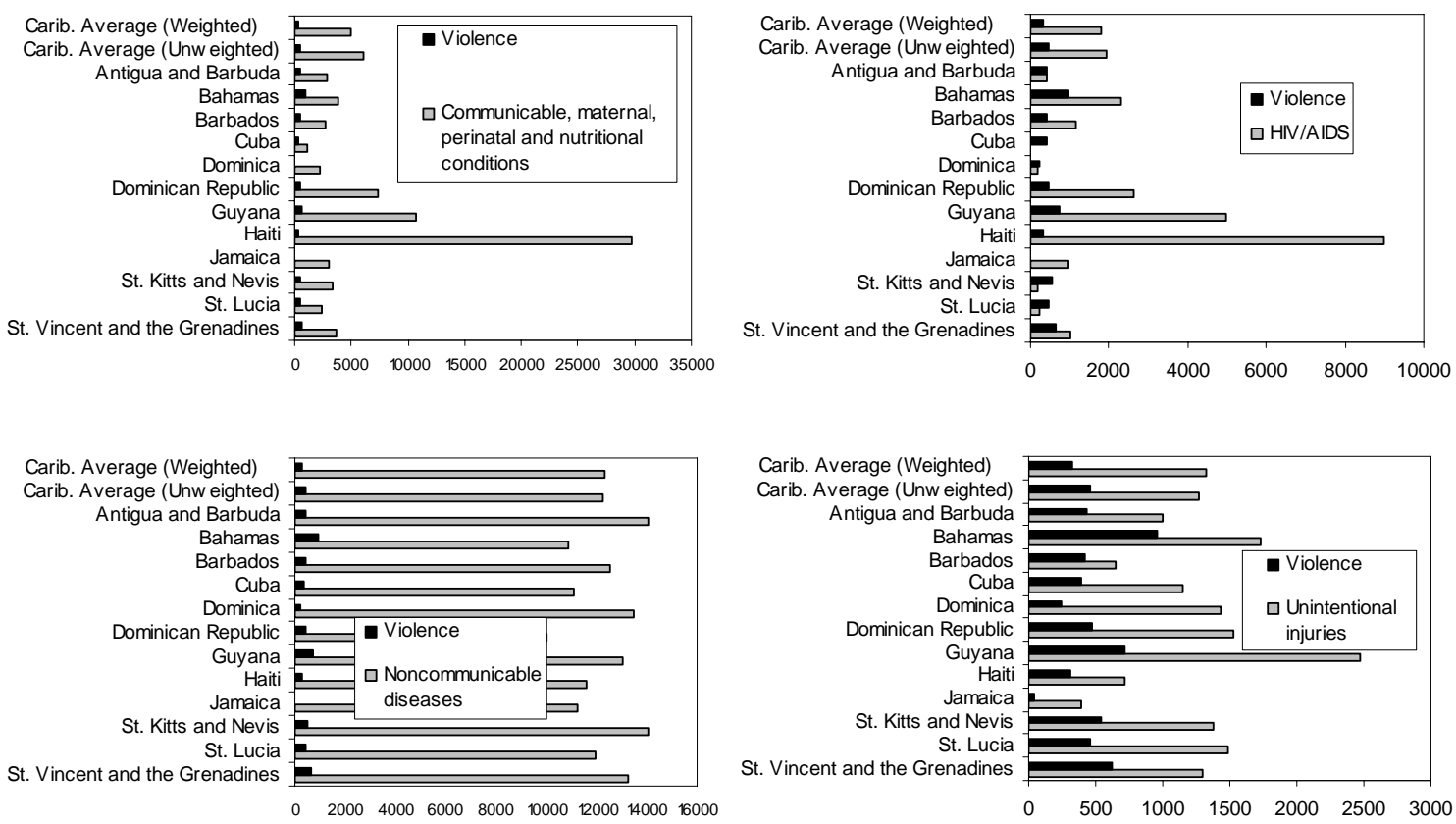

Source: WHO (2002).

4.44 How big is the direct impact of violence on DALYs relative to other causes? Overall, relative to all other causes, the impact seems to be relatively small, although this conclusion must be tentative because of the data problems affecting several countries in the region. In the WHO data, violence account for just 0.37 percent of all DALYs lost 
and 0.90 percent of all deaths in 2002 in the Caribbean. Figure 4.10 shows graphically DALYs lost to some of the other major categories. Other major health conditions, including HIV/AIDS, dwarf violence in terms of their impact on DALYs. For the Caribbean overall, DALYs lost to violence are equivalent to 24 percent of those lost to unintentional injury. ${ }^{64}$ As a whole, the DALY figures suggest that the direct health impact of violence-at least as measured in the WHO figures-may not be the most important part of the effect of crime and violence at a societal level.

\section{THE IMPACT OF ViCTIMIZATION ON SELF-REPORTED LIFE SATISFACTION}

4.45 Another cost of crime and violence is the effect being a victim has on one's quality of life. It is well known that exposure to crime can have long-lasting psychological impacts on the victims and those close to them. However, very little empirical research has been conducted on the relationship between crime and wellbeing. ${ }^{65}$ We analyzed the effect of being a victim or having a family member be a victim on subjective well-being, using Latinobarómetro surveys from 18 countries in Latin America. ${ }^{66}$ The only Caribbean country included in the survey is the Dominican Republic.

4.46 In the Dominican Republic, controlling for a wide variety of personal and socioeconomic characteristics, those who have been victimized (or had family members victimized) in the previous 12 months are 8 percent less likely to say that they are "satisfied" or "rather satisfied" with life. The effect in the Dominican Republic is higher than the average estimated effect of 4.4 percent for the 14 countries surveyed. Full results from the analysis are shown in Annex 4.1.

4.47 It is possible that this reflects in part not a causal effect of victimization but rather the fact that victim and non-victim families differ along other lines relevant to selfsatisfaction. For example, it may be that victimized families tend to live in particular neighborhoods with characteristics that make people both less likely to be satisfied with life and more likely to be victims of crime. The long list of covariates used in the analysis controls for such differences as best as possible using the available data. Overall, the analysis presented here provides reasonably strong evidence that crime has a substantial impact on the quality of life of victimized families and that this effect may be particularly high in the Dominican Republic.

\footnotetext{
${ }^{64}$ The WHO divides injuries into two categories: intentional and unintentional. Subcategories for intentional injuries are self-inflicted injuries, those due to war, and those due to violence. The subcategories for unintentional injuries are as follows: road traffic accidents, poisonings, falls, fires, drownings, and other.

${ }^{65}$ One exception is Powdthavee (2005), which examines crime and subjective welfare data from a 1997 survey in South Africa.

${ }^{66}$ The relevant questions in the survey are "In general terms, how satisfied would you say you are with life? Very satisfied, rather satisfied, not very satisfied, or not satisfied at all?" and "Have you or someone in your family been assaulted, attacked, or the victim of a crime in the last 12 months?”
} 


\section{THE IMPACT OF VIOLENT CRIME ON ECONOMIC GROWTH}

4.48 Another way to assess the costs of crime is to estimate the impact of crime on overall economic growth using cross-country panel data. ${ }^{67}$ The advantage of this approach is that it summarizes the overall economic cost of crime. Because the estimates are based on data from across countries, they reflect an average relationship between crime and growth worldwide. This section reviews estimates produced using this method as part of a study of crime and violence in Brazil (World Bank, 2006b) and considers their implications for Jamaica.

4.49 In this analysis, violent crime rates are measured using national homicide rates. Homicide rates are typically used for cross-country crime studies because they are thought to be least subject to variation in definition and reporting to authorities. The analysis follows the literature on the determinants of growth: GDP per capita is regressed on homicide rates, controlling for a country's level of income inequality, the cost of investment, and average male and female education. ${ }^{68}$

4.50 The measure used for this analysis is "completed homicides", referring to actual homicides. ${ }^{69}$ The analysis employs the Arellano and Bond (1991) GMM estimator, which provides consistent estimates of the effect of the explanatory variables on the outcome under the identifying assumption that the explanatory variables are not correlated to the time-variant components of the error terms. In all cases, the crime data is averages over five-year periods between 1975 and $2000 .^{70}$

4.51 Estimates are presented in Table 4.3. The dependent variable is the log of future GDP per capita, while "Income" as shown in the table is the log of current GDP per capita. The coefficient estimate on the homicide rate is significant and negative. This indicates that a country's homicide rate has a negative impact on subsequent economic growth $^{71}$.

\footnotetext{
${ }^{67}$ Obviously, causality runs in both directions: violence affects growth, but growth — by influencing opportunities for gainful employment-also affects violence. Here, we focus on the causal arrow running from violence to growth. See Chapter 3 for a more complete discussion of these causality issues.

${ }^{68}$ Data on homicides for $1975-2000$ is drawn from the United Nations Survey of Crime Trends and Operations of Criminal Justice Systems. Data on schooling comes from Barro and Lee (2000). Income inequality data comes from Deininger and Squire (1996).

${ }^{69}$ This definition may seem tautological, but international data distinguish between completed and total homicides. Completed homicides are actually consummated homicides, while total homicides include both consummated and attempted homicides.

${ }^{70}$ Dependent variable is average annual per capita growth. Robust standard errors are in parentheses. A constant was included in the model, as were dummies for time period. Observations are for five-year time periods between 1975 and 2000. Note that in this analysis violent crime rates are measured using national homicide rates. Homicide rates are typically used for cross-country crime studies because they are thought to be least subject to variation in definition and reporting to authorities. The analysis follows the literature on the determinants of growth: GDP per capita is regressed on homicide rates, controlling for a country's level of income inequality, the cost of investment, and average male and female education.

${ }^{71}$ The regression estimates imply that violent crime substantially reduces economic growth. A decline of 10 in a country's completed-homicide rate per 100,000 persons is associated with a 2.1 percent increase in average annual growth over the next five years.
} 
Table 4.3: Cross-Country Regression Estimate of the Effect of Violent Crime on Economic Growth

\begin{tabular}{lc}
\hline Variable & Estimates \\
\hline Income & -0.1362 \\
& $(.017)$ \\
Inequality & 0.0013 \\
& $(.0005)$ \\
Male education & 0.0120 \\
& $(.0168)$ \\
Female education & -0.0084 \\
& $(.0179)$ \\
Price level of investment & 0.0000 \\
& $(.0001)$ \\
Homicide rate & $-\mathbf{0 . 0 0 2 1}$ \\
& $(.0006)$ \\
Period Dummies & Yes \\
Countries & 28 \\
Observations & 32 \\
\hline
\end{tabular}

Source: World Bank (2006b).

Note: Standard errors are shown in parentheses.

4.52 We can consider what these estimates imply for potential gains to economic growth from crime reduction in the Caribbean. For 1996-2000, Costa Rica—one of the least violent countries near the Caribbean—had a homicide rate of 8.1 per 100,000 population according to data collected by the UN Office of Drugs and Crime. In contrast, the homicide rates in Jamaica, Haiti, Guyana and the Dominican Republic for the nearest available comparable period were $33.8,33.9,16.1$, and 16.5 , respectively. ${ }^{72}$ What would be the gain in economic growth for these Caribbean countries if they were to bring down their homicide rates to that of Costa Rica? Estimates from this "simulation" are shown in Figure 4.11.

\footnotetext{
${ }^{72}$ The Jamaica homicide rate figure is the average over 1998-2000 from the UN database. Because recent $\mathrm{UN}$ data is not available from the other three countries, homicide rates for those countries are drawn from alternative sources and for varying dates: 2001 household survey (Haiti), and the averages of 1999-2004 police reports (both Guyana and the Dominican Republic).
} 
Figure 4.11 Potential Boost to Annual Economic Growth Rate from Reducing Homicide Rate to Costa Rica Level

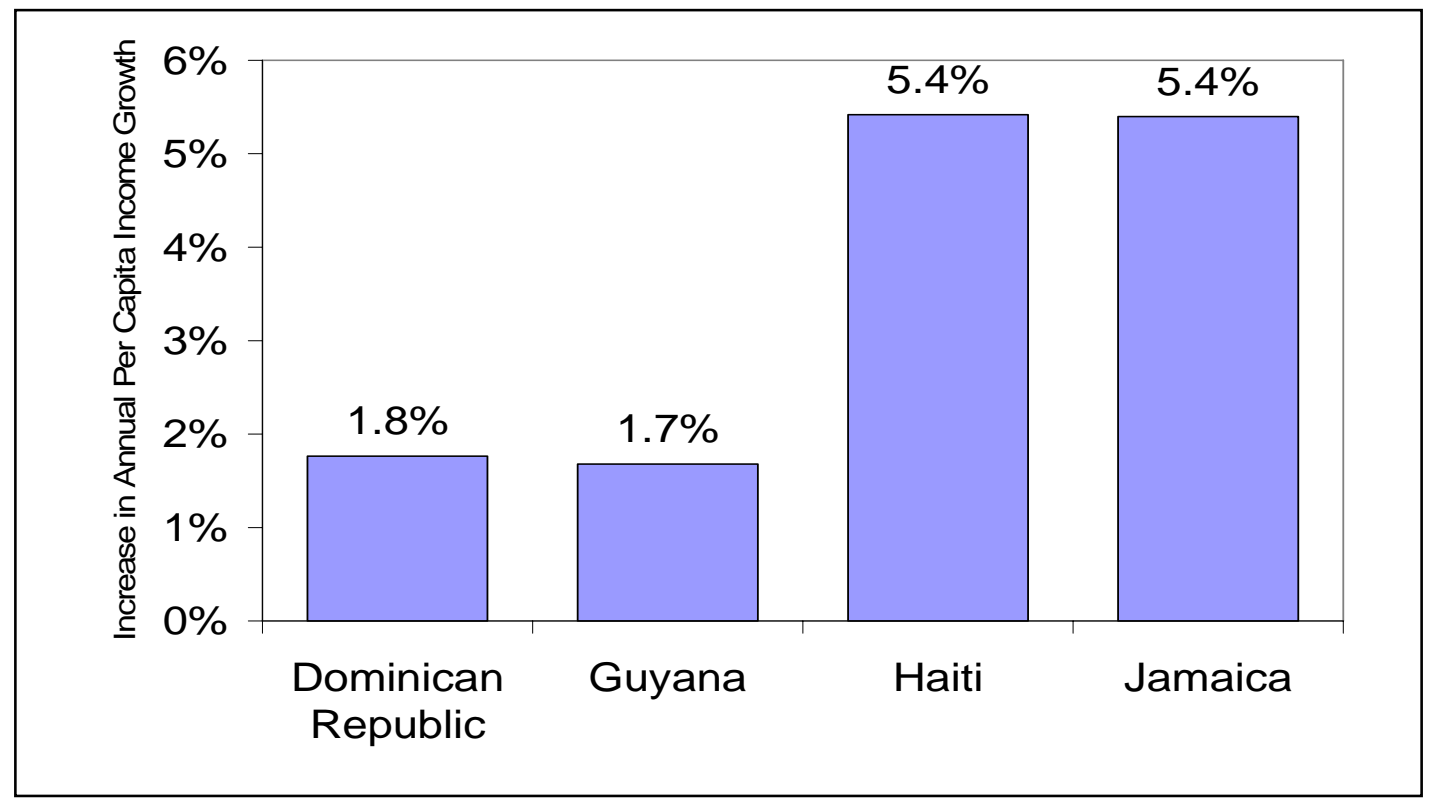

Source: Own calculations.

4.53 The regression results suggest very large potential gains from reduction in violence for Haiti and Jamaica, the two countries in the region with the highest murder rates. The coefficient estimate implies that both countries could boost economic growth per capita by 5.4 percent per year if they were to bring their homicide rates down to the levels of Costa Rica. Guyana and the Dominican Republic would also benefit substantially, with potential growth rate increases of 1.7 percent and 1.8 percent, respectively.

4.54 Because the estimated effects are on annual growth, they are cumulative over time, suggesting that over the long term the impact of crime reduction on welfare would be very high. For example, an increase of per capita growth of 1.8 percent-the figure implied by the simulation for the Dominican Republic-would result over 20 years in a cumulative increase of income per person of 43 percent.

\section{Policy Implications}

4.55 There are a number of ways to consider the costs of crime. Each approach illuminates a different aspect of the impact of crime, and no single approach is comprehensive. Even the accounting approach, which attempts to pull together a large variety of costs in a single measure, is limited to the extent that some costs of crime cannot be quantified; it is also generally limited to the current costs which can be more easily identified, rather than longer-term impacts.

4.56 The work reviewed and presented in this chapter shows that some of the most important costs such as impact on the investment climate and economic growth are those that are usually neglected in many analyses and in public discussions. Most importantly, 
the economic growth effects implied by the dynamic panel estimates are very large. They suggest that the countries of the Caribbean, which suffer from the most severe crime and violence problems, could realize a very large dividend in increased growth from reducing them. 


\section{YOUTH VIOLENCE IN THE CARIBBEAN: A CASE STUDY OF THE DOMINICAN REPUBLIC}

Deaths and injuries from youth violence constitute a major public health, social and economic problem across the Caribbean, including in the Dominican Republic. Youth are overrepresented in the ranks of both victims and perpetrators in the Dominican Republic, and this pattern has become more stark over time, as rates of crime and violence overall have increased. A wide variety of risk factors contribute to the prevalence of youth violence, including poverty, youth unemployment, urban migration, drug trafficking, a weak education system, ineffective policing, the widespread availability of weapons, drug and alcohol use, and the presence of organized gangs. Nonetheless, youth violence is preventable; a broad range of viable strategies for preventing and reducing youth violence exist. Most highly effective programs combine components that address both individual risks and environmental conditions, building individual skills and competencies, training parents for greater effectiveness, improving chances for poor youth to access and complete their secondary education, improving the social climate and safety of school, and providing "second chances" to those who have dropped out of the formal schooling system, including school equivalency programs, job and life skills training, and apprenticeships.

5.1 Youth violence is a high-priority, high-visibility concern across the Caribbean. Not only has violence grown in most of the region in recent decades, but youth are also disproportionately represented in the incidence and severity of this trend, both as victims and as perpetrators. Moreover, violent crimes are being committed at younger ages in many countries. Yet there is growing evidence that youth violence can be prevented and offenders can be rehabilitated when appropriate policies and interventions are adopted (WHO, 2002; US Department of Health and Human Services, 2001; World Bank, 2005c; IADB, 2002; Tolan and Guerra, 1994). This chapter addresses the pressing issue of youth violence and its implications for the Caribbean, with a particular focus on the Dominican Republic. The chapter also provides a set of policy and program recommendations which could prove useful to the region as a whole.

5.2 The overarching conclusion is that although youth violence is a legitimate concern for the region, it is neither intractable nor are youth "the problem." Rather, as detailed by the World Bank's Caribbean Youth Development Report (World Bank, 2003a), youth are a product of a complex set of factors in their environments. They also represent a unique window of opportunity to both prevent and reduce crime and violence in society at large. Evidence from evaluated youth violence prevention programs outside the Caribbean indicates that the earlier the investment in an individual, the greater the chance that violent behaviors can be prevented through adulthood, and the more costeffective the investment (WHO, 2003; World Bank, 2005c; Schweinhart, 2005 and Levitt, 1998). There are a multitude of policies and programs currently underway across the Caribbean to address youth violence. Unfortunately, very few have been subjected to rigorous impact evaluations and, consequently, there is little region-specific knowledge about what works and what does not. However, there is increasing evidence globally on 
the types of youth violence prevention efforts that work, and many of these programs are already being implemented in the sub-region.

\section{SCOPE OF YOUTH CRIME AND ViOLENCE}

5.3 This section provides a brief overview of youth crime and violence occurring in the Caribbean, with a special focus on the Dominican Republic. For the purposes of this report, youth violence is defined as homicide and non-fatal attacks perpetrated by or against a person aged 10-29 years of age. ${ }^{73}$ This age range was selected for three reasons. First, the late adolescent/early adulthood period of 15-29 is generally considered to have the highest risk for all forms of violence globally, and is particularly so in the Caribbean. Second, the early adolescent period (10-14 years) is a growing concern in the region because both quantitative and qualitative evidence points to violent crimes being committed at younger and younger ages. While still considered to be one of the lowest risk groups across the entire lifespan for being a victim of homicide, young adolescents are observed to be increasingly involved in both homicide and other forms of crime and violence. More importantly, they are the age at which many prevention policies may have a greater chance of success. Finally, the age range 10-29 coincides with that used in the only globally comparable data available on youth violence: World Health Organization statistics. $^{74}$

5.4 Data Limitations. As noted elsewhere in this report, general crime and violence data is often difficult to obtain and are often incomplete (see Chapter 1). This challenge becomes even greater when attempting to obtain information on youth in particular. The problem stems from a lack of common and comparable definitions of youth when it comes to crime and violence, as well as weak systems for surveillance and monitoring across what are considered minor (under 18) and adult (18 and older) age ranges. In particular, when attempting to compare data across countries, there are very few indicators beyond homicides that are disaggregated by comparable ages, and the Caribbean has particularly weak youth data compared with much of the rest of Latin America. This report has drawn from both available international quantitative sources (WHO, 2002/2003; PAHO; UNODC) as well as from primary quantitative and qualitative sources in the Dominican Republic (ALEPH, 2006).

5.5 Youth are disproportionately represented in Caribbean crime and violence, both as victims and as perpetrators, and in many of these countries violent crime is being committed at younger ages than in the past. Moreover, there is a growing concern that in a number of countries, the proportion of violent crimes committed by youth, and especially juveniles, has been increasing (UNODC, 2002). In 2005, young Dominicans aged 11-30 accounted for 46 percent of homicide victims, yet only represented 38 percent of the general population. In Jamaica, youth under the age of 25 were responsible for 51 percent of all murders and 56 percent of all major crimes in 2000 (World Bank, 2004). In the Dominican Republic, arrests for homicides by minors under the age of 18 rose over

\footnotetext{
${ }^{73}$ The 10-29 age range thus includes youth and young adults.

${ }^{74}$ Note that the age range will depend largely on available data. Much of the standardized WHO data on youth violence use the 10-29 age range, whereas the official UN MDG definition of youth is 15-24 years old.
} 
the period 1995-2004 from 2 to 113, with over 95 percent male (UNODC, 2002). Similar trends occurred in St. Kitts and Nevis, where in 1990 only 1.2 percent of all crimes were committed by juveniles, yet by 1998, this had increased to 17 percent (UNODC, 2002). A worrisome consequence of these trends is that evidence points to the fact that violent behavior in youth has a strong tendency to continue into adulthood (WHO, 2003; Levitt, 1998).

5.6 Youth as victims. How do youth violence statistics in the Caribbean compare with other countries? Youth homicide rates globally have large variations: for males, the numbers range from 2.5 per 100,000 in Canada and 5.2 in Chile, to 94.8 in El Salvador and 156.3 in Colombia (WHO, 2002). The Latin America and the Caribbean region boasts the highest homicide rate of men between the ages of 15-29 (68.6 per 100,000) in the world, more than three times greater than the global average of 19.4 (Table 5.1).

5.7 In the Dominican Republic in 2002, the adjusted homicide rate was 19.7 (per 100,000) for young Dominicans aged 15-29, compared with 10.2 for all Dominicans (Aleph, 2006). ${ }^{75}$ As Figure 5.1 illustrates, homicide deaths for youth have been growing consistently since 2000, particularly in the 18-29 age range. In 2005, homicides of those ages 11-30 accounted for approximately 46 percent of total homicide deaths. ${ }^{76}$ Young males are particularly affected, with a death rate of 35.3 (per 100,000 inhabitants) in 2002, which is over 80 percent higher than the global average of 19.4 for young men (WHO, 2002). They are also considerably more likely to be victims of homicide than the rest of the Dominican male population (18.3); moreover, they are fifteen times more likely to die from homicide than women as a whole (2.1 per 100,000 inhabitants) and nearly 8 times more than women of the same age group (3.2) (ALEPH, 2006; PAHO, 2006).

5.8 Violence against young women. Though often different in nature, ${ }^{77}$ violence against women is also disproportionately borne by youth in the Caribbean. The most widespread type of violence in the Caribbean is that which occurs within families and intimate relationships, where girls and young women are disproportionately affected, especially if the violence involves sex (PAHO, 2000). See chapter 1 for more on violence against young women.

\footnotetext{
${ }^{75}$ Data obtained from the Procuraduría General Statistics Department.

${ }^{76} \mathrm{Ibid}$. Results of self-report surveys around the world indicate that an overwhelming majority of those who participate in violence against young people are about the same age and gender as their victims; in most cases the offenders are males acting in groups (United Nations, 2003).

${ }^{77}$ Violence against women was defined by a declaration of the General Assembly of the United Nations (Declaration on the Elimination of Violence against Women, 1993) as "any act of gender-based violence that results in, or is likely to result in, physical, sexual or mental harm or suffering to women, including threats of such acts, coercion or arbitrary deprivation of liberty, whether occurring in public or in private life."
} 


\section{Table 5.1 Youth as Victims: Homicide Rates in Select Countries (per 100,000 inhabitants)}

\begin{tabular}{|c|c|c|c|c|c|c|}
\hline Country & Year & Total & $\begin{array}{c}\text { All } \\
\text { Ages } \\
\text { Males }\end{array}$ & $\begin{array}{l}\text { All Ages } \\
\text { Female }\end{array}$ & $\begin{array}{c}\text { Male } \\
\text { Age15-29 }\end{array}$ & $\begin{array}{c}\text { Female } \\
\text { Age15-29 }\end{array}$ \\
\hline Bahamas & 1995-1997 & 14.9 & 26.1 & -- & 48.4 & -- \\
\hline Brazil & $1995 a$ & 16.7 & 23.0 & 4.1 & 81.2 & 6.5 \\
\hline Chile & 1994 & 3.0 & 5.4 & 0.8 & 6.7 & -- \\
\hline Cuba & 1997 & 6.2 & 9.6 & 2.7 & 18.4 & 5.7 \\
\hline Colombia & 1995 & 61.6 & 116.8 & 9.0 & 212.5 & 15.0 \\
\hline Dominican & 2002a & 10.2 & 19.7 & 2.12 & 35.3 & 3.22 \\
\hline Republic & 2005b & 26.41 & 49.9 & 4.4 & -- & -- \\
\hline El Salvador & 1993 & 55.6 & 108.4 & 8.4 & 133.1 & 8.8 \\
\hline Guyana & 1994-1996 & 6.6 & 11.8 & -- & -- & -- \\
\hline Jamaica & $2004 a$ & 55.7 & 102.1 & 10.5 & 188.0 & 14.8 \\
\hline $\begin{array}{l}\text { Trinidad and } \\
\text { Tobago }\end{array}$ & 1994 & 12.1 & 17.1 & 6.6 & 21.6 & -- \\
\hline LAC average & & 19.3 & 34.7 & 4.0 & 68.6 & 6.4 \\
\hline United States & 1998 & 6.9 & 10.7 & 3.1 & 23.6 & 4.6 \\
\hline Canada & 1997 & 1.4 & 1.9 & 1.0 & 3.2 & 1.1 \\
\hline World & & 8.8 & 13.6 & 4.0 & 19.4 & 4.4 \\
\hline
\end{tabular}

Source: World Health Organization. 2003. World Report on Health and Violence. Geneva.

a: Based on data obtained from World Health Organization (August 2006).

b: Estimates from National Police Statistics.

5.9 Youth as perpetrators. Just as they account for a disproportionate share of the victims of violence, young people are also disproportionately its perpetrators, especially young men. In most countries, this is a growing trend. Indeed, statistical data indicate that in virtually all parts of the world, with the exception of the United States, rates of youth crime rose in the 1990s, with many of the criminal offenses related to drug abuse and excessive alcohol use (UNDP, 2003). What little data exist indicate that this phenomenon may be particularly worrisome in the Caribbean. 
Figure 5.1: Homicide Deaths by Age (10-29) in the Dominican Republic (2000-2005)

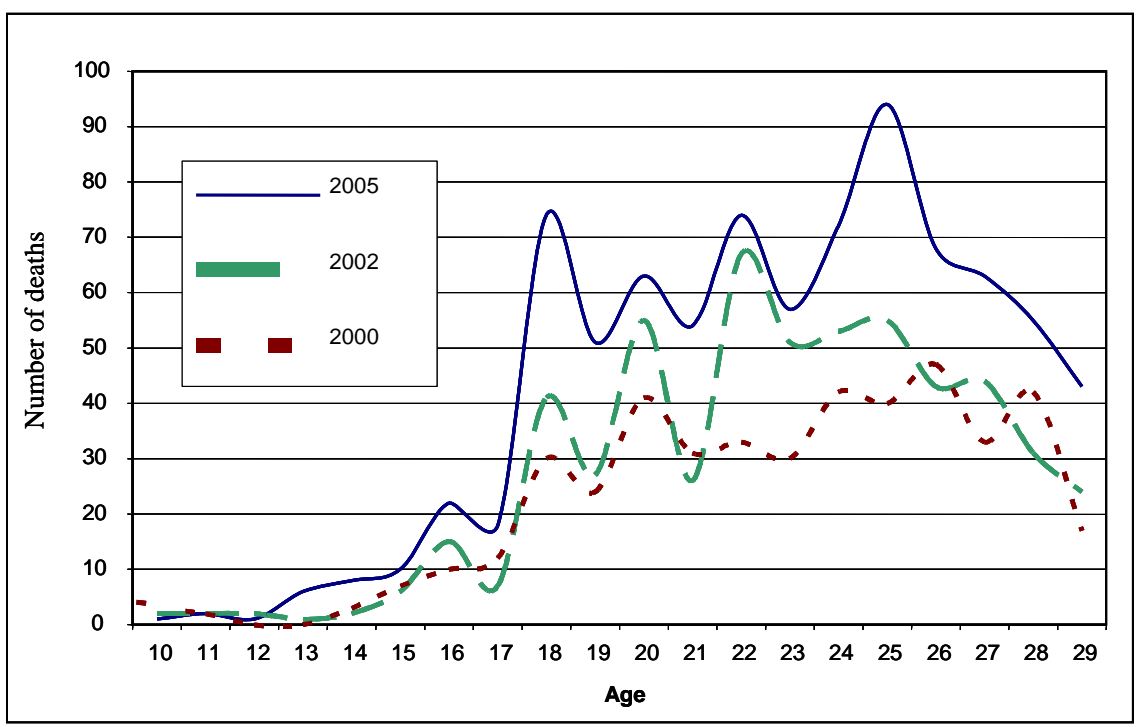

Source: Dominican Republic National Police, unpublished data.

5.10 In Jamaica, for example, the country's homicide rate for 2005, considered the highest in the world, was at an all-time high and over 70 percent of homicides were committed by young men ages 16-30. Shares were similar for shootings (78 percent), robbery (74 percent), and rape (68 percent). In the Dominican Republic, of the current prison population, 62 percent of those arrested for homicide were 16-29 at the time of arrest compared to 71 percent of those arrested for robbery. In the first six months of 2006, 61 percent of new prisoners arrested for homicide were 16-29 and 70 percent for robbery (Procuraduría General de la República Dominicana, 2006).

5.11 Crimes perpetrated by minors (under age 18) in the Dominican Republic have also been on the rise over the past decade. Arrests of minors tripled between 2000 and 2003 and started to decline in 2004 and 2005 (Figure 5.2). However, those arrests related to illegal arms and drugs have shown no sign of decreasing (Dominican Republic National Police, 2006) In fact, whereas over the past decade the most common crimes committed by minors were petty theft (48 percent), drugs (11 percent) and assault (10 percent), those that experienced the most consistent growth were arrests for homicide and illegal arms, with average annual increases over the past decade of 195 percent and 107 percent, respectively. These were followed by average annual increases in aggressive assault (28 percent) and drug arrests (22 percent). ${ }^{78}$ As Box 5.1 illustrates, qualitative data supports the quantitative evidence that younger groups of youth are increasingly involved in violent crime.

\footnotetext{
${ }^{78}$ Author's calculations based on Dominican Nacional Police statistics (1995-2005).
} 


\section{Figure 5.2: Trends of Minor Arrest over Past Decade in the Dominican Republic}

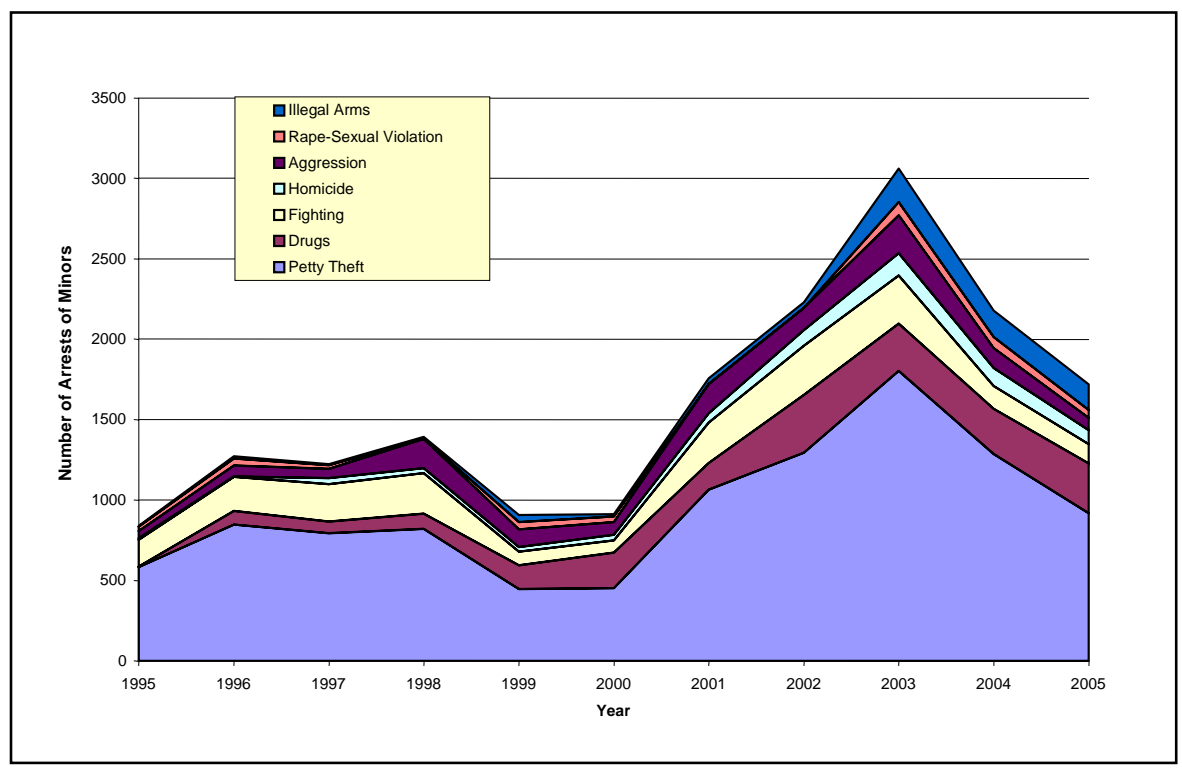

Source: Dominican Republic National Police Crime and Victim Data, 2006.

5.12 Youth focus groups reveal some common characteristics of youth perpetrators of crime. The overwhelming majority of youth currently residing in the Dirección Nacional de Centros de Atención Integral (juvenile corrections center) are young men (136, compared with 3 women). The primary motivation identified for committing a crime was a desire to escape poverty (ALEPH, 2006). Other common characteristics were: growing up in dysfunctional households, having been abused and mistreated, getting an early start in a life of crime (with a reported average age of first crime as 13), consuming illegal drugs, and having dropped out of school.

5.13 Gang and drug related violence has also increased in recent years, with youth as the most visible culprits of this type of crime and violence. Because the criminal justice system in the Dominican Republic does not allow arrest or incarceration of youth below the age of $13,{ }^{79}$ gangs and drug lords are increasingly using younger members to carry out both petty and hard crimes (Box 5.1). This appears to be a trend throughout the subregion (see discussion of gangsterism in next section). As reported in the World Development Report (WDR) 2007, younger gang members are responsible for a disproportionately large share of offenses. The WDR finds that the formal association with a gang is powerful: gang members wield more influence on the violent behavior of their peers than violent non-gang members. What is more, youth gang members tend to commit crimes that are more serious and violent while they are gang members than after they leave the gang (World Bank, 2006c).

\footnotetext{
79 The "Ley 136-03, Código para el Sistema de Protección y los Derechos de Niños, Niñas, y Adolescentes," article 223 states that children under the age of 13 are in no case to be held criminally responsible, and as such, cannot be held for arrest, nor be given any sanction by official authorities. See Guerrero (2005).
} 


\section{Box 5.1: The Sophisticated Extortion of Santo Domingo Gangs and Drug Lords}

There is emerging quantitative and qualitative evidence that younger adolescents are increasingly involved in violent crimes, particularly as they relate to the drug trade:

"Never in the past have we witnessed such sophisticated tactics used by drug lords and young gang members to attract children to carry out their crimes. Over the past three years, we have seen one particularly cruel method that has taken on a frightening momentum, and its impact on our society's children is devastating."

"Young men who we know to be involved in the drug trade (because we have lived in their neighborhood for years) invite young boys-usually 8-12 years old from broken families where the mother has to work - to join in sports activities and games in the neighborhood. These young men have nice clothes, shoes, cell phones, and they become buddies with the children."

"Once they gain their trust, they ask them who they love most in the world. The children respond, and are then told, if you do not steal 3 cell phones a day for us, then we will kill your mother' (or whomever else they have confided is their most beloved person). A 10 year-old child from the barrio has nothing else to hold on to. We have witnessed in the past 6 months hundreds of crimes committed this way ranging from petty theft to murder. These children never see a way out...."

- Interview with a group of Catholic nuns who have served in several of Santo Domingo's most violent neighborhoods for over 15 years. May 20, 2006

\section{FACTORS CONTRIBUTING TO YOUTH VIOLENCE}

5.14 Identification of the key risk factors that contribute to youth violence makes clear that the policy and programmatic responses need to extend across a wide range of professional disciplines, including those of public health, education, and skills training. This section summarizes the current literature discussing these factors with a view to informing policymakers on where to most effectively target interventions. As outlined in Chapter 3, risk factors can be identified at four interrelated levels: i) societal; ii) community; iii) relationships; and iv) individual. In addition to "risk" factors, protective factors are also present at each of the four levels, decreasing the likelihood that youth engage in crime or violence. It is worth emphasizing that the presence of a risk (or protective factor) does not ensure that criminal or violent behavior will (not) occur-it merely increases the likelihood that it will (not). While the analysis here focuses on factors for youth violence in the Dominican Republic, where possible the findings will be placed in a wider Caribbean context.

5.15 Recent empirical research conducted on risk and protective factors for youth in the Caribbean concluded that school attendance/connectedness are the most important factors in reducing violent youth behavior. In particular, the study found that boys (girls) who feel connected to school were 60 percent (55 percent) less likely to engage in violent activity. ${ }^{80}$ In addition, the study showed the significant effects that schools have in reducing drug use, smoking, and alcohol consumption. The study also found that family

\footnotetext{
${ }^{80}$ Analyses were done on the results of a 1997-98 survey of over 15,500 young people 10-18 years of age in 9 Caribbean countries to identify risk and protective factors associated with health compromising behaviors, including violence. See Blum, R.W. et al. (2003).
} 
connectedness, or the presence of a caring adult, served as the second most important protective factor. The analysis concluded that both risk and protective factors are cumulative; if protective influences are held constant and predominant risks are added one at a time, risk behavior rises significantly. Conversely, and perhaps more importantly, when risk factors are held constant and protective factors are added, there is an even greater reduction in reported involvement with violence. ${ }^{81}$

5.16 Societal Level: Some examples of risk factors at this level are poverty, inequality, youth unemployment, an ineffective criminal justice system, and drug trafficking. At the societal level in general, the Caribbean has had a culture of aggression rooted in slavery since colonial times. Today, messages to youth from both regional and international (U.S.) media and music in particular, are often expressions of rage or alienation-anti-women, pro drugs, pro-violence, and materialistic - that influence the decisions that youth make (World Bank, 2003a). For the Dominican Republic, some of the identified trends at this level are as follows:

5.17 Poverty and Inequality. Being raised in poverty has been found to contribute to a greater likelihood of involvement in crime and violence. It is also often related to youth aggression because of increased stress and feelings of hopelessness that may arise from chronic unemployment and other associated factors (IADB, 2002; Weaver and Maddeleno, 1999). The inverse relationship between family income and juvenile crime is well documented globally (World Bank, 2006d). During the deep economic and financial crisis of 2003-2004, extreme poverty doubled from 7 percent to 14 percent (World Bank and IDB, 2006). Violent crimes also rose dramatically; from 2002 to 2005, the rate of violent death nearly doubled from 14.5 to 26.4 per 100,000 residents (Aleph, 2006). ${ }^{82}$ In addition to poverty, the income inequality demonstrated by drug dons, foreign tourists, and the media encourages engagement in easy money activities, including drugs and prostitution (World Bank, 2003a).

5.18 Youth Unemployment. Between 2002 and 2004 youth unemployment jumped from 23 to 31 percent, or more than twice the LAC average (15.2 percent) and the global average (14.4 percent) (World Bank and IDB, 2006). Although data is not available, it is generally agreed that these figures for urban poor youth are significantly higher. The fact that young Dominicans in (or entering) the labor market are at a disadvantage is consistent with findings from the international literature on the effects of demand shocks (Jimeno, J. and Rodriguez-Palenzuela, D, 2002), as well as those observed throughout the Caribbean, where many countries have especially elevated youth unemployment. International comparisons indicate that Barbados, the Dominican Republic, Jamaica, St. Lucia and Trinidad and Tobago have high rates compared to the rest of Latin America (Table 5.2). Evidence from the United States has shown that falling wages and local youth unemployment were partly responsible for the rise in youth crime in the 1970s and 1980s (World Bank, 2006d).

\footnotetext{
81 Ibid.

${ }^{82}$ Note that violent deaths in the Dominican Republic include homicides and deaths resulting from shootings between police and civilians. In 2005, 18 percent of violent deaths were a result of shootings between police and civilians; the remainder were homicides.
} 
Table 5.2: Highlights of Youth in Numbers in Latin America and the Caribbean

\begin{tabular}{|c|c|c|c|c|}
\hline Country & $\begin{array}{c}\text { Youth } \\
\text { Unemployment }\end{array}$ & $\begin{array}{c}\text { Percentage of } \\
\text { youth population } \\
(15-24)\end{array}$ & $\begin{array}{c}\text { Net } \\
\text { Secondary } \\
\text { School } \\
\text { Enrolment } \\
\end{array}$ & $\begin{array}{c}\text { Youth } \\
\text { Fertility } \\
(15-19) \\
\end{array}$ \\
\hline Bahamas & 15.8 & 18.0 & 79 & 49 \\
\hline Barbados & 21.8 & 15.1 & 87 & 46 \\
\hline Dom Rep (2002) & 23.1 & 19.1 & 41 & 94 \\
\hline Dom Rep (2004)a & 31.0 & 19.1 & 38 & N/A \\
\hline Grenada & 27.0 & 24.5 & -- & 69 \\
\hline Jamaica & 34.0 & 18.7 & 75 & 32 \\
\hline St. Lucia & 44.0 & 20.3 & 70 & 46 \\
\hline $\begin{array}{l}\text { St. Vincent and the } \\
\text { Grenadines }\end{array}$ & 36.0 & 20.8 & -- & 22 \\
\hline Trinidad and Tobago & 25.4 & 20.7 & 72 & 13 \\
\hline LAC Average & 15.2 & -- & -- & 52 \\
\hline United States & 10.6 & 14.2 & 85 & 57 \\
\hline
\end{tabular}

Source: World Bank 2004 , World Bank 2005d, and Secretaría de Educación.

5.19 Urban migration is on the rise, with a high share of young migrants who are "unattached" to families, schools or employment. Although large youth cohorts in and of themselves are not always associated with increases in crime and violence, the correlation is stronger when taken in the context of increasing poverty and rapidly growing cities, such as in the urban areas of the Dominican Republic (World Bank and IDB, 2006). Migration flows in the Dominican Republic are very high, with more than 2 million people living in a region other than that of their birth in 2002 (World Bank and IDB, 2006). Whereas 56 percent of Dominicans were living in cities in 1997, that number had reached 64 percent by 2004 (Fares et al., 2006). Nearly 40 percent of Dominicans choosing to resettle are between the ages of 20 and 39 (Fares, et al., 2006).

5.20 Drug trafficking. The Dominican Republic's role as a transit country for the drug trade puts many young Dominicans at risk. This macro level trend disproportionately affects youth in two ways. First, given the immunity of minors from prosecution in adult courts, the relative cost of their involvement in the drug trade is lower than that of their adult counterparts, giving them a perverse comparative advantage. Second, remuneration in the narcotics business tends to be in-kind, and this trend is 
growing in the Dominican Republic, particularly with younger members. ${ }^{83}$ This creates a long-term involvement with the industry of illicit drugs, expanding the client base for the drugs and creating a dependency/addiction among participating youth.

5.21 Community level: Some common risk factors at this level relate to schools, neighborhoods, and police. Examples are lack of school access, school policies, availability of guns, prevalence of drugs, unsafe neighborhoods, police abuse and criminal justice responses at the local level. The presence of these factors in the lives of young Dominicans is as follows:

5.22 Schools. The education sector in the Dominican Republic is characterized by low enrollment rates, high dropout rates, poor quality, and weak funding, the combination of which contributes greatly to the generation of idle and unskilled youth with few opportunities. Only 53 percent of Dominicans complete primary school and the net secondary school enrolment rate is just 38 percent. What is more, the average score on the grade eight national exam in 2004 was 52 percent (Secretaría de Estado de Educación, 2005). As a result, even the lucky few that stay in the system long enough to graduate tend to leave school with a dearth of relevant skills for a successful school-to-work transition. When compared to other Caribbean countries for which UNESCO data is available, the Dominican Republic's 1.1 percent of GDP in education spending in 2004 was by far the lowest among the Latin American and Caribbean countries with available data. ${ }^{84}$ The number of youth who can be considered at risk-poor, out of school, and jobless - is therefore large and growing. This increase is believed to be "a key factor in the rise in crime, violence, gangs and other forms of risky behavior, particularly among the poorest segments of this age group, which see fewer prospects for the future” (World Bank, 2005d).

5.23 Violence in Schools. A disquieting number of students in the Caribbean have witnessed physically violent acts in their schools. As a result many students no longer feel safe in their schools and some drop out (Garner et al., 2003). A 2003 representative sample survey of school children in nine Caribbean countries found that one-fifth of the males carried weapons to school in the previous 30 days and one-tenth had been knocked unconscious in a fight. Over 40 percent reported that sometimes or most of the time they think about hurting or killing someone else (Halcon, 2003). Evidence suggests that abuse by teachers of students is common (World Bank, 2003a). In the Dominican Republic, most youth (54 percent) in a recent survey reported that there was violence in the schools, and 42 percent indicated that they knew of violent acts committed on school grounds (ALEPH, 2006).

5.24 Role of Police. The potential role of the police in crime prevention is weakened by problems within the police force. The majority of respondents in youth focus groups in

\footnotetext{
${ }^{83}$ Interviews with Dominican National Drug Control Agency 2005.

${ }^{84}$ Domestic per pupil public expenditure at the secondary level as a share of GDP per capita was just 3.6 percent in 2003, less than a quarter of the LAC average of 17.8 percent. Moreover, it is the only country with available data in the LAC region where public funds for secondary education decreased by more than 20 percent as a share of GDP during the period 1998-2003; over that period the Dominican Republic's funding decreased by 39 percent. World Bank (2006d)
} 
the Dominican Republic noted that even if they were caught committing a crime, the possibility of buying one's way out through bribes to police was always a feasible option, as well as that of using padrinos (Godfathers) who could intervene on their behalf and have court decisions suspended, or even have prison inmates freed (ALEPH, 2006). The national police itself reports an average of 36 shooting deaths per month by the members of its force (ALEPH, 2006). In 2005, 18 percent of all violent deaths/homicides were a result of police shootings. Though the ages of the victims are not known, anecdotal evidence suggests that a large number of these are youth: one study cited 23 unprovoked killings of street children by los cirujanos ("the surgeons", a police unit that conducts night sweeps) in three neighborhoods of Santo Domingo over an eight-month period (Commins, 2006).

5.25 Availability of guns and other weapons. The proportion of Caribbean adolescent males who carry firearms is extremely high. The survey in nine Caribbean countries mentioned above revealed that 20 percent of male students had carried a weapon to school in the previous 30 days, nearly as many had been in a fight using weapons (World Bank, 2003a). Evidence suggests that these figures are much higher for those who are not students. In the United States, the equivalent figure for high school students (grades 9-12) was 9 percent, less than half (Centers for Disease Control and Prevention, 2003). In the Dominican Republic, between September 2003 and June 2005 alone, the National Police issued more than 178,000 licenses for owning and carrying firearms, the majority of which were handguns (71 percent), shotguns (14 percent) and pistols (14 percent). According to the National Police, at least 75 percent of homicides are committed using these types of weapons (ALEPH, 2006). ${ }^{85}$ For more detailed discussion of community-level risk factors and program responses see Annex 5.1.

5.26 Interpersonal level: The most important actors at this level are the family, peer groups, and teachers, each of which can act as protective and risk factors. For the Dominican Republic, available data points to the following concerns at this level.

5.27 Domestic violence, child abuse and corporal punishment. High levels of domestic abuse and corporal punishment throughout the Caribbean are severe risk factors likely to promote future violent behavior. A recent survey revealed that 22 percent of ever-married women aged 15-49 had been victims of physical violence at the hands of a male partner, and 67 percent had suffered emotional abuse (Caceres, 2004). International evidence suggests that children who witness domestic violence are more likely in the future to engage in delinquent and violent behavior (Smith and Thornberry, 1995; Margolin, 1998). Child abuse is also associated with an increased probability that children engage in delinquent and violent behavior, as well as increased risk of children abandoning the home. More than 40 percent of street kids surveyed by Niños del Camino cited abuse in the home as the leading cause of abandoning their families. Corporal punishment continues to be widespread in the Dominican Republic and elsewhere in the Caribbean, in both schools and homes, and particularly against boys (World Bank, 2003a). Much international evidence links use of corporal punishment to later use of

\footnotetext{
${ }^{85}$ Data obtained from the National Police Statistics office.
} 
violence by children and adolescents; a study in Jamaica has confirmed this link (Meeks, 2001).

5.28 Peers and role models. Most youth in the Caribbean identify parents, entertainers or teachers as role models (Luther, 2002). However, the historical absence of male adult figures in the household for role modeling and mentoring compounds the influence of "negative" role models, particularly for boys. Drug dons are an important source of admiration due to their wealth and power. The drug don and his approachability and interest in recruiting children make him a particularly dangerous role model as youth easily become engaged in his business (World Bank, 2003a).

5.29 Gangsterism and related activities are a large-and growing-problem in the region. According to survey data from the Caribbean Youth Development report, 20 percent of male students and 12 percent of female students surveyed reported having belonged at one point to a gang (World Bank, 2003a). This echoes the marked increase in the number and influence of gangs cited in youth surveys in the Dominican Republic, including one conducted with youth ages 14-17 currently participating in remedial programs where half admitted to belonging to las naciones (ALEPH, 2006). Gangs are highly organized, satisfying the needs of young Dominicans at various levels: at the individual level (through respect, power, authority, recognition, and financial gain), the relationship level (support, caring, friendship, and health services/medical attention), and the community level (rules, training, protection, financial benefits). Gangs are located in all the major cities, though they seem to be expanding into some rural communities.

5.30 Drug trafficking influence. The defining characteristic of Dominican gangsterism is involvement in drug trafficking. The scarcity and low pay of legal jobs; the attraction of the "easy money"; the existence of laws protecting those under 18 from prison (Luther, 2002), and the marketing of drug dons (Barker, 1995) makes involvement in drug trafficking very attractive to youth (World Bank, 2003a). A recent study showed that gang members were 20 times more likely to sell drugs than non-members, and 35 times more likely to collaborate with drug dealers. Even when compared to other vulnerable groups (out of school youth, sex workers, "sankis"86), gang members were still at least three times more likely to be involved in the drug trade. Worldwide, those youth most likely to participate in delinquent or violent activities are usually part of a group, though this association tends to be higher for theft, robbery and rape, and lower for premeditated murder and assault with the intent to inflict grievous bodily harm (United Nations, 2003). ${ }^{87}$ For a more detailed discussion of interpersonal-level risk factors and program responses, see Annex 5.1.

5.31 Individual level: At the individual level, some of the most influential risk factors for youth violence are biological (being male; delivery complications at birth); psychological/behavioral (degree of self regulation and self esteem; low intelligence and low educational achievement, early sexual initiation); and environmental (exposure to

\footnotetext{
86 "Sankis" are generally male prostitutes that offer services to tourists in exchange for having their entertainment costs covered, usually food and alcohol.

${ }^{87}$ Available cross country statistical data show that $60-75$ percent of all juvenile offenses are committed by members of various groups.
} 
violence and conflict in the family; involvement with drugs, alcohol, and tobacco). In the Dominican Republic, some of the key risk factors are the following.

5.32 Drug and alcohol use. Although data on drug and alcohol use are scanty, available evidence suggests a widespread social acceptance of alcohol in nearly all Caribbean countries, and of marijuana in some, among both in-school and out-of-school youth (Barker, 1995). In Jamaica, over three-quarters of students report that alcohol and cigarettes are easily obtainable and 60 percent believe the same about marijuana, while almost half have close friends that smoke "ganja" (National Centre for Youth Development, 2003). In the Dominican Republic, alcohol is very accessible and by far the drug most widely consumed by youth. According to a recent survey conducted among secondary school students, 81 percent had consumed alcohol at some point in their lives, while 85 percent had had the opportunity to consume (Aleph, 2006). ${ }^{88}$ A separate survey finds the mean age at first consumption of alcohol to be 13 years (Luther, et al., 2002). Two characteristics unique to the Dominican Republic are the high rate of non-marijuana drug consumption (63 percent of drugs reported used were drugs other than marijuana), and the high prevalence of tranquilizers and stimulants consumed, at 12.8 percent (females) and 6.5 percent (males), and 6.2 percent (females) and 4.4 percent (males) respectively. These figures were the highest in a recent OAS report on drug consumption among seven countries in the LAC region (Organization of American States, 2004).

5.33 The age of onset of sexual activity in the Caribbean is the lowest in the world (Blum, 2002, as cited in World Bank, 2003a). Data from the Caribbean Health Survey showed that of the 35 percent of students who reported having had sex, initiation occurred before the age of 13 for nearly two-thirds (including 82 percent of males and 52 percent of females), surpassing all other regions for which data is available (Halcon, 2003). In a related study, early initiation of intercourse was found to be predictive of weapon-related violence and gang involvement (among boys and girls), and alcohol use and running away (among girls) (Ohene, 2005). Teenage pregnancy in particular is a pressing concern as it is an important contributor to delivery complications at birth: the Dominican Republic ranks fifth in the Latin America region in number of births among 15-19 year-olds, nearly double the average for the region (Table 5.2). For more detailed discussion of individual level risk factors and program responses see Annex 5.1.

\section{Policy Recommendations for StRengthening the Response to Youth VIOLENCE}

5.34 The fundamental challenge in assessing the effectiveness of youth violence prevention strategies in the Caribbean-and in the Dominican Republic in particular-is that although a multitude of programs exist, there is virtually no evaluated evidence of such interventions to guide policymakers and practitioners in identifying the relative effectiveness (including cost-effectiveness) of strategies and approaches. The recommendations presented here therefore draw on international research and experiences that have been rigorously evaluated and proven effective in order to: i) identify current programs that merit expansion and highlight elements that could improve

\footnotetext{
${ }^{88}$ These figures are for lifetime prevalence (not annual).
} 
existing strategies; and ii) suggest complementary strategies to consider, including some which would require a reassessment of current approaches in light of their relative ineffectiveness.

5.35 Table 5.3 presents widely accepted examples of youth violence prevention strategies that have proven effective-and ineffective-in a range of contexts. ${ }^{89}$ The framework addresses two important considerations: i) the developmental stages of an individual (from early childhood to early adulthood); and ii) the ecological systems through which risks can be addressed (presented in Chapter 3). The strategies presented here are not exhaustive, but are meant to emphasize the spectrum of possible solutions. No single strategy on its own is likely to be sufficient to address youth violence; multiple, concurrent approaches are required. Since much of the current knowledge of effective approaches and programs is based on international evidence, care must be taken to ensure relevance for the particular country and community in which they are implemented.

5.36 In recent years, the Dominican Republic has placed increasing emphasis on finding solutions to the problems of crime and violence in general, and youth violence in particular. As in most countries, this strategy comprises policies that fall into two broad categories: i) those that are control/treatment oriented, using the police, courts and prison system to control the behavior of individuals who engage in violence; and ii) and those that are prevention oriented, either towards the general population or towards individuals considered at risk. Using the international evidence summarized in Table 5.3 and an inventory of over 50 of the most prominent public and non-government programs addressing youth violence in the Dominican Republic, ${ }^{90}$ this section highlights select strategies and programs that merit particular attention for further evaluation and potential expansion. $^{91}$

5.37 Provide holistic violence control/prevention approaches targeted to highviolence communities, emphasizing a combination of community policing and improved public services. This type of approach tends to address risk factors at all levels, if appropriately implemented. It targets youth and their families with much needed basic services (early child care, education, health, security) as well as positive alternatives to crime and violence (through second chance programs, extracurricular activities, life skills and occupational training). Although international evidence of the impact of community policing on reducing crimes is mixed, it does improve the public's perception of safety as

\footnotetext{
${ }^{89}$ Compiled from WHO (2002) ; WHO (2003) ; World Bank (2006); US Surgeon General (2001); Tolan and Guerra (1994), Sherman (1997) and Kellerman et al. (1997).

${ }^{90}$ See Annexes 5.4 and 5.5, which are based on Aleph (2006). Programs were inventoried using the ecological framework, assessing both the level of intervention (individual, relationship, community, and society) as well as the level of prevention targeted (primary prevention or universal coverage; secondary prevention targeted to youth at risk; tertiary prevention geared to reducing violence among high-risk youths or preventing further violence from existing perpetrators).

${ }^{91}$ Programs were selected based on a series of criteria: i) fall within internationally proven strategies for addressing youth violence or have demonstrated effectiveness in the Dominican Republic; ii) have a significant beneficiary population; iii) can be replicated with existing institutional capacity; and iv) where data is available, are shown to be cost-effective.
} 
well as the image of the police (WHO, 2003) ${ }^{92}$ (examples in the Dominican Republic which address part of these objectives include Barrios Seguros and Centros Educativos de Fe y Alegría).

5.38 Expand access/retention in schools for high-risk individuals and communities, with particular emphasis on incentives for early child development and for completing secondary education. ${ }^{93}$ International research underscores consistently the importance of the protective factor of providing disadvantaged children with a strong start in school through quality early child development programs (ages 0-5), as well as that of keeping children in school-and connected to their school-through their adolescence. Long term follow-up studies of prototypes in a range of countries have shown important effects on reducing violence and other delinquent behavior. Moreover, they have proven more cost-effective in the long run than many other options. ${ }^{94}$ Examples in the Dominican Republic include the Fund for Early Education (Fondo de Educación Inicial) and the SOLIDARIDAD program. Neither the Fondo de Educacación Inicial (not surprisingly, given its target population) nor the Solidaridad program offers financial support to keep students in secondary school. Given the high rates of school leaving at the secondary level, expanding SOLIDARIDAD from basic to secondary education may be worth considering (see Annex 5.1).

5.39 Improve school quality, relevance and efforts to incorporate violence prevention into the curriculum, and increase the involvement of parents. Together with local NGOs, the Ministry of Education is actively reforming the curricula, enhancing teacher training to improve the quality of primary and secondary education and reduce abuse in schools, increasing the relevancy of education, as well as actively promoting non-violence in the curriculum. ${ }^{95}$ Through its Decentralization Plan, it also intends to significantly increase parental involvement in school management (World Bank, 2003a).

5.40 Provide "second chances" for youth at risk to complete their formal education, obtain relevant job skills, and/or learn relevant life skills. Programs with flexible schedules designed to allow youth to obtain their primary and secondary education equivalency are a cost-effective way to invest in the human capital development of the large share of youth who have never completed their formal education. Programs offering job skills with job experience (internships) as well as life skills training have been shown to have an important impact on improving the quality of jobs obtained by youth, an important factor in reducing crime and violence (World Bank, 2006b). Examples in the Dominican Republic include Educación Básica Para Adultos

\footnotetext{
${ }^{92}$ See, for example, Buvinic and Morrison 2001. See also DESEPAZ Program in Colombia. WHO (2003b)

${ }^{93}$ Note conditional cash transfer programs in Mexico (Oportunidades), Colombia (Familias en Accion), and Brazil (Bolsa Familia).

${ }^{94}$ US Surgeon General (2001); Kellerman, A. et al.; World Bank. (2006b); Schweinhart L. et al (2005).

${ }^{95}$ Secretaría de Educación programs include, among others the Education Strategic Development Plan (2003) Protección Contra la Violencia, Resolución de Conflictos, Plan de Descentralización, Proyecto de Apoyo para la Calidad Educativa, Uso Indebido de Drogas, Proyecto Multigrado Renovado (see Annex 5.4 for further details)
} 
Table 5.3: Violence prevention strategies by developmental stage and ecological context

\begin{tabular}{|c|c|c|c|c|}
\hline & $\begin{array}{l}\text { Early Childhood } \\
(0-5 \text { years })\end{array}$ & $\begin{array}{l}\text { Middle Childhood } \\
\text { (6-11 years) }\end{array}$ & $\begin{array}{l}\text { Adolescence } \\
\text { (12-19 years) }\end{array}$ & $\begin{array}{l}\text { Early adulthood } \\
(20-29 \text { years })\end{array}$ \\
\hline Individual & $\begin{array}{l}\text { *Early Child Development and } \\
\text { Preschool enrichment programs for at } \\
\text { risk children (a) } \\
\text { * Preventing unintended pregnancies } \\
\text { * Parenting training } \\
\text { * Increasing access to prenatal and } \\
\text { postnatal care }\end{array}$ & $\begin{array}{l}\text { *Parenting training (a) } \\
\text { *Programs providing information } \\
\text { about drug abuse (b) }\end{array}$ & $\begin{array}{l}\text { *Providing incentives for youth at high risk for violence to } \\
\text { complete secondary schooling (a) } \\
\text { * Academic enrichment programs for those at risk of } \\
\text { dropping out } \\
\text { *Individual Counseling (b) } \\
\text { *Probation or parole programs that include meetings with } \\
\text { prison inmates describing the brutality of prison life (b) } \\
\text { *Residential programs in psychiatric or correctional } \\
\text { institutions (b) } \\
\text { *Programs providing information about drug abuse (b) } \\
\text { * Training in the safe use of guns (b) } \\
\text { *Programs modeled on basic military training (b) } \\
\text { *Trying young offenders in adult courts (b) }\end{array}$ & $\begin{array}{l}\text { *Providing incentives to pursue courses in higher } \\
\text { education } \\
\text { * Parenting Training } \\
\text { * Job Training combined with life skills and } \\
\text { internships } \\
\text { * Residential programs for offenders (b) } \\
\text { * Psychotherapy for high-risk youth and offenders (b) }\end{array}$ \\
\hline $\begin{array}{l}\text { Relationship } \\
\text { (e.g. family, } \\
\text { peers) }\end{array}$ & $\begin{array}{l}\text { *Home visitation (a) } \\
\text { *Training in parenting (a) } \\
\text { * Marital and family therapy }\end{array}$ & $\begin{array}{l}\text { *Mentoring Programs (a) } \\
{ }^{*} \text { Targeted incentives to mother to } \\
\text { keep child in school (a) } \\
\text { * Home-School partnership } \\
\text { programs to promote parental } \\
\text { involvement }\end{array}$ & $\begin{array}{l}\text { *Mentoring programs (a) } \\
* \text { Family therapy (a) } \\
\text { *Temporary foster care programs for serious and chronic } \\
\text { delinquents } \\
\text { *Peer mediation or peer counseling (b) } \\
\text { * Gang membership prevention/intervention programs (b) }\end{array}$ & $\begin{array}{l}\text { * Programs to strengthen ties to family and jobs, and } \\
\text { reduce involvement in violent behavior }\end{array}$ \\
\hline Community & $\begin{array}{l}\text { *Monitoring lead levels and removing } \\
\text { toxins from homes } \\
\text { * Increasing the availability and quality } \\
\text { of early child development and child- } \\
\text { care facilities }\end{array}$ & $\begin{array}{l}\text { *Creating safe routes for children } \\
\text { on their way to and from school or } \\
\text { other community activities } \\
\text { *Improving school settings, } \\
\text { including teacher practices, school } \\
\text { policies and security } \\
\text { *Providing after-school programs } \\
\text { to extend adult supervision } \\
\text { * Extracurricular activities }\end{array}$ & $\begin{array}{l}\text { *Creating safe routes for youths on their way to and from } \\
\text { school or other community activities } \\
\text { *Improving school settings, including teacher practices, } \\
\text { school policies and security } \\
\text { *Extracurricular activities/supervised after-school programs } \\
\text { * Positive youth development programs } \\
\text { * Supporting classroom management techniques } \\
\text { * Behavior modification via “thinking” skills } \\
\text { * Providing "second chance" education programs } \\
\text { (equivalency) } \\
\text { * Life skills training } \\
\text { *Training health care workers to identify and refer youths at } \\
\text { high risk for violence } \\
\text { *Community policing } \\
\text { *Reducing the availability of alcohol } \\
\text { *Improving emergency response, trauma care and access to } \\
\text { health services } \\
\text { * National Youth Service Programs } \\
\text { *Buying back guns (b) }\end{array}$ & $\begin{array}{l}\text { *Establishing adult recreational programs } \\
\text { *Community policing } \\
\text { * Proactive arrests } \\
\text { * Directed patrols } \\
\text { * Reducing availability of alcohol } \\
\text { *Improving emergency response, trauma care and } \\
\text { access to health services } \\
\text { * High quality rehabilitation programs } \\
\text { * Imprisonment of high-rate career criminals } \\
\text { * Prison-based drug rehab programs } \\
\text { * National Youth Service Programs } \\
\text { * Corporal punishment in schools (b) } \\
\text { * Citizen patrols (b) } \\
\text { * Social casework: counseling, close supervision and } \\
\text { social services (b) } \\
\text { * Reactive arrests (b) } \\
\text { * Random patrols (b) } \\
\text { *Buying back guns (b) } \\
\text { * Trying young offenders in adult courts (b) }\end{array}$ \\
\hline Societal & $\begin{array}{l}\text { *Deconcentrating poverty } \\
\text { * Reducing income inequality } \\
\text { * Reducing media violence } \\
\text { * Public information campaigns }\end{array}$ & $\begin{array}{l}\text { *Deconcentrating poverty } \\
\text { *Reducing inequality } \\
\text { *Reducing media violence } \\
\text { *Public information campaigns } \\
\text { *Reforming educational systems }\end{array}$ & $\begin{array}{l}\text { *Deconcentrating poverty } \\
\text { *Reducing income inequality } \\
\text { *Public information campaigns } \\
\text { *Reducing media violence } \\
\text { *Enforcing laws prohibiting illegal transfers of guns to youth } \\
\text { *Strengthening and improving police and judicial systems } \\
\text { *Reforming educational systems }\end{array}$ & $\begin{array}{l}\text { *Deconcentrating poverty } \\
\text { *Reducing income inequality } \\
\text { *Job creation programs for the chronically unemployed } \\
\text { *Public information campaigns } \\
\text { *Promoting safe and secure storage of firearms } \\
\text { *Strengthening and improving police and juvenile } \\
\text { justice systems }\end{array}$ \\
\hline
\end{tabular}


and PREPARA (SEE), Juventud y Empleo (SET) and the Aprendices con Don Bosco after-school program.

5.41 Promote strategies using existing youth serving organizations to increase capacity for home visitation and parental training to reduce levels of violence in the home. Home visitation is a proven approach to reducing youth violence and delinquency which exists in many parts of the world. It is targeted to low-income young mothers and families who are expecting or have recently had their first child, and those at increased risk of abusing their children with the objective of providing parenting training, support, counseling, child development monitoring and referrals to outside agencies. It has proven effectiveness in a range of countries with significant long term effects in reducing violence and delinquency, as well as other risk factors such as alcohol abuse (U.S. Department of Health and Human Services, 2001; WHO, 2003; Olds DL et al, 1998; Farrington and Welsh, 1999; Blueprints, 2003.) Examples in the Dominican Republic include PROFAMILIA, IDDI, Don Bosco, Progresando (see Annex 5.5).

\section{Complementary Strategies to Consider}

5.42 Provide positive role models through nation-wide mentoring programs. Wellconducted mentoring programs, which tend to be relatively cost-effective, can reduce aggressive behavior, delay the onset of drug and alcohol usage among youth and boost school retention and performance. These programs also have significant impacts on reduced substance abuse, reduced skipping school, and improved relationships with their families (World Bank, 2003a; U.S. Department of Health and Human Services, 2001; Tierney et al, 2000).

5.43 Open schools after hours and on weekends for supervised extra-curricular activities, training and conflict resolution in high-crime communities. Peak times for juvenile crime are during the hours immediately after school, yet many youth are unsupervised after school because their parents work. After-school programs hold great potential value and deserve serious consideration in community prevention planning. ${ }^{96}$ According to a UNESCO study, participating schools in a similar program in Brazil demonstrated as much as a 60 percent reduction in violence, as compared to other schools in the area. The program also reduced the rates of sexual aggression, suicide, substance abuse, theft, and armed robbery (World Bank, 2006b).

5.44 Pilot national youth service programs, or service-learning programs which give youth practical work experience and life skills while simultaneously helping to meet key development objectives at a national or community level. Jamaica has a National Youth Service program that targets youth 17-24 who are out of school and unemployed. It combines life skills training with 8 months of work exposure in jobs such as teaching aids, health facilitators, early childhood caregivers, environmental aides and information technology (IADB, 2002). Controlled longitudinal studies of the American Conservation and Youth Corps aimed primarily at disadvantaged youth 16-24 found that

\footnotetext{
${ }^{96}$ Several controlled studies have found that well-supervised after-school programs substantially reduce juvenile crime, drug use and vandalism. For more information see: Inter-American Development Bank (2002) and Sickmund et. al (1997).
} 
program participants in a 15-month follow up were much more likely to have worked for pay and were less likely to be arrested vis-à-vis control groups (Jastrab. et al, 1996, 2004; World Bank, 2005c).

5.45 Several strategies have proven effective in reducing significantly the rates of rearrest and recidivism for youth with a history of chronic or violent criminal behavior (Lipsey and Wilson, 1998; U.S. Department of Health and Human Services, 2001). Two model programs for these youth use a family therapy approach, and place strong emphasis on skills training and behavioral change for youth and their parents. These include: i) functional family therapy; and ii) multidimensional treatment foster care using a clinical intervention targeting individual youth with severe criminal behavior and placing them in trained foster home care as an alternative to incarceration, group or residential treatment. Meta analyses have shown that community-based treatment is more successful than residential treatment and that both types of programs have significantly reduced the number of days of incarceration, overall arrest rates, drug use, and program dropouts versus control groups (U.S. Department of Health and Human Services, 2001).

5.46 Reduce emphasis on "mano dura" programs that emphasize harsher penalties, increased arrests, and more police controls. Criminalization, incarceration and suppression are inefficient responses to chronic youth offenders, gang members, and those committing violent crimes. Despite being a common official response by governments, these "mano dura" programs have proven to be the least effective among a range of policy options (World Bank, 2006b). One promising justice system approach with strong deterrent effects is an intensive protective supervision strategy which removes delinquent youths (status offenders) from criminal justice institutions and provides them with proactive and extensive community supervision with trained professionals (U.S. Department of Health and Human Services, 2001).

5.47 Apply existing laws separating incarcerated youth and adults. The imprisonment of child offenders with adults (due to the lack of facilities for young delinquents) is common in the Caribbean (Singh, 2001, as quoted in World Bank, 2003a). The principle of incarcerating young offenders separately from adults has been accepted in the Dominican Republic, but its application is minimal, with many youth ending up in state prisons. Prison conditions range from "poor" to "harsh", with overcrowding being a pressing concern (U.S. State Department, 2006). ${ }^{97}$ Improving prison conditions and separating young offenders are important remedial policies as both concerns are associated with higher recidivism. ${ }^{98}$

5.48 Enforce new legislation requiring the registration of guns. Currently, it is enforced by occasional checkpoints where vehicles must produce the certificates of registration for any firearms in the car. Banning guns during periods known for high violence/homicide could also be considered, such as weekends and holidays. This

\footnotetext{
${ }^{97}$ In 2005, 145 people died in a fire in a cell block that was designed to hold 80 .

98 There are 4 prisons for minors separated by sex. Minors can be prosecuted in either corrective or criminal status. Corrective status is for minor crimes (simple robbery, delinquency, drug use) whereas criminal status is for larger crimes (murders, aggravated robbery). Corrective imprisonment ranges from a few months up until 3 years whereas criminal imprisonment ranges from 1-10 years.
} 
approach was successfully implemented by the municipalities of Cali and Bogota, which witnessed lower homicide rates as high as 20 percent when the ban was in effect (Guerra, 2006; World Bank, 2003b).

5.49 Restrict the availability of alcohol. This has demonstrated positive effects on reducing violence (both criminal and domestic) as well as criminal offenses (both serious and minor related to property and traffic) (WHO, 2003). Given the widespread acceptance of alcohol consumption even at very early ages in the Dominican Republic, a concerted effort to treat alcohol as a drug in all anti-drug programs may have considerable impact on reducing violence. Policies such as higher taxation of alcohol combined with greater enforcement of minimum legal age have demonstrated success in reducing consumption among young people in some countries (WHO, 2003b). In Colombia, alcohol sales were restricted with closing times imposed on bars and nightclubs (Guerrero and Concha-Eastman, 2001).

\section{CONCLUSiONS}

5.50 The most important conclusion of this chapter is that youth violence is a legitimate concern for the region, but it is not an intractable problem. Youth violence is preventable. Although deaths and injuries from youth violence constitute a major public health, social and economic problem across the Caribbean, including the Dominican Republic, a broad range of viable strategies for preventing and reducing youth violence exists. Moreover, it is important to remember that youth are not "the problem," but rather a product of the individual, family, community and social environments in which they live.

5.51 In addition to the thematic conclusions presented above, several cross-cutting recommendations emerge. First, there is an urgent need to develop and strengthen data systems which regularly compile and monitor trends in youth violence (including injuries and deaths, both as victims and perpetrators) across key institutions. Current data is extremely weak and inconsistent, and there is little collaboration across entities. In the Dominican Republic, the Procuraduría General could establish a system by which routine information available from health services, emergency departments, the police, the criminal justice system, and other authorities relevant to youth violence can be compared on an annual basis. Strengthening these systems will provide valuable information for formulating policies and for evaluating them. ${ }^{99}$

5.52 Second, there is a clear need to generate scientific evidence on the patterns and causes of youth violence in specific social settings, as well as the cost to society of such violence. Perhaps more important, however, is the need to generate knowledge on what works to reduce violence through rigorous evaluation of both impact and costs. Only with consistent standards of systematic evaluation of interventions can policy tradeoffs be

\footnotetext{
${ }^{99}$ Uniform standards for defining and measuring youth violence should be incorporated in regular surveillance systems. Included in this should be methods to establish the ratio of fatal to non-fatal cases of violence-related injuries, classified by the method of attack, age and sex of the victim. Such data can then be used to estimate the magnitude of the youth violence problem where only one type of data - such as mortality or morbidity - is available. See WHO (2003).
} 
legitimately addressed. ${ }^{100}$ In particular, there is a need for: i) longitudinal studies evaluating long term impacts of interventions conducted in childhood; ii) evaluations of the impact of interventions in sectors sometimes considered unrelated (e.g., education, health, employment, etc.) on reducing youth violence and other risk factors; iii) studies on cost-effectiveness of prevention (and control) programs.

5.53 Finally, there is a need to improve public awareness of the availability of ongoing interventions, with particular attention paid to high-risk communities and youth. A public information campaign should not be limited to potential beneficiaries, but should also extend to public and civil society groups working in this area as there is considerable lack of knowledge of existing programs in other institutions. Indeed, in the Dominican Republic, as well as across the sub-region, there are a multitude of programs available to address many of the risk factors facing youth. Evaluating their effectiveness and sharing this knowledge across countries with similar issues to confront will contribute enormously to future success in reducing youth violence.

${ }^{100}$ Consistent standards include: i) the application of experimental design; ii) evidence of a statistically significant reduction in the incidence of violent behavior or violence-related injuries; iii) replication across different sites and different cultural contexts; and iv) evidence that the impact is sustained over time. 


\section{CASE STUDY: CRIMINAL DEPORTATIONS AND JAMAICA}

It has been hypothesized that recent crime troubles in the Caribbean could be tied to the activities of deportees who have learned criminal behavior in the developed countries. This report examines the situation in Jamaica, which is one of the Caribbean countries proportionately most affected by criminal deportations. With currently available data, it is possible to conclude that it is unlikely that the average deportee is committing crime in Jamaica. At the same time, it is possible that a minority of deportees is involved in criminal activity. Assisting in reintegration efforts for deported offenders could be a costeffective way for deportee-sending countries to promote development and weaken international crime networks.

6.1. Each year, the United States, the United Kingdom, and Canada deport thousands of people convicted of various crimes to their countries of citizenship in the Caribbean. Between 1998 and 2004, the United States alone deported over 31,000 convicted criminals to the Caribbean. This chapter focuses exclusively on the issue of criminal deportees: people who have been forcibly returned to their country of origin due to their conviction for a criminal offense, such as drug offenses, violent crime, and immigrationrelated crime. The chapter does not discuss the less controversial practice of deporting those who have entered the country without a visa or violated the terms of their visa or residency permit. ${ }^{101}$

6.2. There are few topics in Caribbean criminal justice more contentious than criminal deportation. On the one hand, as the international community has recognized, "It is the right of every nation State to decide who can enter and stay in its territory and under what conditions" (United Nations, 2004). Residence permits are a privilege granted to non-citizens contingent on their good behavior. Clearly, the commission of a crime does not constitute "good behavior," and few would deny the right of host countries to revoke the permits of convicted criminals. This practice is widespread, and Caribbean countries themselves deport non-citizen convicts on a regular basis.

6.3. On the other hand, there is a widely held belief in the Caribbean (as well as in Central America) that recent crime troubles can be tied directly to the activities of deportees "schooled" in crime in the developed countries, especially the United States, Canada, and the United Kingdom. ${ }^{102}$ This chapter looks at the situation in Jamaica, which is proportionately most affected by criminal deportations, and where officials have worried that the country's rising murder rate may be linked to the growing stock of

\footnotetext{
${ }^{101}$ Criminal deportations are distinct from deportations for simple immigration violations like entering the country without a visa or permit. However, the ranks of criminal deportees do include those deported for crimes that are related to immigration. Examples of immigration-related crimes include modifying visa papers, attempting to bribe an immigration official, lying on an immigration-related document, and smuggling migrants.

${ }^{102}$ This view is widely held enough that the CARICOM representatives recently suggested that the InterAmerican Commission on Human Rights intervene to reduce the flow of deportees. See Smith, S, "Carib states want a study on the link between deportation and crime.” Jamaica Gleaner, 16 December 2005.
} 
deported convicts. ${ }^{103}$ Figure 6.1 shows the figures for both homicides and deportee arrivals in recent years. No clear relationship emerges from this graph.

\section{Figure 6.1: Number of Deportees and Number of Murders in Jamaica}

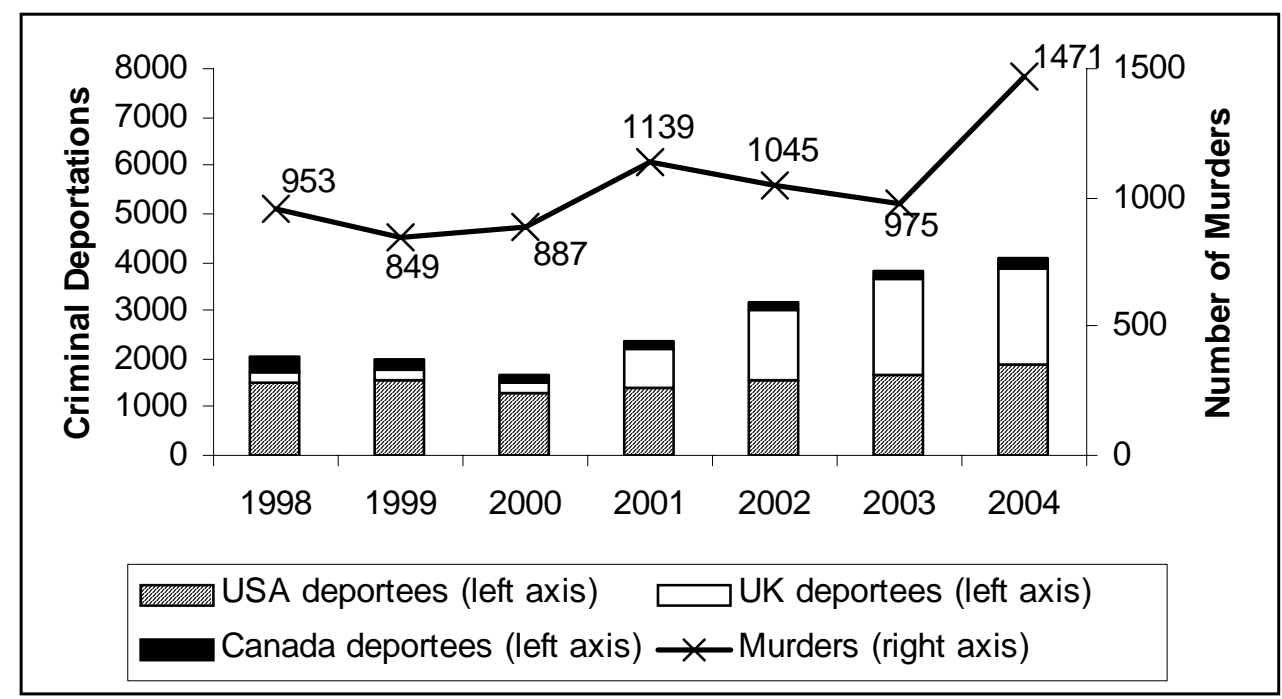

Source: Social and Economic Survey of Jamaica; Jamaica Constabulary Force.

6.4. Some Caribbean commentators have argued that it was conditions experienced in the developed countries, not in their countries of citizenship, which drove these people into criminality. For example, Dr. Prem Misir, Pro-Chancellor of the University of Guyana, asserts, “...criminal deportees have been intensively socialized in the criminal fields in the U.S. These deportees are in full possession of their U.S. criminal tool kit.”104 If Dr. Misir is correct, the question then becomes: who is responsible for criminals born in the Caribbean but made in the developed world? And who should bear the burden of this population, the large and wealthy countries or the small Caribbean countries?

6.5. Of course, the issues are not as clear cut as this. Deportees are not a homogenous group. There are cases of deportees who, in all but their paperwork, were citizens of the developed countries, having been raised there and holding few connections to the countries of their birth. But there are also those who were career offenders in their home countries before venturing out into trans-national organized crime, and those who fall somewhere in the middle, whose criminality may be attributed to experiences in both countries. And even if it were possible to determine where a criminal is made a criminal, this would not answer the broader policy question: how can developing countries cope

\footnotetext{
${ }^{103}$ In his address at the Opening of the Twenty-Fifth Meeting of the Conference of Heads of Government of the Caribbean Community on 4 July 2004, in St. George's, Grenada, then Jamaican Prime Minister PJ Patterson referred to "security concerns arising from the nexus of the narcotics trade, gun-smuggling and criminal deportees." He used similar language in a speech at the CARICOM 30th Anniversary Lecture Series at Medgar Evers College in New York on 2 October 2003, where he referred to "the U.S.-based nexus of the narcotics trade, gun smuggling and criminal deportees." In his address to the Joint Session of The St. Lucian Parliament on 1 July 2004, he referred to "the impact of deportees on the escalating rate of crime.”

${ }^{104}$ Misir, P., "Government tackling globally-rooted crimes.” Accessed on the website of the Guyana Government Information Agency: http://www.gina.gov.gy/archive/researchp/rpgovtacklingcrimes.html
} 
with regular injections of uprooted convicts? And how can this problem be resolved to reduce the spread of transnational criminality?

6.6. This chapter lays out the latest available data on the scale and nature of criminal deportation from the United States, the United Kingdom, and Canada to Jamaica and suggests some ways the issue might be resolved for the benefit of all concerned.

\section{THE SCALE OF THE EXPATRIATE POPULATION}

6.7. To appreciate the scale of the deportations, it is necessary to understand the size of the Caribbean expatriate community. An estimated three million Caribbean-born people were living in the United States at the time of the 2000 Census, about 10 percent of the total immigrant population in the U.S. and about 1 percent of the U.S. national population. The 300,000 Caribbean-born people living in Canada at the time of its 2001 Census also make up about 1 percent of the population of that country. In the United Kingdom, some 250,000 people born in the Caribbean were counted during the 2001 Census.

6.8. In total, 3.5 million Caribbean-born people were living in these three countries in 2000/2001. The figure is perhaps 3.8 million Caribbean-born people as of 2006, ${ }^{105}$ more than are presently living in the countries of Montserrat, Anguilla, British Virgin Islands, the Turks and Caicos Islands, the Cayman Islands, St. Kitts and Nevis, Antigua and Barbuda, Dominica, Grenada, Aruba, St. Vincent and the Grenadines, St. Lucia, the Netherlands Antilles, Barbados, the Bahamas, Martinique, Guadeloupe, Suriname, and Guyana combined.

6.9. About 85 percent of these migrants live in the United States, with the largest pool from Cuba, followed by the Dominican Republic, Jamaica, and Haiti (the four largest independent countries in the Caribbean). Figure 6.2 shows the Caribbean-born populations in the U.S. from several countries. Jamaica has the largest share of its population living in the United States. For every five Jamaicans living at home in Jamaica, there is one living in the United States, with lower ratios for Cuba (9 percent), the Dominican Republic (8 percent), and Haiti (5 percent). According to U.S. Census projections, the U.S. Jamaican-born population was over 600,000 in 2005 (Department of Homeland Security, 2005).

6.10. In Canada, Jamaicans are the most populous group of Caribbean origin living in the country, with just under 122,000 Jamaican-born residents, nearly twice as many as the next largest Caribbean group (Trinidadians), according to the 2001 Census. About 150,000 of the 250,000 Caribbean-born people living in the United Kingdom were Jamaican, according to the 2001 Census. In total, about 683,000 Jamaicans were living in the three countries in 2000/2001, or more than a quarter of the total living in Jamaica at that time. Because these estimates are based on census figures, which may undercount undocumented immigrants, the true number of Jamaican expatriates may be higher.

\footnotetext{
${ }^{105}$ U.S. census projections suggest a Caribbean population of 3.211 million in 2005. Similar projections are not available for Canada and the United Kingdom, but if similar growth were experienced, some 600,000 Caribbean nationals might be seen between the two countries.
} 
Figure 6.2: Caribbean-Born Populations in the United States

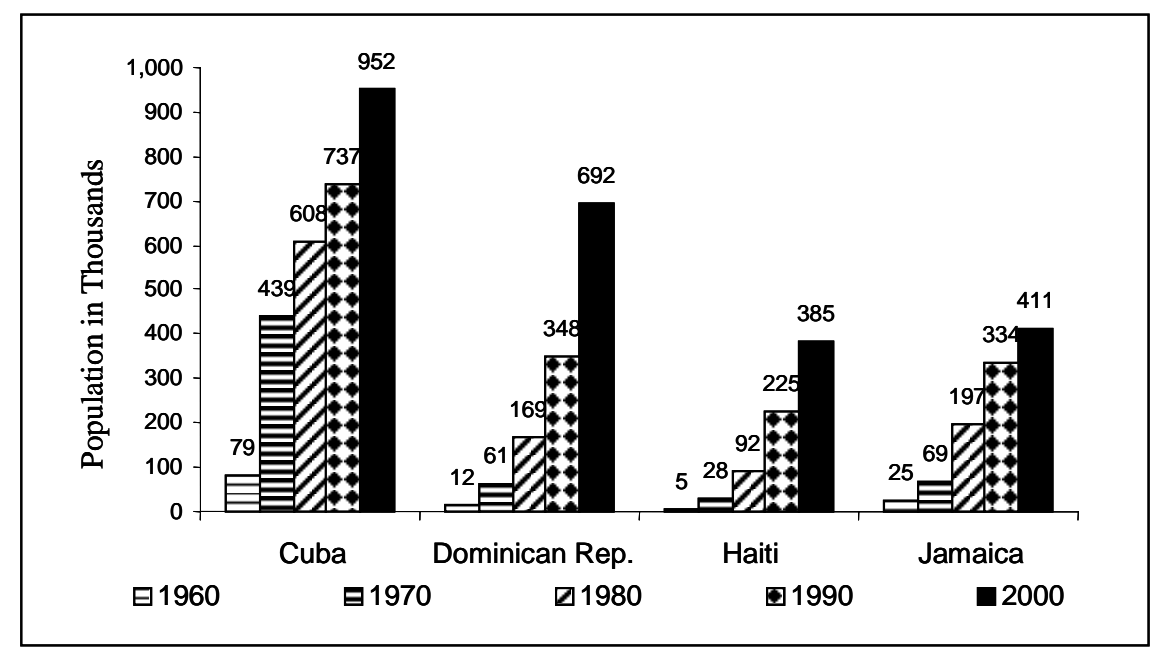

Source: Lapham et al., 1993.

\section{CRIMinAL DEPORTATION}

6.11. Many migrants arrive with limited resources, and some arrive outside the law. Poor migrants may be forced to settle in some of the most crime-ridden neighborhoods of their new countries, and may face ongoing marginalization. It is not surprising that some engage in criminal behavior, are arrested and imprisoned. Whether migrants are more likely to commit crime is hotly debated, and resolving this issue is hampered by a lack of clarity on the number of undocumented migrants (Rumbaut et al., 2006). ${ }^{106}$

6.12. By mid-2004, federal and state prisons in the United States held over 90,000 non-citizens, representing 6.5 percent of the overall prison population and over 20 percent of the federal prison population. The burden on state prisons varied considerably between regions of the country. In the high-immigration state California, over 10 percent of prisoners were non-citizens (Harrison and Beck, 2005). Some 29 percent of federal drug defendants convicted during 2003 were identified as non-citizens, and more than half (56 percent) had at least one prior adult conviction (Bureau of Justice Statistics, 2005).

6.13. Concerns about immigrant crime and the demands it was placing on the U.S. criminal justice system contributed to the passage of the 1996 Illegal Immigration Reform and Immigrant Responsibility Act. This Act made significant changes to the deportations regime, reducing appeals and greatly expanding the definition of deportable "aggravated felonies" to include a range of lesser offenses. ${ }^{107}$ Resources were also

\footnotetext{
${ }^{106}$ At least one study has found that first generation immigrants are less likely to be convicted of a crime than the native born.

${ }^{107}$ The term of "aggravated felony" first appeared in the immigration context in 1988 in the Anti-Drug Abuse Act, where it was limited to murder, drug trafficking and firearms trafficking. This was expanded by subsequent legislation and related case law to include a much wider range of offenses, including most violent crime, theft, and immigration-related offenses, such as document fraud and perjury. The 1996 Act amends the definition of "aggravated felony" by, among other things, lowering the fine and sentencing
} 
directed to ensure that every deportable convict was, in fact, deported. As a result, the number of criminal deportees from the U.S. to the Caribbean more than doubled between 1994 and 2004 (see Figure 6.3).

Figure 6.3: Total Criminal Deportations from the U.S. to the Caribbean

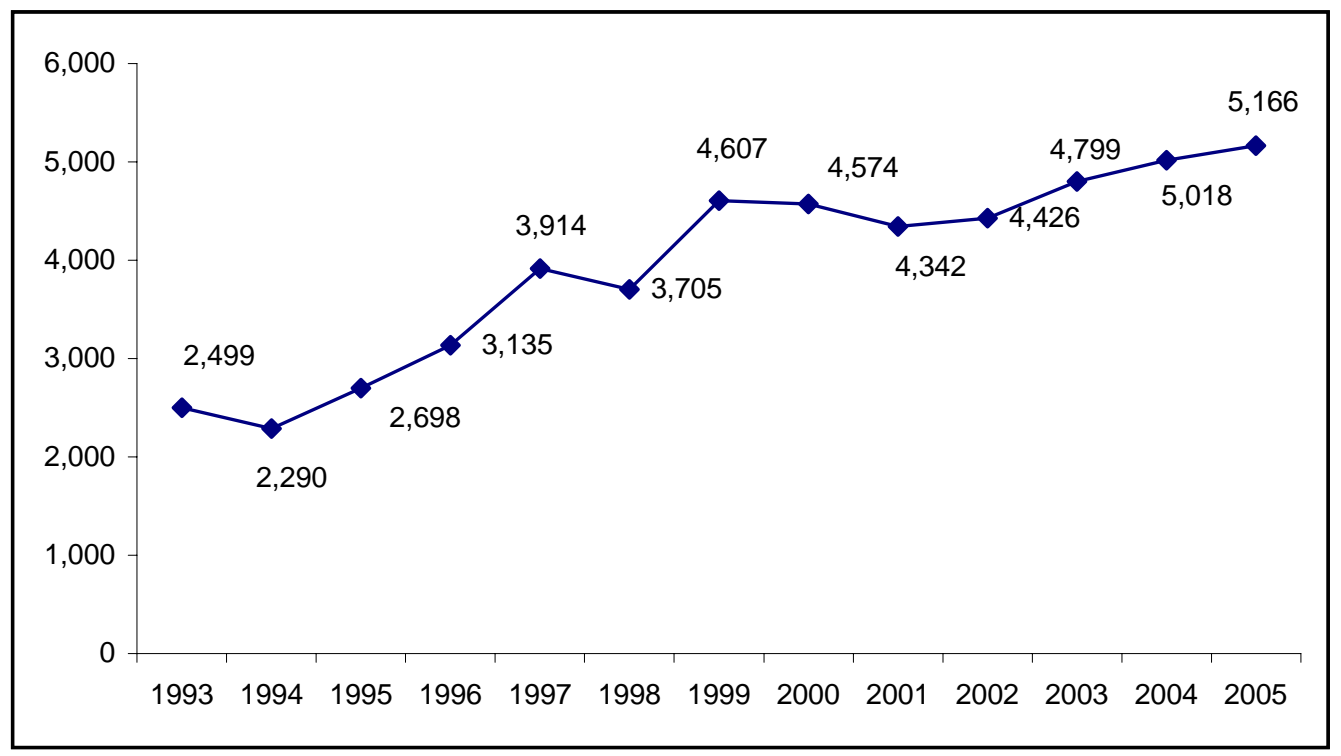

Source: U.S. Department of Homeland Security. ${ }^{108}$

6.14. If the number of prisoners in U.S. federal prisons is examined as a share of the total populations of the home countries of the convicts, then Jamaica contributes the most prisoners per head of population. Not surprisingly, then, Jamaica is the country in the Caribbean with the largest flow of deportees relative to its population, and its lead is growing (see Figure 6.4). An average of 1,200 convicts per year were deported from the U.S. to Jamaica between 1993 and 2004.

6.15. Jamaicans are also the most deported Caribbean population group from the United Kingdom and Canada, largely because they are by far the largest Caribbean population in those countries. Between 2001 and 2004, Jamaica absorbed an average of 2,700 convicts a year from the three countries. In 2003, Jamaica's own current prison population was 4,744 (Walmsley, 2005), so the influx was equivalent to releasing more than half the domestic prisoner population into society every year. In one study on released prisoners in the United States in the mid-1990s, about two-thirds were rearrested within three years. ${ }^{109}$ It is therefore not surprising that Jamaicans might be concerned about an inflow of convicts of this magnitude.

thresholds for many offenses, effectively including relatively minor crimes. Under this law, criminal deportation has been ordered for crimes such as shoplifting and urinating in public. See U.S. Department of Justice Fact Sheet 03/24/97.

${ }^{108}$ Data published (Table 43) online at:

http://www.uscis.gov/graphics/shared/aboutus/statistics/ENF03yrbk/ENF2003list.htm

${ }^{109}$ Data from the United States Bureau of Justice Statistics, accessed on:

http://www.ojp.usdoj.gov/bjs/reentry/recidivism.htm 
Figure 6.4: Criminal Deportees from the U.S. per 100,000 Population
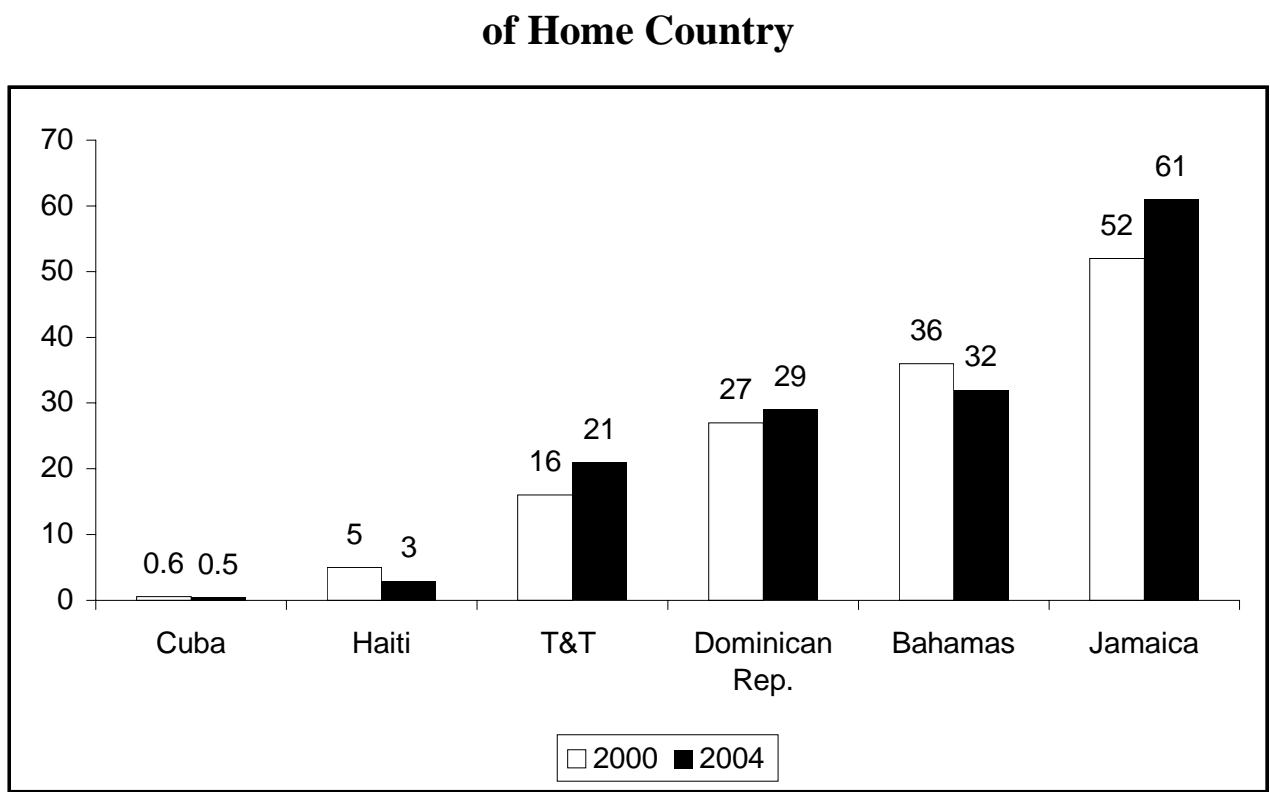

Source: U.S. Department of Homeland Security, 2005.

Figure 6.5: Total Criminal Deportations to Jamaica: 1998-2004

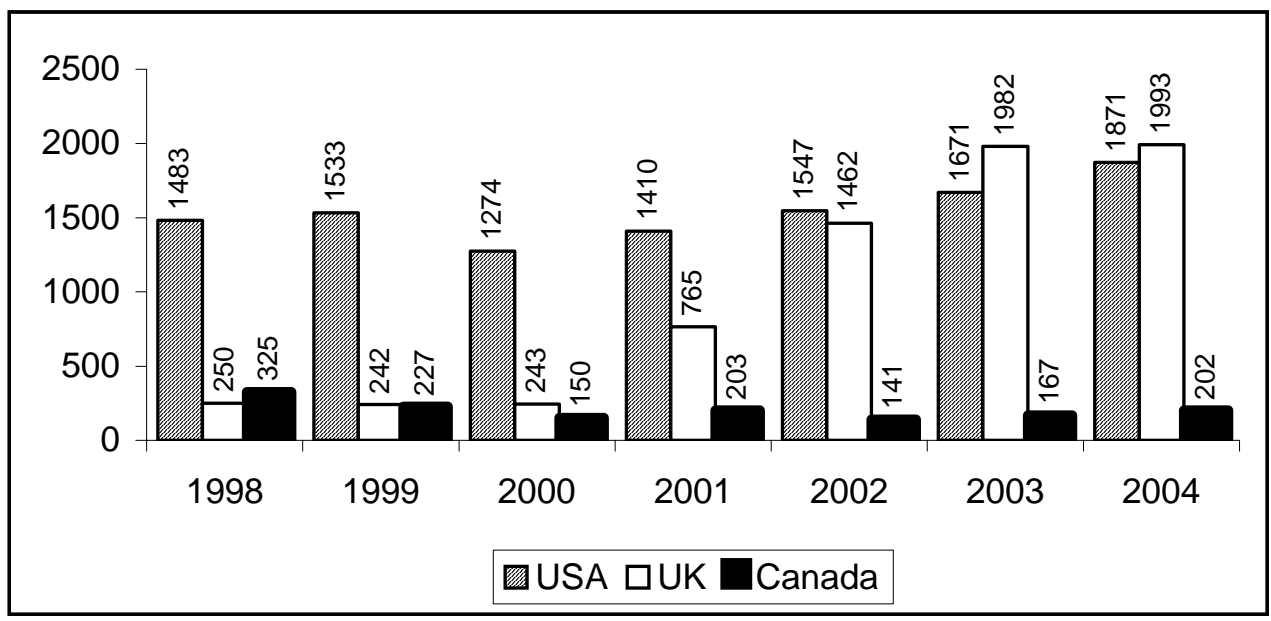

Source: Social and Economic Survey of Jamaica, various years.

6.16. During the late 1990s, the United States was far and away the leading source of criminal deportations to Jamaica, but then deportations from the United Kingdom began to rise rapidly. While the bulk of these deportations were due to immigration-related crime, the number and the share of drug-related deportations increased dramatically from 2001, nearly reaching U.S. levels by 2004. Proportionate to the expatriate Jamaican population in each country, the U.K. today has a greater rate of deporting drug offenders than the U.S. This may be due to the fact that cocaine markets are growing in the U.K., 
and Jamaican "yardie" groups have traditionally been associated with marketing this drug (see National Criminal Intelligence Service, 2005). ${ }^{110}$

6.17. Despite this shift, the U.S. has continued to expel by far the largest number of violent offenders, deporting over 200 convicted murderers and 128 sex offenders to Jamaica between 2001 and 2004, while the U.K. and Canada combined deported 24 murderers and 32 sex offenders between them. On the whole, however, 81 percent of the criminal deportees sent from the three countries between 2001 and 2004 were deported for immigration-related matters, fraud, and drug offenses, which include an unspecified share of drug possession cases ${ }^{111}$ (see Annex 6.1 for detailed statistics on deportations to Jamaica from Canada, the U.K., and the U.S. for the 2001-2004, period, disaggregated by reason for deportation).

\section{Figure 6.6: Drug Deportations to Jamaica from the United States and the United Kingdom}

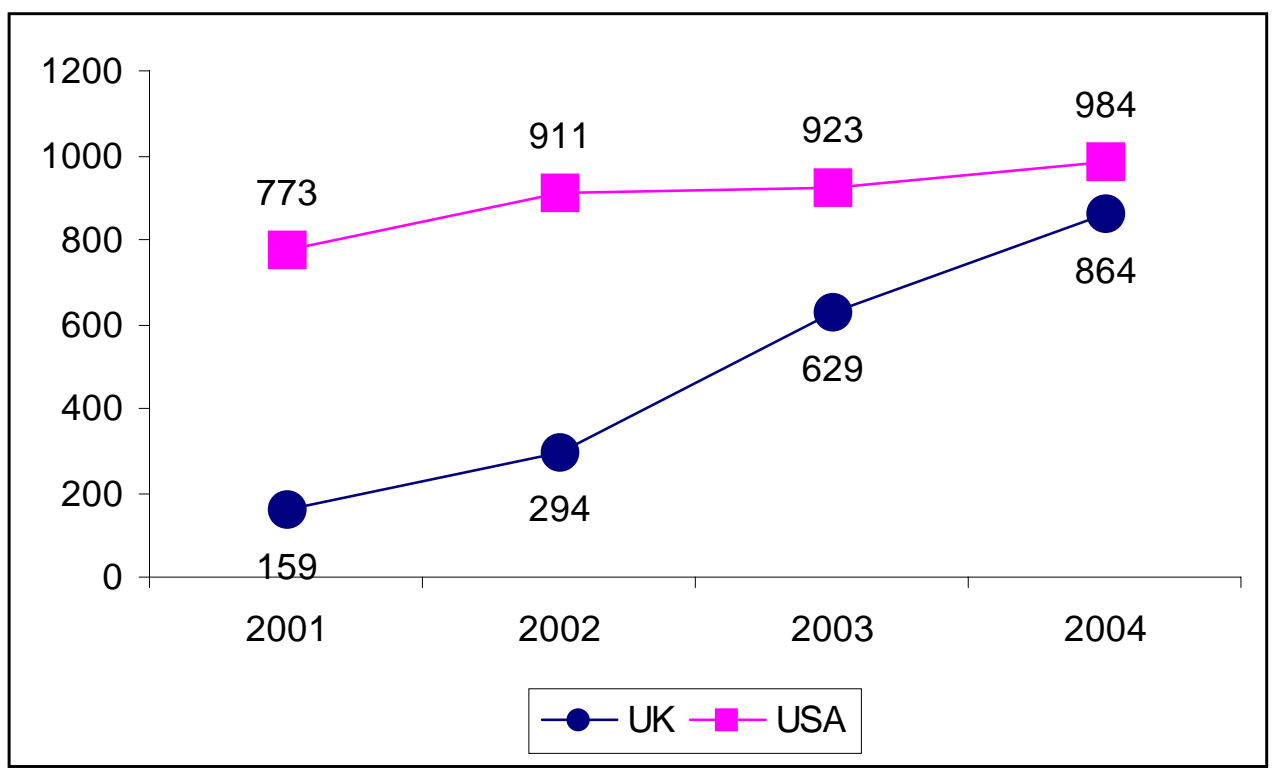

Source: Social and Economic Survey of Jamaica, various years.

\footnotetext{
${ }^{110}$ According to National Criminal Intelligence Service of the United Kingdom, "Hitherto, criminal groups of West Indian origin, mostly Jamaican, were seen to be most prominent in distributing crack cocaine within the U.K. ... However, as [cocaine use] has grown, there have been opportunities for others to become involved... [Today,] most of the detected movements of cocaine trafficked from the Caribbean to the U.K. are smuggled by couriers, many under the control of Jamaican and Trinidadian groups.”

${ }^{111}$ Headley's research, cited below, found that about half those Jamaicans deported for drug offenses between 1997 and 2003 were convicted of drug sales and half for drug possession.
} 
6.18. Thus, the vast majority of the offenders deported (81 percent) were convicted of non-violent crimes. Of course, those deported on the basis of non-violent offenses could be violent criminals, and drug dealers in particular may be more likely than other expatriates to commit violence. It is often easier for police to deport suspected gang members for immigration violations or drug possession, for example, than to bring them to trial for other offenses.

Figure 6.7: Breakdown of Criminal Deportees by Crime Type, All Three Source Countries, 2001-2004

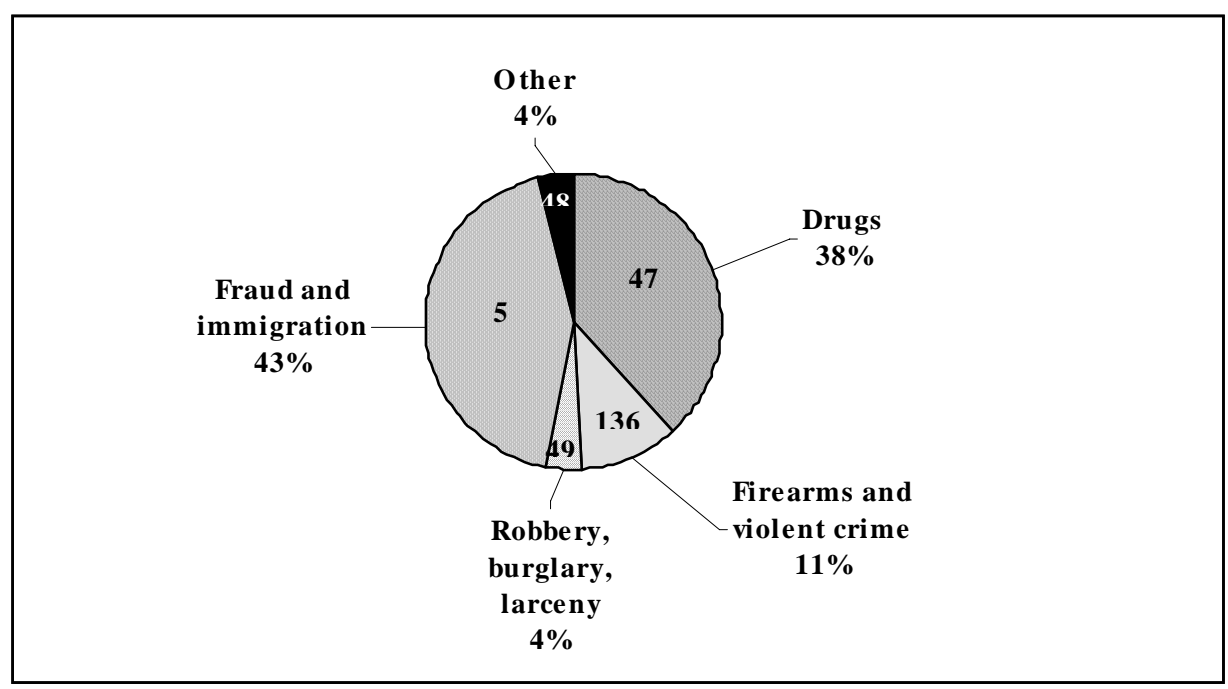

Source: Elaborated from Social and Economic Survey of Jamaica, various years.

6.19. The Ministry of National Security and Justice study cited by the CARICOM Regional Task Force report (2002) found that a majority of deportees had been away for more than five years and that 14 percent of the 1,730 persons deported in 2001 had been away for more than 20 years. The report suggests that deportees who have been away for a long period of time are at higher risk for recidivism because they are likely to be without a social support system in Jamaica.

6.20. Some commentators have argued that many deportees left their home countries at a young age and learned criminal behavior while abroad. To examine this hypothesis empirically, Bernard Headley, a Professor of Criminology at the University of the West Indies, examined 5,174 records of criminals deported from the U.S. between 1997 and 2003. He found that the mean age of entry to the United States was 23 years, nearly out of the high risk age demographic of 15-25, and less than 3 percent arrived before the age of five years (Headley et al., 2005). A fifth arrived during the formative period of 16-20, however, during which experiences in both countries could have had some effect on the course their lives would later take. Thus, while there are some cases of deportees who left Jamaica at young ages and were largely raised in the United States, they constitute a minority of total deportees. 


\section{Figure 6.8: Age on Arrival in the U.S. of Jamaican Criminal Deportees (Percent of Headley's Sample)}

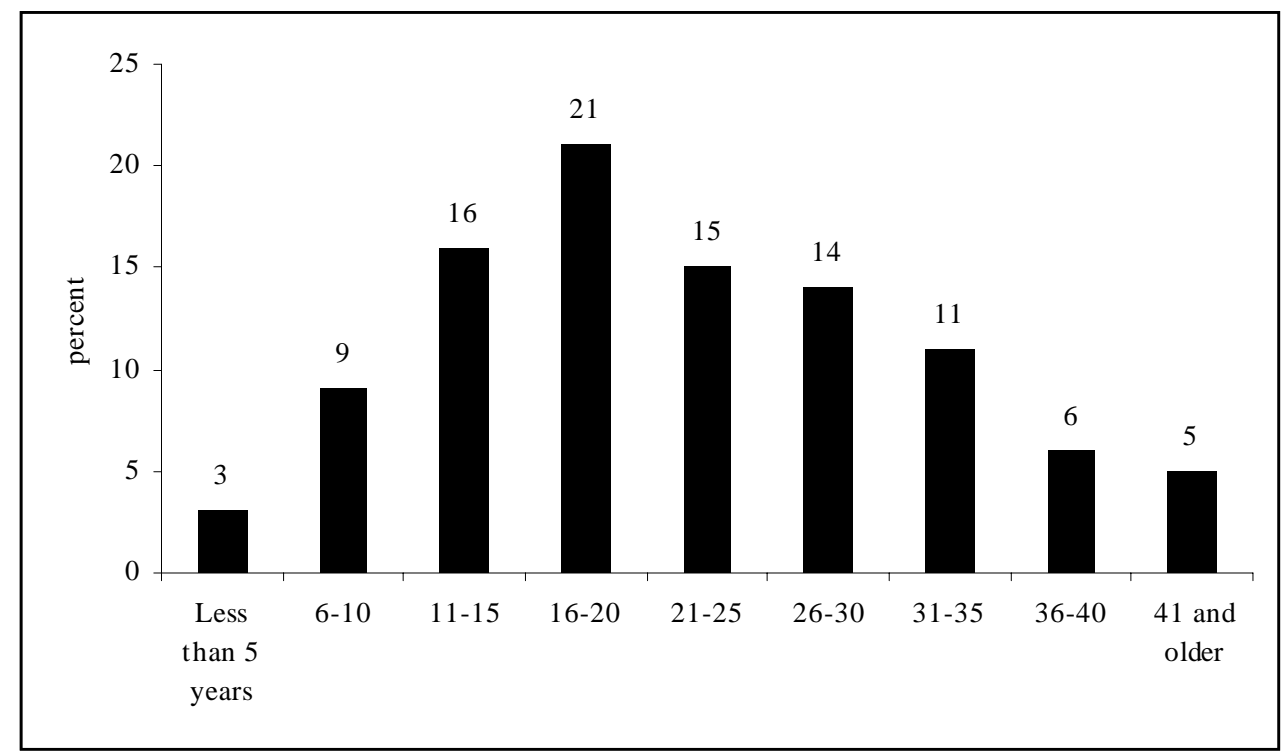

Source: Headley et al, 2005.

6.21. Headley also examined the age at deportation, finding that the vast majority of convicted deportees were no longer young on their arrival in Jamaica, with 62 percent being 31 years or older. Normally, these older men would be less likely to re-offend, particularly with regard to the sort of gang violence with which the deportees are often thought to be associated.

6.22. In summary, the data indicate that the average age of a criminal deportee entering the United States was 23, the average age on deportation was 35, and 81 percent were returned to Jamaica for non-violent offenses. While there is clearly heterogeneity in the pool of deportees, the average deportee does not fit the profile of an individual who is likely to be a violent criminal on return to Jamaica.

6.23. On the other hand, Headley's research also shows that over half (51.2 percent) of the deportees had already been convicted of a crime in the United States prior to the one for which they were deported. And even if the majority of the criminal deportees were deported for non-violent offenses, 224 convicted murderers were included in the flow between 2001 and 2004. Relative to the Jamaica's population, this is not a particularly small number. 


\section{Figure 6.9: Age on Deportation from the U.S. of Jamaican Criminal Deportees}

(Percent of Headley's Sample)

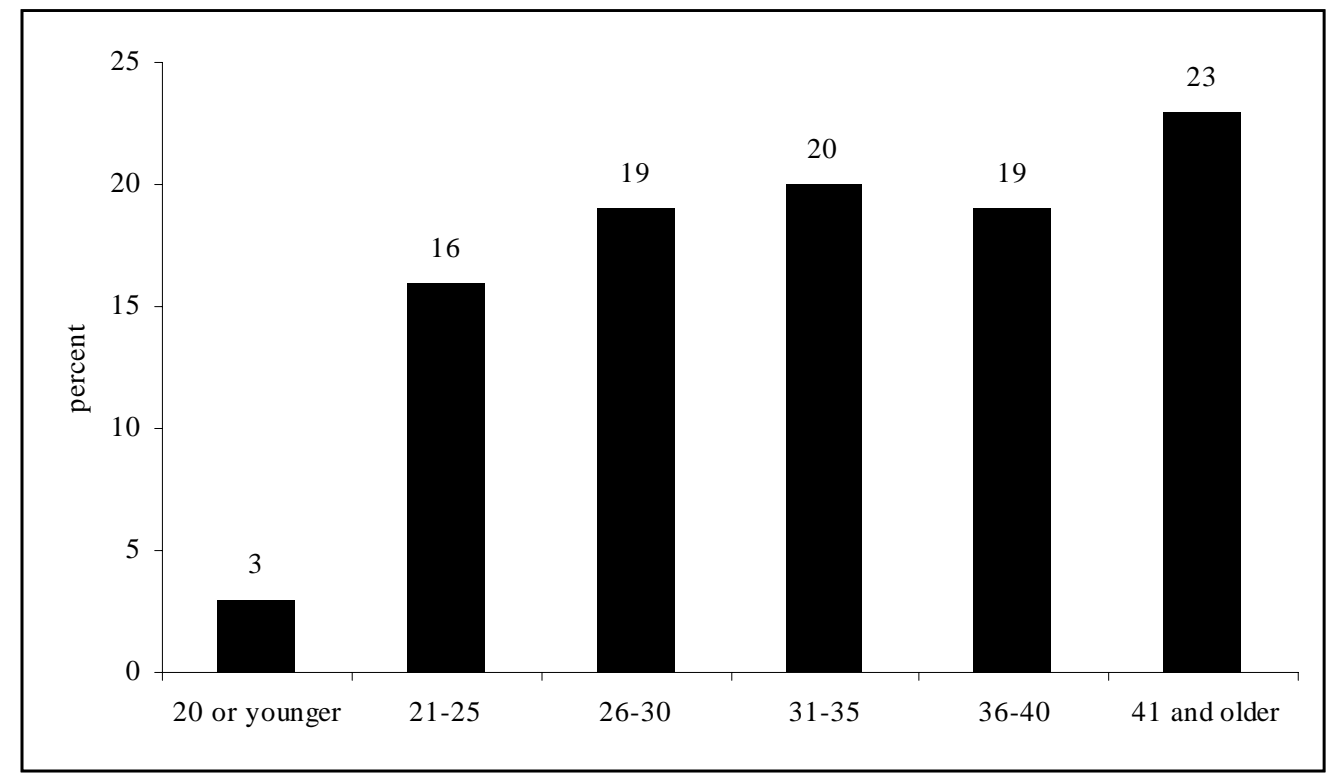

Source: Headley et al, 2005.

6.24. With current available data, it is possible to conclude that it is unlikely that the average deportee is committing violent crime in Jamaica. At the same time, it is possible that a minority of deportees is involved in criminal activity, and a few anecdotal cases have been reported in the press. In such small countries, it does not take a large number of offenders to have a large impact, particularly if they assume a leadership role in criminal gangs on their return or provide perverse role models for youth. Specifically with regard to drug trafficking, their transnational connections and criminal experience could make criminal deportees well-suited for this role.

6.25. Are deportees contributing significantly to Jamaica's crime rate? The clearest way of answering this question would be to keep tabs on the deportees received and determine what share are later charged with an offense. Something like this has actually been done in at least two Caribbean countries: Barbados and Trinidad and Tobago. According to Griffin (2002), of 332 criminal deportees returned to Barbados between 1994 and 2000, only 43 (13 percent) had been charged with a criminal offense at the time of the study. The average length of time between arrival and being charged with a crime was 17 months, and, with the exception of one murder case, most of the deportees were charged with burglary or drug-related offenses. Similarly, in Trinidad and Tobago, of the 565 deportees received between 1999 and 2001 only 83 (15 percent) had been charged with a crime, of whom almost half (47 percent) were charged with larceny or drug offenses (Griffin, 2002).

6.26. The CARICOM Regional Task Force on Crime and Security (2002) reviews the same figures and points out that these figures suggest that crime rates among deportees in those two countries are lower than those for the local criminal population. The Task 
Force argues that the reoffense rate for local criminals in both Barbados and Trinidad and Tobago, and in Jamaica as well, is greater than 50 percent.

6.27. If data is not available that allows us to follow deportees after their arrival in Jamaica, it should still be possible to determine whether deportees are more or less likely to be convicted of a crime than the local population by examining the share of the prison population that has experienced deportation. Of course, Jamaica's low conviction rates (about 25 percent) mean that a lot of suspected criminals are never convicted, so the prison population may not be a true reflection of the criminal population of the country.

\section{POLICY IMPLICATIONS}

6.28. Whether the deportees are responsible for rising crime in Jamaica is a researchable question. Much support could be brought to this contention if the share of those charged with or convicted of crime were shown to disproportionately contain deportees. The government of Jamaica is currently sponsoring research in which deportees, gathered through responses to newspaper ads soliciting interviews, are questioned about their pasts and their behavior. ${ }^{112}$ Whatever the conclusions of this research, the question of who is responsible for these people will remain.

6.29. The United States, the United Kingdom, and Canada absorb much of Jamaica's talent, importing nurses, teachers, athletes, and skilled professionals. In fact, an estimated 85 percent of Jamaica's skilled labor emigrates, largely to these three countries (Ozden and Schiff, 2006). Legally, sovereign states are privileged to eject those parts of the migrant population that do not meet standards. Morally, though, these countries might feel some sense of responsibility for the deportees, especially for those who were raised in the ghettos of three of the richest countries in the world.

6.30. There are several possible approaches these powerful countries could take to cushion the blow of criminal deportations on the islands to the south. In the United States, for example, most convicts are released from prison into some form of community supervision. Conditions are also placed on their release, encouraging legal employment and discouraging association with former criminal associates, for example. These protections and conditions are not present when a convict is deported.

6.31. Of course, providing parole officers and halfway houses involves some costs, and a key reason for the current drive in immigration enforcement, at least in the U.S., is to reduce the country's massive corrections bill. But these costs would likely be less if the programs were conducted in Jamaica. For the convicts that left Jamaica as children, whose families may remain abroad, some form of cultural orientation and networking would be essential if a return to criminality is to be avoided.

\footnotetext{
${ }^{112}$ A forthcoming study conducted by Jamaica's Ministry of National Security and the Planning Institute of Jamaica, will examine the relationship between deportees and crime. The study was not available for review at the time of this writing. CARICOM is also carrying out a survey on deportees in some member countries, the results of which are expected to be available in early 2007.
} 
6.32. The CARICOM Regional Task Force on Crime and Security (2002) recommended that member countries establish Offices for the Resettlement of Deportees modeled after a program in St. Kitts and Nevis, where the Returning Nationals Secretariat is charged with facilitating reintegration of deportees. The Secretariat provides counseling and offers assistance in finding jobs, locating housing, and using social services. In Jamaica, a church-based group known as the Land of My Birth Association has recently started to offer similar services to some deportees (Davidson, 2006).

6.33. The industrialized countries provide a variety of forms of aid to the Caribbean to support development. Subsidizing reintegration for deported offenders could be a very cost effective way of achieving such an end. It would save society the cost, as well as the trauma, of recidivism; reduce criminal justice costs involved in processing and incarcerating repeat offenders; and promote the stability essential to attracting investment and promoting tourism. The end result might be less emigration, reducing the burden of deportation for everyone.

6.34. Moral obligations aside, it is in the self-interest of the United States, the United Kingdom, and Canada to avoid returning dangerous convicts to environments where they are highly likely to offend again. The United States in particular does not benefit from having unstable states just outside its borders. Drug dealers are likely to make use of their connections in both countries to promote further trafficking, and all three countries suffer from cocaine and cannabis imported via the Caribbean or by Caribbean nationals. Exporting criminals could contribute to the building of transnational criminal networks.

6.35. Deportation thinking seems to rest on the premise that the borders are impregnable, when anyone involved in immigration enforcement knows that this is far from the case. Few countries would consider allowing early release of convicts in order to "deport" them to a neighboring city, when this is essentially what deportation accomplishes. It provides immediate relief from corrections expenses, but it releases offenders into an increasingly mobile global community. Headley's sample included over 500 cases where the subject was being deported for at least the second time in the six years included in the study.

6.36. In short, it is not possible for these three countries to simply export their crime problems south. Coming to terms with transnational crime will require dealing with problematic migrants cooperatively. 


\section{CASE STUDY: DRUG TRAFFICKING AND THE NETHERLANDS ANTILLES}

The drug trade is a prime driver of crime across the Caribbean. In the Netherlands Antilles, authorities estimate that 75 percent of crime is drug-related. Some 60 percent of all the cocaine seized in the Caribbean in 2004 was seized in the Netherlands Antilles, and cocaine seizures there increased dramatically between 2001 and 2004. Confronted with large numbers of people attempting to smuggle drugs by commercial flights, authorities implemented a " $100 \%$ Control" policy of screening large numbers of passengers for drugs. Drugs were confiscated from the couriers, but in most cases the couriers themselves were not arrested. The program has been very successful in reducing cocaine smuggling via air courier, and could be tested in other contexts, including other Caribbean countries suffering from drug transshipment. The Antillean example also highlights the need for cooperation between Caribbean transshipment countries and destination countries in maritime interdiction.

7.1. Despite their diversity, the Caribbean countries share a common affliction: they are geographically positioned in the world's largest drug transit zone. South America produces nearly all the world's cocaine. The United States and Europe are responsible for 88 percent of global retail sales of cocaine, a market worth some US\$70 billion in 2003(UNODC, 2005). The gross domestic product of the entire Caribbean was US\$31.5 billion in 2004. (ECLAC, 2006). In other words, the value of the drug flows through the region may exceed the value of the entire licit economy.

7.2. Drug trafficking is associated with significant increases in crime, particularly violent crime and the use of firearms, as violence or the threat of violence regulates transactions in this market. In addition, drug trafficking is associated with moneylaundering, trafficking of firearms, and corruption. Drug use is associated with increases in both violent crime and various types of property crime. For more on recent drug trafficking trends in the Caribbean, see Chapter 2; for regional policy responses to drug trafficking, see Chapter 10.

7.3. CARICOM's Regional Task Force on Crime and Security, speaks of a threepronged strategy to international drug control:

- Eradication or alternative development for producer countries (e.g. Colombia, Peru and Bolivia for cocaine)

- Supply restriction through interdiction operations for transit countries (e.g. Caribbean states); and

- Demand reduction for the main consumer countries (e.g. North America and Europe).(CARICOM, 2002)

7.4. This chapter examines interdiction efforts in the Netherlands Antilles. The Netherlands Antilles are an autonomous part of the Kingdom of the Netherlands. They are comprised of two groups of islands located about $900 \mathrm{~km}$ apart: 
- Curacao and Bonaire, located in the south of the Caribbean, near the coast of Venezuela;

- $\quad$ St. Eustatius, Saba, and St. Maarten, in the Eastern Caribbean. ${ }^{113}$

7.5. The Netherlands Antilles have a population of 183,000 people, (United Nations, 2004; United Nations, 2005) ${ }^{114}$ about 75 percent of whom live on the island of Curacao. The country is relatively well-developed, with a GDP per capita among the highest in the Caribbean, good infrastructure, and an economy based on tourism, financial services, and oil transshipment.

7.6. The Netherlands Antilles was chosen as a case study for two reasons. First, it is one of the Caribbean territories most afflicted by the drug trade and is among the world leaders in cocaine seizures per capita. Second, the government of the Netherlands Antilles, in collaboration with the Dutch government, has undertaken innovative and seemingly successful policies to interdict the supply of cocaine.

7.7. About 100 times more cocaine per capita was seized in the Netherlands Antilles than in the United States in 2004-over nine tons, or just under 50 grams of cocaine for every man, woman, and child on the islands. ${ }^{115}$ Some 60 percent of all the cocaine seized in the Caribbean in 2004 was seized in the Netherlands Antilles, and cocaine seizures increased dramatically between 2001 and 2004 (Figures 7.1 and 7.2). ${ }^{116}$

7.8. The increased flow of drugs though the region is believed to have a powerful impact on the local crime situation. The Netherlands Antilles authorities estimate that 75 percent of the crime on the islands is drug-related. On March 12, 2004, the Antillean government proposed a state of emergency due to the levels of crime afflicting the society, opening the door for both Dutch and Antillean military to participate in internal security operations. This was in response to a rapid increase in the number of crimes seen in Curacao. Drug-related murders increased from 12 in 2002 to 29 in 2003. Other islands experienced similar problems. The murder rate in St. Maarten went from 20 per 100,000 in 2001 to 47 per 100,000 in 2003. ${ }^{117}$

\footnotetext{
${ }^{113}$ St. Maarten is half of an island, the other half being St. Martin, a French territory. Aruba was part of the Antilles until 1986, when it became a separate country within the Kingdom of the Netherlands. While drug trafficking through Aruba used to be a major issue, it is much less so today. Aruba was removed from the US State Department's list of major drug producing and transit countries in 1999. The reason for this decline is unclear.

${ }^{114}$ World Population Prospects: The 2004 Revision and World Urbanization Prospects: The 2003 Revision, http://esa.un.org/unpp, accessed 25 July 2006.

115 The Netherlands Antilles ranked eighth in the world in terms of gross cocaine seizures in 2004, just behind the Netherlands and just ahead of Bolivia and Brazil.

116 In addition to a possible increase in real volumes transiting the region, the dramatic rise in seizure figures is likely the result of a shift from an early focus largely on airport interdiction to intelligence-led operations against major traffickers, which only began to pick up around 2001. This was also the time that the Coast Guard of the Netherlands Antilles and Aruba (CGNAA) came on line, after being equipped with three cutters in 1999.

${ }^{117}$ Information on population and number of murders from the Central Bureau of Statistics Netherlands Antilles Statistical Yearbook as quoted on their on-line database: http://www.cbs.an/stat.asp.
} 
7.9. As Figure 7.2 shows, the Netherlands Antilles have not always been at the epicenter of the global cocaine trade. ${ }^{118}$ Recently, a number of things have changed. Law enforcement efforts have made it less likely that cocaine shipments depart directly from Colombia than in the past, and more likely that they come from a secondary country, particularly Venezuela. Between much of the Venezuelan coastline and the rest of the world lie the islands of Curacao, Bonaire, and Aruba, so maritime cocaine shipments are likely to pass through the territorial waters of these countries. In addition, there is much commercial sea traffic between Venezuela and the Netherlands Antilles, which are just a few kilometers offshore. ${ }^{119}$ This traffic provides cover for drug shipments that can then be forwarded by sea or by air.

\section{Figure 7.1: Kilograms of Cocaine Seized in Caribbean Territories in 2004}

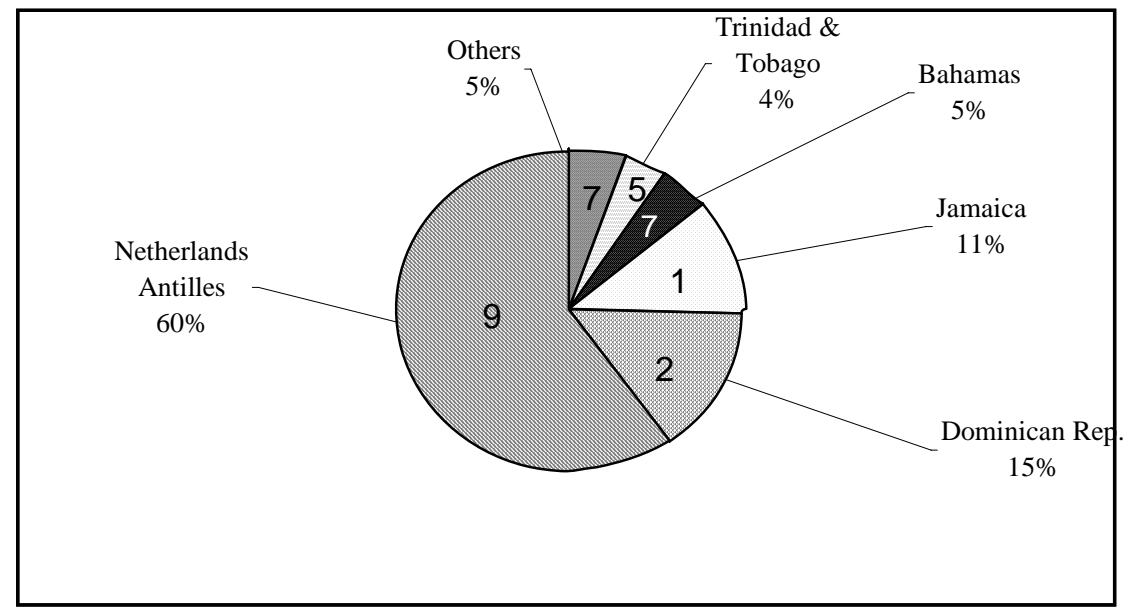

Source: UNODC Delta database.

7.10. The islands' continued membership in the Kingdom of the Netherlands has also been important. While cocaine use in the United States is down since the 1990s, it has been increasing in Europe. The European portion of the Kingdom of the Netherlands is one of the two main points of entry for cocaine to Europe. ${ }^{120}$ The Netherlands Antilles have suffered from high rates of unemployment since the closure of the Shell refinery in

\footnotetext{
${ }^{118}$ In the early days of the Colombian cartels, large volumes of drugs were flown by private planes into the United States, their main destination. Improvements in radar response put an end to this, and shipments became increasingly maritime. Again, most sea routes from Colombia to the U.S. did not pass through the most populous areas of the Dutch Caribbean.

${ }^{119}$ Curacao is less than $65 \mathrm{~km}$ off the coast of Venezuela. Venezuela is the source of 52 percent of imports to Antilles. See Economist Intelligence Unit, “Netherlands Antilles Country Report.” London: EIU, June 2006.

${ }^{120}$ The other being Spain. About 65 percent of the cocaine seized in Europe in 2004 was seized in Spain and the Netherlands. According to Europol, "Cocaine is also shipped from South America to Europe via the Caribbean Islands. This in part can be explained due to the historical links that exist between the Caribbean and some European countries, for example Curacao and the Netherlands ...” See Europol, "Drugs 2006.” The Hague: Europol, 2006, p. 3.
} 
the late 1980s, creating a pool of potential couriers with European passports (Central Bureau voor de Statistiek, 2006). ${ }^{121}$

Figure 7.2: Kilos of Cocaine Seized in the Netherlands Antilles, 1980-2004

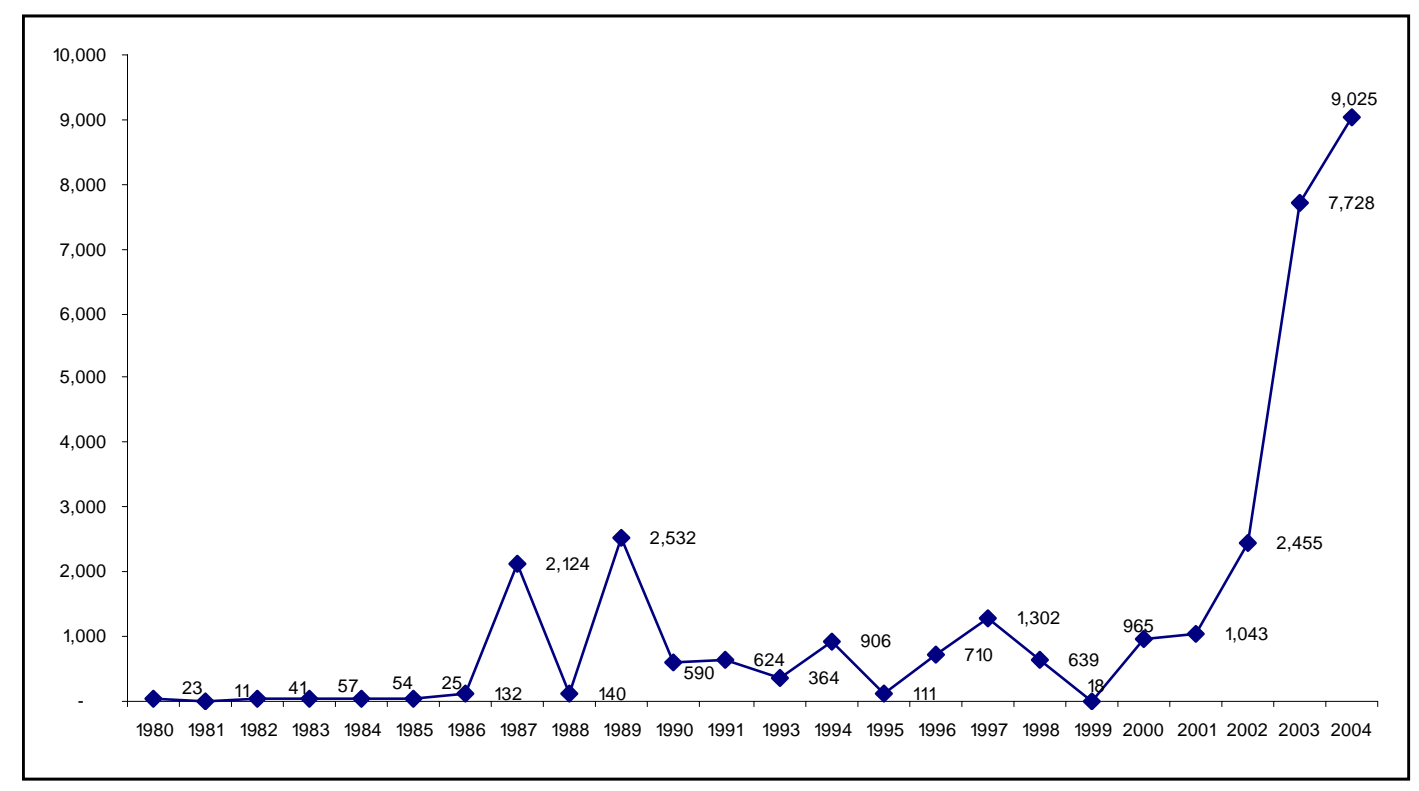

Source: UNODC Delta database.

7.11. A final factor in the remarkable seizure totals relates not to the existence of the flow of drugs but rather to their detection. Assisted by the Dutch Royal Navy and the Coast Guard for the Netherlands Antilles and Aruba (a common agency of the three countries in the Kingdom), Antillean law enforcement has intercepted some massive shipments in recent years, shipments that might have been missed by less well-resourced agencies, or only apprehended on arrival in Europe. Further, both the Antilleans and the mainland Dutch have also taken an innovative approach to stopping what had been a virtual stampede of couriers on commercial air flights. At least until recently, they have had a "drug focused" (as opposed to courier-focused) interdiction policy at the airports, a policy that is discussed further below.

\section{DRUG TRAFFICKING ON COMMERCIAL AIR FLIGHTS: AN INNOVATIVE POLICY RESPONSE}

7.12. It is estimated that 30 tons of cocaine enter Europe on commercial air flights every year, and that Schiphol International Airport in Amsterdam has been one of the primary points of entry (Europol, 2006). In 2000, 4.3 tons of cocaine were seized at Schiphol (INCB, 2001), and by August 2001, the flow of cocaine from the Netherlands Antilles had reached crisis proportions. An innovative approach became necessary. The first priority became stopping the ingress of drugs, even if that meant identifying more couriers than could possibly be prosecuted.

${ }^{121}$ In 2005, unemployment was 15 percent on Curacao, including 44 percent among youth. 
7.13. Toward this end, the " $100 \%$ Control" policy was implemented, in which flights landing in Schiphol originating from the Dutch Caribbean, Suriname, or Venezuela are subject to extensive searches. ${ }^{122}$ Rather than attempting to scare off potential smugglers with the threat of incarceration, the Dutch approach was based on increasing the rate of interdiction to the point that smuggling becomes unprofitable. In other words, the focus was on the drugs, rather than the couriers, and was based on incapacitation, rather than traditional deterrence. Europol described the mechanics of the policy in this way:

Crews, passengers, their luggage, the cargo and the planes are systematically searched. Couriers with amounts of less than $3 \mathrm{~kg}$ of cocaine are not detained, unless they are arrested for the second time or another criminal offense is involved. Instead, the drugs are confiscated and the smugglers are sent back. Couriers who have been identified are registered on a blacklist, which is provided to KLM, Dutch Caribbean Airlines and Suriname Airways (Europol, 2005, emphasis added).

7.14. Detecting the couriers is not easy, because most carry the cocaine in their intestines. These "swallowers" (slikkers) ingest little balls (bolletjes) of cocaine, an average of 90 per courier, usually wrapped in two latex glove fingers and coated in wax (National Ombudsman, 2006). ${ }^{123}$ If one of these bursts, the courier usually dies of an overdose. Consequently, this form of couriering appeals most to people who are reckless, desperate, or ignorant. In other words, it appeals to people who are difficult to deter with the threat of incarceration in a European prison.

7.15. The first recorded case of cocaine swallowing in the Netherlands Antilles was in 1983. This form of couriering appears to have been exploited early on by West African organized crime groups, which have utilized body couriers to traffic drugs between markets all over the world. The great advantage of using commercial flights is that any criminal entrepreneur with a small amount of capital can try, and this makes the method attractive to the loose, flat networks that typify West African organized crime. The West Africans soon abandoned personally couriering the drugs in favor of hiring people less likely to be searched, starting with Brazilians. Today, East Europeans feature prominently in the courier ranks. However, arrest statistics of the Dutch Royal Military Police, responsible for enforcement at Schiphol Airport, show that 46 percent of those arrested for drug offenses in 2004 were Antilleans (Trimbos Institute, 2005).

7.16. West African networks also pioneered the use of the "shotgun" approach, where multiple couriers are placed on the same flight with the hopes that a few will get through. Traffickers recognize that law enforcement authorities can only arrest a limited number of couriers on any given day, as each requires extensive paperwork and subsequent court time. Once a few are detected, attention turns away from the rest of the passengers. By sending several couriers on one flight, traffickers are virtually guaranteed that some of

\footnotetext{
${ }^{122}$ In practice, flights from Ecuador and Peru are also subject to $100 \%$ control, as all flights from these countries stop over in the Dutch Caribbean.

${ }^{123}$ It has also been alleged that cat or goat intestines have been used as wraps as they are apparently more difficult to detect.
} 
their drugs will get through. At least, that was true before the $100 \%$ Control strategy was put in place.

7.17. Drug smuggling remains an attractive option for young islanders. While Antilleans are Dutch citizens and thus benefit from extensive social protections, just getting by may not be enough for some young people. Caribbean youth often speak of the "easy money" to be gained through the drug trade, as compared to the near impossible employment situations many face (World Bank, 2003a). Participation in the drug trade offers a tempting way to earn some relatively significant income quickly.

7.18. Under 100\% Control, suspected couriers are taken aside and questioned. Once officials have a firm basis for suspicion, the suspects are given the option of proving their innocence by submitting to a body scan. Alternatively, they are kept in custody until their intestines empty themselves, whereupon culpability is positively ascertained. The Dutch authorities even offer a receipt for the drugs taken, so that couriers can explain the loss to their employers.

7.19. The strategy appears to have been remarkably successful. Between 1 January 2004 and 1 April 2006, just under 4,000 flights were examined, 6,147 couriers were identified and 7.5 tons of cocaine were seized, ${ }^{124}$ accounting for more than half of the cocaine seized at Schiphol airport. This amounts to $1.2 \mathrm{~kg}$ per courier, over 70 percent of whom carried the contraband internally (National Ombudsman, 2006). Figure 7.3 shows the decline in the number of couriers detected arriving from Curacao at Schiphol. While the controls have remained quite consistent throughout, the number of couriers detected has dropped dramatically, from a peak of 463 couriers in the second quarter of 2004 to less than 20 per quarter today, a 96 percent reduction.

7.20. The actions at Schiphol are only part of the story. ${ }^{125}$ The approach was actually initiated at Hato International Airport in Curacao in 2002, and today is being extended to other airports in the Netherlands Antilles, particularly St. Maarten. Here, all passengers are screened and those identified as potential couriers are questioned. Those identified as couriers are given the option of proving their innocence, and thus being allowed to board the plane, by submitting to an x-ray scan. Only about one in ten suspected couriers elect to be scanned, and some of these are proven to be guilty. Those who refuse are not allowed to board the plane and are not given a refund on their ticket, so failure to board is tantamount to an admission of guilt.

\footnotetext{
${ }^{124}$ To put this quantity in perspective, it is more cocaine than was seized annually in any but the top 10 cocaine-seizing countries in 2004.

${ }^{125}$ The importance of the actions on the Antilles side is demonstrated by the lesser success of the $100 \%$ Control strategy for couriers originating from Suriname, an independent country where cooperation has not been as close with the European Dutch.
} 


\section{Figure 7.3: Couriers Detected Arriving at Schiphol from Curacao, by Quarter}

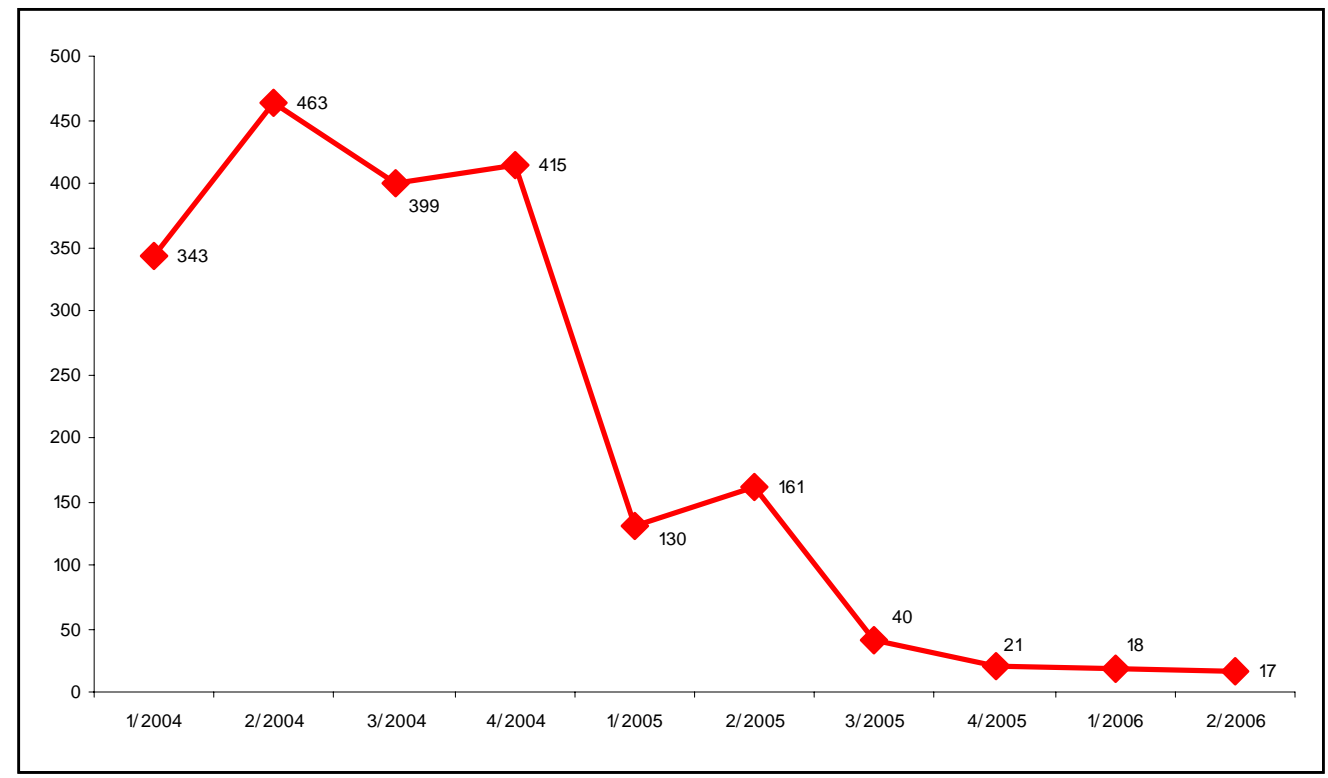

Source: Netherlands Ministry of Justice.

7.21. When this procedure was initiated, up to 100 people a weekend were denied boarding. Between mid 2002 and 2004, at least 13,000 people sacrificed their air ticket rather than face the body scan (Bureau for International Narcotics and Law Enforcement Affairs, 2005).

7.22. Thus, the remarkable seizures at Schiphol were just the residual that evaded the initial screening. On this basis, the authorities estimate that between 80 and 100 couriers per day were passing through the airport in 2003. This was cut to 10 a month by October 2005 (Bureau for International Narcotics and Law Enforcement Affairs, 2006). This reduction was accomplished not by draconian sentencing of the mules, but by making the route unprofitable to the traffickers organizing them.

7.23. The impact of this screening on organized crime was manifest in the violent response the airport team frequently encountered in the early days of the program. In 2003, they suffered at least seven firearm attacks in the airport, as well as threats and assassination attempts while off duty. At one stage, the body scan team was forced to suspend operations due to the threats they had received.

7.24. On those occasions where couriers are prosecuted and convicted in the Netherlands Antilles, they are given, in some cases, an alternative to incarceration: passport forfeiture. As part of a sentencing agreement, convicted couriers surrender their passport for a specified period of time (up to three years). The Netherlands Antilles government has collected over 800 passports in this way. As with the $100 \%$ Control strategy, the intent is to incapacitate the couriers without the costs of incarceration. 
7.25. While displacement effects would need to be tallied to properly evaluate the impact of this intervention, the $100 \%$ Control strategy has apparently disrupted what was once a major trafficking route. Of course, the resources required to individually scrutinize every flight and passenger come at a cost, but these expenses are likely to be less than those of processing and incarcerating an endless stream of hapless mules.

7.26. The $100 \%$ Control strategy is not without its critics. The Dutch National Ombudsman ${ }^{126}$ recently issued a report critical of the program in several respects (National Ombudsman, 2006). The Ombudsman regards as particularly objectionable the detention and search of innocent people, which comprise about one quarter of all suspects, and their treatment even when exonerated. ${ }^{127}$ Earlier practices, which involved body cavity searches, were abandoned on the advice of the Ombudsman. The policy has also been attacked by national leaders from the Dutch Caribbean. Suriname's President Ronald Venetiaan called the policy "inhumane, barbaric, and primitive." ${ }^{\text {"28 }}$ It was also loudly condemned by Anthony Godett, who was set to become Prime Minister of the Netherlands Antilles before he was incarcerated on fraud and corruption charges.

7.27. This places the Dutch in a difficult position. They have a strategy that apparently works, and that is intended to be both more humane and more cost effective than incarcerating those that risk death by swallowing kilograms of cocaine. To be effective, however, a large number of people need to be searched, including some who may prove to be innocent. A more restrictive approach would risk failing to capture a sufficient share of the drug flow to make the route unviable.

7.28. Abandoning the approach altogether is unthinkable, as there is evidence that the former torrent would resume immediately if there were a break in policy. For example, on December 26, 2005, two flights from Curacao to Schiphol were offered to accommodate the flow of returning tourists, one of which was scheduled uncharacteristically early in the morning. Apparently, couriers assumed that controls would be lighter or absent for the earlier flight, but had an unpleasant surprise when they arrived at Hato International. Dozens of no-shows left the fully-booked flight half empty. ${ }^{129}$

7.29. Since Schiphol airport is now seeing only a courier a week from Curacao, the detention of innocent people is likely to be minimal, but re-routing may mean that other airports are likely to adopt a similar strategy, ${ }^{130}$ so the challenge of creating an evenhanded and less controversial approach remains. There is a need for further research on the costs and benefits of the $100 \%$ Control system, and frank discussion of the ways it

\footnotetext{
${ }^{126}$ This office is tasked with investigating complaints against civil servants on behalf of the public.

${ }^{127}$ As of mid-2006, some 2,271 people proved to be 'negatieve slikkers' out of 8,576 people searched, according to information provided by the Netherlands Ministry of Justice.

${ }^{128}$ Cairo, I, 'Suriname to complain against Dutch drug inspections'. Caribbean Net News, 20 March 2006.

${ }^{129}$ Anecdote relayed in an interview with the Dutch Ministry of Justice, 27 July 2006.

130 The Netherlands is not the only country in the world to receive flights from the Antilles, or to find couriers on those flights. For example, Canada arrested at least eight traffickers carrying over 100 grams of cocaine apiece on commercial air flights from the Antilles in 2004, according to the UNODC Major Seizures Database.
} 
could be improved. The fact that some difficulties have been encountered with implementation does not mean the central principle-drug, rather than courier, interdiction — has been invalidated.

7.30. Of course, commercial air flights are only one of the vectors through which cocaine transits the Netherlands Antilles, and not necessarily the most significant one. The $100 \%$ Control approach has seized 7.5 tons of cocaine in two years, but multi-ton seizures can be made in a single instance of maritime interdiction. Since the share of sea shipments seized is almost certainly much less than the share of air couriers apprehended, it is likely that the vast majority of the cocaine traffic is maritime.

\section{MARITIME TRAFFICKING}

7.31. The first boat trip cocaine encounters on the Netherlands Antilles route is the short passage from the coast of Venezuela to Curacao, about $65 \mathrm{~km}$ away. This trip is essential whether the drug will ultimately be trafficked by sea or by air. Traditionally, gofast boats carrying between half a ton and a ton of cocaine have been used. But in 2004, the authorities noted a shift to smaller shipments (50-500 kg) in smaller, slower boats, including fruit and fishing boats (UNODC, 2004).

7.32. On arrival in the Netherlands Antilles, cocaine destined for onward maritime shipment is generally consolidated. An estimated 230 tons of cocaine enter the European Union annually via maritime shipments and air freight, an unknown share of which transits the Netherlands Antilles (Europol, 2006). Large seagoing vessels have been used to bring this contraband to Spain, increasingly via West Africa. The extent of containerized traffic of narcotics to Europe is debated. There are few concrete cases, but U.S. authorities suggest that this is an active trafficking vector (U.S. Department of State, 2006).

7.33. The United States also receives cocaine from the Netherlands Antilles, often trafficked via go-fast boats and in the holds of leisure sea craft from St. Maarten to Puerto Rico, but this flow is not considered a significant source of the United States' supply. However, law enforcement cooperation between the United States, Colombia, and the Netherlands Antilles has led to some significant drug arrests in recent years.

7.34. Detecting maritime trafficking requires intelligence work and a dedicated interdiction force. In 1996, the Coast Guard for the Netherlands Antilles and Aruba (CGNAA) emerged as a distinct entity after acquiring three cutters designed for combating drug traffickers. It continues to work with the Royal Navy of the Netherlands (RNN) in making major seizures. In 2004, the Netherlands Antilles saw their largest seizure ever when some 2.5 tons of cocaine and $28 \mathrm{~kg}$ of heroin were seized. But since that time, numerous large maritime seizures have been made:

- On June 25, 2005, 1.8 tons of cocaine was seized by the CGNAA and RNN (Netherlands Ministry of Justice, 2006).

- On July 21, 2005, a Venezuelan craft carrying $792 \mathrm{~kg}$ was seized (Netherlands Ministry of Justice, 2006). 
- On August 27, 2005, a joint U.S./Dutch effort seized over two tons of cocaine from the Bolivian flagged $\mathrm{M} / \mathrm{V}$ Sea Atlantic (U.S. Drug Enforcement Administration, 2005).

7.35. While final seizure figures for 2005 have not yet been released, these three seizures alone would amount to about half the cocaine seized in 2004, a record year.

7.36. Of course, the Netherlands Antilles and Aruba are situated between Venezuela and Europe, just off the Colombian border. This location means that shipments directly from Venezuela to Europe often pass through Antillean/Aruban waters incidentally. In short, the CGNAA and the RNN are doing a lot of Europe's interdiction work close to the source. These seizures may have little to do with the Netherlands Antilles or the Antilleans.

7.37. All indications are that Venezuela will continue to grow as a conduit for cocaine, and this is likely to mean that maritime seizures in the Netherlands Antilles will remain high. As the Colombian government continues to make progress, those elements of the FARC and the AUC committed to conflict or criminal incomes are likely to withdraw into Venezuela. The small Caribbean countries will need international support if they are to continue to form the front line in maritime cocaine interdiction.

\section{POLICY IMPLICATIONS}

7.38. Looking strictly at the seizure figures, one might see the disproportionate use of the small Netherlands Antilles for drug trafficking as an indictment of Dutch drug policy. The reality is more complicated than that. The Netherlands Antilles are somewhat unique in their geographic vulnerability, particularly with regard to maritime trafficking. In essence, they constitute Europe's (and, to a lesser extent, the United States') first line of defense against drug shipments coming from the Venezuelan coast. The high seizure figures are largely a product of remarkable police work, and should be commended, not condemned.

7.39. The fact that the Netherlands Antilles are preferred by air couriers is another matter. This is undoubtedly tied to the fact that the Netherlands is a key drug distribution center for Europe, which in turn is tied to the perception that the Dutch are soft on drugs. But here again the Netherlands have risen to the challenge and, at considerable expense and effort, have managed to stem what was once a major source of cocaine supply to Europe. Not only that, they managed to do so in a way that did not destroy the lives of the troubled youth and addicts that comprise the corps of international drug mules.

7.40. Of course, even eliminating the Netherlands Antilles as a drug transit area altogether will not stop the flow of drugs, and displacement effects are inevitable. French authorities are already asserting that Charles de Gaulle airport is increasingly being targeted by air couriers, and lesser airports are also seeing increased drug traffic. In August of 2006, almost $40 \mathrm{~kg}$ of cocaine was seized from French and Dutch nationals in six separate incidents at Orly airport in France. Cocaine seizures in nearby Trinidad and 
Tobago have skyrocketed since the program really began to take off in 2003, although whether this is strictly a displacement effect is unclear.

Figure 7.4: Cocaine Seizures in Trinidad and Tobago

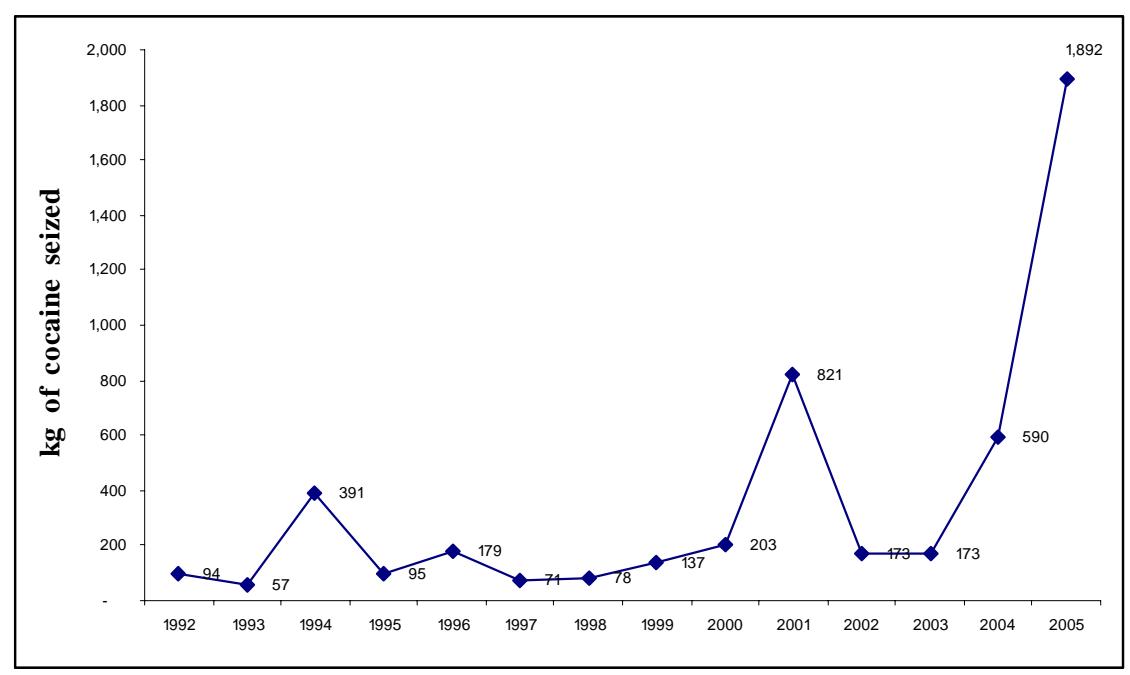

Source: UNODC Delta database.

7.41. Despite their success, the Dutch seem intent on disavowing the drug-centered interdiction approach, having faced considerable international criticism before all the numbers were in. Today, they are quick to insist that all couriers will be prosecuted, but often neglect to mention that this is only possible because the numbers have declined so radically, due in no small part to the fact that not every courier was prosecuted in the past. This reluctance to promote drug-centered interdiction is unfortunate, because the $100 \%$ Control experiment represents an innovation worthy of further promotion and testing.

7.42. Of course, Caribbean countries may object to the intense scrutiny of passengers arriving from their countries. But the alternative, involving the arrest and prosecution of many Caribbean nationals for drug trafficking, may be even less palatable. Officials positively identified over 6,000 couriers arriving at Schiphol from the Dutch Caribbean in less than three years, at least half of whom were Antilleans. In the absence of a drugfocused policy, all these people might be in Dutch jails today.

7.43. Focusing on the drugs rather than the couriers is a powerful approach because it defeats the "shotgun" technique, where traffickers are willing to sacrifice an endless stream of gullible couriers so long as sufficient quantities of drugs arrive for them to make a profit. It has proven itself to work in the case of the Netherlands Antilles, and could be tested in other contexts, including other Caribbean countries suffering from drug transshipment. Once there is clear evidence that a particular routing is being used by drug mules, measures similar to the $100 \%$ Control approach could be taken at both source and destination airports. Drug-focused interdiction bypasses the couriers, who, willing to risk their lives for a few thousand Euros, are unlikely to be deterred by threat of incarceration. 
Instead, it speaks directly to the traffickers in the language they understand: it renders drug routes unprofitable.

7.44. The Antillean example also highlights the need for cooperation between Caribbean transshipment countries and destination countries in maritime interdiction, as called for by CARICOM's Regional Task Force on Crime and Security (CARICOM, 2002.) Given that small Caribbean countries have inherent limitations in law enforcement capacity, a little assistance can go a long way.

7.45. Of course, this case study does not deal with all elements of the drug puzzle in the Caribbean; the Caribbean Regional Task Force on Crime and Security identified several challenges beyond successful interdiction:

- On the demand side, to reduce demand and treat and rehabilitate drug abusers.

- On the supply side, to find ways to counter the attraction of cultivation of illicit crops as a means of livelihood.

- In terms of rehabilitating those convicted of drug possession, to introduce a penal system that places greater emphasis on uniform, non-custodial sentences for drug abusers and minor drug offenses, with the aims of promoting rehabilitation, and reducing prison overcrowding. 


\section{THE CONTRIBUTIONS OF CRIMINAL JUSTICE SYSTEMS TO THE CONTROL OF CRIME AND VIOLENCE: A CASE STUDY OF JAMAICA AND THE DOMINICAN REPUBLIC ${ }^{131}$}

Criminal justice reform is a key component of broader multi-sector approaches to reducing crime and violence in the Caribbean. In recent years, traditionally organized, criminal justice institutions have been faced with demands that they respond more effectively to increasing levels and new forms of crime and violence. Ongoing debates over the ability of criminal justice organizations to reduce crime levels make it clear that their impact can be overstated and that improving sector performance at best affects the proximate-and not the fundamental-causes of crime. Nonetheless, in response to citizen demands many nations in the Caribbean region are attempting to reform and modernize sector institutions, combining higher budgets (to allow increased staffing and the creation of more service units) with improved management, upgrading of personnel and personnel administration, new technologies, and the introduction of new operating procedures. Most of this work has been done with police, courts, prosecutors, and public defenders; very little has been attempted with prisons despite their potential role in deterring crime and rehabilitating offenders. There is also an increasing focus on developing management information systems and performance indicators for better problem diagnosis, tracking of system outputs, monitoring reform programs, and increased accountability to citizens. This chapter reviews these developments in the context of two of the largest countries in the region: Jamaica and the Dominican Republic. It also reviews some of the statistics generated as a means of tracking recent trends and gaps in reform strategies. Although most reform efforts have focused on individual institutions, two important lessons emerge: (i) the need to pursue better coordination among institutions, including the introduction of information systems capable of tracking systemic performance, and (ii) the desirability of linking criminal justice reforms to a broader, multi-sector strategy of crime and violence prevention.

\section{INTRODUCTION: CRIMINAL JUSTICE REFORM IN CIVIL AND COMMON LAW SYSTEM}

8.1 Although there has been a tendency in the Caribbean to over-rely on law-andorder responses to crime and violence (as opposed to other, more prevention-oriented approaches - see Chapter 9), the criminal justice system remains an essential tool in crime and violence control and, to some extent, in their prevention. Academics and researchers specializing in the topic remain divided as to the real impact of the criminal justice system on reducing crime. As James Q. Wilson-an early proponent of the strict responses to crime and the author of the original "broken windows" thesis-has written,

\footnotetext{
${ }^{131}$ This chapter is based on a background paper by Todd Foglesong (Senior Program Associate at the Vera Institute of Justice in New York and Senior Research Fellow at the Kennedy School of Government) and Christopher Stone (Daniel and Florence Guggenheim Professor of the Practice of Criminal Justice, Kennedy School of Government, Harvard University). The authors are grateful to Andres Rengifo and Glendene Lemard for research assistance and reviews of drafts of the background paper. Additional material on Jamaica was provided by Florence Darby (independent consultant), and on the Dominican Republic by Linn Hammergren (World Bank). Linn Hammergren and Stephanie Anne Kuttner drafted this chapter.
} 
"There is no silver bullet that will reduce crime, much less eliminate it...[N]o one can satisfactorily explain changes in crime rates “(Wilson, 2004).

8.2 This uncertainty, however, cannot be an excuse for inaction, especially for governments facing increasing levels of crime and violence and citizen demands that they do something about them. This is still more critical in countries whose criminal justice systems have languished unattended for decades, lack the technical and human resources to respond to less traditional types of crime, have not adopted new standards of transparency and accountability, or have themselves been penetrated by political and occasionally, criminal elements.

8.3 Criminal justice reform is part of a broader law and justice reform movement that began twenty years ago in the Latin American region, and somewhat more recently, in Eastern Europe (Hammergren, 2002). Lessons can be drawn from this broad international experience, as well as from experiences in the Caribbean (IADB and Caribbean Group for Cooperation in Economic Development, 2000).

8.4 One frequent observation is that criminal justice reform can be very difficult, if not impossible, absent sufficient political will. Stakeholder support that reinforces the political will to reform is equally indispensable and thus a good understanding of reform supporters and potential detractors, both within the criminal justice system and society more broadly, is key to designing the appropriate reform strategy. A second important lesson is that success of these efforts depends on aligning the work of the different institutions within the system, and of the system as a whole with a larger, multi-sector crime and violence prevention strategy. Until recently, these two elements tended to be overlooked, occasionally with very unfortunate results. ${ }^{132}$

8.5 In the Caribbean region, the two major legal traditions or families, common and civil law, have taken somewhat different approaches to criminal justice reform. In the civil law systems (and especially those of Spanish and French origin), the initial emphasis was on modernizing criminal procedural codes to effect a shift from inquisitorial to more accusatory systems and incorporate more rights for the defendant. The due process emphasis was a logical reaction to the abuses of prior authoritarian regimes and also

\footnotetext{
${ }^{132}$ A donor-sponsored effort to recreate a Haitian police force in the 1990s, for example, floundered in part because of inadequate attention to other elements of the criminal justice chain. Courts and prosecution continued to operate much as before in processing cases - slowly, inefficiently, and impaired by politicization and corruption - and moreover provided no more check than they ever had on police abuses. Prisons, which received still less attention, were quickly overcrowded by those arrested by the police, meaning that inmates suffered from inhumane conditions, went long periods without being seen by a judge, and occasionally protested by staging riots and further damaging already inadequate facilities. This truncated reform has been reviewed critically by many experts, including some who were involved in its implementation. For a summary of the initial process, see Rachel Neild, "La Reforma Policial en Haiti: Un Triunfo sobre la Historia,” in Lilian Bobea, Soldados y Ciudadanos en el Caribe, Santo Domingo: Flacso, 2002, pp. 285-308. Although, as the title suggests, Neild does not discount the successes of the effort, she is quite clear that failures to attack related problems like political intervention and an unreformed judiciary were already (in 1998, when the article was written) threatening to undercut the accomplishments.
} 
followed trends already underway in continental Europe. ${ }^{133}$ The incorporation of crime control objectives came slightly later, so that some of the initial legal changes occasionally appear to conflict with the pursuit of crime control. While there is no inherent contradiction between due-process and crime-control in procedural codes, codes written to advance only one of these objectives can undermine progress in the other. ${ }^{134}$ More importantly, it is increasingly recognized that law reform does not automatically advance either end, and thus that more attention must be paid to rationalizing organizational structures, improving internal management and oversight, human resource development, and the introduction of new technologies and technical skills. Progress here has been spotty, partly because of the financial investments required, and partly because of the resistance of interests vested in the inefficiencies of the traditional systems.

8.6 In the common law countries, legal change has been less emphasized and more importance has been given to upgrading and strengthening institutional capacities. As in the civil law countries, there is an emerging consensus on the importance of integrated reform programs that simultaneously improve and coordinate the functioning of different actors and institutions within the criminal justice system — that is, to ensure linkages between police reform, reorganization of prosecution agencies, strengthening of the judiciary's capacity and independence, and modernizing correctional systems. However, as in the civil law nations, effecting coordination in fact is far more difficult than espousing it in principle.

8.7 Traditional criminal justice systems from both legal families react to crime by incapacitating offenders though incarceration, sending a deterrent message to potential offenders, and providing the society with a sense of justice. The approach is usually popular with the public, but as even sympathetic experts like Wilson note, its efficacy is subject to dispute; it still requires sophisticated strategies, inter-institutional coordination, and strict oversight; and absent these conditions, it can lend itself to corrupt and abusive application.

8.8 More modern systems stress additional elements: (i) preventive policing; (ii) more strategic approaches to prioritizing crimes for investigation and prosecution; (iii) rehabilitation of prison inmates and re-entry programs to reduce recidivism; and (iv) use of alternative sentencing, fast track procedures, and conciliation with the victim for minor offenses. All of these additions are intended to make more efficient use of resources and

\footnotetext{
133 Throughout Latin American and the Caribbean, entrenched authoritarian regimes often used the police and other criminal justice agencies as a means of repressive control. Even after a democratic transition, the structures and practices introduced for this purpose may be hard to eradicate, but unless they are reversed, other reform activities are unlikely to work and may even have perverse consequences. Community policing and other preventive tactics in the hands of a corrupt, irresponsible police force may be an invitation to harassment of citizens. More independent judges insufficiently monitored by their own institutions may remain susceptible to bribes and favoritism.

${ }^{134}$ As just one example, many of the early reformed codes stipulated that within ten days of the initiation of an investigation, the person(s) targeted had to be informed so that they could prepare their defense. While for simple crimes this may pose little problem, for those of a more complex nature (e.g. drug trafficking, money laundering, and grand corruption), the provision could stop the investigation in its tracks. Poorly drafted provisions about police-prosecutorial coordination also commonly aggravated conflicts between the two institutions. Hammergren, op cit.
} 
to maximize the impact on discouraging crime before it happens or on limiting its further effects.

8.9 The following sections first describe the criminal justice reforms currently under way in the Dominican Republic and Jamaica. This brief overview provides the context for a subsequent comparative performance analysis based on statistics recorded by the two countries. A final section discusses governance structures that are conducive to successful reform.

\section{COUNTRY CASES: TWO APPROACHES TO CRIMINAL JUSTICE REFORM}

\section{The Dominican Republic}

8.10 The Dominican Republic, while one of the few civil law countries in the Caribbean, is a quintessential example of the broader Latin American justice reforms. Trujillo’s thirty-one year dictatorship (1930-1961) was accompanied by a centralized, ad hoc domination of all governance institutions, including those in the justice sector. With the advent of democracy, this system was quickly replaced by party-based, patronage politics in which governmental elites used public employment as a means of consolidating coalitions and rewarding followers. ${ }^{135}$ Low official salaries and massive turnovers at the end of every administration increased the incentives to seek irregular supplements and to dedicate little effort or time to one's official job.

8.11 In the justice sector, the results were predictable-inefficiency, high levels of corruption and abusive practices, poor service delivery, and low public confidence (Hasbun et al., 1999). In the 1990s, public discontent with the situation, spearheaded by a local NGO, FINJUS, provoked a series of reform measures (Salcedo, 2003). ${ }^{136}$ The first set involved: the introduction of a new system for appointing Supreme Court justices, ${ }^{137}$ the Court-supervised renewal of a good part (70 percent) of the rest of the bench via transparent, merit-based examinations of seated members and aspirants; the creation of a judicial career path; and, increased funding to improve judicial salaries and finance equipment, infrastructure, and training programs.

8.12 A second, more far-reaching reform was the adoption of a new criminal procedure code in 2002. In line with regional trends, the code featured more accusatorial

\footnotetext{
${ }^{135}$ Low-level police officers were one exception. Since their jobs are dangerous and poorly paid, there is not an abundance of would-be recruits. Higher-level officials, however, were frequently chosen for their political connections, not their probity or inclination to encourage better police work. For a discussion of the general problem, with some reference to the police and judiciary, see World Bank, Dominican Republic Public Expenditure Review: Reforming Institutions for a More Efficient Public Expenditure Management. Washington, D.C.: the World Bank, Report No. 23852-DO, March 15, 2004.

${ }^{136}$ For a discussion of the reforms and of the complaints leading up to them.

${ }^{137}$ Justices had formerly been appointed by the legislature. The change was introduced by constitutional amendment in 1994 but not put into effect until 1997. It established a judicial council, headed by the national president and with members from other branches of government and the private bar, which met solely for the purpose of filling vacancies in the court. The council's deliberations and the list of candidates were made more transparent, thereby, at least in the first round, discouraging appointments based solely on political allegiance.
} 
elements and a greater role for public prosecutors and defense. With donor assistance, the old public defense system, based on court-appointed lawyers, was converted to a formal career with measures to supervise public defenders' performance. This eliminated a major source of corruption; many former defenders were known for taking and offering bribes and charging for theoretically "free" representation of indigent clients. Donors have also been active in supporting programs to improve and professionalize public prosecution, but here progress has been far slower. A career system has only been partially implemented for ordinary prosecutors, with the Attorney General and the district prosecutors (who oversee other members of the institution in their respective geographic jurisdictions) still appointed and removed by the Executive.

8.13 With strong support from local NGOs, a new police law was enacted in 2004. Its aim was to demilitarize the national force, promote professional development, improve internal oversight, and increase accountability to civil society (Bobea, 2003; Grullon, 2003). Unfortunately, the law's implementation has faced resistance from those within and outside the police force interested in retaining the traditional practices. While there have been some interesting experiments with new policing techniques (see Box 8.1), the institution's public image remains poor, and there are strong indications of continuing police involvement in criminal activities and in shaping investigations to favor the politically and economically powerful. ${ }^{138}$

8.14 The Dominican criminal (and wider) justice reform thus remains half-completed. There are progressive elements in all the basic institutions who are interested in promoting further change, but more efforts are needed to finish the job of rooting out the corrupt and inefficient (Participación Ciudadanía, 2004). ${ }^{139}$ With the exception of the largely untouched prison area and public defense, budgets are arguably high enough and the sheer quantity of employees sufficient to do better, but there are problems related to how resources are used, the quality of professional and support staff, and the incentives shaping their behavior.

\footnotetext{
${ }^{138}$ For a discussion of police corruption, see DR1, January 20, 2005 citing comments by a delegation of experts from the John Jay College of Criminal Justice, New York and from FLACSO, http://www.dr1.com/news/dnews012005.shtm. The former notes that the "difficulties include the low wages paid to police officers, the bad reputation the force has for rampant corruption in the ranks, and lack of facilities to do the job." FLACSO's accompanying comment is that "crime in the DR is closely linked to the corruption levels within the police and the unskilled police officers" See also the U.S. State Department country report on human rights for 2005 (http://222.state.gove/g/drl/rls) which notes problems originating in a failure to vet police recruits and World Bank Country Memorandum on the Dominican Republic which notes (p, 156) that 48 percent of firms surveyed reported paying bribes to police. http://www-

wds.worldbank.org/external/default/main?menuPK=64187510\&pagePK=64193027\&piPK=64187937\&the

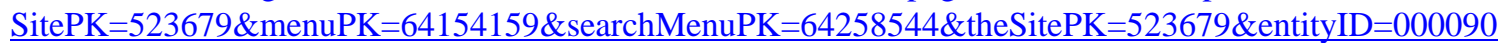
341 20061122101801\&searchMenuPK=64258544\&theSitePK=523679

${ }^{139}$ On court and prosecutorial inefficiency in handling corruption cases, FINJUS has been particularly outspoken, noting that as of early 2005, and despite numerous high level scandals (most notably Baninter and PEME, the job-creation program), there had yet to be a single conviction. See www.redinter.org/Democracria-al-dia/41135.
} 
8.15 Both the criminal procedures and police reforms arguably placed too much faith in the ability of law to alter behaviors and to overcome traditional practices. Slowness in reforming the public prosecution and the police force has so far impeded more radical change. There are also unfortunate signs of some backsliding in the judiciary, especially in the handling of corruption cases involving political and economic elites (Participación Ciudadanía, 2004). Cases have been dismissed, delayed or had charges reduced because of what the judges term prosecutorial incompetence and what the prosecutors claim is judicial collusion. As this and the troubled relations between police investigators and prosecutors suggest, the reform has also paid insufficient attention to the need to coordinate activities across institutions.

8.16 Thanks in part to donor support, the police, judiciary, prosecution and defense have established systems to track activities in each institution. The court's actions in this area in fact date to before the reforms. However, it is not evident that the resulting information is being used to monitor reform progress and detect problems, and there has so far been no effort to link the databases of the separate institutions so as to be able to assess their joint handling of cases in which they all participate. Although the Dominican Republic has recently established a national council to develop a multi-sector strategy for dealing with crime, the country's track record with such special committees has not been positive. Often composed of agency heads or prominent local experts, they frequently possess moral authority, but few resources and technical staff to support their work.

\section{Jamaica}

8.17 As a former British colony and current member of the Commonwealth, Jamaica already has a common law, accusatorial justice system. Pending the establishment of a Caribbean Court of Justice, its court of last resort is the United Kingdom Privy Council. Its Appeals Court is the highest local body. At the next level, its Supreme Court includes a panel to try major felonies, and another to handle gun issues. The more numerous magistrate courts have criminal divisions to handle minor crimes. Their approximately fifty members also serve on a series of specialized courts for traffic, family and juvenile matters. Jamaica also has roughly 8,000 justices of the peace. As they are not lawyers, their judicial role (for example, sitting on the 14 Petty Sessions Courts) is restricted to handling very minor disputes. Their more common functions are clerical or notarial, signing passport applications, certifying the identity of applicants for drivers licenses and the like.

8.18 Contrary to practices elsewhere in the Commonwealth Caribbean, the 1962 Constitution created a separate prosecution body, the Director of Public Prosecutions (DPP), thus eliminating the use of police prosecutors for criminal cases in any of its courts. The 7,200-member Jamaica Constabulary Force (JCF) is responsible for most policing. Its efforts can be supplemented in some areas by the Jamaica Defense Force (JDF). The country has eight adult prisons and four juvenile detention facilities, all of which are overcrowded and in physical disrepair. Segregation of other groups (e.g. the mentally ill) needing special attention, rehabilitation and reintegration programs, and programs for young offenders are either deficient or non-existent because of resource constraints and popular opposition to putting more funds into prison reform. 
8.19 Jamaica has faced a high and increasing level of violent crime for the past thirty years, with drug trafficking and organized gangs playing a major role. ${ }^{140}$ While crime has traditionally been highest in urban areas and especially in the inner-city slums of the Kingston metropolitan area, police contend that their anti-crime measures have forced criminals into rural areas where rates are rising as well. Prison crowding and public outrage are also increased by the delays in investigating and prosecuting criminal cases. The small court and prosecution systems are swamped, and the non-use of plea bargaining and alternative dispute resolution (ADR) for minor crimes tends to delay trials inordinately. While corruption, especially in the police, is sometimes blamed for the perceived failure to bring the guilty to justice, more important factors appear to be the inadequate numbers of judges and prosecutors, poor police and general system image, especially in low-income communities, and a consequent tendency for citizens to take more direct methods in hand (Darby, 2006). ${ }^{141}$ Poor community relations have been aggravated by what the government calls a "suppression of crime culture" originating in the 1974 Suppression of Crimes Act. The act gave the police extensive search and seizure powers without a warrant. Only repealed in 1993, it is said to have influenced an entire generation of police officers who felt empowered to act without due process constraints.

8.20 Over at least the past decade, the government has introduced a number of measures to improve overall efficacy and efficiency while eliminating abusive practices. Donors have been instrumental here, although also facing complaints of a failure to coordinate their own actions. Citizens and NGOs have also been invited to participate in these efforts. As regards expediting court cases, measures include the establishment of night courts, a drug court, and regional gun courts, as well as the expansion of the number of magistrates; the enforcement of the rule that Clerks of Courts (prosecutors in the Magistrates Courts) be attorneys, the inclusion of a trained court administrator in each court, training of stenographers for Magistrates Courts, a 2000 amendment to the Criminal Justice (Reform) Act of 1978 that allows judges to impose non-custodial sentencing options, a Criminal Justice (Plea Negotiation and Agreements) Act (2004) and, in civil justice, the development of new Procedures Rules, case management systems, and ADR mechanisms. The government proposes to extend the case management system to criminal cases as well. In January 2006, the cabinet announced a five-year program to reform the justice system, to coordinate its own actions as well as donor assistance. Although not legally mandated, both the courts and the DPP have begun to provide Parliament with periodic reports on their activities.

8.21 On the police side, the revocation of the Suppression of Crimes Act represents a first step. In 1999, the Police Public Complaints Authority (PPCA) was established. While functioning, it investigates only a fraction of fatal shootings by police, in a country with one of the highest rates of police killings in the Western Hemisphere. Amnesty International reports the PPCA head as saying that "he did not consider it appropriate or possible to hold the Jamaican police accountable to the same standards as other countries,

\footnotetext{
${ }^{140}$ A poll done by Stone Polls in August, 2006, found 64 percent mentioning crime as the most important problem, followed by joblessness (20.7 percent) and leadership (1.7 percent)

${ }^{141}$ As Darby notes, there are problems with police corruption as well, especially as regards collusion with drug gangs.
} 
due to the high level of gun-related crime in the country,” (Amnesty International, 2001). The government has also introduced a number of initiatives to partner with law agencies in other countries as a means of combating organized criminal gangs, improving security in marginalized communities by providing training to and facilitating partnerships with community members, strengthening border control of illegal drugs, creating community action committees to encourage community-based crime control, and creating a Police Civilian Oversight Committee. Like the reforms in the other sector agencies, most of these are too new to evaluate their chances of success or even sustained implementation.

8.22 Although sheer quantities of human and financial resources are often less of a problem than claimed, it would be hard to contend, given the levels of crime and violence, that they are not problematic in Jamaica. Existing resources might be more efficiently deployed and controlled, and there is certainly room for managerial and legal change to combat court delays. However, the low judge and prosecutor to population ratios (3.2 and 3.1 per 100,000 inhabitants as compared to the Dominican Republic's 7.0 and 8.0 respectively and a Latin American average for judges of 8.1), while characteristic of the English style common law system, seem inadequate to the existing challenges either in processing cases or detecting and prosecuting police malfeasance.

8.23 There is also an interesting lesson here for the Dominican Republic in the failure of Jamaica's accusatory system to meet citizen performance standards, especially since both countries currently confront complaints of uncontrolled police abuse, poor community relations, and low clearance rates for major crimes. Clearly an accusatory system does not resolve these problems automatically, and more direct actions must be taken.

\section{A QUANTITATIVE EVALUATION OF SYSTEM PERFORMANCE: PERFORMANCE STATISTICS AND INDICATORS}

8.24 The somewhat disappointing returns to many standard reform initiatives have prompted researchers, policy makers, and practitioners of legal and judicial reform to search for better ways of assessing the performance of justice systems and tracking progress in reform programs (World Bank, 2005b). Their universal conclusion is the need to improve the statistics collected by organizations on their own operations and to encourage the development of management information systems and their constant monitoring and analysis by those making organizational policy.

8.25 Management information systems can be used to: i) diagnose and measure the nature and scope of the initial workload (e.g., numbers and types of crimes reported); ii) evaluate the performance and operational effectiveness of individual institutions within the system (e.g., numbers of police investigations completed and of cases transferred from police to prosecutors, percentage of investigations or tried cases resulting in a conviction, recidivism rates upon release from prison, etc.); iii) determine whether the individual institutions in the system (police, prosecutors, judicial system, prisons) are 
working in alignment; ${ }^{142}$ and iv) identify the impact of the system on the broader objective of reducing crime and violence. They can also be used to develop a series of indicators to track the most critical outputs and impacts and to help outside observers understand and evaluate the reformers' efforts.

8.26 Indicators are best produced not by ad hoc efforts to measure outputs currently of interest, but through the routine registration of basic data on work processes by those carrying them out, and the transfer of key information to centralized databases where the data can be reviewed and analyzed for its broader implications. When the process is linked to the wide-spreading adoption of automated "case" files, it should not represent extra work for the front-line employees. Such systems, once in place, provide management a very potent tool for reviewing organizational performance and identifying and diagnosing problems. They also facilitate the creation of new indicators as they are needed.

8.27 The following sections draw on statistics currently recorded by the governments of the Dominican Republic and Jamaica to develop a series of comparative indicators on the performance of their criminal justice system. As the accompanying discussion suggests, the indicators are useful in signaling where problems may exist, but a full understanding of their significance and causes requires a contextual analysis of additional statistics and quite probably a review of the raw data on which they are based.

\section{MEASURING THE SYSTEM’s WORKLOAD: REPORTED OFFENSES}

8.28 The first of all variables that must be tracked is the workload that the criminal justice system experiences. While the uniformed police in particular undertake a variety of tasks that does not involve the processing of individual cases, the number of reported offenses is the single best indicator of systemic workload. This information can be used in tandem with knowledge of the resources required to process an average case to get a sense of whether current resources are proportionate to the scale of the problem.

8.29 Having a unified set of national statistics on crime is critical to understanding organizational performance and improving crime prevention interventions-recognizing, of course, that under-reporting may mean that only a small fraction of certain crimes will be reported. Unfortunately, the government of the Dominican Republic is unable to generate a unified set of national figures on the number of crimes recorded. The collection of information about offenses in the Dominican Republic is left to the separate agencies of law enforcement (such as the National Division for the Control of Drugs) and, within the national police, divided up by different divisions responsible for their

\footnotetext{
${ }^{142}$ Systemic alignment allows the disparate elements of the criminal justice system to work together in harmony. It, for example, would allow: i) the prosecution to reinforce and multiply the effectiveness of the police, rather than inadvertently undermining police actions; ii) the provision of services to victims of past crimes to improve citizens' confidence in the criminal justice system and hence contribute to the reduction of future crimes; and iii) the appropriate sentencing of those committed of crimes (youth facilities, prisons, alternative sentences, etc.) to maximize rehabilitation.
} 
investigation. Because these separate institutions use different language, frames, and reports to record these data, there is no clear national portrait of all crime. ${ }^{143}$

8.30 Jamaica, in contrast, aggregates information about all reports of crime in the department of statistics of the Jamaican Constabulary Force (JCF). The JCF receives reports from commanders in each parish and then sorts them into six categories of "major crimes." Unfortunately, at least according to one police official, the reliability of these figures is suspect. ${ }^{144}$ The Jamaican Constabulary Force had some 7,200 ranking personnel at the end of 2005 to deal with 1,674 murders, yielding a ratio of 4.30 officers per murder. ${ }^{145}$ For comparative purposes, in South Africa, there are some 120,000 police officers and 19,000 murders, for a ratio of six to one. ${ }^{146}$ In the Dominican Republic in 2005, there were about 26,000 police officers (Centro de Estudios de Justicia de las Américas, 2004-2005) and 2,400 murders in 2005, for a ratio of about 11 to one. ${ }^{147}$ While useful as a first approximation of workload, international comparisons of police/murder or police/population ratios are sometimes problematic. ${ }^{148}$

\section{Institutional Performance Measures}

\section{Police Performance Indicators: Clearance Rates for Homicide}

8.31 As in almost all countries, the police in Jamaica and the Dominican Republic routinely measure their "clearance" rate at which dockets leave their authority and become the primary responsibility of the prosecuting authority. ${ }^{149}$ This is a key performance indicator for both uniformed personnel and investigating officers, as both parties play a key role in gathering information and witnesses, and apprehending suspects. Acceptance of the case by prosecutors and judicial authorities indicates that the police have built a sound case. Police do not generally track the processing of the case through the justice system or otherwise monitor the rates at which arrests yield

\footnotetext{
${ }^{143}$ Within the national police, the function of analyzing crime and violence is greatly dispersed. Beneath the Office of the Chief of Police (Jefatura), there are a few data analysts as well as a Department of Statistics, along with a more recent creation, the Department of Mapping. The Division of Criminal Intelligence (DINTEL), formerly the Secret Service, has its own analytical unit and statistics division. The Division for the Investigation of Crimes (DICRIM) is supported by a Department for the Analysis and Processing of Information, but its subordinate operational investigative units, such as the Departments of Homicide, Robbery, and Auto Theft, also have their own data collectors and analysts. Each of these departments and operations, moreover, receives different quantities and types of information.

${ }^{144}$ Interview with senior police official.

145 This is below the official allocation of roughly 8,000 positions, an indication of accompanying recruitment problems.

146 http://www.saps.gov.za

${ }^{147}$ The Dominican government does compile national homicide figures, released through the office of the Attorney General.

${ }^{148}$ Differing distributions of types of crime across countries, different policing models (preventive vs. reactive, beat patrol vs. car patrol, etc.) mean that comparing ratios across countries is problematic. More fundamentally, the number of offenses reported is endogenous: improved police-community relations will result in more incidents reported to police and lower personnel to offense ratios, but this may be the result of good performance rather than an indicator of insufficient personnel and associated poor performance.

${ }^{149}$ The police consider a crime cleared if a person is arrested for the offense or if they conclude that the crime was committed by a person who subsequently dies. Some police forces also consider a crime cleared if they have named a suspect (usually in an arrest warrant) who has not yet been apprehended.
} 
convictions, as this largely depends on the activity of prosecutors. Of course, the police continue to play a role right up to the time of conviction, and therefore it is important that the performance of the system as a whole be monitored by a higher authority.

8.32 The national police force in the Dominican Republic does not track clearance rates for homicide separately from other crimes against the person (e.g., robbery, assault). Nevertheless, unpublished information compiled by the police about the number of reported violent crimes for which the police had made an arrest shows that in the last four months of 2005 and first month of 2006, the police recorded 1,643 "crimes against the person” and made arrests in 33 to 40 percent of such cases.

8.33 Analysts in DICRIM, the Division for the Investigation of Crimes, are trying to improve this indicator, for in its present form it does not distinguish between old and new cases (e.g., one cannot tell what portion of the 111 cases solved in September came from the 83 cases pending in August). They also hope to separate homicide from assault and robbery, which they suspect have lower rates of clearance, but they have yet to overcome the technical and administrative hurdles to such an assessment.

8.34 A more discriminating measure of clearance rates can be composed with data collected by the Statistics Department of the Jamaican Constabulary Force. Table 8.2 shows how this Department sorts reported homicides into categories by "motive" - that is, the circumstances which a police investigator or statistician considers to have caused the act of violence. ${ }^{150}$ It records clearance rates ("C/up") for each type of newly reported homicide. ${ }^{151}$ These vary from a low of zero in cases of drug-related murders in 2005, to a high of 83 percent for "other criminal acts” in the first six months of 2006.

Table 8.1: Homicide Clearance Rates in Jamaica by “Murder Motive,” 2005 and 2006 (January 1-July 16)

\begin{tabular}{|c|c|c|c|c|c|c|c|c|}
\hline \multirow[b]{3}{*}{ Murder Motive } & \multicolumn{4}{|c|}{2006} & \multicolumn{4}{|c|}{2005} \\
\hline & \multicolumn{4}{|c|}{ Clup } & \multirow[b]{2}{*}{ Reported } & & \multicolumn{2}{|c|}{ Clup } \\
\hline & Reported & $\%$ of total & $\mathbf{N}$ & $\%$ & & $\%$ of total & $\mathbf{N}$ & $\%$ \\
\hline Drug Related & 15 & $2 \%$ & 11 & $73.3 \%$ & 15 & $2 \%$ & 0 & $0.0 \%$ \\
\hline Gang Related & 159 & $22 \%$ & 44 & $27.7 \%$ & 224 & $24 \%$ & 61 & $27.2 \%$ \\
\hline Domestic & 22 & $3 \%$ & 14 & $63.6 \%$ & 26 & $3 \%$ & 18 & $69.2 \%$ \\
\hline Other Criminal Act & 335 & $47 \%$ & 278 & $83.0 \%$ & 423 & $46 \%$ & 260 & $61.5 \%$ \\
\hline Not Yet Established & 182 & $26 \%$ & 0 & $0.0 \%$ & 240 & $26 \%$ & 0 & $0.0 \%$ \\
\hline Total & 713 & $100 \%$ & 347 & $48.7 \%$ & 928 & $100 \%$ & 339 & $36.5 \%$ \\
\hline
\end{tabular}

8.35 As a measure of police performance, clearance rates are key. The job of detectives or judicial police is to build a prosecutable case against a suspect in each instance of serious crime they record. Of course, cases may emerge to be unfounded or

150 Mr. Barrett, the deputy director of the statistics department, explained that, in reviewing police reports of homicide and other crimes, the disparity between the reported facts of the case and the account of the investigator sometimes compels him to redefine the motive for the murder. Personal interview, July 17, 2006.

${ }^{151}$ A separate table tracks the number of murders from "previous years" that are cleared. 
the interests of justice may not support a prosecution, so clearance rates will never be 100 percent. Furthermore, "clearances" achieved at the scene of the crime-through witness identification, direct police observation, or even the death of the suspect-are weaker indicators of performance, since they are inflated by good fortune and violent confrontations. ${ }^{152}$ But given that the share of these "easy" clearances is not likely to vary over time, police can still strive to better the rate at which they handle the more difficult cases. $^{153}$

8.36 In order to give an assessment of how these clearance rates compare internationally that is fair to the police, additional information is required, including the number of active cases per homicide detective. In general, though, the overall homicide clearance rate in Jamaica is comparable to that in other countries with sound police forces and similar levels of economic development.

\section{External Accountability Measures: Complaints against the Police}

8.37 Of course, high clearance rates cannot be the only indicator by which the police are judged. Excessive zeal as well as baser motives can lead police to run afoul of the law, and success in combating crime must be leavened with respect for human rights. For this reason, it is essential that the number and nature of complaints against the police be tracked.

8.38 Complaints against the police are a mixed indicator. On the one hand, they reveal sometimes shocking misconduct, and the media coverage given to these events can undermine confidence in the system. On the other hand, they indicate that the public has sufficient faith in the system to report these offenses. Changes in the number of offenses recorded, particularly in periods of transition, could be more indicative of an increase in citizen awareness and participation in the complaints system than of real changes in the incidence of misconduct.

8.39 In Jamaica, two separate bodies collect complaints from civilians against the police: a Department of Internal Affairs within the JCF and the Police Public Complaints Authority (PPCA) within the Ministry of Justice. There is little public information about the work of either of these entities. Still, there are signs that the government of Jamaica is trying to improve their effectiveness as accountability mechanisms. The National Security Strategy for Jamaica, promulgated by the Ministry of National Security in May 2006, recommends that, as part of the strategic review of the JCF, there be an assessment that would "examine legislative and higher level administrative structures, such as the Police Services Commission (PSC) and Police Public Complaints Authority (PPCA), in

\footnotetext{
${ }^{152}$ Some police forces, including the JCF, consider a crime cleared if the suspect is killed. In nearly onequarter of the cases of robberies considered cleared by the JCF, the suspect had been killed by police officers or civilians.

${ }^{153}$ Additional refinements to the clearance rate could help the police promote equity in their policing and adherence to certain human rights standards. For example, police statisticians could develop a measure of equity by distinguishing between clearance rates in poor versus affluent districts-recognizing, of course, that factors beyond the police control in the short run such as problematic police-community relations may reduce clearance rates in poorer districts.
} 
order to facilitate an effective civilian oversight mechanism for proper accountability for its performance and conduct,” (Ministry of National Security, 2006).

8.40 In the Dominican Republic, the Office of Internal Affairs is charged with holding police accountable for misconduct. Its director is appointed by the President, not the Chief of Police, and thus enjoys some independence and autonomy. This office has an independent investigative capacity within its staff of 214, although its resources are stretched. It can initiate its own investigations as well as act on complaints it receives from the public. In the past, when this office recommended disciplinary proceedings against police officers, these were typically adjudicated by a police tribunal. Increasingly today, however, according to the new director, complaints substantiated by the office are brought before ordinary courts. ${ }^{154}$

8.41 Between August 2005 and May 2006, the period for which detailed information is available, the department received 637 complaints, an average of two per day. ${ }^{155}$ Nearly three-quarters of these complaints were substantiated through investigations, an extraordinarily high percentage for any country. Just over half of the complaints (319) involved allegations of physical aggression or death threats by officers. This indicator suggests both high levels of misconduct and good performance by the Office of Internal Affairs in holding individual police officers accountable to professional standards.

8.42 The office is currently designing a stronger information management system, which should improve both the reliability and the range of data available for performance measurement. If that new system were to include information (currently not recorded) about the complainants, it would allow the office to measure the equity in its own responsiveness, especially to poor and vulnerable groups.

8.43 In neither Jamaica nor the Dominican Republic do the formal accountability mechanisms reach beyond oversight of the police. There is no national justice commissioner or ombudsman for the receipt and investigation of complaints against other institutions in the criminal justice system.

\section{Prosecution and Adjudication Performance Indicators: Prisoners Awaiting Trial or Sentence}

8.44 The most common indicator for measuring prosecutorial performance is the rate of convictions. While a certain share of cases accepted from the police may be dismissed in the interest of justice, the decision of the prosecutorial authority to undertake the expense of a trial must be hinged on a belief that the accused is guilty and the case can be

\footnotetext{
${ }^{154}$ Interview with General Daisy Liriano.

155 In 2005, the department of internal affairs investigated nearly 7,000 matters of disciplinary and other infractions. It requested indictments for 123 officers, and submitted another 363 to the police tribunal to consider their suspension or removal from the national police force. In addition to this sum, 111 officers were suspended, and another 96 released from the force as a result of complaints of domestic violence, improper use of firearms, robbery, and other acts. See "Memoria Annual 2005," unpublished report, National Police.
} 
won. The number and nature of convictions therefore remain the primary measure of prosecutorial effectiveness.

8.45 But in addition to effectiveness, the efficiency and the equity of the prosecutor's work are key. Trial verdicts must be delivered as quickly as possible so that the innocent may be released and the guilty can undergo rehabilitation. Failure to do so has serious consequences, including overcrowding of prisons. As a result, the share of prisoners awaiting trial is a another key indicator of criminal justice system performance.

8.46 In countries where the system has collapsed, such as Haiti, as many as 80 to 95 percent of all inmates may be awaiting trial, (Vera Institute of Justice , 2006; National Center for State Courts and USAID, 2006) ${ }^{156}$ and the situation is nearly as bad in many parts of the Caribbean. Undue delays in the processing of cases are a violation of the human rights of prisoners awaiting trial. In addition, in countries like the Dominican Republic, where prison cells are seriously overcrowded, rehabilitation work becomes impossible, and again, human rights concerns emerge. It is thus essential that criminal justice systems strive to reduce the share of prisoners awaiting trial (see Clouatre, 2002). ${ }^{157}$

8.47 Good management statistics can help identify the problems and their sources and track the impact of reform measures. However, few courts, and neither of those surveyed here, currently capture sufficient statistical data on system-wide performance to permit this kind of analysis ${ }^{158}$. Thus, we are left with one global indicator, the percentage of unsentenced prisoners.

\footnotetext{
156 “Prolonged Pretrial Detention in Haiti”, July 2002 gives the lower figure. A recent study by the National Center for State Courts indicates that in Port-au-Prince, the numbers in 2005 approximated 95 percent, although nearly all the detainees faced charges for major felonies.

${ }_{157}$ There are several ways of doing this. One is to increase the efficiency of the prosecutorial process, which involves coordinating a wide range of criminal justice actors. The police must take the capacity of the justice system into account when engaging in discretionary arrests, such as those encountered in mass "sweep" operations. Judicial hours must be reasonable. (In many countries, judges sit for absurdly short hours each day due to entrenched traditions that have not responded to present-day reality. In Haiti, for example, the courts of first instances (Courts of Assizes) conduct hearings on serious felonies only twice a year, thereby extending pre-trial detention periods Court management (record keeping, scheduling practices) is important. The provision of pre-trial screening and legal reforms can allow for the release of many non-violent accused who would otherwise be held with no bail or with bail set beyond their means.

${ }^{158}$ Where adequate records are kept at the courtroom level, analysts can use case file samples to investigate potential problems - delays and their causes, differential treatment of parties or types of cases, and even signs of corruption. However, absent direct access to web-based, electronic files, this is time consuming and costly work. For an example, see World Bank, 2003, An Analysis of Court Users and Uses in Two Latin American Countries. Washington D.C: The World Bank, Report No. 269666
} 
Figure 8.1: Sentenced and Un-sentenced Prison Inmates in the Dominican Republic: May 2003 to May 2006

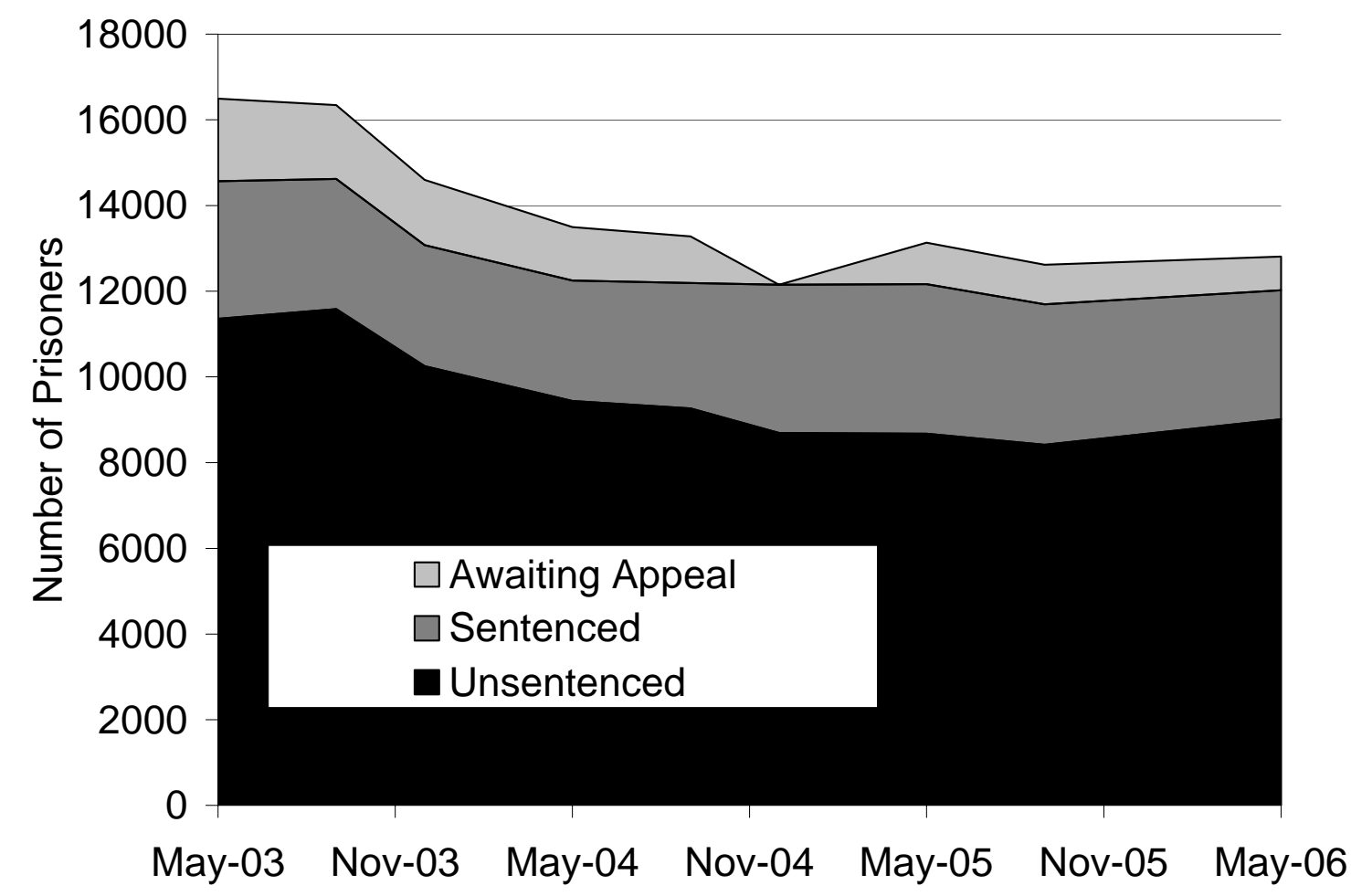

8.48 In the Dominican Republic between May 2003 and September 2004, when the new code of criminal procedure went into effect, the total population in custody declined from 16,491 inmates to 12,806 . As the Figure 8.1 shows, most of this reduction came from the ranks of unsentenced inmates and the number awaiting the outcome of appeals. ${ }^{159}$ From September 2004 through May 2006, however, there has been no major change in the number of inmates. The number of unsentenced prisoners initially declined, but then rose again toward the end of 2005; this group still comprises nearly 70 percent of all persons in custody. ${ }^{160}$

\section{Prison Performance Indicators: Escapes, Deaths, and Violence in Custody}

8.49 The role of the prison system is to prevent prisoners from committing crimes while in custody and to work toward their rehabilitation. The former goal is easily measured in the rate of escapes and the amount of violence in prisons. The latter, often summarized in some form of recidivism rate, is much more difficult to capture.

8.50 Figure 8.2 shows the indicators measured in the Dominican Republic, including deaths in custody and non-lethal violence. The indicators are difficult to interpret in this

\footnotetext{
${ }^{159}$ On average, another 100 to 140 inmates were in custody each day pending the ruling of a cassation court.

${ }^{160}$ Prisons in general are substantially over-crowded: the system has a legal capacity of just over 9,000.
} 
form because they show absolute numbers rather than rates per prison population. As seen in the earlier discussion of pretrial detention, the prison population in the Dominican Republic was substantially higher in 2003 than the stable level it maintained from 2004 through mid-2006. When recalculated as rates, the level of deaths in custody appears to be steadily increasing from 48 deaths per 10,000 prisoners in 2003, to 58 in 2004, and to 68 in 2005. The figures for the first five months suggest that the prisons may be experiencing their first decline in recent years, back down to an annual rate of 49 deaths per 10,000 prisoners. The prison administration does not report the reasons and circumstances of these deaths, so the relative contribution of crowding, illness, and violence to these problems cannot be determined.

8.51 The changes in the number of escapes (Figure 8.2) are perplexing whether or not these are calculated as rates. The huge annual swings in the numbers of escapes reported make any comparisons with other countries meaningless, since the security of the prisons will seem relatively loose or tight depending on the year. In 2006, there were 24 escapes in the first five months of the year. ${ }^{161}$

Figure 8.2: Prison Deaths, Escapes, and Recaptures, Dominican Republic

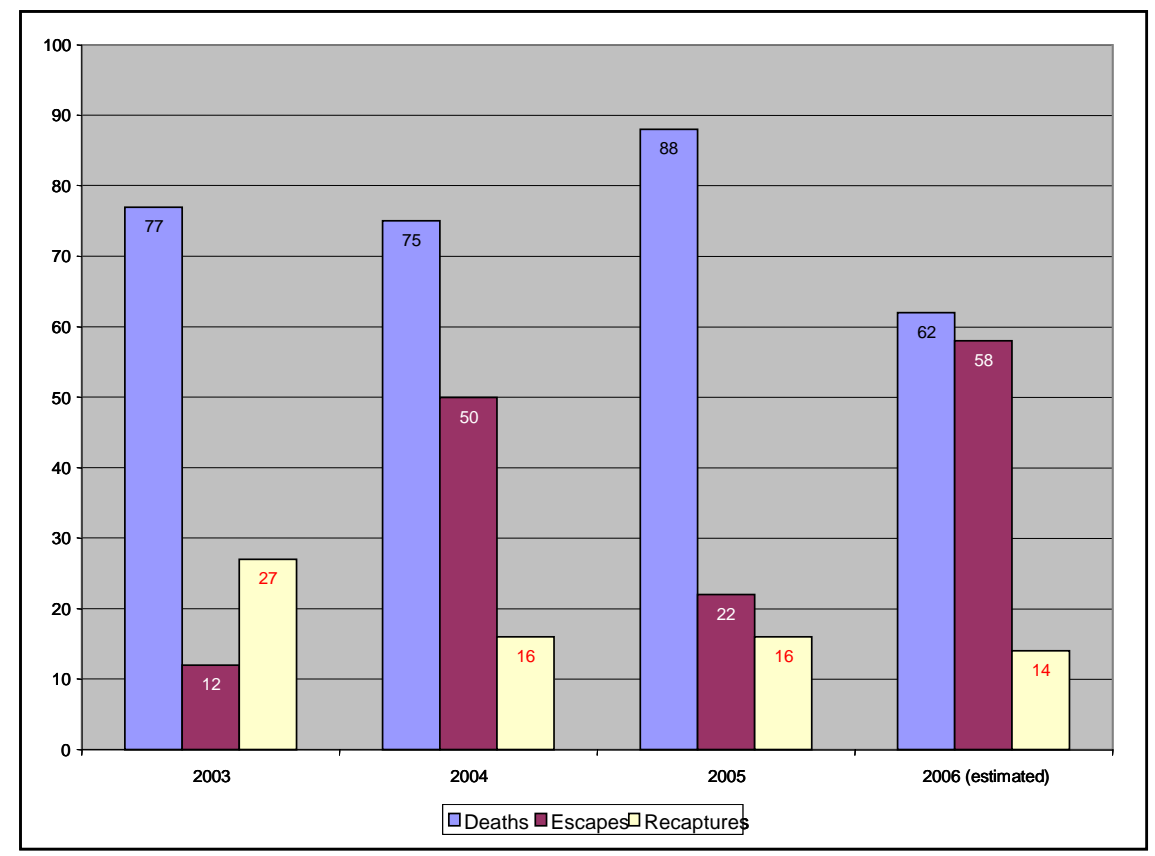

Source: Dirección General de Prisiones, Procuraduría General de la República

Notes: In 2005, an additional 138 inmates died during a fire. The estimate for 2006 is based on 26 deaths, 24 escapes, and 6 recaptures in the first five months of the year.

8.52 The Department of Correctional Services in Jamaica also tracks this kind of information with additional detail, including the level of non-lethal violence. The prisons in Jamaica report substantial reductions from five years ago in both the number of unnatural deaths and the number of violent incidents in custody (Figure 8.3). In 2001,

\footnotetext{
${ }^{161}$ The number of "recaptures" in 2003 exceeds the total number of escapes because of a large number of escapes in the preceding years.
} 
there were 17 unnatural fatalities out of a total of 33 deaths in prison. In 2005, there were 8 unnatural deaths out of a total of 20. In 2000, there were 153 violent incidents reported in adult institutions. This number decreased to 92 in 2005. The numbers of violent incidents appears to have increased in 2004 and again in 2005, but the Director of the Department of Correctional Services attributes this to better systems of reporting. There were seven escapes from prison in 2004, and none the following year, although a "massive escape" from the Tower Street facility was apparently foiled in $2005 .{ }^{162}$

\section{Figure 8.3: Unnatural Deaths and Violent Incidents in Jamaican Prisons, 2000-2005}

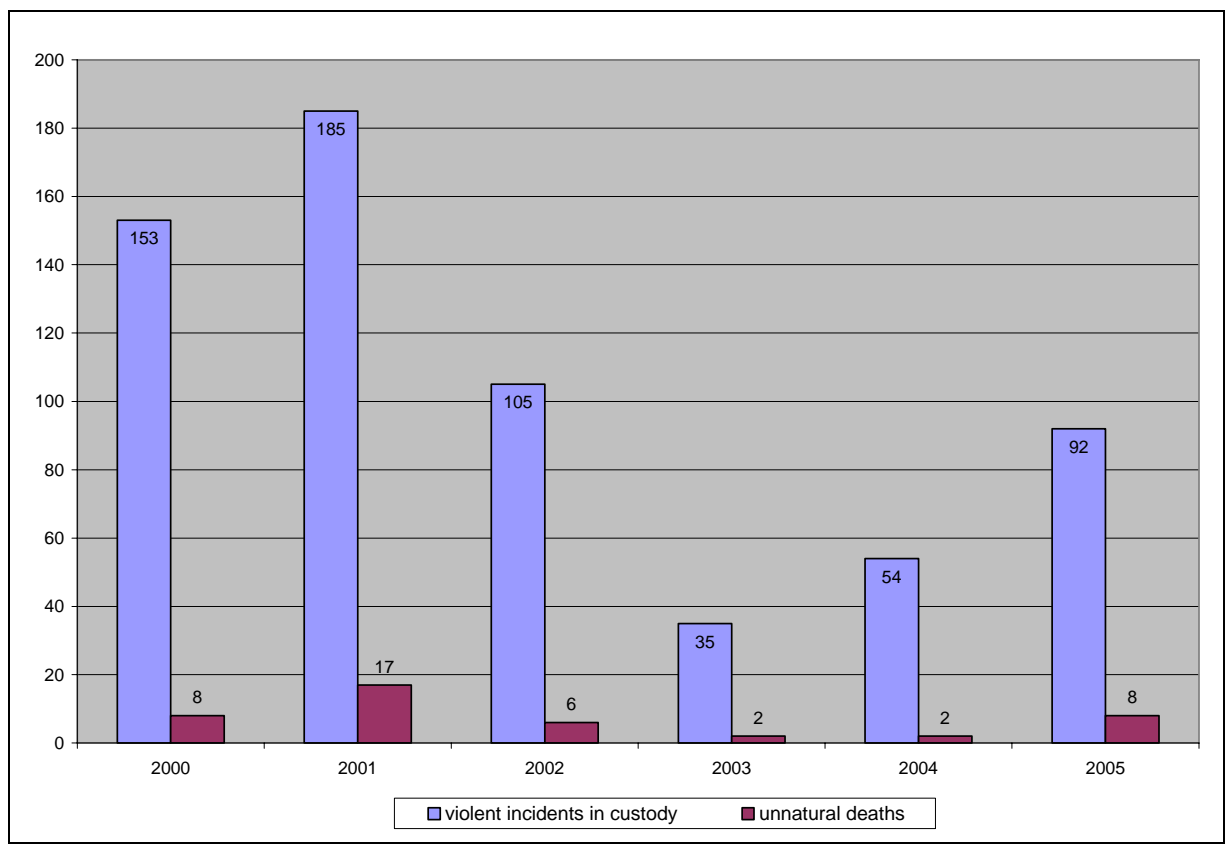

Source: Department of Correctional Services, Annual Report, 2005.

8.53 The Department of Correctional Services in Jamaica is eager to develop a wider range of indicators, including measures of recidivism. The Department is beginning to collect and report information on the number of persons admitted to prison who have previously been incarcerated. At first glance, an increase in this number might appear to reflect an increase in recidivism, but it is equally or more likely to reflect changes in the performance of other institutions of the system. For example, if increases in the numbers of police lead to increases in arrests, the numbers of prisoners with prior incarcerations should increase. If sentencing legislation is toughened, if prosecutors become more aggressive in their charging decisions or more effective at obtaining convictions, or if judges become more punitive in their sentencing, the result will be an increase in the number of prisoners with prior records of incarceration, even if recidivism remains flat. Perhaps most likely of all, if community surveillance of people returning from prison becomes more effective - as is occurring in almost every country - then returning prisoners will be especially vulnerable to re-arrest and re-incarceration, creating a false impression of rising recidivism.

\footnotetext{
${ }^{162}$ Some of this information is now available on the website of the Department of Correctional Services, http://www.dcsj.net/p/stats.htm
} 
8.54 A better measure, and one more widely used globally, is the percentage of prisoners released in a particular year who are re-admitted within three or five years. This indicator is also ambiguous-responsive to enforcement efforts as well as changes in actual criminal conduct by released prisoners-but it is better than the alternatives. Moreover, it could be calculated by the Department of Corrections on its own, once it puts in place record systems that accurately identify new persons admitted with their prior records.

8.55 Even better, however, would be systems that track the re-arrest of released prisoners, or surveys that capture the experiences of released prisoners in much shorter time periods. Such data, focusing on recidivism in the first month, quarter, and year after release, would allow officials and prevention programs to identify some of the proximate causes of re-offending.

\section{IMPACT INDICATORS: USING CRIME AND ARREST DATA FOR CRIME PREVENTION}

8.56 The discussion above has shown that the Dominican Republic and Jamaica, while making serious efforts to improve, still have a way to go in improving their performance measurement and the basic functioning of their criminal justice systems. The systematic collection of performance statistics, the generation of key indicators, and benchmarking for improvement should become a routine part of criminal justice system management, and performance against these indicators should be published and used as part of the budget allocation process. These figures should also be made available at the precinct level, so that local constituencies can hold their public servants accountable.

8.57 Could the criminal justice systems in these two countries be doing more to reduce crime and violence? That question necessitates looking beyond the indicators discussed above and delving more deeply into the mechanisms by which the activities of the justice sector actually contribute to reductions in crime and violence. In countries around the world, officials are asking themselves such questions, producing a global shift of strategic thinking within criminal justice.

8.58 More sophisticated indicators must capture the extent to which the criminal justice system acts proactively to eliminate the proximate causes of crime and violence. Such a criminal justice system would analyze crime patterns and use arrest powers strategically.

\section{Measuring and Understanding Crime: Analyzing Crime Patterns}

8.59 Officials in the Dominican Republic are experimenting with ways of using the data that allow them to see more deeply into the proximate causes of crime that law enforcement might then target. Specifically, the police in the Dominican Republic are beginning to track the level, timing, and movement of crime as part of the Barrio Seguro Program, using digitalized maps and census data from the National Office of Statistics (see Box 8.1 for a description of the Barrio Seguro Program.) An initial draft of a "calendar of crime," prepared by the Unit for the Analysis and Processing of Information within DICRIM, records the time and days in which offenses committed in public in each 
of the neighborhoods tend to occur (Secretary of the State of Interior and Police of the Dominican Republic). ${ }^{163}$

8.60 These efforts to measure and understand crime are promising not only because the police can adjust the frequency, routes, and number of officers on patrol in response to this analysis, thereby increasing the efficiency of deployments, but also because the public can use this knowledge both to avoid victimization and to more effectively participate in efforts to reduce crime.

\section{Measuring Impacts of Specific Criminal Justice Instruments: Reducing crime by using arrest powers strategically}

8.61 Because the police often conceive of arrest as the end of their work, prosecutors and courts see it as the beginning, and the work of managers of jails and prisons can be burdened by unnecessary arrests, governments need impartial assessments of the systemlevel impact of arrest on crime and justice.

8.62 Based on data supplied by the police, it is possible to estimate that there currently are between 50,000 and 55,000 arrests each year in the Dominican Republic. Few of these roughly 50,000 annual arrests are pursued further by the justice system. According to data from the Ministerio Público, judges granted 12,237 requests to continue an arrest in the twelve month period of September 2004 to August 2005. In 5,318 of these instances (43.4 percent), a judge later ordered the suspect held in pretrial detention pending the outcome of trial. ${ }^{164}$ Beyond this, very little can be said as the government does not track the proportion of people arrested who were later held accountable for their behavior by the justice system.

8.63 The use of arrest powers by the police in the Dominican Republic, in short, is not typically followed by prosecution and even less likely to be followed by imprisonment. From a crime reduction perspective, this might be a good thing. If serious crime is reduced in areas where such stops are made, the police may be making an important contribution to public safety. Moreover, if the police are conducting stops within the law, and if the consequences for those stopped are brief and bearable, then the police may be using arrest powers in ways that reinforce the rule of law. However, to ensure this is the case, there need to be systems in place to verify that arrest powers are being used efficiently and within the law.

\footnotetext{
${ }^{163}$ These efforts are being supported by a partnership between John Jay College of Criminal Justice and the Secretary of the State of Interior and Police of the Dominican Republic. See the report on the website of the Ministry, www.seip.gov.do/2006/web/acuerdos documentos.php

${ }^{164}$ The Supreme Court is in the process of installing a system by which to track the number of requests for arrest and detention that are granted by the judiciary. Personal Communication with Nestor Borroa, Department of Statistics, Supreme Court of the Dominican Republic.
} 


\section{Box 8.1: Using Crime Data and Analysis to Formulate a Multi-Sectoral Crime Prevention Strategy: the Barrio Seguro Program in Capotillo}

In July 2005, the government of the Dominican Republic launched the Democratic Security Plan (Plan de Seguridad Democratica). This plan was prepared by the Secretary of Interior and Police, the National Police and the Office of the Attorney General with the support of the Inter-American Institute of Human Rights, the John Jay College of New York, the University of Florida and Newlink Political Consulting firm. The Plan includes both preventive and control measures to reduce crime.

The Plan established specific objectives based on the diagnosis of the security problem in the Dominican Republic. Based on a situational analysis and after identifying the cities/barrios with the highest level of crime, a pilot plan called Barrio Seguro (Safe Neighborhood) was implemented in Capotillo with the intention to both reduce and prevent crime.

Capotillo, compared to seven other crime-affected neighborhoods in the National District, had recorded the highest levels of incidents related to drug trafficking, street delinquency, armed robbery, organized crime and gangs, as revealed by background analysis for the Democratic Security Plan. From January to August 2005 there were 30 homicides recorded in Capotillo; this is equivalent to an annualized homicide rate of 118 per 100,000 residents. The inability of the police to control crime in Capotillo had led to deterioration in public confidence: only $17 \%$ of the population believed that the police was doing a good job, and $80 \%$ of the population considered the police to be corrupt.

Barrio Seguro was designed on the basis of data reported in the Democratic Security Plan. The program began in August 2005 and key interventions included:

- Increased police patrols in 30 previously identified hot spots.

- The addition of 230 specially trained police to patrol Capotillo. They were equipped with 3 new vehicles and 14 motorcycles for street patrol, as well as with a refurbished police station.

- Situational crime prevention measures included infrastructure improvements to: i) facilitate access to and exit from the area; ii) provide street lighting; and iii) create new recreational areas for public use.

- Investments targeting youth included: construction of new classrooms and development of cultural workshops and sports clinics.

- General prevention programs included literacy programs and civic educational promoted by the office of the First Lady through its Progresando Program which is targeted to educate and help single mothers and their children.

In total, the government allocated RD $\$ 46$ million pesos (US\$1.4 million) to execute the Plan in Capotillo.

Barrio Seguro began to demonstrate positive results in Capotillo after only two months. Assaults and robbery declined 85 percent between early August and the end of September, 2005. No crime-related death was reported in this two-month period.

From January to August 2006, there were 9 homicides in Capotillo, compared to 30 registered during the same period in 2005-a 70 percent reduction. The success of the Plan in Capotillo inspired its replication in 12 other neighborhoods, beginning in January 2006.

While it is too early to definitively categorize Barrio Seguro as a success story (the project has not yet been subject to a rigorous impact evaluation), the approach is promising. It incorporates many principles that have shown to be effective internationally: i) complementarity between prevention and control initiatives; ii) policing focusing on hot spots and based on quantitative data on crime patterns; iii) use of situational crime prevention measures; and iv) involvement of the community and civil society organizations. 
8.64 Specifically, two features of the arrests raise concerns. Only a small proportion is reviewed by prosecutors or scrutinized by courts, and the stops themselves are not subject to independent oversight. A modern justice system that relies on stops and arrests for minor offenses to suppress crime still needs a means to assure that the police are acting within the law in their interactions with the public. Equally important, the impact of these stops and arrests on crime is uncertain, for the police do not yet analyze whether their stops are followed by a reduction of crime in the immediate vicinity of the police actions.

8.65 In the case of Jamaica, it is possible to provide a superficial analysis of the relationship between arrest and reported crime. In 2005, according to police data, there were 15,746 arrests in Jamaica. In the same year, there were 8,461 reported "major" crimes - murder, shooting, rape, carnal abuse, robbery, burglary, larceny. There were, in other words, nearly twice as many arrests as major reported crimes. This ratio suggests that the Jamaican police are using arrest powers to deal with many "minor" offenses. ${ }^{165}$

8.66 In Jamaica, there is reason to worry that the use of arrest powers is not strategically targeted on high crime areas. The overwhelming majority of arrests in Jamaica took place in "rural" regions - that is, outside the metropolitan area where nearly half the population resides. The name "rural" may be misleading, since many rural areas have urban centers with populations over 100,000. Still, 72 percent of all arrests took place outside the metropolitan area, while 57 percent of all major crimes were reported inside the metropolitan area. ${ }^{166}$ It is possible that recorded crime is lower outside the metropolitan area precisely because arrest powers are used so vigorously; alternatively, it is possible that crime is heavily under-reported in "rural" areas, or, as police now claim (see above) that urban criminals have been driven outside the major cities. Still, this anomaly calls out for further investigation.

8.67 A third way to measure the strategic use of arrest powers is to examine the relationship of arrests to imprisonment. This calculation can be made in both Jamaica and the Dominican Republic. In Jamaica in 2005, the average daily prison population was reported as 3,982, approximately one-fourth of the number of annual arrests. In the Dominican Republic that year, the prison population was 12,858 , or roughly the same ratio to arrests as in Jamaica. Again, these ratios could indicate that arrests are being used to manage crime in many cases wholly apart from penal sanctions. This use of arrest powers to manage crime directly, rather than merely to take an offender the first step on the way to prison, is increasingly considered a sign of good police strategy if it is targeted, measured for its effect on crime, and reviewed by an independent authority (Weisburd and Braga). It is important that these steps be taken in the Dominican

\footnotetext{
${ }^{165}$ For example, state and local police departments in the United States in 2004 cleared 62.6 percent of murder offenses, 55.6 percent of aggravated assaults, 41.8 percent of forcible rapes, and 26.2 percent of robbery offenses. The data for major property crimes showed that agencies cleared 18.3 percent of larcenytheft offenses, 13.0 percent of motor vehicle theft offenses, and 12.9 percent of burglary offenses.

${ }^{166}$ The data on recorded crimes and police arrests comes from the Department of Statistics of the Jamaican Constabulary Force, which generously shared information and insights about crime analysis and problem identification.
} 
Republic and Jamaica, especially in light of local critics' contention that such practices serve other, less desirable purposes. ${ }^{167}$

\section{CONCLUSION: FROM ORGANIZATIONAL REFORM AND PERFORMANCE MEASUREMENT TO INTERAGENCY GOVERNANCE}

8.68 In both case study countries and throughout the Caribbean, the on-going organizational reforms and stepped-up efforts to measure performance will require concerted attention over the near to medium term. However, to achieve their broader goals, the reforms will also require inter-agency governance mechanisms and incentives for individual agencies to align their individual programs. If sector-wide governance mechanisms are to succeed, their authority must go beyond performance monitoring to include real executive powers. ${ }^{168}$ The recent history of police and justice reforms in both Jamaica and the Dominican Republic illustrates this need.

8.69 Today, both governments are poised to introduce better instruments of interagency governance. In December 2005 and again in May 2006, the Ministry of National Security of Jamaica disseminated for public comment a green paper on public safety, in which it proposed, among other things, to locate responsibility for the implementation of such a strategy in the office of the Prime Minister (Ministry of National Security, 2006). ${ }^{169}$ In July 2006, the President of the Dominican Republic decreed the establishment of a National Security Council, whose job is to "plan, produce, coordinate, and evaluate the use of inter-institutional information for the prevention of crime.”170

8.70 The plans for the Security Council in the Dominican Republic are more advanced than in Jamaica, and yet its success is not assured. In order to succeed, the new National Security Council will need a staff and other resources that make it a real instrument of governance, as well as a composition that does not simply represent the leadership of individual agencies or repeat membership on other inter-governmental committees. It will also need special skills to ensure the alignment of criminal justice system statistics and indicators and to coordinate efforts to prevent crime.

8.71 Finally, in both Jamaica and the Dominican Republic, innovations in governance should look beyond the criminal justice system for assistance in crime prevention. Victim services, indigent defense, addiction treatment, other public health services, and youth programs might all be brought together in the service of reducing crime and violence.

\footnotetext{
167 See Bobea, op cit. As Bobea's article predates the new Dominican police law, which she helped to promote, there may have been positive changes since its enactment. However, considering long-standing, and well-documented abuses in that country, the introduction and careful monitoring of a more strategic and transparent approach to the use of arrests would seem especially essential.

168 An example of sector-wide coordination currently limited to performance measurement is the role played by the National Commission for the Coordination of the Reforms in Chile. For a discussion of these challenges, see Measuring Progress Toward Safety and Justice: A Global Guide to the Design of Performance Indicators Across the Justice Sector, Vera Institute of Justice, 2004. www.vera.org/indicators

169 The non-government organization, Jamaicans for Justice, released a parallel strategy paper, "Road Map to A Safe and Secure Jamaica,” whose preparation was supported by an opposition leader.

${ }^{170}$ For a report of the decree, see www.presidencia.gov.do/frontend/articulo.php?id=4225
} 
Governance structures need to be created to manage these efforts as part of a coordinated crime prevention strategy. 


\section{GUNS AND CRIME: A CASE STUDY OF TRINIDAD AND TOBAGO ${ }^{171}$}

The rise of crime in the Caribbean has been characterized by the increased use of more powerful weapons, resulting in higher mortality levels. In 2004, Trinidad and Tobago experienced 160 firearm murders in 2004, 450 firearm woundings and 1500 non-injury firearm incidents. A major factor contributing to the surge of guns-related criminality in the region is the trafficking of narcotics which has facilitated the availability of firearms. The firearms required for protection of the contraband during transportation are smuggled in along with the drugs. Within these environments which promote the demand for weapons, reducing gun ownership is a difficult undertaking. Better gun registries, marking and tracking can help, as can improved gun interdiction in ports. In the long term progress will hinge on changes in the drug trade, changes in the gun culture, and progress in the implementation of international treaties and agreements on Small Arms and Light Weapons.

9.1. As violence has increased in the Caribbean, so too has the use of firearms. Increasingly, more powerful weapons are being used, resulting in higher mortality levels. The Caribbean has a long history of smuggling, and, as in the past, firearms are used in the transportation of illegal goods. "Guns and the illegal trade in drugs have formed a symbiotic relationship which has seen the emergence of increasing violence throughout the communities regionally" (WINAD, 2006). This chapter describes the situation in the Caribbean with respect to guns, crime, and violence. Trinidad and Tobago was selected as a case study, as it has seen a particular sharp rise in firearm-related violence over the last few years.

9.2. The CARICOM Regional Task Force on Crime and Security recently commissioned a report on the proliferation of small arms and light weapons (SALW) in the Caribbean (CARICOM, 2002). The resulting report identified three levels of SALW proliferation in the region: countries with established high levels and patterns of armed crime (Jamaica); countries with emerging high levels of armed and organized criminality (Guyana, Trinidad and Tobago); and countries with indications of increased use and availability of small arms (Antigua and Barbuda, Barbados, Dominica, Grenada, St. Kitts and Nevis, Saint Lucia, St. Vincent and the Grenadines).

9.3. At that time, it was determined that, among CARICOM countries, only Jamaica fell in the first category, with indications that military-type weapons were available and that paramilitary units were operating (Burrows and Matthias, 2003). If such an evaluation were done today, Trinidad and Tobago might also be included in this tier, as the murder rate has doubled since 2002. With 160 firearm murders in 2004, these were just the tip of the iceberg with above 450 firearm woundings and 1,500 non-injury firearm incidents. ${ }^{172}$

\footnotetext{
${ }^{171}$ This chapter is based on a background paper prepared by Yvette Holder, consultant.

${ }^{172}$ Crime Reports from the Trinidad and Tobago Police Service.
} 
Figure 9.1: Distribution of Injury Deaths by Type of Injury: Trinidad and Tobago, 1999-2003

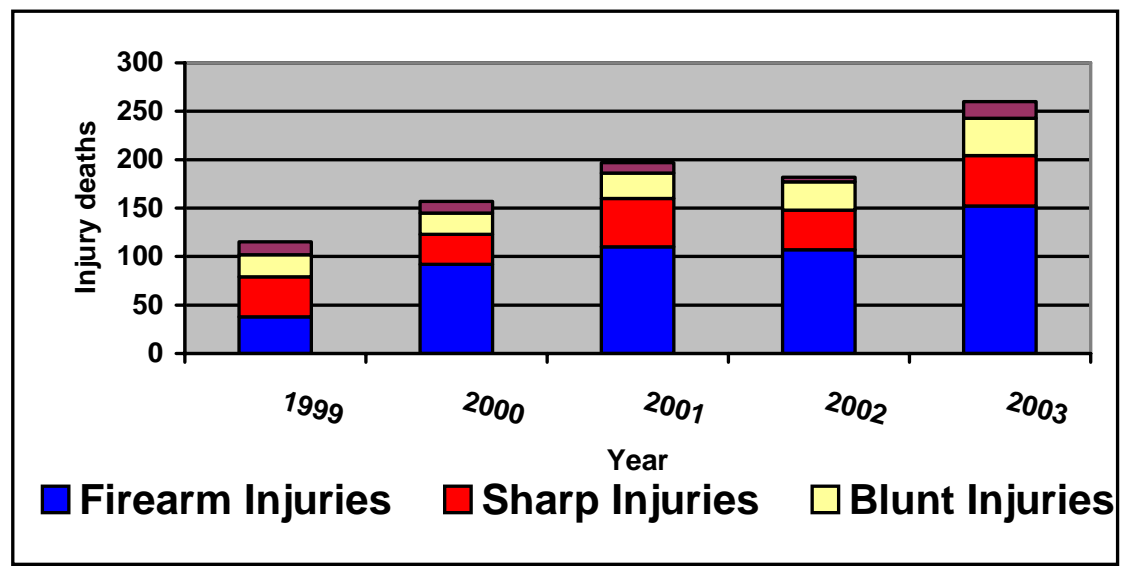

Source: Central Statistical Office, Trinidad and Tobago.

9.4. For many countries of the English-speaking Caribbean, the majority of assaults and homicides were committed in past years with blunt or sharp weapons. The trend toward increased use of firearms in the commission of crime began in the 1970s in Jamaica, so that a court was established in 1974 solely dedicated to gun-related matters. In Trinidad and Tobago this change began in 2000. Before 2000, firearms were responsible for less than one-third of all homicides. By May 2006, this percentage had risen to 74 percent (see Figure 9.1 and Table 9.1). The percentage of homicides attributed to firearms in Trinidad and Tobago lies well within the range of rates of 60 percent to 93 percent seen in Latin America (Guerrero, 1998).

9.5. The share of woundings committed with a firearm has actually decreased as the number of murders with firearms has increased. This is likely a reflection of the increasing lethality of weapons used (see Table 9.2).

Table 9.1: Murders Committed in Trinidad and Tobago Using a Firearm, 2001-2006

\begin{tabular}{cccc}
\hline Year & $\begin{array}{c}\text { Number of Murders } \\
\text { Committed with Firearms }\end{array}$ & $\begin{array}{c}\text { Total Number } \\
\text { of Murders }\end{array}$ & $\begin{array}{c}\text { Percent Murders } \\
\text { Committed with Firearms }\end{array}$ \\
\hline 2001 & 82 & 151 & 54 percent \\
2002 & 102 & 172 & 59 percent \\
2003 & 158 & 229 & 69 percent \\
2004 & 182 & 259 & 70 percent \\
2005 & 273 & 386 & 71 percent \\
Jan-May 2006 & 123 & 166 & 74 percent \\
\hline
\end{tabular}

Source: Modus Operandi, Trinidad and Tobago Police Service 
Table 9.2: Woundings Committed in Trinidad and Tobago Utilizing a Firearm, 2000-2005

\begin{tabular}{ccc}
\hline Year & $\begin{array}{c}\text { Total Number } \\
\text { of Woundings }\end{array}$ & $\begin{array}{c}\text { Percent Woundings } \\
\text { Committed with Firearms }\end{array}$ \\
2000 & 383 & 53 \\
2001 & 470 & 43 \\
2002 & 649 & 49 \\
2003 & 790 & $\mathrm{n} / \mathrm{a}$ \\
2004 & 615 & 40 \\
2005 & 724 & 40 \\
\hline
\end{tabular}

Source: Modus Operandi, Trinidad and Tobago Police Service.

\section{SOURCES}

9.6. There are several sources for these firearms. They may be diverted from legal owners in the country, or they may be purchased overseas (legally or illegally) and smuggled into the country. Diverted weapons come from both private owners and the protective services. In Trinidad and Tobago, authorized users of legal arms are robbed and sometimes killed for their weapons. Army and police guns go missing at intervals, and weapons that are stored at police stations for safe-keeping, especially those whose owners may be deceased, are also targets for diversion to criminal use. It is believed, however, that diverted firearms are not the main source of weapons involved in crime. That role is filled by weapons smuggled into the country (Holder, 2006).

9.7. Smuggled firearms are sourced from South and Central American manufacturers of light arms, among others. Suppliers are from Brazil (which is licensed to manufacture Beretta, Colt, and Taurus makes); Venezuela (Smith \& Wesson); Mexico; and the Dominican Republic (Klare and Anderson, 1996). These countries all make firearms for domestic sale and for export, ostensibly to governments and licensed private owners.

9.8. Weapons manufactured or otherwise available in South America are smuggled through Venezuela, Suriname and Guyana to Trinidad and Tobago via fishing vessels and private pleasure boats. Some proceed to the United States and Europe, all part of the northward shipping of contraband. Weapons from the United States and Canada are transported southward in the shipping of the proceeds from the sale of illegal drugs. ${ }^{173}$

9.9. Guns and other weapons are also available from disbanded guerrilla troops in post-conflict situations. Some of these are weapons that were supplied covertly two decades ago by the Cold War powers to friendly insurgents in the region. Within the Caribbean region, there is a stock of weapons surplus from previous armed conflict such as the Grenada intervention. Other countries with armed instability such as Haiti,

173 Certain established routes have been defined (Burrows and Matthias, 2003). These are: Jamaica southwards through the Caribbean island chain; Guyana/Trinidad and Tobago northward through the same chain; St. Lucia - St. Vincent and the Grenadines - Martinique triangle, and; St. Maarten - Antigua - St. Vincent and the Grenadines. 
Nicaragua and Guatemala can also be source and destination countries for the supply of illegal arms.

9.10. Another major source of firearms is the United States, the world's leading manufacturers of arms. Production, sale and exports of all arms from the United States are subject to a variety of laws and regulations which govern the conditions under which the sales may occur and stipulate the use to which firearms may be put, even when transferred to a third party. These laws and regulations pose few or no obstacles to those wanting to buy a handgun, and unevenly enforced export regulations have made the U.S. a major supplier of illicit arms to Latin America and the Caribbean. Latin American governments report that more than half of all unlawfully acquired firearms were of U.S. origin (Klare and Anderson, 1996).

9.11. One of the main strategies employed by arms traffickers to procure guns is the use of "straw purchasers." These are acquaintances, relatives or persons hired to purchase guns in the United States from gun dealers, at gun shows or directly from manufacturers. ${ }^{174}$ Larger orders are sometimes procured through use of counterfeit importation certificates, with the involvement of gullible or corrupt local government officials of the transit country. Trading on the knowledge that end-use checking is sloppy, these shipments are procured for an apparently legitimate use and then forwarded to a third country. Guns thus obtained become part of the stockpile of weapons available on the black market.

9.12. Finally, there are also cases of persons purchasing firearms at a gun shop in a foreign country and bringing them into the country undetected among luggage. Guns so purchased may or may not be licensed and registered for use in the destination country.

9.13. All of these guns, procured from the above-mentioned sources and by the various mechanisms, contribute to the stockpile of circulating illicit firearms. However, due to poor forensic investigation of firearm-related crimes and non-existent tracking of firearms, it is not possible to know what contribution each of these sources makes to the problem of guns and criminality in Trinidad and Tobago.

\section{REGISTRATION OF FIREARMS AND SEIZURES OF ILLEGAL WEAPONS}

9.14. In Trinidad and Tobago, the Organized Crime, Narcotics and Firearm Bureau (OCNFB) was established in 2004. Under the Firearms Act, the Commissioner of Police is empowered to keep a national Firearms Register, although the actual existence of this database is unclear.

\footnotetext{
${ }^{174}$ Attention has focused on a group of Californian handgun manufacturers-including Jennings, Bryco and Lorcin - whose weapons have been implicated in many violent crimes in the U.S. and whose security arrangements are said to have been questionable. The weapons, mainly $9 \mathrm{~mm}$ and more recently .38 pistols are available, affordable (approximately US\$ 50), small enough to be easily concealed but lethal. Wintemute, G. "Ring of Fire: The Handgun Makers of Southern California.” Davis, California. http://www.pbs.org/wgbh/pages/frontline/shows/guns/ring/companies.html
} 
9.15. Seizures of firearms by the police and, more recently, the Organized Crime, Narcotics and Firearm Bureau have risen from 132 in 2000 to 199 in 2005 (Table 9.3). It is not clear whether this increase is due to increased enforcement efforts or to a greater supply of illegal weapons.

9.16. The vast majority of the weapons seized are the $9 \mathrm{~mm}$ pistols and .38 revolvers commonly used by criminal groups everywhere. Military weapons are rare. The seized weapons are disposed of according to the direction of the Magistrate presiding over the case. They may be returned to circulation either as additions to the Police armory or auctioned. This adds to the fluidity of the legal status of weapons and makes the need for identification and tracking even more critical.

Table 9.3: Firearm Seizures in Trinidad and Tobago

\begin{tabular}{cccc}
\hline Year & $\begin{array}{c}\text { Firearms } \\
\text { Confiscated } \\
\text { by Police }\end{array}$ & $\begin{array}{c}\text { Firearms seized } \\
\text { by the OCNFB }\end{array}$ & $\begin{array}{c}\text { Ammunition seized } \\
\text { by the OCNFB }\end{array}$ \\
\hline $\mathbf{2 0 0 0}$ & 132 & & $\ldots$ \\
$\mathbf{2 0 0 1}$ & 138 & $\ldots$ & $\ldots \ldots$ \\
$\mathbf{2 0 0 2}$ & 146 & $\ldots$ & 1215 \\
$\mathbf{2 0 0 3}$ & $179($ Sept 15) & $\ldots$ & 1592 \\
$\mathbf{2 0 0 4}$ & Not available & 73 & 238 \\
$\mathbf{2 0 0 5}$ & 175 & 24 & $\ldots$ \\
\hline Jan-Mar. 2006 & Not available & 9 & $\ldots$ \\
\hline
\end{tabular}

Source: Modus Operandi, Trinidad and Tobago Police Service.

\section{DEMAND}

9.17. Understanding the epidemiology of guns and criminality, is clearly useful in design interventions and monitoring their effectiveness. One way to do this systematically and thoroughly is through the use of a tool used in determining risk of injury: Haddon's matrix (Haddon, 1972). The matrix examines the characteristics of persons involved in gun-related crime, the instruments or vectors/agents, and the physical circumstances and socio-economic factors that contribute. The analysis is conducted along a temporal axis for each component, looking at the factors that pre-dispose, those that facilitate during the event, and those that hinder recovery after the event.

9.18. The application of the matrix to gun-related crime and the issues that may affect it are illustrated in Table 9.4. The discussion below will focus on some of the principal risk factors for hosts (young men of low socio-economic status); the physical and social environment (ghettos, garrison communities and gun culture); and agent/vector (drug trafficking and gun-related criminality).

\section{VICTIMS, PERPETRATORS AND THEIR ENVIRONMENT}

9.19. Across the region, certain characteristics are common to both perpetrators and victims in gun violence. Research conducted in Latin America and the Caribbean shows 
that the majority of victims and perpetrators of violence are young men of low socioeconomic status, with a low level of education and poor prospects for income generation, who have witnessed violence at close range. These findings are consistent with those from a study that showed the effects of socio-economic status, educational levels, family functioning and exposure to violence on levels of aggression and delinquency in Jamaican children (Samms-Vaughan, 2000). In Trinidad and Tobago, more than half (59 percent) of the victims of fatal firearm assaults were males aged 15-34 years.

9.20. Across the hemisphere, the communities from which at-risk persons originate and in which the acts of gun-related criminality tend to be concentrated bear many similarities. Called "ghettos" in North America, barrios marginales, villas miseria, barrios callampa, pueblos jovenes or favelas in Latin America (depending on the country) and "garrison communities" in the Caribbean, they tend to be urban, densely populated and underserved, with lower than national levels of most social indicators and standards of living. The term "garrison community", originally described the urban enclaves of violence such as Trench Town in Jamaica, which supported the competing political parties in the 1960s and 1970s. Now it refers to those communities where poverty and violence combine to produce a space of high levels of personal insecurity for community residents (WINAD, 2006). Not only in Jamaica, but also in Guyana (Buxton) and Haiti (Cite Soleil) as well as in Trinidad and Tobago (Laventille), these communities are the foci of crime and violence.

\section{Figure 9.2: Police Reports of Narcotics Possession and Murders, and Certified Firearm Homicides, Trinidad and Tobago, 1992-2005}

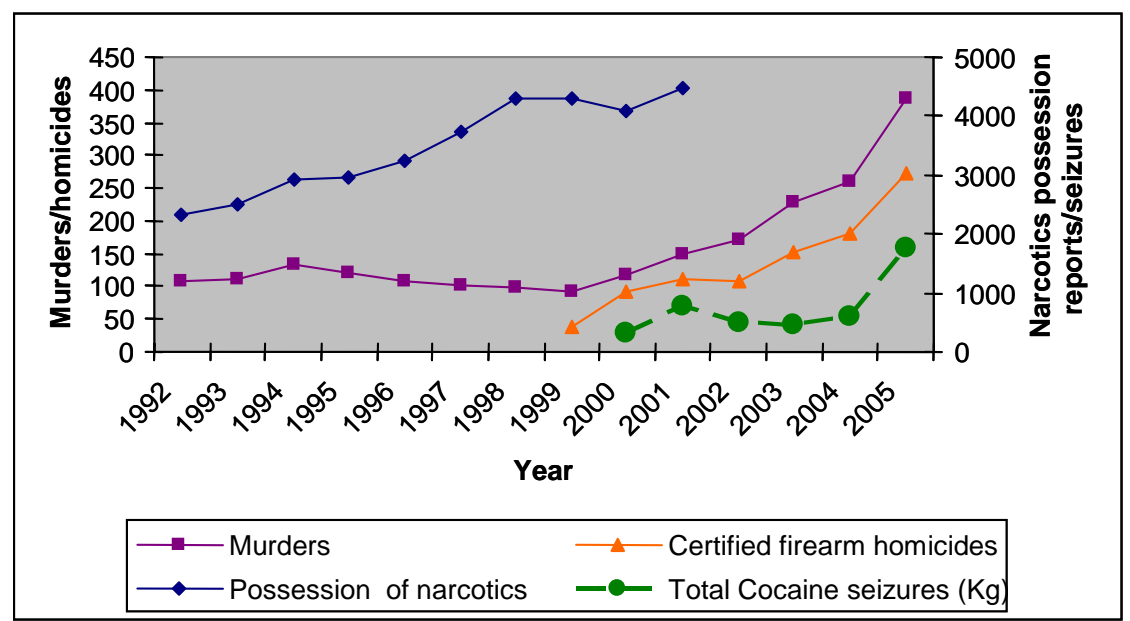

Sources: Central Statistical Office, Trinidad and Tobago, Drug Interdiction Unit, Trinidad and Tobago Police Service.

\section{DRUG-TRAFFICKING AND GUN-RELATED CRIMINALITY}

9.21. A major factor contributing to the surge of guns-related criminality in the region is the trafficking of narcotics, which has facilitated the availability of firearms. More specifically, the firearms required for protection of the contraband during transportation are smuggled along with the drugs. The illegal drugs are also traded for foreign exchange 
and for illegal firearms from the U.S. These weapons are used for protecting turf, for intimidating customers and competitors, for empowering recruits into the distribution networks (or gangs), for maintaining discipline within them and for executing informers. In fact, drug trafficking has spawned a vibrant industry, namely, guns for hire (see Box 9.2) - a service particularly useful to addicts who need to commit crimes to support their habit and hence perpetrate more violent crimes. From this has spun off another criminal industry, contract murders (Holder, Y. 2006). Figure 9.2 shows how narcotics, firearms and related crimes have seen a similar upward trend in recent years. 
Table 9.4: Modified Haddon Matrix Applied to the Analysis of Gun-Related Criminality (GRC)

\begin{tabular}{|c|c|c|c|c|}
\hline & Host (victim, perpetrator) & Agent/vector (firearm and bullets) & environment & Social environment (societal) \\
\hline $\begin{array}{l}\text { Pre-event } \\
\text { (before gun- } \\
\text { related } \\
\text { criminal act) }\end{array}$ & $\begin{array}{l}\text { Factors predisposing to } \\
\text { involvement in GRC - male } \\
\text { youth, low SES, aggressive, } \\
\text { poor education, under- } \\
\text { employed }\end{array}$ & $\begin{array}{l}\text { Factors predisposing involvement of guns } \\
\text { viz. availability of and access to guns - } \\
\text { drug-trafficking, inability to trace guns } \\
\text { and identify and destroy supply routes, lax } \\
\text { control of gun import/exports }\end{array}$ & $\begin{array}{l}\text { Physical environments pre- } \\
\text { disposed to GRC - certain } \\
\text { locations, times etc. }\end{array}$ & $\begin{array}{l}\text { Factors in the socio-economic } \\
\text { environment that pre-dispose for } \\
\text { GRC-GRC as an acceptable form of } \\
\text { social behavior or employment; } \\
\text { corruption; narco-trafficking }\end{array}$ \\
\hline $\begin{array}{l}\text { Event (when } \\
\text { gun is taken } \\
\text { out and fired) }\end{array}$ & $\begin{array}{l}\text { Personal factors protecting or } \\
\text { exposing persons involved in } \\
\text { GRC }\end{array}$ & $\begin{array}{l}\text { Factors affecting ability to inflict injury - } \\
\text { lethality of guns and ease of use }\end{array}$ & $\begin{array}{l}\text { Factors of the physical } \\
\text { environment that facilitate } \\
\text { GRC-exposure of victims } \\
\text { or protection of } \\
\text { perpetrators }\end{array}$ & $\begin{array}{l}\text { Factors of the socio-economic } \\
\text { environment that facilitate GRC e.g. } \\
\text { protection of perpetrators including } \\
\text { non-involvement }\end{array}$ \\
\hline \multirow[t]{3}{*}{$\begin{array}{l}\text { Post-event } \\
\text { (after victim } \\
\text { is shot)) }\end{array}$} & $\begin{array}{l}\text { Factors that lessen the effects } \\
\text { of the event on persons } \\
\text { involved in GRC e.g. } \\
\text { emergency treatment, }\end{array}$ & \multirow[t]{3}{*}{$\begin{array}{l}\text { Factors influencing ability of gun to inflict } \\
\text { injury after the event e.g. availability of } \\
\text { gun for re-use in another crime }\end{array}$} & $\begin{array}{l}\text { Factors that influence the } \\
\text { effects of GRC e.g. escape } \\
\text { routes for perpetrators; }\end{array}$ & $\begin{array}{l}\text { Factors that affect the results of } \\
\text { GRC e.g. emotional and financial } \\
\text { support to families (of both victim } \\
\text { and perpetrator); }\end{array}$ \\
\hline & rehabilitation of victim; & & $\begin{array}{l}\text { emergency routes for } \\
\text { victims; }\end{array}$ & risk of reprisals \\
\hline & $\begin{array}{l}\text { apprehension, detention and } \\
\text { rehabilitation of perpetrator }\end{array}$ & & $\begin{array}{l}\text { rapid response to events } \\
\text { culminating in swift justice }\end{array}$ & $\begin{array}{l}\text { expeditious and just resolution of } \\
\text { cases - ineffective policing, } \\
\text { outdated and irrelevant legislation, } \\
\text { weak judiciary }\end{array}$ \\
\hline
\end{tabular}

Notes: GRC = Gun-related crime; SES = Socio-economic status 


\section{Box 9.1: Young Men, Drugs, and Guns}

In Trinidad and Tobago, young men, especially those just out of prison and those with little prospect of employment, are targeted by drug suppliers who control the communities, empowered by the illegal guns that they possess and the profits of their illicit trade (WINAD, 2006). These recruits are approached with a quota of cocaine and the necessary weapons to protect their turf. Refusing the offer will mean continued hardship and deprivation, or even death. The situation is further exacerbated by political patronage, whereby these communities are the beneficiaries of poverty alleviation projects which are often controlled by the community drug supplier.

Despite the great risk of death or injury and the lesser risk of detection, the sale and distribution of narcotics within the territory have proven lucrative for those persons engaged in the trafficking. Established in structured networks with suppliers, distributors, couriers, retailers, and enforcers, there are 66 known gangs with more than 500 members, according to the Ministry of National Security in the Republic of Trinidad and Tobago. Some of these gangs now engage in kidnapping, with ransom demands that include heroin and cocaine.

In addition to these economic factors, sociological factors also play a role in the fascination of male youth with guns. Disadvantaged, disenfranchised, dispossessed, influenced by a constructed stereotype of masculinity which embraces violence, and threatened by surrounding social and economic forces, young males feel empowered by the possession of a gun. With a gun, they can instill fear, settle disputes to their satisfaction, command respect and demand sexual favors. Indeed, for the first ten months of 2005 in Jamaica, 16 percent of rapes were at gunpoint (Amnesty International, 2002). For \$TT 100, the price of a gun and ammunition, a young man with nothing apparently going for him, can purchase some self-esteem for one hour. With a gun and in a group of others who share the same negative feelings, a "posse", he is protected, he belongs and he has worth. Forces such as these drive the demand for firearms.

Source: Holder, 2006

\section{Policy IMPlications}

9.22. Consideration of the issues described in Haddon's matrix should guide the formulation of interventions. If acts of gun-related violence are considered as an event in a spectrum of actions that begins with those factors that operate during the pre-event phase of the matrix, then decision makers are presented with a host of opportunities to prevent the occurrence or recurrence of gun-related criminal acts. Those interventions that act upon factors that predispose involvement in gun-related crime and the environment are discussed in more detail in the chapters on youth violence, drugs, criminal justice reform, and the policy chapter. Here, the discussion is limited to those interventions that are specific to guns and criminality. Table 9.5 lists the various possible interventions that are specific to guns and ranks them according to their potential impact as well as priority and difficulty. Few of these interventions have been subjected to rigorous evaluation, particularly in the Caribbean context. However, some have shown enough promise that they are worth trying and are discussed below.

9.23. Gun Control: Since there is no domestic manufacturing of firearms in the Englishspeaking Caribbean, one obvious option would be to ban guns altogether. Effectiveness of such a measure is highly debatable, however, as shown by the experiences in other countries. In fact, opponents of gun control laws point out that Jamaica, despite banning guns, has had an increasing gun homicide rate, as did the United Kingdom and some states in Australia. 
Supporting this view is the fact that in various countries of the region, a "gun-for-rent" market has emerged, effectively sidestepping potential supply reductions. However, various measures can be put in place that can make gun control more effective.

9.24. Most gun control legislation in the Caribbean is aimed principally at legally acquired firearms, is poorly enforced, and has little impact on illicit guns. A systematic strategy that is more likely to be effective is one that first addresses the acquisition of illegal firearms, as it is believed that only a minority of registered arms are used to commit crimes. The first step in blocking the illicit trafficking of light arms would involve tight controls of vendor and purchaser, with strictly enforced regulations governing:

- Local sales with thorough background checks, close scrutiny of purchasers to deter the use of "straw purchasers" and an index of suspicious persons who purchase more than one gun in a stipulated time period. Annual inspection and licensing of firearms with follow-up may also serve as a deterrent.

- Exportation of firearms with documented approval after thorough checks by the supplying or manufacturing state on the bona fides of the purchasers, the use to which the firearms would be put and verification of their final destination. These checks should involve the authorities of the receiving state including the issuance of an import license.

- Importation of firearms with the issuance of an import license by the authorities of the purchaser's state.

- Transfer of firearms as per exportation and importation with notification of the supplier state.

- Preventing the illicit trafficking in light arms is a responsibility to be shared among the producing, selling, and destination states, whether intermediary or end-users, with open and transparent communication among all. A good place to start is with the signing, ratification, and enforcement of international treaties and conventions such as the United Nations Protocol on the Illicit Trafficking in Firearms and the Organization of American States' Inter-American Convention against the Illicit Manufacturing of and Trafficking in Firearms, Ammunition, Explosives and other Related Materials. Many states in the region have not signed, much less ratified, these international agreements (see Box 9.2 on the UN resolution and Plan of Action on Small Arms and Light Weapons.) ${ }^{175}$

\footnotetext{
${ }^{175}$ Arms control was also an important issue at the 2004 Hemispheric meeting of the Ministers of Security in Quito. LAC countries called on all gun manufacturing countries - and on the USA in particular - to tighten up their gun manufacturing and export measures to reduce the diffusion of guns in the region.
} 
Table 9.5. Possible Interventions Specific to Guns and Criminality

\begin{tabular}{|c|c|c|c|}
\hline Priority & High Impact & Medium Impact & Low Impact \\
\hline High & $\begin{array}{l}\text { Intensified air and sea-port surveillance } \\
\text { Training of Customs officers to search for } \\
\text { guns and their components } \\
\text { Training of Police officers for improved gun- } \\
\text { related crime investigations } \\
\text { Promotion of and compliance with } \\
\text { international treaties and conventions to } \\
\text { abolish the illicit trade in firearms }\end{array}$ & Intensified patrols and searches (difficult to sustain) & $\begin{array}{l}\text { Bullet-proof vests; self-defense } \\
\text { mechanisms }\end{array}$ \\
\hline \begin{tabular}{|l|} 
Medium to \\
High
\end{tabular} & $\begin{array}{l}\text { Improved emergency health services for gun } \\
\text { trauma } \\
\text { Acquisition of gun forensics and ballisitic } \\
\text { examination capability } \\
\text { Marking and tracing of guns to identify routes } \\
\text { and modes of illicit gun trafficking }\end{array}$ & $\begin{array}{l}\text { Implementation and enforcement of regulated } \\
\text { procedures for the licensing, training in the use and } \\
\text { storage of guns } \\
\text { Storage and disposal of seized guns }\end{array}$ & $\begin{array}{l}\text { Institution of a Gun Court to expedite } \\
\text { cases }\end{array}$ \\
\hline Low & $\begin{array}{l}\text { Resocialization from a "gun culture” } \\
\text { Counselling to reduce risk of reprisals }\end{array}$ & Gun buy-backs & Gun control/prohibition \\
\hline
\end{tabular}




\section{Box 9.2: UN Resolution and Plan of Action on Small Arms and Light Weapons}

The impact of gun violence has not gone unnoticed by the international community, albeit quite late. Since 2001, at several international fora, many under the aegis of the United Nations, world leaders expressed grave concern at the negative effects on development, peace, security and human rights posed by the illicit trade in Small Arms and Light Weapons. The United Nations General Assembly endorsed a resolution addressing the negative humanitarian and development impact of illicit or excessive Small Arms and Light Weapons and proposed a Program of Action that calls on States to take steps to curtail the illicit traffic of Small Arms and Light Weapons.

The Program of Action to Prevent, Combat and Eradicate the Illicit Trade in Small Arms and Light Weapons in All Its Aspects defines measures that governments of member states should take to control the black market trade in arms. It not only makes recommendations on the control of imports, exports and transfers to prevent diversion to illicit use, but also requires member states to

- Make illicit gun production/possession a criminal offense

- Establish a national coordination agency on small arms

- Identify and destroy stocks of surplus weapons

- Keep track of officially-held guns

- Disarmament, Demobilizations \& Re-integration (DDR) of ex-combatants, including collection and destruction of their weapons

- Support regional agreements and encourage moratoria

- Mark guns at point of manufacture for identification and tracing

- Maintain records of gun manufacture

- Engage in more information exchange

- Ensure better enforcement of arms embargoes

- Include civil society organizations in efforts to prevent small arms proliferation

Sources: WHO, 2001; UN, 2001.

9.25. Improved interdiction of illegal guns. Until cessation of the black market trade in light firearms becomes a reality, a "stop-gap" measure is to thwart as effectively as possible all efforts to land illegal guns. For the island countries of the Caribbean, this requires intensive surveillance of the coastline by naval police equipped with suitable watercraft. This is an expensive but necessary undertaking, especially for small island countries, as improved marine surveillance serves several purposes. Not only does it deter arms trafficking but also drug trafficking, piracy and trafficking in people.

9.26. The second means of illegal entry of firearms is their carriage through an official port of entry (air or sea) without detection. Legally entering yachtsmen or airline passengers, and their possessions, are subject to search by customs officers who are trained to seek dutiable goods and drugs, not firearms. To stem this, it is imperative that customs officers be trained to search for guns, to be able to recognize their component parts and to be aware of the methods of concealment of firearms and ammunition.

9.27. Marking, Registration and Licensing: The final source of firearms for use in criminal activity is the in-country diversion of legally acquired firearms and ammunition to illegal use. To prevent the re-use of weapons in gun-related crimes, it is critical that guns should be traceable and that weapons seized should be securely stored and properly disposed of. This requires effective procedures for acquisition, marking, licensing, registration, operation and storage. 
National gun registries are rare in the Caribbean. Licensing and use of firearms should also include an emphasis on the control of and accountability for ammunition, and not just for the firearm. Careful oversight needs to be given to the secure storage of firearms (both private and public storage), with clear guidelines on storage requirements, strict control with rigorous inspection procedures including a checklist, reporting format, periodicity, audits of ammunition and general accountability. These protocols need to apply to civilian users, rifle clubs, private security firms, Police Services, and the Defense Force.

9.28. Criminal Justice System: Firearms enforcement requires police officers with the necessary forensic technology and knowledge to effectively gather, preserve and present evidence. This technology should include a forensic facility that especially provides for firearm forensics and ballistic examinations required for solving gun-related crimes. For every state to possess this facility may be burdensome and expensive. But it should certainly be possible to have it available in the largest Caribbean states or, at the very least, as a shared regional resource. The establishment of a "Gun Court", such as the one Jamaica has had since 1974, would expedite the processing of firearms cases.

9.29. Data: Analysis of the situation with respect to gun-related criminality, the investigation and solving of cases, the monitoring of interventions, all require data-which does not currently exist in an easily accessible or useable form. Furthermore, with respect to guns and criminality, given the linkages with other countries within the Caribbean region and on the American and European continents, these data need to be compatible and comparable so that it may be shared among all stakeholders. Registries with information on purchasers, gun markings and tracings, databases on ballistics, on gun transfers and movements are but a few of the useful data tools in the fight against guns and crime. Mechanisms need to be instituted for the sharing of information within countries across agencies and sectors and across countries to facilitate the tracking of firearms used in the commission of crimes and the identification of persons engaged in the smuggling of firearms.

\section{Box 9.3: Gun Buybacks}

One well-known intervention that has been used to withdraw illegal guns from circulation has been that of gun buybacks. Attempted in several countries in Latin America and the Caribbean, buybacks have met with variable success. The exercise in Saint Lucia, where \$EC 2,500 (about US\$1,000) was offered for each illegal working gun tendered, was hailed a success for recovering 150 guns in the course of ten months. Yet the Trinidad offer of \$TT10,000 (about US\$1,600) per firearm attracted few takers (Holder, Y. 2006). Proponents of gun buybacks maintain that every gun turned in is one less available for perpetrating crime, while opponents argue that the guns turned in are not the ones used in crime. The international literature on the effectiveness of gun buybacks is rather pessimistic about their effectiveness (U.S. Surgeon General, 1999; Cook et al., 2001; Kennedy et al., 1996; Sherman, 2001; Retuer and Mouzos, 2003). 


\section{PUBLIC POLICY OF CRIME AND VIOLENCE PREVENTION: REGIONAL AND NATIONAL APPROACHES}

Policy makers have several complementary approaches at their disposal with which to address crime and violence. Sector-specific approaches-such as criminal justice, public health, and conflict transformation/human rights-have a role to play, as do cross-sectoral approaches, such as crime prevention through environmental design and citizen security. The criminal justice approach is the most widely known and used, but it does have limitations and should not be the sole approach employed. Public health approaches are appropriate for addressing youth and gender-based violence, and crime prevention through environmental design has the potential to rapidly lower crime in specific locations.

In terms of policy making at the regional level, CARICOM has taken several important steps to deal with crime and violence, focusing on those issues which transcend national boundaries; perhaps the most important has been the creation of the Regional Task Force on Crime and Violence. At the national level, the formulation of national plans to address crime and violence is crucial, since these plans allow for cross-sectoral collaboration and promote serious discussions on priorities in resource allocation. There are multiple entry points for public policy to reduce crime and violence. The key is to select policies and interventions that have a proven track record of success or that are extremely promising. A mix of highly cost effective long-run approaches (including investment in prevention programs with young children and families) can be combined with other interventions (such as situational crime prevention) that can provide quick impacts on crime.

10.1 This chapter provides an overview of sector and cross-sectoral approaches to crime and violence prevention in the Caribbean. It then makes the case that crime and violence are an issue of economic development for the region and that an integrated, multi-sectoral response (encompassing more than the criminal justice system) is needed. Finally, the chapter offers some preliminary recommendations at the national and regional levels.

\section{Sectoral And Cross-Sectoral Approaches}

10.2 In the Caribbean and most other regions, efforts to prevent violence have focused on urban violence (except in post-conflict situations). Table 10.1 summarizes these efforts, distinguishing between sector-specific approaches (such as criminal justice, public health, and conflict transformation and human rights) and cross-sectoral approaches (such as crime prevention through environmental design, community-driven development and citizen security), and identifying the goals, types of violence addressed and typical interventions for each (Monseret al., 2005).

\section{Sector-specific approaches}

10.3 Among sector-specific approaches, the criminal justice approach is perhaps the bestknown; it tries to reduce crime and violence through higher arrest rates, higher conviction rates, and longer sentences. Criminologists often distinguish between deterrence effects (dissuading 
potential criminals from committing crimes) and incapacitation effects (preventing criminals from committing crimes because they are imprisoned). The criminal justice approach aims to reduce crime through both deterrence and incapacitation effects.

10.4 The criminal justice approach-which involves work with police, prosecutors, the judiciary, and prisons - is favored by politicians who want to generate rapid decreases in crime and violence. Police and judicial reform is urgent both to reduce impunity and address deeper issues involving justice, corruption, and human rights abuses; impunity plays a large role in promoting economically-motivated crime in the Caribbean and elsewhere. In the corrections area, serious reforms and additional investment are needed if prisons are to have any prospect of rehabilitating inmates, instead of just preventing them from committing crimes during their stays in prison.

10.5 At the same time, the criminal justice approach has serious limitations:

- To the extent that police and judicial institutions are inefficient and in need of reform, the injection of additional resources without reform may not produce the desired results.

- In the case of police, there is some evidence from the United States that simply putting more uniformed officers on the street does not reduce crime. Such officers must be in the right place and at the right time, which requires some sophistication in detecting crime patterns and allocating police resources (Felson 1994).

- There is a risk in pursuing a piecemeal approach where individual institutions (police, judiciary, prosecutors, prisons) are reformed one at a time. As Chapter 8 makes clear, the various institutions in the criminal justice system must be aligned with one another. Thus, systemic reform is generally more desirable than piecemeal reform.

- Other types of investment-focused on prevention rather than control—are generally more cost-effective in reducing crime than investments focusing on crime control (Greenwood, 1998; USDOJ, 2004; Sansfaçon et al, 1999; World Bank, 2006b).

10.6 The public health approach is another sector-specific approach. Often called the epidemiological approach, it involves four steps: defining the problem and collecting reliable data, identifying causes and risk factors for violent behavior, developing and implementing interventions, and analyzing and evaluating the effectiveness of violence prevention interventions (Mercy et al., 1993; WHO, 2004). In the Caribbean, the public health approach has been used with an emphasis on youth violence as well as injury prevention. One example of this approach is the Injury Surveillance System that was created by the Ministry of Health in Jamaica.

10.7 The public health approach has the great advantage of being evidence-based. Interventions are tailored to address risk factors that are most important in a given locale, and there is significant emphasis on evaluating the impacts of the interventions. The one disadvantage of this approach is that many of its most important interventions-such as programs to reduce unintended pregnancies and to promote early childhood development and parental training - may have payoffs in terms of reduced violence only after some time has passed. But not all public health-inspired interventions have delayed effects: limiting the 
availability of alcohol and providing recreational and mentoring programs to remain in school, for example, may all produce relatively quick impacts. ${ }^{176}$

10.8 The conflict transformation and human rights approach promotes nonviolent conflict resolution through mediation, negotiation, and enforcement of human rights. Often used in postconflict settings, it has also been employed by NGOs working to promote enfranchisement of marginal communities and their citizens. Another innovative option is community peacebuilding efforts which directly involve citizens; according to Harriott (2004), popular involvement at the community level can strengthen the moral authority of the state's control institutions, as well as improve their effectiveness. This approach also focuses on the state's role in ensuring citizens' rights to be free from victimization and the threat of violence (Moser et al., 2005). This approach is employed by the Dispute Resolution Foundation in Jamaica, which works with warring factions in communities to mediate, establish ceasefires and community codes of conduct, and teach conflict resolution skills.

\section{Cross-sectoral approaches}

10.9 The crime prevention through environmental design (CPTED) and the urban renewal approach are based on the premise that characteristics of the physical environment influence the amount of crime that occurs - and thus, that crime can be reduced by modifying the physical environment to make it more difficult and risky (and less rewarding) for potential criminals to commit crime. This approach involves interventions in the planning, design, and management phases of urban development projects (Moser et al., 2005). Importantly, this approach can address not only objective levels of crime, but also residents' fear of crime. It is usually used in the context of community-based, multi-sector "urban renewal" programs that attempt to address the causes of crime through targeted social, economic, and situational crime prevention measures in specific "hot spot” neighborhoods. See Box 10.1 for an example of this approach in Jamaica.

10.10 Citizen security initiatives (also known as "public safety”), as developed by several countries in the Caribbean and Latin America-often with the support of the Inter-American Development Bank-are eminently cross-sectoral in nature. They typically involve violence prevention using the public health approach, combined with investments in criminal justice and, more recently, crime prevention through environmental design. The best-known of these initiatives has been in Bogota, where homicides rates were reduced by more than half between 1994 and 2000 (Mockus, 2001). The IDB-financed Jamaica Citizen Security and Justice Project is a regional example of this approach. In addition, Guyana has just received approval of two IDB loans for a Citizen Security project (that will include police modernization and institutional strengthening of the Ministry of Home Affairs, Crime and Violence Observatory, and community interventions) and a Justice Sector Reform project which will include interventions in the prison system.

\footnotetext{
${ }^{176}$ For a complete list of potential interventions targeting youth violence, classified by developmental stage of youth, level of the ecological model (individual, relationship, community or society), and probable effectiveness, see Chapter 5.
} 
Table 10.1. Public Policy approaches and interventions to address urban violence

\begin{tabular}{|c|c|c|c|}
\hline $\begin{array}{l}\text { Policy approach } \\
\text { Sector-specific }\end{array}$ & Goal & $\begin{array}{l}\text { Types of violence } \\
\text { addressed }\end{array}$ & Typical interventions \\
\hline \multirow{4}{*}{$\frac{\text { Sector-specific }}{\text { Criminal justice }}$} & \multirow{4}{*}{\begin{tabular}{|lr} 
Deterring & and \\
controlling & violence \\
through & higher \\
arrest & and \\
conviction rates and \\
more & severe \\
punishment &
\end{tabular}} & $\begin{array}{ll}\text { - } & \text { Crime } \\
\text { - } & \text { Robbery } \\
\text { - } & \text { Corruption }\end{array}$ & Judicial reform \\
\hline & & $\begin{array}{ll}\text { - } & \text { Crime } \\
\text { - } & \text { Robbery }\end{array}$ & Police reform \\
\hline & & $\begin{array}{ll}\text { - } & \text { Delinquency } \\
\text { - } & \text { Robbery } \\
\text { - } & \text { Gender-based violence }\end{array}$ & $\begin{array}{l}\text { Accessible justice systems } \\
\text { Mobile courts }\end{array}$ \\
\hline & & - Gender-based violence & $\begin{array}{l}\text { Community policing } \\
\text { Women’s police stations }\end{array}$ \\
\hline Public health & $\begin{array}{l}\begin{array}{l}\text { Preventing } \\
\text { violence }\end{array} \text { by } \\
\text { reducing } \\
\text { individual } \\
\text { factors }\end{array}$ & $\begin{array}{l}\text { - } \text { Youth violence } \\
\text { - Gender-based violence } \\
\text { - Homicide }\end{array}$ & $\begin{array}{l}\text { Preschool programs } \\
\text { Home visitation programs } \\
\text { School-based social development } \\
\text { programs } \\
\text { Restriction of alcohol sales } \\
\text { Restrictions on gun ownership } \\
\text { Gun buy back programs }\end{array}$ \\
\hline \multirow[t]{2}{*}{$\begin{array}{l}\text { Conflict } \\
\text { transformation } \\
\text { and human rights }\end{array}$} & \multirow{2}{*}{$\begin{array}{l}\text { Resolving conflict } \\
\text { nonviolently } \\
\text { through } \\
\text { negotiation and } \\
\text { legal enforcement } \\
\text { of human rights by } \\
\text { states and other } \\
\text { social actors }\end{array}$} & - Political violence & \multirow[t]{2}{*}{$\begin{array}{l}\text { Traditional systems of justice } \\
\text { Government human rights advocates } \\
\text { or ombudsman } \\
\text { Civil society advocacy NGOs }\end{array}$} \\
\hline & & $\begin{array}{ll}\text { - } & \text { Institutional violence } \\
\text { - } & \text { HR abuses } \\
\text { - } & \text { Arbitrary detention }\end{array}$ & \\
\hline \multicolumn{4}{|l|}{ Cross-sectoral } \\
\hline $\begin{array}{l}\text { Crime prevention } \\
\text { through } \\
\text { environmental } \\
\text { design / urban } \\
\text { renewal }\end{array}$ & $\begin{array}{l}\text { Reducing violence } \\
\text { by focusing on the } \\
\text { settings of crime } \\
\text { rather than the } \\
\text { perpetrators }\end{array}$ & $\begin{array}{ll}\text { - Economic violence } \\
\text { - Social violence }\end{array}$ & $\begin{array}{l}\text { Local level programs } \\
\text { Urban renewal programs } \\
\text { Integrated slum upgrading programs }\end{array}$ \\
\hline $\begin{array}{l}\text { Citizen } \\
\text { security/public } \\
\text { safety }\end{array}$ & $\begin{array}{l}\text { Using cross-sector } \\
\text { measures to } \\
\text { prevent or reduce } \\
\text { violence }\end{array}$ & $\begin{array}{ll}\text { - } & \text { Economic violence } \\
\text { - Social violence }\end{array}$ & $\begin{array}{l}\text { National level programs } \\
\text { Local level programs }\end{array}$ \\
\hline \multirow{2}{*}{$\begin{array}{l}\text { Community- } \\
\text { driven } \\
\text { development } \\
\text { (CDD)/ }\end{array}$} & \multirow{2}{*}{$\begin{array}{lr}\text { Rebuilding } & \text { social } \\
\text { capital, trust, and } \\
\text { cohesion r in } \\
\text { informal } \\
\text { formal and } \\
\text { institutions }\end{array}$} & - Youth gangs & Community-based solutions \\
\hline & & - Gender-based violence & $\begin{array}{l}\text { Crisis services for victims } \\
\text { Ongoing support and prevention } \\
\text { Communication campaigns } \\
\text { School programs } \\
\text { Programs for perpetrators }\end{array}$ \\
\hline
\end{tabular}

Source: Adapted from Moser et al. (2005) and Moser and Winton (2002). 
10.11 The Community-Driven Social Development approach focuses on rebuilding social cohesion in informal and formal institutions using small, participatory and demand-driven projects that aim to create trust by building on the strengths and assets of poor communities affected by violence. This approach has been particularly used to fight gang violence and domestic violence. In the Caribbean, this approach has often been adopted by NGOs (see Box 10.2 for a description of such a program in Trinidad and Tobago), although successful projects increasingly are adopted and scaled-up by government programs such as the DFID-supported Citizen Security Initiative in Jamaica.

\section{REGIONAL INITIATIVES TO ADDRESS CRIME AND VIOLENCE}

10.12 The preceding chapters have made clear that many of the factors contributing to crime and violence in the Caribbean-drug and weapons trafficking, money laundering, and deportees - transcend national boundaries. As such, they call for regional or international approaches and interventions that go beyond the local- or national-level responses described in the previous section.

10.13 Regional cooperation in combating transnational organized crime and drug trafficking requires a standardized legal regime. The internationally accepted vehicle for this standardization is the United Nations system of drugs and crime conventions, namely the three drug conventions (the 1961 Single Convention on Narcotic Drugs, the 1971 Convention on Psychotropic Substances, and the 1988 Convention against the Illicit Traffic in Narcotic Drugs and Psychotropic Substances) the Convention against Transnational Organized Crime (including the protocols on Trafficking in Persons, Smuggling of Migrants, and Illicit Manufacturing of and Trafficking in Firearms) and the Convention against Corruption. While nearly every country in this region has ratified the drug conventions, compliance is much less in the case of the crime conventions, particularly the firearms protocol and the Convention against Corruption.

10.14 Some of the Caribbean's regional security institutions were designed to deal with earlier, more traditional threats to national security. The Regional Security System (RSS), for example, was created in 1982 by the Eastern Caribbean States (and Barbados) in response to the threat perceived from the Marxist government of Grenada. ${ }^{177}$ Its Memorandum of Understanding stipulates that if a member state's security was threatened, it has the right to request assistance from other members of the RSS. Initially, the RSS was conceived as a mutual defense treaty against external aggression or internal coup attempts.

10.15 Much later, in 1996, the memorandum of understanding was upgraded into a treaty. This greatly expanded the scope of issues that the RSS would tackle. Article 4 of the treaty describes the purpose of the RSS to be the promotion of cooperation in: i) interdiction of traffic in illegal drugs; ii) national emergencies; iii) search and rescue; iv) immigration control; v) fisheries protection; vi) customs and excise control; vi) maritime policing; vii) natural and other disasters; viii) pollution control; ix) combating threats to national security; $x$ ) prevention of smuggling; and xi) the protection of offshore installations and exclusive economic zones (Dillon, 2004). While the RSS's remit has expanded dramatically, its capabilities have not. Consequently, its ability to deal with issues such as drug and arms trafficking is limited. Important limitations

${ }^{177}$ Grenada, Montserrat, and St. Kitts and Nevis--did not initially sign the RSS MOU. 
include the obvious fact that its operations are not Caribbean-wide and that there is limited coordination between the RSS and the national police forces of the OECS countries (Dillon, 2004).

\section{Box 10.1. Crime and Violence Prevention Components in Bank-Financed Integrated Slum Upgrading Operations - Jamaica Inner Cities Basic Services for the Poor Project}

The World Bank is supporting the operationalization of local crime and violence prevention in Jamaica through the development of a specific project component in the Inner Cities Basic services for the Poor Project. The component seeks to take advantage of the infrastructure and social investments taking place and mainstream prevention at the local level into the overall project. In terms of the approaches described above, the component adopts an urban renewal approach complemented with a citizen security focus at the local level.

The component focuses specifically on the reduction of the very high levels of homicide, youth violence, and associated risk factors in the participating inner cities. Particularly important are the synergies between infrastructure provision, upgrading, and situational prevention on the one hand, and communitybased "social prevention" activities on the other. The overall objective is a comprehensive intervention at the neighborhood level that is closely coordinated with other relevant donor, government, and nongovernmental programs addressing crime and violence and their associated risk factors in these neighborhoods. The component has five subcomponents:

- Diagnostics: Crime and violence mapping of the micro areas using police statistics and where possible using Geographical Information Systems (GIS); the victimization section in the baseline surveys; and, community-based and situational diagnostics.

- Situational prevention: measures that reduce opportunities for particular crime and violence problems through spatial interventions such as Crime Prevention Through Environmental Design (CPTED) methodology and urban renewal. This method is mainstreamed in the infrastructure works of the projects through the training of the architects, engineers and other technical staff. It includes the planning and installation of social infrastructure such as community centers, playing fields, public lighting, and zinc fence removal and installation of safe alternatives. This methodology is quite new in the LAC region but has been successfully piloted in countries such as Chile, Brazil, and Colombia.

- Social Prevention: support of both immediate mitigation and conflict resolution activities in addition to other preventive and capacity enhancement interventions that will have a mediumand long-term impact on levels of public safety. In particular, the component finances a menu of initiatives in five broad categories to be tailored to the individual needs of each community: (1) mediation and conflict resolution; (2) alternative livelihoods and skills development; (3) family support services, (4) youth education and recreation; and (5) CBO capacity-building.

- Community Liaison Officers: The role of these technical experts in community organization and crime and violence prevention at the neighborhood level is to: carry out community-based diagnostics; formulate participatory community safety plans and strategies; liaise and coordinate with other relevant agencies and associations, in particular with Community Safety Councils and the Police; coordinate closely with those designing infrastructure to ensure integration of CPTED principles; identify and work with at-risk youth in the community; organize and mobilize the community around the concept of safety though community campaigns (e.g. community clean-up/painting days, community safety festival, etc.); initiate additional projects such as summer camp for at-risk youth.

- Monitoring and Evaluation component: Evaluations of the components have been designed and will be carried out. While evaluation data from these Bank-financed projects are not yet available, similar community-based integrated interventions have yielded dramatic results. 


\section{Box 10.2. The Pride in Gonzales Initiative, Port of Spain, Trinidad and Tobago: A Community-Driven Social Development Approach}

The Pride of Gonzales initiative was begun in 2003 in a violence-ravaged, Port of Spain suburban community of approximately 1,000 households. It was the brainchild of the community's parish priest after there had been six murders in a five-week period.

The initiative is a collaboration of CITY, the Ministry of National Security, the City of Port of Spain, the Canadian Institute of Planners, the University of the West Indies and the community of Gonzales. Some of the successful partnerships include: a partnership with the Ministry of Public Utilities to improve the piped water supply and street lighting; a partnership with the Water \& Sewerage Authority to upgrade water delivery to the area; and partnership with the Ministry of National Security to provide a different kind of policing. There has been an upsurge in social activities in the community such as football competitions, an Easter extravaganza, Christmas events for children, and an annual children's camp.

Other activities include an adolescent/human formation program, remedial education programs, programs in arts (dance, photography, video, and music) and sports. There have been clean-up activities and community notice boards have been set up. An Internet café, three homework clinics, gang intervention activities, capacity building for community leaders as well as counseling and crisis intervention strategies are all part of the ongoing initiative.

The initiative has transformed the community into a model one. Unfortunately, the period of peace was broken in August 2006 by two murders executed in one week. The challenge will be in seeing how the community will respond to this new threat of violence.

Sources: Catholic News, July 23, 2006; Sunday Newsday, July 23, 2006.

10.16 CARICOM has undertaken several important steps to deal with emerging regional security issues. The Caribbean Financial Action Task Force (CFATF) was created in 1992 by a ministerial meeting in Kingston, Jamaica, to address the issue of money laundering. The CFATF Secretariat monitors members' implementation of the Kingston Ministerial Declaration through the following activities:

- Self-assessment of the implementation of the recommendations

- An ongoing program of mutual evaluation of members

- Co-ordination of, and participation in, training and technical assistance programs

- Biannual plenary meetings for technical representatives

- Annual ministerial meetings

10.17 In the area of drug trafficking, CARICOM established the Secretariat Regional Coordinating Mechanism for Drug Control in 1997. CARICOM members have signed several international conventions and multilateral plans of action. Member states are signatories to the Barbados Plan of Action of May 1996; the Action Plan of October 1996 for the implementation of the Anti-drug Strategy in the Hemisphere; the Bridgetown Plan of Action emanating from the May 1997 Caribbean/U.S. Summit; and the European Union/Latin America/Caribbean Action Plan following the first EU/LA/Caribbean Summit in June 1999 (CARICOM, 2000). While Caribbean countries have signed many multilateral agreements, most activities to combat drug 
trafficking are in the context of bilateral arrangements (mostly with the U.S.) rather than as part of regional initiatives (Dillon, 2004). As a result, most of the focus is on interdiction and supply reduction.

10.18 Perhaps the most important regional initiative in the area of crime and violence reduction was the Regional Task Force on Crime and Security (RTFCS). The Conference of Heads of Government of CARICOM, meeting in Nassau in July 2001, charged the RTFCS to identify the major causes of crime in the region and to recommend approaches to deal with related problems such as drugs and weapons trafficking. The RTFCS was composed of representatives of each member state, a representative of the RSS and of the Association of Caribbean Commissioners of Police. Two of the region's most respected criminologists, Anthony Harriott (UWI, Mona Campus) and Ramesh Deosaran (UWI, St. Augustine) also participated in the Task Force.

10.19 The Task Force identified the following principal security threats to the region: illegal drugs, illegal firearms, corruption, rising crime against persons and property, criminal deportees, growing lawlessness, poverty and inequity, and terrorism; for the areas of illegal drugs, illegal firearms, terrorism and deportees, the report included a short discussion of key issues, challenges and a rather long list of detailed recommendations at both national and regional levels (CARICOM, 2002). ${ }^{178}$ The Task Force presented its report to a meeting of heads of government in July 2002; the recommendations of the Task Force were endorsed by this meeting.

10.20 A second important regional study on crime in the Caribbean was produced by the United Nations Office on Drugs and Crime in 2004. Authored by Anthony Harriott, the report offered a series of policy recommendations focusing on the need to develop national capacity to prepare crime control plans and modernizing of criminal justice systems, including the police and correctional services. ${ }^{179}$ Importantly, this report also called for research to evaluate existing interventions and identify good practice approaches.

10.21 Caribbean Heads of Government endorsed a new Management Framework for Crime and Security in July 2005; this framework establishes a Council of Ministers responsible for security and law enforcement, a Policy Advisory Committee, and an Implementation Agency to implement CARICOM policy initiatives in this area. Steps were also taken to created mechanisms for regional coordination and cooperation in regional intelligence sharing (RIC, immigration, narco-trafficking, customs) and the accompanying CARICOM Treaty on Mutual Cooperation on Fighting Crime is being passed into domestic law in various countries (e.g. Guyana’s parliament passed this into law in May 2006).

10.22 Thus, there have been serious efforts at the regional level to understand the factors driving crime and violence in the Caribbean and to begin to formulate a regional policy response. These responses, however, are still in their infancy. For example, small-scale drug interdiction

\footnotetext{
178 The key findings from these sections have been incorporated into the relevant sections of this report.

${ }^{179}$ Specific recommendations for modernizing the police included increasing the use of technology, improving training, applying effective management tools and strengthening accountability, and improving police-citizen relations. The only specific recommendation for reform of correctional systems was to examine alternatives to imprisonment and to reduce recidivism, although no detail was provided on how to achieve this reduced recidivism.
} 
campaigns have been carried out in coordinated fashion by the region's police forces (under the aegis of the Association of Caribbean Commissioners of Police) over brief periods of time, but there is limited ongoing international cooperation. In the area of weapons control, the United Nations Regional Centre for Peace, Disarmament and Development in Latin America and the Caribbean has carried out a number of trainings for law enforcement officials on the commercial trade and trafficking in firearms, using a "train the trainers" methodology. Beyond capacity building, however, regional collaboration in combating weapons trafficking has been limited.

10.23 It is important to note that many of the issues facing the Caribbean transcend regional boundaries. Demand for drugs emanates from Europe and the United States; deportees are sent back to the region from the United States, the United Kingdom and Canada; many weapons that are trafficked are sourced from the United States.

10.24 No regional strategy in these areas can hope to succeed without significant support from these OECD countries. This support has frequently been lacking, especially for weapons control and deportees. As Peter Phillips, the Jamaican Minister of National Security commented in the area of weapons control, "Strategies to interdict the flow of drugs from south to north must be supported by greater efforts to restrict the flow of guns in the reverse direction." ${ }^{180}$ In the area of deportees, this report identified important interventions that could be undertaken by deporting countries in order to minimize the negative impact of deportees on crime in the Caribbean; these interventions have the potential not only to reduce crime in the Caribbean, but also to put a dent in international crime syndicates that conduct business in the United States and elsewhere. Similarly, and as pointed out in the case study on drug interdiction in the Netherlands Antilles, Caribbean countries will require support from OECD countries to finance some of the more costly elements of interdiction strategies (naval patrols, radar, etc.).

\section{PRIORITY STEPS TO ACHIEVE REDUCTIONS IN CRIME AND VIOLENCE IN THE CARIBBEAN}

10.25 Caribbean governments have come to recognize that crime and violence are an important development issue. This is buttressed by the evidence in Chapter 4 which documents that crime and violence exact a serious toll on growth in Caribbean countries; conversely, reducing crime and violence will generate growth and reduce poverty. The implication is clear: violence and crime reduction should be considered an important element of development policy making - at the national, regional, and international levels. It therefore also means that crime and violence is a key issue for the traditional development partners of these countries. To date, support in this area by the donor community has been somewhat piecemeal. Donors need to work closely with their Caribbean partners to coordinate action and assistance across a range of interventions.

10.26 In general, there has been an over-reliance on the criminal justice approach to crime reduction in the region, to the detriment of other complementary approaches which can be effective in reducing certain types of crime and violence. Over the last few years, however, several countries such as Jamaica and the Dominican Republic are increasingly investing in different approaches. At the same time, it is also crucial to note that certain types of crime and

\footnotetext{
180 “The battle for security”, remarks by Peter Phillips (Jamaican Minister of National Security) at the annual Wilton Park Conference (London, September 2005).
} 
violence-in particular, organized crime and drug trafficking-are largely impervious to prevention approaches; a criminal justice-focused approach is essential in dealing with them.

10.27 The important role that preventive approaches can play is now beginning to be recognized:

- Crime prevention through environmental design (CPTED) has significant potential to generate rapid decreases in property crime and some forms of inter-personal violence. The region is just beginning to explore this kind of situational crime prevention (see Box 10.1).

- Integrated citizen security approaches have seen initial success in Capotillo in the Dominican Republic (see Box 8.1 for more detail on the Capotillo experience) and should be explored elsewhere. These programs, by combining modern methods of policing with prevention interventions undertaken by both government and non-governmental organizations, are extremely promising.

- The public health approach, which focuses on modifying risk factors for violent conduct, is especially promising for addressing violence against women and youth violence. A good example of a program targeting risk factors for violent behavior are the Centros Educativos de Fe y Alegría (Educational Centers of Faith and Happiness) in the Dominican Republic, which integrate services for poor and excluded communities, including formal education (pre-K through $12^{\text {th }}$ grades, under agreement with the Ministry), religious education, nutrition and health services, life skills training, vocational training, parenting training, and community mobilization.

- The conflict transformation/human rights approach has not been used in a significant way in the Caribbean. To the extent that violence and crime are "not simply a matter of ordinary criminality but rather the outcome of a profoundly political power dynamic... [one can] make the case for a more unconventional short-term response to this violence” (Harriott, 2004b). Such innovative options might include community peace-building efforts. Harriott goes on to make the case that direct involvement of citizens and communities "tends to strengthen the moral authority of the state's control institutions and improves their effectiveness."

\section{Recommendations at the national level}

10.28 The report of the Regional Task Force on Crime and Security shied away from making detailed recommendations at the national level: "The differences in the nature of the crime problem across the region make it difficult, indeed imprudent, to try to elaborate recommendations that are applicable at the national levels” (CARICOM, 2002).

10.29 This is an accurate assessment. The region is far too heterogeneous for one-size-fits-all recommendations for interventions at the national level. The chapters in this study, however, do provide sufficient evidence to make a few key recommendations that can guide policy making.

1. This report has culled many different sources of data to present as comprehensive a picture as possible of crime and violence in the Caribbean. Yet it is clear that there are major data gaps that hinder policy making at both national and regional levels (see Box 10.3). Chief among them are information systems that allow policy makers (and citizens) to track 
crime trends and gauge the impact of interventions. Also important are victimization surveys, undertaken at regular intervals, which permit comparison of crime levels both over time and across countries. Victimization data is essential, both to design interventions and to hold policy makers accountable for the results of their strategies to reduce crime and violence. Violence against women has become more visible in many regions of the world due to the collection of data from internationally validated, specialized victimization surveys. The Caribbean, however, is a notable exception: there is little in the way of serious data collection on violence against women, and none of the data are comparable across countries.

\section{Box 10.3. The need for better data on crime}

The measurement of crime is a complex exercise, considerably complicated by the lack of internationally comparable data. The best data on crime come from standardized victim surveys, such as those conducted under the International Victims of Crime Surveys (ICVS) program. Unfortunately, only one Caribbean country-Barbados-has conducted such a survey. Other victim surveys are helpful, but suffer from a lack of international comparability, due to differences in methodology.

Even standardized victim surveys suffer from several weaknesses. They can be expensive, particularly if the desired sample is large. Large samples are necessary to ascertain variations in crime victimization by geographic region or population group, or to learn more about the nature of particular crimes, especially low-incidence crimes such as murder. This information is very useful in designing crime prevention interventions and is not available from any other source. General victim surveys also fail to produce reliable data on certain sensitive topics, such as sexual offenses and domestic violence, for which specialized surveys are required. Household surveys fail to capture the impact of crimes on businesses which again requires specialized surveys. But despite these limitations, ICVS surveys remain the best source of standardized crime information, their greatest limitation being the lack of funding for their widespread and recurrent administration.

Data produced by the police on the crimes reported to them is the most commonly used form of crime data because it is readily available, but it suffers from both under-reporting and lack of international comparability, due to differences in crime definitions and administrative recording procedures. The United Nations biennial Survey of Crime Trends and Operations of Criminal Justice Systems (CTS) attempts to overcome some of the comparability issues by asking member states to re-categorize crime incidents according to standardized definitions. Unfortunately, at the time of this writing, in the Caribbean only Bermuda and Suriname have replied to the Ninth Survey, which covers the period 2003-2004.

Crime is a politically sensitive issue and it is understandable that some governments may be loathe to expose themselves to international comparison. But comparisons are inevitably made on the basis of the raw police figures, and these comparisons are often unfair. Furthermore, crime is increasingly a transnational issue, and good crime data is essential in the quest for collective solutions. For these reasons, countries that are serious about tackling crime should participate in both the ICVS and CTS programs. Regional organizations concerned with crime issues, such as CARICOM, can help coordinate participation of members in these data collection programs.

2. Good policy making to reduce crime and violence does not happen by accident. The Regional Task Force on Crime and Security (CARICOM, 2002) called for the development of national crime control master plans and the establishment of national crime commissions to ensure multi-sectoral collaboration. National plans allow for cross-sectoral collaboration and serious discussions about the priorities in resource allocation; equally importantly, they offer a vehicle for the involvement of civil society organizations, where 
much of the expertise in violence prevention resides. While the Task Force recommendations have been heeded in some countries, in some they have not. Preparation of a national plan should be a priority in these countries.

3. National crime control master plans should recognize the complementarity of violence/crime prevention and control. The issue is not of prevention versus control, but rather the appropriate mix for local conditions. It is important to recognize that not all prevention interventions have long gestation periods and not all control interventions will have immediate impacts.

4. The reform of under-performing criminal justice systems should be a priority. Reform initiatives will have a greater probability of success if information systems and associated performance measurement indicators are used to chart progress in improving efficiency and quality of services and if attention is paid to ensuring that individual agencies in the criminal justice system are in alignment with one another and not working at crosspurposes. Modernization of policing through the use of information systems and problemoriented policing is a key element of criminal justice sector reform.

5. Youth violence is a particularly important issue in many countries. While there are a multitude of programs in the region to address youth violence, few if any have been subject to rigorous impact evaluation. At the same time, there is a wealth of information about what works in youth prevention in the U.S. and a few other developed countries. In the short run, regional policy makers could borrow from this toolkit of proven programs such as early childhood development and mentoring programs, interventions to increase retention of highrisk youth in secondary schools, and opening schools on after-hours and on weekends to offer youth attractive activities to occupy their free time. In the medium and long run, impact evaluations should systematically document what works in youth violence prevention in the Caribbean.

\section{Recommendations at the regional level}

10.30 Good policy making at the national level is important but not enough. Many of the issues facing the Caribbean transcend national boundaries and require a coordinated regional response. Important first steps have been taken with the creation of the Regional Task Force on Crime and Security, its 2002 report, and the new Management Framework for Crime and Security, created in 2005. While the creation of the Management Framework is an important step, much remains to be done in terms of funding these new institutions and ensuring that they have adequate staffing and effectively influence policy making at the national level.

10.31 Specific recommendations at the regional level include:

1. In the area of deportees, CARICOM has an important role to play in negotiating with developed nations for more support for the reintegration of deportees. At a minimum, this support can take the form of improved coordination and information flows between deporting agencies and Caribbean governments. More ambitiously, CARICOM could explore options for deporting nations to fund deportee reintegration programs. With or without international financing, more services should be offered to reintegrate deportees, along the lines of those provided by the Office for the Resettlement of Deportees in St. Kitts and Nevis. Serious studies on the issue of deportees are needed-both to quantify 
the impact of deportees on national crime rates, and to measure the cost-effectiveness of deportee reintegration programs. ${ }^{181}$

2. The chapter on drug trafficking provides a successful case of interdiction of cocaine in the Netherlands Antilles. Given that Caribbean countries are transit and not producer countries for cocaine, interdiction needs to be complemented by other strategies outside of the region (principally demand reduction in consumer countries and eradication and/or alternative development in producer countries). Within the region, policies focusing on mitigating the damage from drugs should focus on limiting the availability of firearms and on providing meaningful alternatives to youth.

3. Gun ownership is an outgrowth of the drug trade and, in some countries, a legacy of party politics and associated garrison communities. Within these environments which promote the demand for weapons, reducing gun ownership is a difficult undertaking. At the regional level, coordination between law enforcement agencies on intelligence and interdiction are important. At the national level or sub-regional level, better gun registries, marking and tracking can help, as can improved gun interdiction in ports. Long run and sustained reduction in the demand for guns, however, will hinge on progress in combating drugs and on changing the cultural factors which increase the demand of young men for weapons.

4. In general, regional coordination will be essential to minimize displacement effects. Particularly in the area of drug trafficking, successful national efforts may lead to criminal activities being displaced to other countries in the region. If displacement is to be avoided, it is essential that information be shared and that policies and interventions be coordinated.

\section{Final considerations}

10.32 The different approaches to crime and violence prevention outlined in the first section of this chapter mean that there are multiple possible entry points to reduce crime and violence. In one instance, the most promising approach may be in the context of a slumupgrading project; in another, in the context of a reform of the health service; in a third, in the context of a reform of the criminal justice system. There is no one "ideal” approach. The common denominator is that successful interventions are evidence-based, starting with a clear diagnostic about types of violence and risk factors, and ending with a careful evaluation of the intervention's impact which will inform future actions.

10.33 In general, a successful approach at that national level will involve multiple interventions. Evidence from developed countries suggests that some of the most cost-effective prevention interventions focus on children and families. Since some of these may pay dividends only in the medium- to long-run, they must be complemented by interventions that can generate significant short-run reductions in crime and violence. Candidates in this latter group include integrated citizen security approaches (which, as seen above, combine modern methods of policing with prevention interventions undertaken by both government and non-governmental

\footnotetext{
${ }^{181}$ At the time of the writing of this report, a CARICOM survey on deportees was forthcoming. The findings and recommendations were to be presented to the CARICOM Ministers of National Security and Heads of Conference and were not available at the time of this writing.
} 
organizations), situational crime prevention, and programs which address the immediate needs of youth at high risk for violent or criminal behavior. 


\section{REFERENCES}

Alda, E., Buvinic, M., and Lamas, J. 2005. "Emphasizing Prevention in Citizen Security: The Inter-American Development Bank's Contribution to Reducing Violence in Latin America and the Caribbean.” Inter-American Development Bank, Sustainable Development, Department Best Practices Series.

Aleph. 2006. “Estudio sobre la violencia juveniles.” Dominican Republic: Santo Domingo.

Alleyne D. and Boxill I. 2003. "The impact of crime on tourist arrivals in Jamaica.” International Journal of Tourism Research 5(5): 381-391

Álvarez, C. 2004. "La Educación en la Republica Dominicana: Logros y Desafíos Pendientes.” Serie de estudios Económicos y Sectoriales. RE2-04-015, Inter-American Development Bank. Washington DC.

Amnesty International, “Jamaica, Killings and Violence by Police: How many more victims?” April 2001. New York: Amnesty International.

Amnesty International. 2002. "Sexual Violence against Women and Girls in Jamaica.” Report of June $22^{\text {nd }}$, 2002, Amnesty International. http://web.amnesty.org/library/Index/ENGAMR380022006.

Arthur, C. 2006. “Murder in the Caribbean - How Does Haiti Compare?” Alterpresse, February 3. Available at http://www.alterpresse.org/spip.php?article4074.

Arscott-Mills, S., Gordon G., McDonald A., Holder Y and Ward, E. 2002. “A profile of Injuries in Jamaica.” Injury Control and Safety Promotion. 9(4): 227-234.

Associated Press. 2004. “Minister: Jamaican Crime Hurting Tourism.” August 30, 2004. CNN

Barker, G. 1995. "Situational Analysis of Drug Abuse among Youth at-Risk in the Caribbean: A Needs Assessment of Out-of-School Youth in St. Vincent and the Grenadines, Trinidad and Tobago, St. Maarten and Jamaica.” Mimeo. UNDCP.

Barker, G. and Fontes, M. 1996. "Review and Analysis of International Experience with Programs Targeted on Youth At-Risk.” LASHC Paper Series No. 5. World Bank, Washington, DC.

Barro, R. and Lee J.W. 1996. "International Measures of Schooling Years and Schooling Quality.” American Economic Review 86(2): 218-23.

Barro, R.J., Lee, J.W. 2000. "International Data on Education Attainment: Updates and Implications.” Washington D.C.: NBER. 
Becker, G. 1968. "Crime and Punishment: an Economic Approach.” The Journal of Political Economy 76(2): 169-217.

Bloom, D. et al. 2001. "Globalization, Liberalization and Sustainable Human Development: Progress and Challenges in Jamaica.” Jamaica Country Assessment Occasional Paper, UNCTAD/EDM/Misc.176. New York: United Nations Development Program.

Blum, R.W. and M. Ireland. 2004. "Reducing Risk, Increasing Protective Factors: Findings from the Caribbean Youth Health Survey.” Journal of Adolescent Health (35): 493-500.

Blum, R.W., et al. 2003. "Adolescent Health in the Caribbean: Risk and Protective Factors.” American Journal of Public Health, 93(3): 456-460.

Blum, R. W. 2005. Risk \& Protective Factors in the Lives of Youth: The Evidence Base. World Bank HDNCY Youth Development Lecture Series 11/01/05. Available at: www.worldbank.org/childrenandyouth

Bobea, L (ed.). 2003. Entre el crimen y el castigo: Seguridad ciudadana y control democrático en América Latina y el caribe. Caracas: Editorial Nueva Sociedad.

Bobea, L. 2003. "Economía política de la inseguridad y desafíos a las políticas de seguridad ciudadana en la República Dominicana: cero toleranica bajo la mirilla,” in L. Bobea (ed.) Entre el crimen y el castigo: Seguridad ciudadana y control democrático en América Latina y el caribe. Caracas: Editorial Nueva Sociedad.

Brea de Cabral, M. and E. Cabral Ramirez. 2005. “Aumenta la violencia en la República Dominicana?” Articulos Trabajos, Psicologica Cientifica, junio.

Bureau for International Narcotics and Law Enforcement Affairs. 2002. International Narcotics Control Strategy Report 2002. Washington, D.C.: United States Department of State.

Bureau for International Narcotics and Law Enforcement Affairs. 2005. International Narcotics Control Strategy Report 2005. Washington, D.C.: United States Department of State.

Bureau for International Narcotics and Law Enforcement Affairs. 2006. International Narcotics Control Strategy Report 2006. Washington, D.C.: United States Department of State, p. 176.

Bureau of Justice Statistics. 2005. Compendium of Federal Justice Statistics 2003. Washington, D.C.: Department of Justice.

Bureau of Statistics. 2006. Statistical Bulletin. Georgetown, Guyana: Government of Guyana. Available at http://www.statisticsguyana.gov.gy

Burrows C. and Matthias, P. 2003. "Combating the Proliferation of Small Arms and Light Weapons in the Caribbean.” Unpublished paper, Trinidad \& Tobago. 
Buvinic, M. and A. Morrison. 1999. “Violence Prevention: Technical Notes.” Washington, D.C.: Inter-American Development Bank.

Buvinic, M. et al. 1999. "Violence in Latin America and the Caribbean: A Framework for Action.” Washington, D.C.: Inter-American Development Bank.

Cabral Ramirez, E. and M. Brea de Cabral. 2006. "Violencia en la Republica Dominicana: Tendencias Recientes.” Psicología Cientifica.com. Artículo Publicado el 02 de diciembre de 2003

http://www.psicologiacientifica.com/bv/psicologia-96-1-violencia-en-la-republicadominicana-tendencias-recientes.html

Caceres, F. and G. Estevez. 2004. Violencia Conyugal en la Republica Dominicana: Hurgando Tras sus Raices. Santo Domingo: PROFAMILIA.

Cambridge, U. 2005. "Another bombing in Port of Spain." Trinidad Express, 28 October 2005.

Caribbean News Net. 2005. “Jamaica’s Murder Rate Hits All-time High.” November 25 Kingston, Jamaica.

CARICOM. 2000. “Regional drug control activies.” Paper prepared for Rotary International's Model CARICOM Youth Summit, December.

CARICOM Regional Task Force on Crime and Security. 2002. Report on Crime and Security. Available at:

http://www.caricom.org/jsp/community/regional_issues/crime_and_security_task_force_r eport_2002.pdf

Center for the Study of Prevention of Violence. 2003. "Blueprints for Youth Violence Prevention.” University of Colorado Includes Specific Case Studies on Bullying Prevention, Mentoring Programs, Family Therapy, Parent Training and others. Available at: www.colorado.edu/cspv

Centers for Disease Control and Prevention. 2003. "Youth Risk Behavior Surveillance System (YRBSS).” Atlanta: CDC.

Centers for Disease Control and Prevention. 2005. Measuring violence-related attitudes, behaviors, and influences among youths: A Compendium of Assessment Tools, Second edition. Atlanta: CDC.

Central Bureau voor de Statistiek. 2006. "Eerste Resultaten Arbeidskrachtenonderzoek Curaçao 2005.” Willemstad: Centraal Bureau voor de Statistiek.

Central Statistical Office, Ministry of Planning, Government of the Republic of Trinidad and Tobago, Unpublished Reports. 
Central Statistical Office. 2006. "Population, Social \& Vital Statistics.” Port of Spain: Ministry of Planning and Development, Government of the Republic of Trinidad and Tobago. Available at http://cso.gov.tt/statistics/pdf/Table3_1998-1999.pdf

Centro de Estudios de Justicia de las Américas. 2005. "Report on Judicial Systems in the Americas 2004/5.” Santiago: CEJA.

CEPAL and FNUAP. 2000. Juventud, Población y Desarrollo en América Latina y el Caribe: Problemas, Oportunidades y Desafíos. Serie Libros No. 59. Santiago: CEPAL.

CEPAL y OIJ. 2004. La Juventud en Iberamérica: Tendencias y Urgencias. Santiago: CEPAL.

CEPAL y OIJ. 2004. Programa Regional de Acciones para el Desarrollo de la Juventud en America Latina: 1995-2000. Santiago: CEPAL.

City of Minneapolis, Department of Health and Family Support. 1998. "Promising Approaches to Youth Violence Prevention: A Program Planning Guide.” Minneapolis: City of Minneapolis.

Clouatre. D. 2002. "Haiti”, in H. Kritzer (ed.), Legal Systems of the World, Volume II. Santa Barbara, California: ABC-CLIO.

Collihan, M. amd C. Danopoulos. 1993. "Coup Attempt in Trinidad: Its Causes and Failure." Armed Forces and Society 19:435.

Cornell, D. G. 2003. "What Works in Youth Violence Prevention.” Virginia Youth Violence Project. Charlottsville, Virginia: University of Virginia. Available at www.curry.edschool.virginia.edu/curry/centers/youthviolence.

Cunninghan, W. and M. Correia. 2003. "Caribbean Youth Development: Issues and Policy Directions.” Washington, D.C. World Bank.

Darby. F. 2006. "Background Paper on Criminal Justice in Jamaica.” Washington, D.C.: World Bank.

Davidson, Taneisha. 2006. "Deportees Get a Reception with a Difference.” Jamaica Observer. Kingston, Jamaica: September $3^{\text {rd }}$

De Albuquerque, K., and J. McElroy. 1999a. "Tourism and Crime in the Caribbean.” Annals of Tourism Research 26:968-984.

De Albuquerque, K., and McElroy J. 1999b. “A Longitudinal Study of Serious Crime in the Caribbean.” Caribbean Journal of Criminology and Social Psychology 26: 968-984

Deininger K and L. Squire. 1996. “A New Data Set Measuring Income Inequality.” World Bank Economic Review 10 (3): 565-591. 
Demographic and Health Surveys. "Understanding Domestic Violence.”

http://measuredhs.com/topics/gender/profiles/understanding_domviol_2004_11.cfm..

Calverton, MD: Macro International.

Demombynes G. and B. Ozler. 2005. “Crime and Local Inequality in South Africa.” Journal of Development Economics 76: 265-292

Department of Homeland Security. 2005. Yearbook of Immigration Statistics 2005. Washington, D.C.: Department of Homeland Security.

Department of State. 2006. International Narcotics Control Strategy Report 2006. Washington D.C.: USDOS.

Dillon. E. 2004. "Regional Security Cooperation: Traditional and non-Traditional Areas," in Griffith Invelaw (ed.), Caribbean Security in the Age of Terror: Challenge and Change. Kingston: Ian Randle Publishers.

Direction Centrale de la Police Judiciaire. 2005. “Aspects de la criminalité et de délinquance constaté en France en 2004, Tomé 2. “ Paris: Direction Centrale de la Police Judiciaire.

Docquier, F. and A. Marfouk. 2006. "International migration by education attainment, 19992000,” in Ç Özden and M. Schiff (eds.), International Migration, Remittances, and the Brain Drain. Washington, D.C.: World Bank and Palgrave Macmillan.

Drug Enforcement Administration. 1996. "Colombian heroin a major threat.” Press release 3, September 1996.

Dunn, H. and L. Dunn. 2002. People and Tourism: Issues and Attitudes in the Jamaican Hospitality Industry.” Kingston, Jamaica: Arawak Publications.

Economic Commission for Latin America and the Caribbean. 2005. Panorama social de América Latina 2005. Santiago: ECLAC. .

Economic Commission for Latin America and the Caribbean. 2006. Statistical Yearbook 2005. Santiago: ECLAC.

Elbers, C., Lanjouw, J., and Lanjouw, P. 2003. "Micro-Level Estimation of Poverty and Inequality.” Econometrica 71(1): 355-364.

Ellis H. 1991. "Report on Research into the Causes of Crime and Violence in Jamaica: a Study of Prison Inmates.” Kingston: National Task Force on Crime and Violence.

Ellsberg, M. and L, Heise. 2005. "Researching Violence against Women: A Practical Guide for Researchers and Activists." Geneva: WHO and PATH. 
Europol. 2004. “2004 European Union Organised Crime Report.” Luxembourg: Office for Official Publications of the European Communities.

Europol. 2005. "European Union Situation Report on Drug Production and Drug Trafficking 2003 - 2004.” The Hague: Europol.

Europol. 2006. “Drugs 2006.” The Hague: Europol.

Fajnzylber, P. et al. 2000. “Crime and Victimization: an Economic Perspective.” Economía 1 (1): 219-278.

Fares, J. et al. 2006. "How are Youth Faring in the Labor Market? Evidence from Around the World." Background paper for the WDR 2007.” Washington D.C.: World Bank.

Farrington, D.P. and Welsh, B.C. 1999. "Delinquency Prevention using Family-Based Interventions.” Institute of Criminology, University of Cambridge; Department of Criminal Justice, University of Massachusetts at Lowell. Children and Society 13 (4): 287303

Felson, M. 1994. Crime and Everyday Life: Insight and Implications for Society. Thousand Oaks, CA: Pine Forge Press.

Fenley M 2000. "The Prevention of Youth Violence - A Framework for Community Action.” Atlanta: Centers for Disease Control and Prevention.

Francis, A., A. Harriott, et al. 2003. “Crime and Development: The Jamaican Experience.” University of the West Indies (Mona Campus).

García-Moreno, C., Cansen, H., Watts, C., Ellsberg, M., and Heise, L. 2005. WHO Multi-country Study on Women's Health and Domestic Violence against Women. Initial results on prevalence, health outcomes and women's responses. Geneva, Switzerland: World Health Organization.

Gaviria, A., 2000. “Comment on Crime and Victimization: an Economic Perspective.” Economia 1 (1): 288-303.

Glaser E. et al. 1996. “Crime and Social Interactions.” Quarterly Journal of Economics 11: 507548.

Gottfredson, D. et al. 1995. “The Schools” in J.Q. Wilson and J. Petersilia (eds.) Crime. San Francisco: Institute for Contemporary Studies.

Greenwood 1996 "Responding to Juvenile Crime: Lessons Learned.” The Future of Children, 6 (3): 75-85. 
Greenwood, P.W., Model, K.E., Rydell, C.P. 1998. Diverting Children from a Life of Crime: Measuring Costs and Benefits. Santa Monica, CA: Rand Corporation.

Griffin, C. 2002. "Criminal Deportation: The Unintended Impact of US Anti-crime and Antiterrorism Policy along its third Border.” Caribbean Studies 30 (2).

Grullon, A. 2005. “Analysis: Dominican Republic’s Drug Problem.” United Press International, Santa Domingo, February 4.

Guerra N.G., and K. R. Williams. 1996. A Program Planning Guide for Youth Violence Prevention: a Risk-Focused Approach. Boulder, Colorado: University of Colorado, Center for the Study and Prevention of Violence.

Guerra, N.G. 2005. "Youth Crime Prevention. Community Based Crime and Violence Prevention in Urban Latin America and the Caribbean.” World Bank Water, Disaster Management, and Urban Development Group. Latin America and Caribbean Region. World Bank: Washington D.C.

Guerra, N.G. 2006. "Youth at Risk in Latin America and the Caribbean: Preventing Violence and Crime Policy Recommendations for the World Bank Toolkit.” Background paper prepared for the World Bank. Washington D. C.: World Bank.

Guerrero, R. and Concha-Eastman, A. 2001. "An epidemiological approach for the prevention of Violence. The DESAPAZ Program in Cali, Colombia.” World Health and Population 4 (1).

Guerrero R. 1998. "Study of the Magnitude of Violence. Violence in Latin America: Policy Implications.” Cambridge, Massachussetts: David Rockefeller Center for Latin American Studies.

Guerrero, I. 2005. "Delincuencia juvenil en la República Dominicana." Available at http://html.rincondelvago.com/delincuencia-juvenil-en-la-republica-dominicana.html

Guevara, R. 2002. "Drug Corruption in Guatemala and the Dominican Republic: Rogelio E. Guevara.” From: Congressional Testimony October 10, 2002, Federal Document Clearing House.

Gunst, L. 1999. 'Born fi' Dead: A Journey into the Jamaican Posse Underworld. Edinburgh: Cannongate.

Guyana Bureau of Statistics. 2005. Statistical Bulletin July-September. Georgetown, Guyana: Guyana Bureau of Statistics.

Guyana Government Information Agency. 2004. "Murder Rate Decreased Significantly.” Georgetown, Guyana: Government Information Agency. 
Haddon, W.A. Jr. 1972. “A Logical Framework for Categorizing Highway Safety Phenomena and Activity..” Journal of Trauma 12(3):193-207.

Halcon, L. et al. 2003. “A portrait of adolescent health in the Caribbean.” American Journal of Public Health 93 (11): 1851-7.

Halcon, L. et al. 2000. "A portrait of adolescent health in the Caribbean.” University of Minnesota and PAHO. Minneapolis.

Halcón, L. et al. 2003. “Adolescent Health in the Caribbean: A Regional Portrait.” American Journal of Public Health: 93:1851-1857.

Hammergren, L. Forthcoming. Envisioning Reform: Conceptual and Practical Obstacles to Improving Judicial Performance in Latin America. University Park: Penn State Press, 2007.

Hammergren, L. 2002. Twenty Years of Reforms and Not a Consensus in Sight: DonorSupported Criminal Justice Reform. Washington DC: World Bank.

Hermann, B. and Haddad, E. 2003. "Estimating Urban Amenities Implicit Prices: Evidences from Sao Paulo City.” University of Sao Paulo, Brazil.

Harriott, Anthony. 2004a. "Fear of Criminal Victimization in a Reputedly Violent Environment”, in A. Harriott et al. Crime and Criminal Justice in the Caribbean. Kingston: Arawak Publications.

Harriott, Anthony. 2004b. “The Jamaican Crime Problem: Some policy considerations”, in A. Harriott et al. Crime and criminal justice in the Caribbean. Kingston: Arawak Publications.

Harrison, P. and Beck, A. 2005. "Prison and Jail Inmates at Midyear 2004,” Bureau of Justice Statistics, U.S. Department of Justice, Office of Justice Programs, Washington, D.C., April 2005, NCJ 208801. For a complete copy of this report, please see http://www.ojp.usdoj.gov/bjs/pub/pdf/pjim04.pdf

Hasbun, J. et al. 1999. "Estudio cualitativo sobre el acceso al sistema judicial dominicana.” Background paper prepared for the World Bank and FINJUS. Washington D. C.: World Bank.

Hawkins, D. et al. 2000. "Predictors of Youth Violence. “ Juvenile Justice Bulletin. Washington, D.C.: US Department of Justice.

Headley, B. and Jones, M. eds. 2005. Deported Volume 1: Entry and Exit Findings Jamaicans Returned Home from the U.S. Between 1997 and 2003. Unpublished, Kingston. 
Heise, L., Ellsberg, M., and Gottemoeller, M. 1999. “Ending Violence against Women.” Population Reports, Series L, No. 11. Baltimore: Johns Hopkins University School of Public Health.

Holder, Y. and F. Mutota. 2006. "Guns and Criminality: A Case Study of Trinidad and Tobago.” Background paper prepared for the World Bank study on Crime and Violence in the Caribbean, Washington D.C.: World Bank.

Howell, J.C. 1998. Youth Gangs: An Overview. Washington, D.C.: US Department of Justice.

Instituto Dominicano de Desarrollo Integral. 2006. "Informe de resultados de sesiones focales de grupos temáticos con jóvenes en republica dominicana." Background consultations for the World Development Report 2007.

Inter-American Development Bank and Caribbean Group for Cooperation in Economic Development. 2000. "Challenges of Capacity Development: Towards Sustainable Reforms of Caribbean Justice Sectors.” Washington, D.C.: IDB.

Inter-American Development Bank. 2002. "Youth Violence Prevention.” Technical Note 10 in M. Buvinic and A. Morrison (eds.), Technical Notes: Violence Prevention. Washington, D.C.: IDB.

Inter-American Development Bank. 2002b. "Profile I Jamaica. Background document for preparing a Youth Development Program, project JA-0119.” Washington, D.C.: IDB.

Inter-American Development Bank. 2003. "Inequality, Exclusion and Poverty in Latin America and the Caribbean: Implications for Development.” EC/IDB Seminar: Social Cohesion in Latin America and the Caribbean, June.

International Action Network on Small Arms "Central America, Mexico and the Caribbean Region” at http://www.iansa.org/regions/camerica/camerica.htm

International Narcotics Control Board. 2001. "Annual Report of the International Narcotics Control Board.” United Nations: Vienna, Austria.

Jamaica Constabulary Force Statistical Department. 2000. .Jamaica Constabulary Force Crime Review 1999. Kingston, Jamaica.

Jastrab, J. et al. 1996. "Impacts of Service: Final Report on the Evaluation of American Conservation and Youth Corps.” Washington, D.C.: ABT Associates.

Jastrab, J., et al. 2004. "Serving Country and Community: A Longitudinal Study of Service in AmeriCorps.” Washington D.C.: ABT Associates. 
Jimeno, J. and D. Rodriguez-Palenzuela. 2002. "Youth Unemployment in the OECD:

Demographic Shifts, Labour Market Institutions, and Macroeconomic Shocks.” Working Paper No. 115. Brussels: European Central Bank.

Judson R.A. and A.L. Owen. 1999 "Estimating Dynamic Panel Data models: a Guide for Macroeconomists.” Economics Letters 65(1): 9-15.

Kellerman, A. et al. "Preventing Youth Violence: a Summary of Program Evaluations.” Seattle, WA: University of Washington Urban Health Initiative.

Kishore, S. and K. Johnson. 2004. "Profiling Domestic Violence: A Multi-country Study.” Calverton, MD: Measure DHS.

Kiviet, J.F. 1995. “On Bias, Inconsistency, and Efficiency of Various Estimators in Dynamic Panel Data Models.” Journal of Econometrics, 68 (1): 53-78.

Klare, M. and Anderson, D. 1996. A Scourge of Guns: The Diffusion of Small Arms and Light Weapons in Latin America. Washington, D.C: Arms Sales Monitoring Project, Federation of American Scientists. http://www.fas.org/asmp/library/scourge

Kolbe A and R. Hutson. 2006. "Human Rights Abuse and other Criminal Violations in Port-auPrince, Haiti: a Random Survey of Households.” Lancet 368:864-73.

Kowlessar, G. 2006. “Express Kidnappings.” The Trinidad Guardian, March 5, 2006. Trinidad and Tobago.

Latinobarómetro. 2005. Informe Latinobarómetro. 2005. Santiago de Chile: Corporación Latinobarómetro. Available at www.latinobarómetro.org.

Lapham, S. et al. 1993. "We, the American Foreign Born.” Washington, D.C.: United States Department of Commerce, Economics and Statistics Division, Bureau of the Census.

Leung, S.F. 1995. “Dynamic Deterrence Theory.” Economica 62: 65-87.

Levitt, S. 1998. “Juvenile Crime and Punishment.” Journal of Political Economy 106 (6): 11561185.

Lipsey, M. W., \& Wilson, D. B. 1998. "Effective interventions with serious juvenile offenders: A synthesis of research.” In R. Loeber \& D. P. Farrington, eds., Serious and violent juvenile offenders: Risk factors and successful interventions. Thousand Oaks, CA: Sage.

Lumpe L. 1997. “U.S. Policy on Small/Light Arms Exports” from Proceedings of American Academy of Arts and Sciences Conference on Controlling Small Arms. Washington, D.C.: AAAS. 
Luther, D. et al. 2002. "Caribbean Qualitative Youth Study: Dominican Republic and St. Lucia,” LCSPG/World Bank, draft. Washington D. C.: World Bank.

Maharaj, P. 2004. “\$40 m Paid out in Ransom.” Trinidad and Tobago Express. July 12.

Mansingh A. and Ramphal, P. 1993. "The Nature of Interpersonal Violence in Jamaica and its Strain on the National Health System.” The West Indian Medical Journal 42 (2): 53-56.

Margolin, G. 1998. "Effects of domestic violence on children,” in P. Trickett and C. Schellenbach (eds.), Violence against Children in the Family and Community. Washington, D.C.: American Psychological Association.

Mathers C.D. et al. 2003. “The Global Burden of Disease in 2002: Data Sources, Methods and Results. GPE Discussion Paper No. 54. Geneva: World Health Organization.

McAlister, A. 1998. La violencia juvenil en las Américas: estudios innovadores de investigación, diagnóstico y prevención. Washington DC: Pan-American Health Organization.

McDonald, L. and H. Frey. 1999. "Families and Schools Together: Building Relationships." Juvenile Justice Bulletin. Washington, D.C.: US Department of Justice.

Meeks-Gardner, J. 2001. “A case control study of family and Social Determinants of Aggression in Jamaican Children.” Kingston: Planning Institute of Jamaica.

Mercy, J., Rosenberg, M., Powell, K., Broome, C., and W L Roper. 1993. "Public Health Policy for Preventing Violence.” Health Affairs 12 (4): 7-29.

Ministry of Justice. 2005. “Annual Report of the Coast Guard of the Netherlands Antilles and Aruba."

Ministry of National Security. 2006. "National Security Strategy for Jamaica: Toward a Secure and Prosperous Nation. Green Paper. Kingston: Ministry of National Security.

Mocan H. et al. 2005. “A Dynamic Model of Differential Human Capital and Criminal Activity.” Economica 72(288): 655-681.

Mockus, A. 2001. Cultura ciudadana, programa contra la violencia en Santa Fe de Bogotá, Colombia, 1995-1999. Washington, DC: Inter-American Development Bank

Mogensen, M. 2005. “Corner and Area Gangs of Inner-city Jamaica”, in L. Dowdney (ed.) Neither war nor peace. Rio de Janeiro: Viva Rio.

Morrison, A. and M.B. Orlando. 2005. "The Costs and Impacts of Gender-Based Violence in Developing Countries: Methodological Considerations and New Evidence.” Working Paper Series: Washington, D.C.: World Bank. 
Moser, C. and J. Holland. 1997. “Urban Poverty and Violence in Jamaica”, in: World Bank Latin America and Caribbean Studies: Viewpoints. Washington, D.C.: World Bank.

Moser, C. and B. van Bronkhorst. 1999. "Youth Violence in Latin America and the Caribbean: Costs, Causes and Interventions.” Sustainable Development Working Paper No. 3, Urban Peace Program Series. Washington D.C.: World Bank.

Moser, C., Winton A., and Moser, A. 2005. "Violence, Fear, and Insecurity among the Urban Poor in Latin America.” In M. Fay, ed. The Urban Poor in Latin America. Washington DC: World Bank.

National Alliance of Gangs Investigators Associations, "National Gang Threat Assessment 2005.” Washington, D.C.: Bureau for Justice Assistance, 2005.

National Center for State Courts and USAID. 2006. "Pretrial Detention in Haiti.” Washington, D.C.: USAID.

National Centre for Youth Development. 2003. “National Youth Policy.” Kingston: Ministry of Education, Youth and Culture.

National Clearinghouse on Child Abuse and Neglect. 2001. "Understanding the effects of maltreatment on early brain development.” Washington, D.C.: Department of Health and Human Services.

National Criminal Intelligence Service. 2005. "The Threat from Serious and Organized Crime 2004/5 - 2005/6.” London: NCIS.

National Drug Intelligence Center. 2005. “National Drug Threat Assessment 2005.” Washington, D.C.: United States Department of Justice.

National Drug Intelligence Center. 2004, 2003, 2002. “National Drug Control Strategy Reports.” Washington DC: Department of Justice.

National Institute on Drug Abuse. 2005. “Monitoring the Future: Overview of Key Findings.” Washington D.C.: NIDA

National Ombudsman. 2006. "100\%-Controles op Schiphol: Over bolletjesslikkers en onschuldige slikverdachten.” The Hague: Office of the National Ombudsman.

Office to Monitor and Combat Trafficking in Persons. 2005. "Human Trafficking Report 2005.” Washington D.C: United States Department of State.

Oficina Nacional de Estadística. 2005. República Dominicana en Cifras. Santo Domingo: ONE.

Ohene, S, Ireland, M, and R. Blum. 2005. The Clustering of Risk Behaviors among Caribbean Youth. Maternal and Child Health Journal. 9 (1): 91-100. 
Olds, D.L. 1998. “Long-term effects of Nurse Home Visitation on Children's Criminal and Antisocial Behavior: A 15-Year Follow Up of a Randomized Controlled Trial.” Journal of the American Medical Association 280: 1238-1244.

Organization of American States. 2004a. "Comparative Report on Nationwide School Surveys in Seven Countries.”. Washington: D.C.: Inter-American Drug Abuse Control Commission.

Özden, Ç. and M. Schiff (eds.). 2006. International Migration, Remittances, and the Brain Drain. New York: Palgrave MacMillan and the World Bank.

Pan American Health Organization. 2004. "Activa Project: Cultural Norms and Attitudes towards Violence in Selected Cities in L:atin America and Spain.” Washington, D.C.: PAHO.

Phillips,. P. 2005. “The battle for security.” Annual Wilton Park Conference (September). London.

Posada, C.E. 1994. "Modelos económicos de la criminalidad y la posibilidad de una dinámica prolongada.” Planeación y Desarrollo 25: 217-25.

Presidencia de la República Dominicana. 2006. SOLIDARIDAD—La Revista, Numero 1. Santo Domingo: Presidencia de la Republica.

Presidencia de la República Dominicana, Consejo Nacional de Drogas. 2006. "Plan Nacional Anti-Drogas 2000-2005.” Santo Domingo.

President's Commission on Organized Crime. 1986. “America's Habit: Drug Abuse, Drug Trafficking, and Organized Crime.” Washington, D.C.: President’s Commission.

Procuraduría General de la República Dominicana. 2006. “Prison Population Statistics..”Santo Domingo:

Procuraduría General de la Republica Dominicana, Departamento de Prevención de la Corrupción Administrativa. 2006. “Acta de Acusación: Imputados: Ramón Buenaventura Báez Figueroa, Marcos Antonio Báez Cocco, Vivian Altagracia Lubrano Carvajal del Castillo, Luis Rafael Alvarez Renta y Jesua Maria Troncoso Ferrua. Querellante: Banco Central de la Republica Dominicana, Superintendencia de Bancos y Banco Intercontinental.” Santo Domingo.

Procuraduría General de la Republica Dominicana. 2006. “Los Lineamientos de la Política Criminal dentro de los parámetros del Plan Nacional de Seguridad Democrática para la Republica Dominicana.” Santo Domingo.

Procuraduría General de la República Dominicana. 2006. “Informe sobre muertes violentas del enero - diciembre 2005.” Santo Domingo. 
Procuraduría General de la República Dominicana. 2006. Plan de Seguridad Democrática. Departamento de Estadísticas.

Robles, M. 2005. "Dominican Republic Poverty Map” in Dominican Republic Poverty Assessment. Washington, D.C.: World Bank and Inter-American Development Bank.

Rogers, D. 1999. "Youth Gangs and Violence in Latin America and the Caribbean: A Literature Survey.” LCR Sustainable Development Working Paper No. 4. Washington D.C.: World Bank.

Royal Canadian Mounted Police Criminal Intelligence Directorate. 2005. "The Drug Situation in Canada - 2004.” Ottawa: Royal Canadian Mounted Police.

Rumbaut, R. et al. 2006. "Debunking the Myth of Immigrant Criminality: Imprisonment Among First- and Second-Generation Young Men.” Washington, D.C.: Migration Policy Institute.

Runyan, C. 1998. "Using the Haddon Matrix: Introducing the Third Dimension.” Injury Prevention 4:302-307.

Russell, J. and X. Solórzano. 2001. "Políticas de adolescentes y jóvenes: experiencias de Colombia, República Dominicana y Nicaragua.” Geneva: World Health Organization, Adolescent Health and Development Department.

Sah, R. 1991, "Social Osmosis and Patterns of Crime.” Journal of Political Economy 99(6): 1272-1295.

Salcedo, C.R.C. 2002. "Transparency in the Selection of Supreme Court Justices in the Dominican Republic.” Due Process of Law Foundation: Washington DC. Available on the DPLF website at www.dplf.org/frameset_pub_span.htm

Sanchez, J.F. and T. Osicka. 2006. "Note on Children and Youth Demographics in Rural and Urban Settings.” World Bank Children and Youth Unit, Human Development Network. Washington D.C.: World Bank.

Sansfaçon, D. and B. Welsh. 1999. Crime Prevention II: Comparative Analysis of Successful Community Safety. Montreal: International Centre for the Prevention of Crime.

Schneidman, M. 1996. "Targeting At-Risk-Youth: Rationales, Approaches to Service Delivery and Monitoring and Evaluation Issues.” LASHC Paper Series 2. Washington D. C.: World Bank.

Schweinhart L. et al. 1993. "Significant Benefits: The High/Scope Perry Preschool Project Study Through Age 27.” Ypsilanti, MI: High/Scope Educational Research Foundation.

Schweinhart, L.J. et al. 2005. "Lifetime Effects: The High/Scope Perry Preschool Study Through Age 40.” Ypsilanti, Mich.: High/Scope Educational Research Foundation. 
Secretaría de Estado de Educación y Cultura. 2003. Education Strategic Development Plan. Santo Domingo.

Secretaría de Estado de Educación y Cultura. 2005. "Experiencia de descentralización de la educación en la República Dominicana.” Santo Domingo.

Secretaría de Estado de Educación. 2005. Manual Operativo: EBA y PREPARA. Santo Domingo.

Secretaría de Estado de la Juventud. 2004. Informe de Situación. Santo Domingo.

Secretaría del Trabajo. Programa de Juventud y Empleo: Manual Operativo. Santo Domingo.

Secretariado Técnico de la Presidencia y Oficina Nacional de Estadística. 2005. "Encuesta nacional de hogares de propósitos múltiples.” Santo Domingo.

Sherman, L. 1997. "Preventing crime: what works, what doesn’t, what’s promising." Washington, D.C.: National Institute of Justice.

Sickmund, M. et al. 1997. "Juvenile Offenders and Victims: 1997 Update on Violence.” Washington D.C.: Office of Juvenile Justice and Delinquency Prevention.

Simms-Vaughan, M. 2000 "Cognition, educational attainment and behavior in a cohort of Jamaican children: A Comprehensive Look at the Development and Behaviors of Jamaica’s Eleven Year Olds.” Kingston: Planning Institute of Jamaica.

Singh, W. 2001. “Children, the Law and Juvenile Justice.” In Barrow, C. ed. Children’s Rights Caribbean Realities. Kingston: Ian Randle Publishers.

Smith, C. and T. Thornberry. 1995. "The relationship between childhood maltreatment and adolescent involvement in delinquency." Criminology 33(4): 451-73.

Southern California Center of Excellence on Youth Violence Prevention. 2004. The Complete Red Team Report, Including the Youth Violence Prevention Blueprint: Goals and Action Strategies. Riverside, California. Available at www.stopyouthviolence.ucr.edu

Stamler, R. et al. 1985. "Illicit traffic and abuse of cannabis in Canada." Bulletin on Narcotics, Vol 37(4): 37-49.

Sullivan, M. 2006. "Caribbean Region: Issues in U.S. Relations." Congressional Research Service Report for Congress. Washington, D.C.: CRS.

Thornton T. et al. 1998. Best Practices of Youth Violence Prevention - A Sourcebook for Community Action. Atlanta: Centers for Disease Control and Prevention. 
Tierney, J. P., and J. Baldwin Grossman, with N. L. Resch. 2000. "Making a Difference: An Impact Study of Big Brothers Big Sisters.” Philadelphia: Public/Private Ventures.

Tolan, P. and N. Guerra. 1994. "What Works in Reducing Adolescent Violence: an Empirical Review of the Field.” Boulder: CO: University of Colorado Center for the Study of Violence Prevention.

Transparency International. 2006. “Global Corruption Barometer 2006 Report.” Berlin: TI, 2005.

Trimbos Institute. 2005. “National Drug Monitor, Annual Report 2004.” Utrecht: Trimbos Institute.

UNICEF - Jamaica. 2005. "Violence against Children in the Caribbean Region: A Desk Review.” Kingston: UNICEF.

United Nations. 2001 "United Nations Programme of Action to Prevent, Combat and Eradicate the Illicit Trade in Small Arms and Light Weapons in All Its Aspects.” UN Document A/CONF.192/15.

United Nations 2003. World Youth Report: The global situation of young people. United Nations publication - Sales No. E.03.IV.7

United Nations. 2003. World Urbanization Prospects: The 2003 Revision. New York: United Nations.

United Nations. 2004. World Urbanization Prospects: The 2004 Revision. New York: United Nations.

United Nations. 2004. "Programme of Action of the United Nations International Conference on Population and Development.” Cairo: United Nations.

United Nations. 2004. World Population Prospects: The 2004 Revision. New York: United Nations.

United Nations. 2005. World Population Prospects: The 2005 Revision. New York: United Nations.

United Nations. 2005. World Youth Report 2005. New York: United Nations.

United Nations. 2006 "Report of the Secretary-General on the United Nations Stabilization Mission in Haiti.” February 3,2006. Document S/2006/60.

United Nations Country Team. 2005. United Nations Common Country Assessment of Development Challenges in Guyana. Georgetown: UN, May 2005. 
United Nations Development Programme. 2006. Human Development Report 2006. New York: UNDP.

United Nations International Drug Control Programme. 2002. "Fact Sheet on Inhalants and Solvents: Inhalant/Solvent Use in the Caribbean.” Barbados. Available at http://www.unodc.org/pdf/barbados/caribbean_factsheet_inhalantsolvent_2002.pdf

United Nations Office on Drugs and Crime. 2002. "Crime Trends in the Caribbean and Responses.” Report submitted to UNODC by A. Harriott. Vienna: UNODC.

United Nations Office on Drugs and Crime. 2004. Annual Reports Questionnaire. ARQ data, June 25, 2004

United Nations Office on Drugs and Crime. 2004. "The value of illegal drug exports transiting the Caribbean: 1981-2000.” Caribbean Regional Office, United Nations Office on Drugs and Crime.

United Nations Office on Drugs and Crime. 2005. Crime and Development in Africa. Vienna: UNODC.

United Nations Office on Drugs and Crime. 2006. World Drug Report. Vienna: UNODC.

U.S. Department of Health and Human Services. 2001. Youth violence: a report of the Surgeon General. Rockville, Maryland: U.S. Department of Health and Human Services, CDC, Substance Abuse and Mental Health Services Administration, and National Institutes of Health.

US Department of Justice, Office of Juvenile Justice and Delinquency Prevention. 2004. Blueprints for Violence Prevention. Boulder, CO: University of Colorado at Boulder.

U.S. Department of Labor, Bureau of International Labor Affairs. 2004. "Dominican Republic: Government Policies and Programs to Eliminate the Worst Forms of Child Labor." Washington, D.C.: Department of Labor.

U.S. Department of State. 2002. "Country Report: Dominican Republic.”

U.S. Department of State. 2003. International Narcotics Control Strategy Report 2003. Washington, D.C.: Department of State.

U.S. Department of State. 2004. "Informe referente a las prácticas de derechos humanos en la República Dominicana.”

U.S. Department of State. 2006. “Country Report on Human Rights Practices: Dominican Republic.” Washington D.C. 
U.S. Department of State. 2006. International Narcotics Control Strategy Report 2006. Washington, D.C.: Department of State.

U.S. Department of State Bureau of Consular Affairs. March 2006. “Colombia,” Consular Information Sheet.

United States Drug Enforcement Administration, "Caribbean Corridor Initiative leads to 9 arrests and seizure of 4,488 pounds of cocaine.” DEA Press Release. September 5, 2005.

Vera Institute of Justice. 2004. "Measuring Progress toward Safety and Justice: A Global Guide to the Design of Performance Indicators Across the Justice Sector.” New York: Vera Institute.

Walker, S., Grantham-Mcgregor, S., Himes, J., Williams, S., and Bennett, F. 1994. "Nutritional and Health Determinants of School Failure and Dropout in Adolescent Girls in Kingston, Jamaica.” Washington, DC: International Center for Research on Women.

Walmsley, R. 2003. “Global incarceration and prison trends.” Forum on Crime and Society 3(2).

Walmsley, R. 2005. World Prison Populations List: Sixth Edition. London: Kings College, International Centre for Prison Studies.

Ward, E. et al. 2002.“The Establishment of a Jamaica All-injury Surveillance System.” Injury Control and Safety Promotion 9(4): 219-225.

Weaver, K. and Maddaleno, M. 1999. "Youth Violence in Latin America: Current Situation and Violence Prevention Strategies.” Revista Panamericana de Salud Pública 5 (4/5): 338344.

WHO. 2001. "Small Arms and Global Health.” WHO Contribution to the UN Conference on Illicit Trade in Small Arms and Light Weapons, July 9-20, 2001.

WHO. 2002. World Report on Violence and Health. Geneva: WHO.

WHO. 2003. "Youth Violence and Alcohol Fact Sheet.” Geneva: WHO.

Wilson, J. Q. 2004 “Crime and Public Policy.” In Wilson and Petersilia, eds. Crime: Public Policies for Crime Control. Institute for Contemporary Studies: 537-538.

Wintemute G. 1994. Ring of Fire: The Handgun Makers of Southern California. Davis, California: 1995-2007 WGBH Educational Foundation. Available at http://www.pbs.org/wgbh/pages/frontline/shows/guns/ring/companies.html

Women’s Institute for Alternative Development. 2006. “A Human Security Concern: The Traffic, Use and Misuse of Small Arms and Light Weapons in the Caribbean.” Republic of Trinidad and Tobago, Port of Spain: WINAD. 
World Bank. 2000. "Trinidad and Tobago: Youth and Social Development - An Integrated Approach for Social Inclusion.” Report No. 20088-TR. Washington, D.C.: World Bank.

World Bank 2003a; World Bank. 2003. Caribbean Youth Development: Issues and Policy Directions. Cunningham, Wendy and Correia, Maria. Washington, D.C.

World Bank. 2003b. “A Resource Guide for Municipalities: Community Based Crime and Violence Prevention in Urban Latin America.” Washington, D.C: World Bank.

World Bank. 2004. "Youth in Numbers.” Latin America and Caribbean Social Protection Unit. Washington, D.C.: World Bank.

World Bank, 2004b. “Guyana Poverty Reduction Strategy - Progress Report 2004.” Washington, D.C.: World Bank.

World Bank. 2005a. "Public Sector Transformation: Preliminary Public Opinion Research Survey in Four OECS Member States.” Paper presented to the OECS Public Sector Reform Group, Eastern Caribbean Central Bank, St. Kitts, April 11, 2005.

World Bank. 2005b. "Performance Measures Topic Brief.” Available at http://web.worldbank.org/WBSITE/EXTERNAL/TOPICS/EXTLAWJUSTINST/0,,conten tMDK:20756997 menuPK:2025688 pagePK:210058 piPK:210062 theSitePK:1974062, 00.html

World Bank. 2005c. "Youth Crime Prevention.” Course Module developed by Nancy Guerra for the Community Based Crime and Violence Prevention Courses. LCSFP. Washington, D.C.: World Bank.

World Bank. 2005d. “Dominican Republic Youth Development Loan.” Project Appraisal Document. Report No. 34235-DO. Washington DC

World Bank, 2006a. Dominican Republic Country Economic Memorandum: The Foundations of Competitiveness. Washington: World Bank.

World Bank. 2006b. Crime, Violence and Economic Development in Brazil: Elements for Effective Public Policy. Report No. 36525. Washington, D.C.: World Bank.

World Bank. 2006c. "Preventing Youth Risky Behavior through Early Child Development.” Youth Development Notes Series 1(3). Human Development Network. Washington, D.C.: World Bank.

World Bank. 2007. World Development Report 2007. Washington, D.C.: World Bank.

World Bank and IDB. 2006. Dominican Republic Poverty Assessment: Achieving More ProPoor Growth. Report No. 32422-DO. Washington, D.C.: World Bank. 
World Drug Report. 2006. Volume 2: Statistics, page 385. New York: United Nations Publications. Available at http://www.unodc.org/unodc/en/world_drug_report.html

World Travel and Tourism Council. 2004. "The Caribbean: Impact of Tourism on Jobs and the Economy.” London: WTTC.

Zohoori, N. et al. 2002. "Non-fatal Violence-Related in juries in Kingston, Jamaica: a Preventable Drain on Resources.” Injury Control and Safety Promotion 9(4):255-262. 


\section{ANNEXES}

\section{Annex 1.1. Caribbean Leaders on Crime}

In his 2006 New Year's address, former Jamaican Prime Minister P.J. Patterson said, "Without a doubt, the high level of violent crime remains our most troubling and pressing problem.” He was not alone among Caribbean leaders emphasizing the issue at that time: crime also featured prominently in the New Year's addresses of Prime Minister Patrick Manning of Trinidad and Tobago, President Bharrat Jagdeo of Guyana, and St. Lucia's Prime Minister Kenny Anthony. Prime Minister Anthony stated that reducing crime will be his government's number-one priority in 2006, displacing unemployment. In opening the Parliament of Trinidad and Tobago in September 2005, President George Maxwell Richards said the country was in crisis due to the escalating crime rate in that country, and acknowledged that more than 100,000 people had signed a petition demanding government action on crime.

\section{Annex 1.2. Tourism and the Caribbean Economy}

In 2004, the broader tourism economy was estimated to be responsible for some $15 \%$ of the region's GDP and over 15\% of total employment. Recent data suggests that it is growing in significance relative to other sectors. Some countries - including Antigua and Barbuda and the British Virgin Islands - owe over $75 \%$ of their economies to travel and tourism. According to the World Travel and Tourism Council, "Crime, harassment and other forms of anti-social behavior ... are some of the major threats to the development of the [Caribbean tourism] industry. Such problems frustrate national and regional efforts to maintain the region's image as a safe, clean and hospitable destination. Whether or not such concerns are supported by data, it is the perception that matters most to the uninformed traveler, including potential travelers to the Caribbean. (World Travel and Tourism Council, 2004).

For example, tourism is by far the largest foreign-exchange-generating sector in Jamaica, with its gross foreign exchange receipts almost equaling the earnings from all merchandise exports. According to one review of Jamaica's economy, “...although the number of tourists affected by crime is low (in Jamaica, as elsewhere, the least privileged bear the heaviest burden from crime), fear of crime undoubtedly affects the Jamaican tourism industry. According to one recent survey, nearly 70 per cent of hotel owners sampled mentioned crime as an important problem for their business (Bloom et al., 2001)." Similarly, the government of Guyana, in its 2004 progress report on it Poverty Reduction Strategy, argues, "The violent crime wave over the last two years had deeply reduced the number of tourists visiting Guyana (World Bank, 2004b).”

\section{Annex 1.3. Emigration and Crime}

The seven countries with the highest skilled highest emigration rates in the world are all in the Caribbean (Docquier and Marfouk, 2006). Guyana has the world's worst skilled 
emigration rate (89\%), and, according to the 2005 Progress Report on Guyana's Poverty Reduction Strategy, crime and violence are driving human capital overseas: "In spite of some improvement in the crime and security situation, Guyana continues to lose its critical entrepreneurial and professional skills to migration...the crime and security situation will have to be tackled and dealt with definitively if Guyana is to minimize the migration of its highly trained professionals and entrepreneurs whose skills and resources are needed to propel growth.” The United Nations Common Country Assessment of Guyana quotes a 2003 survey canvassing 1757 secondary school students in which 47\% responded that they would leave Guyana permanently soon or within five years. Crime, violence and racism were cited overwhelmingly the most prominent negative factors motivating this intended migration (United Nations Country Team, 2005).

\section{Annex 1.4. Caribbean Police Forces and Prison Populations}

The number of police per capita in the Caribbean is generally high by international standards (with the exception of countries like Haiti, which has one of the lowest rates of coverage in the world). But this figure can be deceptive, as during high season, tourist inflows can swell the population. For example, the Bahamas, with a resident population of about 321,000, received nearly 1.5 million stay-over tourist arrivals in 2003. Further, high police to public ratios in low population countries do not mean the same thing as

they do in high population countries. A large share of total coverage may be required to cover basic logistic and supervisory functions, leaving a proportionately smaller share for field duties. In addition, high ratios may conceal low real numbers, and these personnel may be responsible for large land and sea areas.

In a global ranking of 211 countries from the highest prison to public ratios to the lowest, Bermuda ranks second, US Virgin Islands third, Cuba fourth, Suriname fifth, Cayman Islands sixth, Belize seventh, St Kitts and Nevis ninth, and the Bahamas $11^{\text {th }}$ (Walmsley, 2005). In many countries in the region, the prison populations are growing at a rapid rate. The prison population increase in the Dominican Republic (38\% over 3.5 years) is particularly notable (Walmsley, 2003). 


\section{Annex 2.1. The Jamaica Cannabis Trade}

Jamaica was said to have been the source of one third of herbal cannabis consumed in the United Kingdom in the late 1970s, but it appears to comprise less than $7 \%$ of the market today (UNODC, 2004). Jamaica provided 14\% of the United States market share in 1984, but today this figure is likely much less (President's Commission on Organized Crime, 1986).

In Canada, cannabis of Jamaican origin increased its share in the illicit market from $10 \%$ in 1983 to 20\% in 1984 (Stamler et al., 1985). Today, it has been largely displaced by high potency local production, and constitutes an estimated $5 \%$ of the herbal supply and $10 \%$ of the hashish supply, according to the UNODC Annual Reports Questionnaire (ARQ) 2004. France recently reported that it received 9\% of its cannabis from "the Caribbean" in the ARQ.

\section{Annex 2.2. Patterns of Drug Transshipment by Organized Criminal Groups}

The Colombian Cali and Medellin cartels preferred and used the Caribbean corridor starting in the late 1970s. In the 1980s, most of the cocaine entering the United States came through the Caribbean into South Florida. But interdiction successes caused the traffickers to reassess their routes. By 1998, about $59 \%$ of the cocaine went via Central America/Mexico, 30\% via the Caribbean, and 11\% via direct commercial sea freight or air flights. In 1999, the flows across the Mexican border dropped to about $54 \%$, flows via the Caribbean increased to $43 \%$, and only $3 \%$ arrived directly from South America. By 2000, the ratios shifted to 66 percent Central America/ Mexico and 33 percent Caribbean, with a decrease in the use of Haiti and Puerto Rico and an increase in the use of Jamaica. By 2003, the ratio was 77 percent through Central America/Mexico and 22 percent via the Caribbean. Today, it is estimated that only 10 percent of U.S. cocaine transits the Caribbean. (For details, see the various editions of the National Drug Threat Assessment, produced by the National Drug Intelligence Center of the United States Department of Justice.) With regard to the role of enforcement, The resident's 2005 National Drug Control Strategy says, "For years, about one-third of the cocaine heading toward the United States was moved through the Greater Antilles toward Florida. Approximately 10 percent of the total U.S. supply was handled by two organizations, one run by Colombian ... Elias Cobos-Muñoz and the second headed by Melvin Maycock and Pedro Smith. A 29-month DEA-led investigation led to the arrest of all three ... as well as more than 50 of their colleagues in Colombia, Panama, Jamaica, the Bahamas, the United States, and Canada. More important, it disrupted organizations supplying an estimated 10 percent of the cocaine imported into the United States-roughly 30 metric tons per year. In seeming confirmation of this disruption, which was amplified by the deployment of international forces following the ouster of President Jean Bertrand Aristide in Haiti, intelligence estimates assess that there has been a significant reduction in the amount of cocaine flowing through the central and eastern Caribbean to the United Statesfrom roughly one-third of total flow to perhaps 10 percent.” 


\section{Annex 2.3. Dates of Large Seizures of Cocaine Entering Canada from Caribbean Countries in 2004}

The following information comes from the UNODC's Major Seizure Database, as reported by the Canadian government.

- Jamaica: 3 January, 7 January, 28 January, 2 February, 14 February (twice), 3 March, 9 March, 13 March (twice), 15 March, 16 March, 24 March, 4 April, 23 May, 8 June (twice), 9 June, 14 June, 18 June, 27 July, 1 August, 7 August, 19 August, 30 August, 4 September, 6 September, 26 September, 8 October, 28 October, 11 December, and 19 December.

- Trinidad and Tobago: 5 May, 10 May, 27 May, 19 February, 4 August, 9 December, and two on 13 December.

- $\quad$ Netherlands Antilles: 7 February (twice), 15 February, 10 March, 21 March, 13 June (twice), and 24 October.

- Guyana: 12 July, 2 September, 10 September, 14 December, as well as almost 400 ecstasy tablets on 2 September.

- $\quad$ St. Vincent and the Grenadines: 2 Feb and 27 Feb.

- Haiti: 20 January, 21 January, and 25 August.

- St. Lucia: at Toronto, $4 \mathrm{~kg}$ on 8 March, $17 \mathrm{~kg}$ on 22 August, as well as $1 \mathrm{~kg}$ on 3 September.

- Grenada: at Toronto, less than $1 \mathrm{~kg}$ on 9 February.

- Barbados: at Toronto, $7 \mathrm{~kg}$ on 25 February.

- Suriname: at Calgary, less than $1 \mathrm{~kg}$ on 30 March.

- $\quad$ Dominica: at Trudeau, $7 \mathrm{~kg}$ seized on 31 December.

Most cocaine entering Europe is transshipped in large container ships destined for Spain or Portugal, but a substantial amount also enters through commercial air flights to Spain and the Netherlands. It is estimated by Europol that up to 250 tons enters the EU each year by sea, and that many European-based groups source their cocaine directly from Central America and the Caribbean (Europol, 2004). According to local law enforcement, in parts of the Eastern Caribbean the majority of cocaine transiting the country is destined for Europe, including Antigua and Barbuda (60 percent to the United Kingdom), Barbados (59 percent to the United Kingdom), Grenada (70 percent to Europe) and St. Lucia (60 percent).

\section{Annex 2.4. Organized Crime in Jamaica and the Dominican Republic}

Jamaican "posses" (in the Eastern United States) and "yardies" (in the United Kingdom) pioneered the crack cocaine markets in these countries, as well as being an important source of cannabis. Today, their dominance has been reduced. Today in New York, Jamaican criminal groups are the most prominent cannabis distributors overall, 
particularly for wholesale and midlevel quantities. They are also active in other parts of the Northeast, including Philadelphia, Boston, and Washington, D.C., as well as in the West, including Los Angeles and Phoenix/Tucson (National Drug Intelligence Center, 2005).

According to National Criminal Intelligence Service of the United Kingdom, "Hitherto, criminal groups of West Indian origin, mostly Jamaican, were seen to be most prominent in distributing crack cocaine within the U.K. ... However, as [cocaine use] has grown, there have been opportunities for others to become involved... [Today] most of the detected movements of cocaine trafficked from the Caribbean to the U.K. are smuggled by couriers, many under the control of Jamaican and Trinidadian groups (National Criminal Intelligence Service, 2005).”

Dominican groups started out street distribution of cocaine in the United States, primarily in the urban areas of the Northeast, though their connections with Colombian traffickers. Today, they dominate cocaine wholesaling in the Northeast, particularly in cities like New York, Boston, and Philadelphia, working closely with Colombian suppliers. They are said to supply local gangs such as the Crips in the Northeast and the Latin Kings in Chicago. Throughout the United States, of the 26 percent of law enforcement agencies polled who said there was an association between the gangs in their area and organized crime, 13 percent mentioned Dominican drug organizations (National Alliance of Gangs Investigators Associations, 2005). According to the response of the U.S. authorities to the UNODC Annual Reports Questionnaire, Dominicans were far and away the foreign group most arrested for cocaine and heroin trafficking in 2004. Dominican groups also play a role in the drug trade in other parts of the Caribbean, notably, in Puerto Rico, and are frequently seen as crew members on go-fast boats. They are also increasingly visible in European cocaine trafficking.

\section{Annex 2.5. Jamaat-al-Muslimeen in Trinidad and Tobago}

In 1990, Trinidad and Tobago was the subject of an attempted coup d'état by a radical Islamic group called Jamaat-al-Muslimeen, alleged to have links with Libya and Sudan. The police headquarters was bombed, a government building and the national television station were taken, and the Prime Minister and other parliamentarians were taken hostage for five days. During this time, looting and rioting were widespread in the capitol, Port of Spain, and 31 people were killed. The group surrendered after an amnesty was negotiated, and is presently active as a political party with parliamentary representation. Members of the group have subsequently been prosecuted for serious violent crimes such as murder and kidnapping, including the group's leader, Imam Yasin Abu Bakr. In 2005, there were five minor bomb attacks in Trinidad in the course of four months. The fourth of these, on 14 October, resulted in five arrests: Imam Yasin Abu Bakr and four teenagers. All were later released. 


\section{Annex 3.1. Caribbean Homicide Data Sources}

Data for the cross-country econometric analysis is taken from the database collected by the United Nations Office of Drugs via its Survey of Crime Trends and Operations of Criminal Justice Systems. The dataset for the econometric analysis was limited to countries for which there were observations in at least three consecutive five-year periods. This limited dataset included three Caribbean countries: Barbados, Jamaica, and Trinidad and Tobago.

For the purposes of the scatter plots shown in Figure 3.2, UNODC data was supplemented by homicide data from a variety of sources to expand the number of Caribbean countries in the sample. Sources include national statistical publications, data gathered from national police forces by De Albuquerque and McElroy (1999b), and in the case of Haiti, a national household survey. In cases where the original data was in terms of numbers of homicides (rather than rates), rates per 100,000 population were calculated using population figures taken from the World Bank's World Development Indicators (WDI) database. Due to variations in reporting rates and definitions, data from nonUNODC sources is not strictly comparable to UNODC data.

\section{Table A3.1 Caribbean Crime Data Sources for Cross-Country Graphical Comparisons}

\begin{tabular}{|c|c|c|c|c|}
\hline & $\begin{array}{l}\text { Population } \\
\text { (2004) }\end{array}$ & $\begin{array}{l}\text { \% Population (of } \\
\text { Caribbean } \\
\text { countries with } \\
\text { homicide data) }\end{array}$ & $\begin{array}{c}\text { Homicide } \\
\text { Rate per } \\
100000\end{array}$ & Source \\
\hline $\begin{array}{l}\text { Antigua \& } \\
\text { Barbuda }\end{array}$ & 80085 & $0.4 \%$ & 6.8 & $\begin{array}{l}\text { average 1990-96, De } \\
\text { Albuquerque and McElroy } \\
\text { (1999b) }\end{array}$ \\
\hline Barbados & 268881 & $1.2 \%$ & 7.9 & average 1998-2000, UNODC \\
\hline Dominica & 71460 & $0.3 \%$ & 8.3 & $\begin{array}{l}\text { average 1998-2000, UNODC } \\
\text { average 1999-2004, govt. report, }\end{array}$ \\
\hline $\begin{array}{l}\text { Dominican } \\
\text { Republic }\end{array}$ & 8767870 & $39.1 \%$ & 16.5 & $\begin{array}{l}\text { Oficina Nacional de Estadística } \\
\text { (2005) } \\
\text { average 1990-96, De }\end{array}$ \\
\hline Grenada & 105747 & $0.5 \%$ & 7.1 & $\begin{array}{l}\text { Albuquerque and McElroy } \\
\text { (1999b) } \\
\text { average 1999-2004, govt. report, }\end{array}$ \\
\hline Guyana & 750232 & $3.3 \%$ & 16.1 & Bureau of Statistics (2006) \\
\hline Jamaica & 2644592 & $11.8 \%$ & 33.8 & $\begin{array}{l}\text { average 1998-2000 UNODC } \\
\text { 2001, estimate based on “violent } \\
\text { deaths" reported in ECVH }\end{array}$ \\
\hline Haiti & 8406941 & $37.5 \%$ & 33.9 & $\begin{array}{l}\text { survey } \\
\text { average 1990-95, De }\end{array}$ \\
\hline $\begin{array}{l}\text { St. Kitts \& Nevis } \\
\text { Trinidad \& }\end{array}$ & 46985 & $0.2 \%$ & 10.2 & $\begin{array}{l}\text { Albuquerque \& McElroy } \\
\text { (1999b) } \\
\text { average 1998-99, govt. report, }\end{array}$ \\
\hline Tobago & 1301307 & $5.8 \%$ & 7.4 & Central Statistical Office (2006) \\
\hline
\end{tabular}

Note that there is tremendous uncertainty in the figure for Haiti. The 95 percent confidence interval on the 2001 estimate ranges from 8 to 60 per 100,000. The point 
estimate, 33.9 per 100,000, is derived from a survey-based estimate of 2734 homicides nationally. Using their own survey in Port-au-Prince, Kolbe and Hutson (2006) estimate that there were 8000 homicides in Port-au-Prince during the 22 months following JeanBertrand Aristide's overthrow in February, 2004. (This is equivalent to 4364 homicides per year.) In contrast, Arthur (2006) draws from reports of several non-governmental organizations that track homicides in Haiti and estimates that the total for 2005 was far lower: approximately 900 in Port-au-Prince and 50 in the rest of the country.

\section{Annex 3.2. Micro-Regression Results}

Table A3.2: Risk Factor Regression Results - Jamaica

\begin{tabular}{|c|c|c|c|c|c|}
\hline Variables & Murder & Shooting & Robbery & Wounding & $\begin{array}{l}\text { Praedial } \\
\text { Larceny }\end{array}$ \\
\hline \multicolumn{6}{|l|}{ Household-Level Variables } \\
\hline \multirow[t]{2}{*}{ Consumption per-capita (log) } & -0.0008 & -0.0012 & 0.0222 & -0.0021 & 0.0061 \\
\hline & {$[-2.09]^{\star \star}$} & {$[-2.30]^{\star \star}$} & {$[15.99]^{\star \star \star}$} & {$[-3.21]^{\star \star \star}$} & {$[8.57]^{\star \star \star}$} \\
\hline Dummy female head == 1 (d) & $\begin{array}{r}0.0020 \\
{[8.29]^{\star \star \star}}\end{array}$ & $\begin{array}{l}-0.0002 \\
{[-0.84]}\end{array}$ & $\begin{array}{l}-0.0056 \\
{[-7.58]^{\star \star \star}}\end{array}$ & $\begin{array}{l}-0.0007 \\
{[-1.94]^{*}}\end{array}$ & $\begin{array}{l}-0.0030 \\
{[-7.73]^{\star \star \star}}\end{array}$ \\
\hline \multirow{2}{*}{$\begin{array}{l}\text { Males age } 15-24 \\
\text { (\% hh population) }\end{array}$} & 0.0014 & 0.0037 & -0.0109 & 0.0053 & -0.0052 \\
\hline & {$[2.28]^{\star \star}$} & {$[5.47]^{\star \star *}$} & {$[-5.05]^{\star \star \star}$} & {$[6.14]^{\star \star \star}$} & {$[-4.45]^{\star \star \star}$} \\
\hline \multirow{2}{*}{$\begin{array}{l}\text { Population age } 25+\text { with secondary educ } \\
\text { (\% adult population within the household) } \\
\text { Household Size }\end{array}$} & $\begin{array}{l}0.0003 \\
{[1.19]}\end{array}$ & $\begin{array}{l}0.0009 \\
{[2.55]^{\star \star}}\end{array}$ & $\begin{array}{l}-0.0097 \\
{[-10.75]^{\star \star \star}}\end{array}$ & $\begin{array}{l}0.0008 \\
{[1.85]^{\star}}\end{array}$ & $\begin{array}{l}-0.0042 \\
{[-8.72]^{\star \star \star}}\end{array}$ \\
\hline & $\begin{array}{r}0.0003 \\
{[5.60]^{\star \star \star}}\end{array}$ & $\begin{array}{r}0.0003 \\
{[3.64]^{\star \star \star}}\end{array}$ & $\begin{array}{r}0.0033 \\
{[13.32]^{\star \star *}}\end{array}$ & $\begin{array}{l}0.0002 \\
{[1.57]}\end{array}$ & $\begin{array}{r}0.0009 \\
{[6.99]^{\star \star \star}}\end{array}$ \\
\hline \multicolumn{6}{|l|}{ Enumeration District-Level Variables } \\
\hline Consumption per-capita (log) & $\begin{array}{l}-0.0024 \\
{[-4.19]^{\star \star \star}}\end{array}$ & $\begin{array}{l}-0.0017 \\
{[-2.42]^{\star \star}}\end{array}$ & $\begin{array}{l}0.0180 \\
{[9.34]^{\star \star \star}}\end{array}$ & $\begin{array}{l}-0.0063 \\
{[-7.06]^{\star \star \star}}\end{array}$ & $\begin{array}{r}0.0070 \\
{[7.11]^{\star \star \star}}\end{array}$ \\
\hline Inequality Index (GINI) & $\begin{array}{l}0.0002 \\
{[0.17]}\end{array}$ & $\begin{array}{l}-0.0010 \\
{[-0.53]}\end{array}$ & $\begin{array}{r}-0.0016 \\
{[-0.33]}\end{array}$ & $\begin{array}{l}-0.0006 \\
{[-0.25]}\end{array}$ & $\begin{array}{r}0.0084 \\
{[3.49]^{\star \star \star}}\end{array}$ \\
\hline $\begin{array}{l}\% \text { of households female headed } \\
\text { (\% district households) }\end{array}$ & $\begin{array}{l}0.0037 \\
{[2.54]^{\star \star}}\end{array}$ & $\begin{array}{l}0.0096 \\
{[5.44]^{\star \star \star}}\end{array}$ & $\begin{array}{l}0.0186 \\
{[3.92]^{\star \star \star}}\end{array}$ & $\begin{array}{l}-0.0004 \\
{[-0.17]}\end{array}$ & $\begin{array}{l}0.0001 \\
{[0.02]}\end{array}$ \\
\hline $\begin{array}{l}\text { Males age } 15-24 \\
\text { (\% district population) }\end{array}$ & $\begin{array}{l}0.0665 \\
{[4.13]^{\star \star \star}}\end{array}$ & $\begin{array}{l}0.0249 \\
{[1.20]}\end{array}$ & $\begin{array}{l}-0.1060 \\
{[-1.86]^{\star}}\end{array}$ & $\begin{array}{l}0.0687 \\
{[2.55]^{\star \star}}\end{array}$ & $\begin{array}{l}-0.0451 \\
{[-1.52]}\end{array}$ \\
\hline $\begin{array}{l}\text { Population age } 25+\text { with secondary educ } \\
\text { (\% adult population within the district) }\end{array}$ & $\begin{array}{l}-0.0017 \\
{[-1.97]^{\star \star}}\end{array}$ & $\begin{array}{l}-0.0026 \\
{[-2.33]^{\star \star}}\end{array}$ & $\begin{array}{l}-0.0173 \\
{[-5.61]^{\star \star \star}}\end{array}$ & $\begin{array}{l}-0.0031 \\
{[-2.24]^{\star \star}}\end{array}$ & $\begin{array}{l}-0.0088 \\
{[-5.75]^{\star \star \star}}\end{array}$ \\
\hline Dummy urban == 1 & $\begin{array}{l}0.0008 \\
{[1.94]^{\star}}\end{array}$ & $\begin{array}{l}0.0009 \\
{[1.48]}\end{array}$ & $\begin{array}{r}0.0096 \\
{[6.89]^{\star \star \star}}\end{array}$ & $\begin{array}{l}0.0045 \\
{[9.80]^{\star \star \star}}\end{array}$ & $\begin{array}{l}-0.0024 \\
{[-2.60]^{\star \star \star}}\end{array}$ \\
\hline Population Density (log) & $\begin{array}{l}0.0005 \\
{[4.26]^{\star \star \star}}\end{array}$ & $\begin{array}{c}0.0008 \\
{[5.20]^{\star \star \star}}\end{array}$ & $\begin{array}{r}-0.0052 \\
{[-13.72]^{\star \star \star}}\end{array}$ & $\begin{array}{l}-0.0003 \\
{[-1.77]^{\star}}\end{array}$ & $\begin{array}{r}-0.0030 \\
{[-15.75]^{\star \star \star}}\end{array}$ \\
\hline$\%$ of crimes reported to police & $\begin{array}{l}-0.0008 \\
{[-2.15]^{\star \star}}\end{array}$ & $\begin{array}{l}-0.0026 \\
{[-5.44]^{\star \star \star}}\end{array}$ & $\begin{array}{l}-0.0073 \\
{[-5.24]^{\star \star \star}}\end{array}$ & $\begin{array}{l}-0.0036 \\
{[-5.69]^{\star \star \star}}\end{array}$ & $\begin{array}{r}-0.0180 \\
{[-25.90]^{\star \star \star}}\end{array}$ \\
\hline Dummy for rich district & $\begin{array}{l}0.0001 \\
{[0.38]}\end{array}$ & $\begin{array}{l}-0.0005 \\
{[-1.34]}\end{array}$ & $\begin{array}{c}-0.0048 \\
{[-5.41]^{\star \star \star}}\end{array}$ & $\begin{array}{l}0.0006 \\
{[1.09]}\end{array}$ & $\begin{array}{l}0.0008 \\
{[1.58]}\end{array}$ \\
\hline Pseudo R-squared & 0.0451 & 0.029 & 0.0441 & 0.02 & 0.077 \\
\hline Model chi-square & 456 & 361 & 2662 & 361 & 2218 \\
\hline Obs. P & 0.0037 & 0.0048 & 0.0024 & 0.0336 & 0.0133 \\
\hline Pred. P & 0.0028 & 0.004 & 0.0021 & 0.0288 & 0.0088 \\
\hline $\mathrm{N}$ & 205505 & 204883 & 204925 & 204708 & 203727 \\
\hline
\end{tabular}

Source: Analysis of Jamaica 2001 Population and Housing Census. Results shown are marginal effects from probit regressions using data from Jamaica's three high-crime parishes: Kingston, St. Andrew, and St. Catherine. Robust z statistics in parentheses. Praedial larceny is the term for the theft of agricultural products from farms.

* significant at $10 \%,{ }^{* *}$ significant at $5 \%$, * significant at $1 \%$ 
Table A3.3: Risk Factor Regression Results - Dominican Republic

\begin{tabular}{|c|c|c|c|c|}
\hline Variables & $\begin{array}{c}\text { Vehicle } \\
\text { Theft }\end{array}$ & Burglary & Mugging & $\begin{array}{l}\text { Personal } \\
\text { Theft }\end{array}$ \\
\hline \multicolumn{5}{|l|}{ Household-Level Variables } \\
\hline \multirow[t]{2}{*}{ Quality of Life Index } & 0.03 & 0.03 & 0.02 & 0.05 \\
\hline & {$[2.03]^{\star *}$} & {$[3.62]^{\star \star \star}$} & {$[2.74]^{\star \star \star}$} & {$[7.87]^{\star \star \star}$} \\
\hline \multirow[t]{2}{*}{ Dummy Female Head = 1 (d) } & 0.01 & 0.004 & 0.002 & 0.005 \\
\hline & [1.38] & {$[0.89]$} & {$[0.79]$} & [1.59] \\
\hline \multirow{2}{*}{$\begin{array}{l}\text { Male age } 15-24 \\
\text { (\% hh population) }\end{array}$} & 0.024 & -0.017 & 0.006 & 0.00 \\
\hline & {$[1.30]$} & {$[-1.21]$} & {$[0.61]$} & {$[0.04]$} \\
\hline $\begin{array}{l}\text { Population age } 25+\text { with secondary educ } \\
\text { (\% adult population within the household) }\end{array}$ & $\begin{array}{l}-0.002 \\
{[-0.23]}\end{array}$ & $\begin{array}{r}0.012 \\
{[2.09]^{\star \star}}\end{array}$ & $\begin{array}{r}0.014 \\
{[3.70]^{\star * \star}}\end{array}$ & $\begin{array}{l}0.002 \\
{[0.50]}\end{array}$ \\
\hline \multirow[t]{2}{*}{ Household size } & 0.006 & 0.000 & -0.002 & 0.001 \\
\hline & {$[4.05]^{\star \star \star}$} & {$[0.22]$} & {$[-2.20]^{\star \star}$} & {$[1.14]$} \\
\hline \multicolumn{5}{|l|}{ Province-Level Variables } \\
\hline \multirow[t]{2}{*}{ Per capita income } & 0.025 & 0.009 & -0.008 & 0.000 \\
\hline & {$[0.92]$} & {$[0.52]$} & {$[-0.62]$} & {$[0.01]$} \\
\hline \multirow[t]{2}{*}{ Inequality Index (GINI) } & -0.159 & -0.184 & -0.075 & -0.07 \\
\hline & {$[-1.67]^{*}$} & {$[-2.76]^{\star \star \star}$} & {$[-1.56]$} & {$[-1.44]$} \\
\hline \multirow[t]{2}{*}{ Unemployment Rate } & 0.041 & 0.047 & 0.053 & 0.093 \\
\hline & {$[0.48]$} & {$[0.77]$} & {$[1.20]$} & {$[2.08]^{\star *}$} \\
\hline \multirow{2}{*}{$\begin{array}{l}\% \text { of households female headed } \\
\text { (\% province households) }\end{array}$} & -0.455 & -0.425 & -0.648 & -0.409 \\
\hline & {$[-0.84]$} & {$[-1.16]$} & {$[-2.38]^{\star \star}$} & {$[-1.52]$} \\
\hline \multirow{2}{*}{$\begin{array}{l}\text { Male age } 15-24 \\
\text { (\% province population) }\end{array}$} & 0.812 & 0.929 & -0.219 & -0.099 \\
\hline & {$[0.58]$} & [1.07] & {$[-0.34]$} & {$[-0.16]$} \\
\hline \multirow{2}{*}{$\begin{array}{l}\text { Population age } 25+\text { with secondary educ } \\
\text { (\% adult population within the province) }\end{array}$} & -0.02 & 0.095 & 0.178 & 0.04 \\
\hline & {$[-0.19]$} & [1.33] & {$[3.73]^{\star \star *}$} & {$[0.79]$} \\
\hline \multirow[t]{2}{*}{ Dummy Urban == 1} & 0.022 & 0.017 & 0.015 & 0.012 \\
\hline & {$[3.70]^{\star \star \star}$} & {$[3.96]^{\star \star \star}$} & {$[4.76]^{\star \star \star}$} & {$[3.95]^{\star \star \star}$} \\
\hline \multirow[t]{2}{*}{ Population Density (log) } & 0.012 & 0.012 & 0.017 & 0.012 \\
\hline & {$[2.58]^{\star \star \star}$} & {$[4.31]^{\star \star \star}$} & {$[7.96]^{\star \star \star}$} & {$[5.87]^{\star \star \star}$} \\
\hline \multirow[t]{2}{*}{$\%$ of crimes in province reported to police } & -0.004 & 0.018 & 0.002 & -0.003 \\
\hline & {$[-0.06]$} & {$[0.52]$} & {$[0.07]$} & {$[-0.10]$} \\
\hline Pseudo R-squared & 0.027 & 0.021 & 0.084 & 0.051 \\
\hline Model chi-square & 95.061 & 208.414 & 525.811 & 294.519 \\
\hline Obs. P & 0.063 & 0.080 & 0.049 & 0.047 \\
\hline Pred. P & 0.058 & 0.076 & 0.038 & 0.039 \\
\hline $\mathrm{N}$ & 7054 & 18596 & 18606 & 18599 \\
\hline
\end{tabular}

Source: Own analysis of 2005 ENHOGAR survey. Per capita income and inequality figures at the province level are from poverty map constructed using the 2002 census. See Robles (2005).

Notes: Results are marginal effects from probit regressions. Robust z statistics in parentheses. Quality of Life Index is a basic needs welfare index at the household level constructed using the ENHOGAR 2005 data.

Burglary refers to theft in the home. Mugging is theft involving assault to a person. Personal theft is theft of personal items like a cell phone, radio, etc.

* significant at $10 \%$, ** significant at $5 \%$, *** significant at $1 \%$ 
Table A3.4: Risk Factor Regression Results - Haiti

\begin{tabular}{|lrrrr|}
\hline Variables & Robbery & Burglary & Injured & Mugging \\
\hline Household-Level Variables & & & & \\
Per capita Income (log) & 0.007 & 0.012 & 0.00 & 0.003 \\
& {$[2.26]^{\star \star}$} & {$[3.22]^{\star \star \star}$} & {$[0.32]$} & {$[2.93]^{\star \star \star}$} \\
Unemployment & 0.001 & 0.014 & -0.002 & 0.001 \\
(\% of hh population +10 ages) & {$[0.28]$} & {$[2.56]^{\star \star}$} & {$[1.23]$} & {$[0.52]$} \\
Dummy female head == & 0.011 & 0.01 & 0.001 & -0.001 \\
& {$[1.35]$} & {$[1.16]$} & {$[0.53]$} & {$[0.19]$} \\
Male age 15-24 & -0.003 & 0.006 & -0.004 & -0.002 \\
(\% hh population) & {$[0.37]$} & {$[0.63]$} & {$[1.91]^{\star}$} & {$[0.88]$} \\
Population age 25+ with secondary educ & 0.009 & -0.016 & 0.001 & -0.001 \\
(\% adult population within the household) & {$[1.07]$} & {$[1.37]$} & {$[0.49]$} & {$[0.33]$} \\
Dummy Urban == 1 & 0.055 & 0.019 & 0.002 & 0.013 \\
& {$[5.81]^{\star \star *}$} & {$[2.11]^{\star \star}$} & {$[1.12]$} & {$[3.52]^{\star \star \star}$} \\
Household Size & 0.003 & -0.002 & 0.00 & 0.001 \\
& {$[1.64]$} & {$[0.79]$} & {$[0.37]$} & {$[2.34]^{\star \star}$} \\
\hline Observations & 4477 & 4477 & 4477 & 4477 \\
Pseudo R2 & 0.043 & 0.017 & 0.031 & 0.068 \\
Obs. P & 0.060 & 0.068 & 0.004 & 0.011 \\
Pred. P & 0.053 & 0.065 & 0.003 & 0.008 \\
\hline
\end{tabular}

Source: Own analysis of 2001 ECVH survey.

Notes: Results are marginal effects from probit regressions. Robust $\mathrm{z}$ statistics in parentheses.

* significant at $10 \%,{ }^{* *}$ significant at $5 \%$, *** significant at $1 \%$ 
Annex 4.1. Impact of Crime Victimization on Satisfaction with Life

\begin{tabular}{|c|c|c|c|c|}
\hline \multirow{2}{*}{$\begin{array}{l}\text { Explanatory Variable } \\
\text { Respondent or family member victim of } \\
\text { crime in last } 12 \text { months }\end{array}$} & \multicolumn{2}{|c|}{ All of Latin America } & \multicolumn{2}{|c|}{ Dominican Republic only } \\
\hline & \multirow{2}{*}{$\begin{array}{l}-0.044 \\
-0.012\end{array}$} & \multirow[t]{2}{*}{$* * *$} & \multirow{2}{*}{$\begin{array}{l}-0.080 \\
-0.083\end{array}$} & \multirow{2}{*}{$\begin{array}{l}* * \\
* *\end{array}$} \\
\hline Female & & & & \\
\hline \multicolumn{5}{|l|}{ Age Groups } \\
\hline $26-40$ & -0.067 & $* * *$ & -0.149 & $* * *$ \\
\hline $41-60$ & -0.123 & $* * *$ & -0.181 & $* * *$ \\
\hline 61 and older & -0.119 & $* * *$ & -0.155 & $*$ \\
\hline \multicolumn{5}{|l|}{ Educational Level } \\
\hline Primary Incomplete & 0.016 & & 0.037 & \\
\hline Primary Complete & 0.008 & & 0.049 & \\
\hline Secondary Incomplete & 0.013 & & -0.021 & \\
\hline Secondary Complete & 0.033 & $* *$ & 0.009 & \\
\hline Superior Incomplete & 0.032 & & -0.017 & \\
\hline Superior Complete & 0.046 & $* *$ & -0.004 & \\
\hline \multicolumn{5}{|l|}{ Socioeconomic Level (self - rated) } \\
\hline Good & -0.057 & $* * *$ & -0.020 & \\
\hline Fair & -0.098 & $* * *$ & -0.048 & \\
\hline Poor & -0.119 & $* * *$ & -0.110 & \\
\hline Very Poor & -0.133 & $* * *$ & -0.121 & \\
\hline \multicolumn{5}{|l|}{ Marital Status } \\
\hline Married & 0.015 & $*$ & 0.022 & \\
\hline Formerly married & -0.016 & & 0.081 & \\
\hline \multicolumn{5}{|l|}{ Current Occupation } \\
\hline Independent worker & 0.105 & $* * *$ & 0.015 & \\
\hline Public employee & 0.162 & $* * *$ & -0.024 & \\
\hline Private employee & 0.137 & $* *$ & -0.008 & \\
\hline Retired & 0.109 & $* * *$ & -0.045 & \\
\hline Housework & 0.107 & $* * *$ & 0.058 & \\
\hline Student & 0.125 & $* * *$ & 0.078 & \\
\hline \multicolumn{5}{|l|}{ Previous Occupation } \\
\hline Independent: Owner & -0.002 & & -0.111 & \\
\hline Independent: Farmer & 0.036 & & & \\
\hline Independent: Self-employed & -0.028 & & -0.035 & \\
\hline Independent: Professional & & & -0.172 & \\
\hline Salaried: Professional & -0.016 & & & \\
\hline Salaried: Manager & -0.036 & & & \\
\hline Salaried: Mid employee & -0.044 & & 0.077 & \\
\hline Salaried: Other & -0.056 & & 0.052 & \\
\hline \multicolumn{5}{|l|}{ Asset ownership and access to services } \\
\hline Color TV & -0.014 & $* * *$ & -0.040 & \\
\hline Refrigerator & 0.036 & $* *$ & -0.041 & \\
\hline Own house & 0.022 & $* * *$ & 0.051 & \\
\hline Computer & 0.034 & $* * *$ & -0.035 & \\
\hline Laundry machine & 0.039 & & 0.026 & \\
\hline Telephone & 0.014 & $* *$ & -0.020 & \\
\hline Car & 0.021 & & 0.060 & \\
\hline Second house & 0.019 & & 0.085 & \\
\hline Potable water & 0.012 & & 0.023 & \\
\hline Warm water & -0.010 & & -0.093 & $*$ \\
\hline Sewage system & -0.002 & & 0.051 & \\
\hline Checking account & 0.019 & $* * *$ & 0.074 & \\
\hline Credit card & 0.048 & $* * *$ & 0.028 & $* *$ \\
\hline Health insurance & 0.029 & & 0.048 & \\
\hline Country dummies? & yes & & no & \\
\hline Pseudo R -squared & 0.087 & & 0.077 & \\
\hline Model chi -square & 2066.316 & & 93.599 & \\
\hline Observations & 18681 & & 998 & \\
\hline
\end{tabular}




\section{Table A5.1: Risk Factors and Policy Responses to Youth Violence in the Dominican Republic \\ Annex 5.1}

\section{(Community Level)}

\section{Risk Factor}

Poor educational

quality, school

dropouts, low

completion rates

Unsupervised youth

after school

$\begin{array}{ll}\mathbf{C} & \\ \mathbf{O} & \\ \mathbf{M} & \\ \mathbf{M} & \text { Lack of second } \\ \mathbf{U} & \text { chance opportunities } \\ \mathbf{N} & \text { for school dropouts } \\ \mathbf{I} & \text { to complete education } \\ \mathbf{T} & \text { and obtain job and } \\ \mathbf{Y} & \text { life skills }\end{array}$

\section{Lack of healthy youth-related activities}

Insecure

neighborhoods and routes for youth to take to school

Police brutality directed at youth

\section{Policy Response}

MOE Strategic

Development

Plan

\section{Weakness}

Lack of funding

Few schools and overcrowding in poorest neighborhoods

Unmotivated and poorly trained teachers

Birth certificate barriers to enroll -huge obstacle for undocumented

Dominicans and Haitian-born

Min of Labor, MOE, and

INFOTEP (Juventud y

Empleo, Educación Básica Hasn’t focused on high-risk areas

de Adultos, PREPARA)

Ministry of Sports,

Education and

Recreation created

-sports complexes

-organized leagues

Municipalities and Plan de Seguridad Nacional (Barrio Seguro)

Plan de Seguridad

Democrática, Police Abuse

Prevention Center
Limited scope (drug prevention)

Solely an emphasis on sports

stage under Barrio Seguro

Low reporting of abuses

Weak enforcement mechanisms

\section{Recommendation}

1) Provide adequate funding to match, at a minimum, the average for LAC

2) Strengthen efforts to strengthen educational system with particular focus on high-risk communities, including building schools and classrooms (esp. secondary); ongoing teacher training in classroom management and non-violence; increase salaries and availability of didactic materials

3) Remove barriers to register for school (especially for the undocumented by providing birth certificates)

4) Promote supervised after-school programs on school premises or in existing community centers

5) Expand programs with particular emphasis on strengthening life skills training in both the equivalency education programs as well as the job training programs. Actively promote programs in high-risk communities

6) Continue building/renovating complexes only in high risk communities, combined with supervised after-school and weekend programs; Continue expansion of sports leagues

(7) Expand to all high-violence communities, with emphasis on streetlights, community policing

(8) Enhance Police training (esp. in community policing, problem solving, human rights), strengthen Police Abuse Prevention Center (qualified investigators, improved transparency, effective follow up with communities, punitive actions for police offenders) 
Table A5.2: Risk Factors and Policy Responses to Youth Violence in the Dominican Republic

(Relationship level, including family, peers, caregivers)

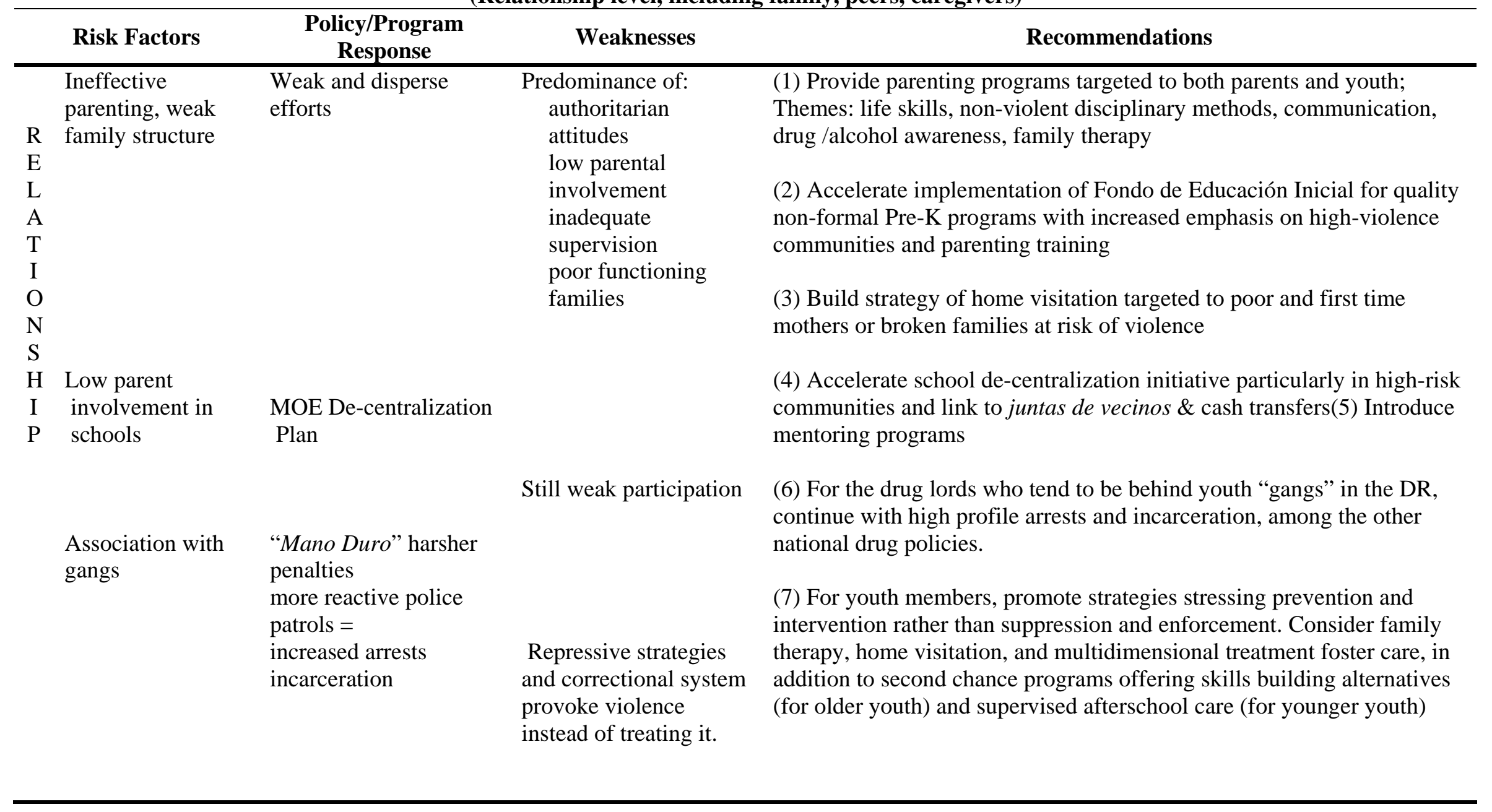


Table A5.3: Risk Factors and Policy Responses to Youth Violence in the Dominican Republic

(Individual Level)

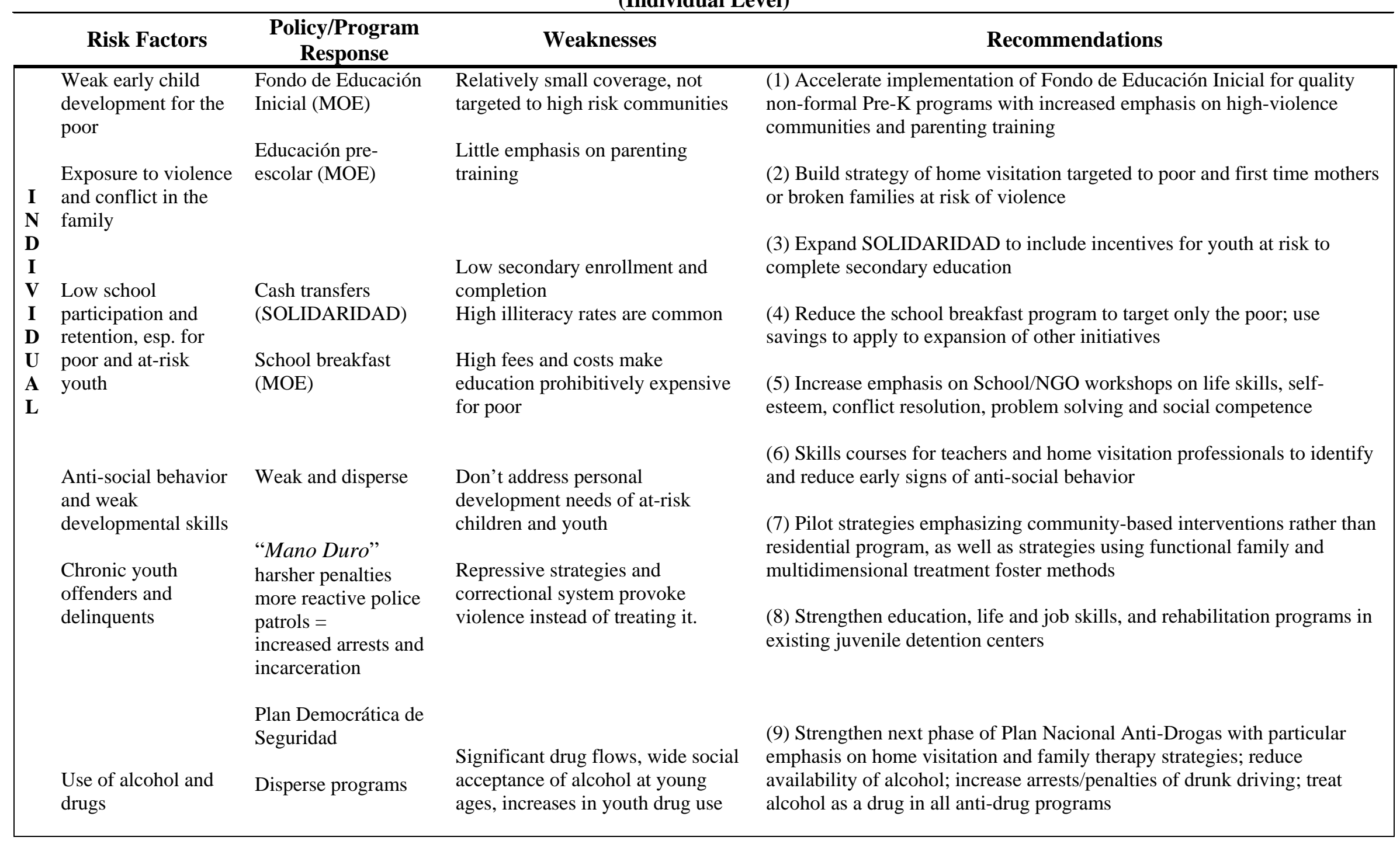




\section{Annex 5.2}

\section{INVENTORY OF GOVERNMENTAL INITIATIVES FOR YOUTH VIOLENCE PREVENTION IN THE DOMINICAN REPUBLIC.}

\section{Initiatives Implemented by Governmental Organisms}

\begin{tabular}{|c|c|c|c|c|c|c|}
\hline INSTITUTION & \multicolumn{3}{|c|}{ INITIATIVE TO PREVENT AND REDUCE YOUTH VIOLENCE } & \multicolumn{2}{|c|}{$\begin{array}{c}\text { TARGET } \\
\text { POPULATION }\end{array}$} & BENEFICIARIES \\
\hline \multirow[t]{2}{*}{$\begin{array}{l}\text { 1. Consejo Nacional de la } \\
\text { Niñez (CONANI). } \\
\text { (National Counsel of } \\
\text { Children) }\end{array}$} & $\begin{array}{l}\text { 1. Vacúnate Contra el Abuso. } \\
\text { (Vaccine Yourself } \\
\text { Against Abuse) }\end{array}$ & $\begin{array}{l}\text { - Control the abuse and mistreatment } \\
\text { of children and youth } \\
\text { - Promote conducts for the healthy } \\
\text { development of children and youth } \\
\text { - Increase youth self teem }\end{array}$ & $\begin{array}{l}\text {-Awareness and } \\
\text { orientation campaigns }\end{array}$ & $10-29$ & Nacional & 50,000 NNA \\
\hline & $\begin{array}{l}\text { 2. Proyecto de Vida. } \\
\text { (Life Project) }\end{array}$ & $\begin{array}{l}\text { Increase youth self -esteem and life } \\
\text { skills }\end{array}$ & -Cooperative learning & $10-29$ & $\begin{array}{l}\text { Provinci } \\
\text { al }\end{array}$ & 1,500 \\
\hline \multirow[t]{2}{*}{$\begin{array}{l}\text { 2. Consejo Nacional de } \\
\text { Drogas. } \\
\text { (Drugs National } \\
\text { Counsel) }\end{array}$} & $\begin{array}{l}\text { 3. Fortalecimiento Grupal e } \\
\text { Individual. (Individual } \\
\text { and Group Capacity } \\
\text { Building) }\end{array}$ & $\begin{array}{l}\text { Preventive measures within } \\
\text { communitarian organizations, with an } \\
\text { emphasis on capacity building of } \\
\text { community leaders. }\end{array}$ & $\begin{array}{l}\text {-Communitarian capacity } \\
\text {-Home visits }\end{array}$ & $10-29$ & $\begin{array}{l}\text { Provinci } \\
\text { al }\end{array}$ & 500 \\
\hline & $\begin{array}{l}\text { 4. Plan Nacional Antidrogas } \\
\text { (2000-2005) }\end{array}$ & $\begin{array}{l}\text { Overall strategy for prevention of } \\
\text { narcotrafficking, drug use and abuse, } \\
\text { including treatment, rehabilitation and } \\
\text { social insertion programs }\end{array}$ & $\begin{array}{l}\text { - Narcotrafficking control } \\
\text { and inspection (and } \\
\text { statistics) } \\
\text { - Moneylaundering control } \\
\text { - Justice administration } \\
\text { - Prevention training } \\
\text {-Treatment, rehabilitation } \\
\text { and labor market } \\
\text { reinsertion }\end{array}$ & All ages & National & $\mathrm{n} / \mathrm{a}$ \\
\hline
\end{tabular}




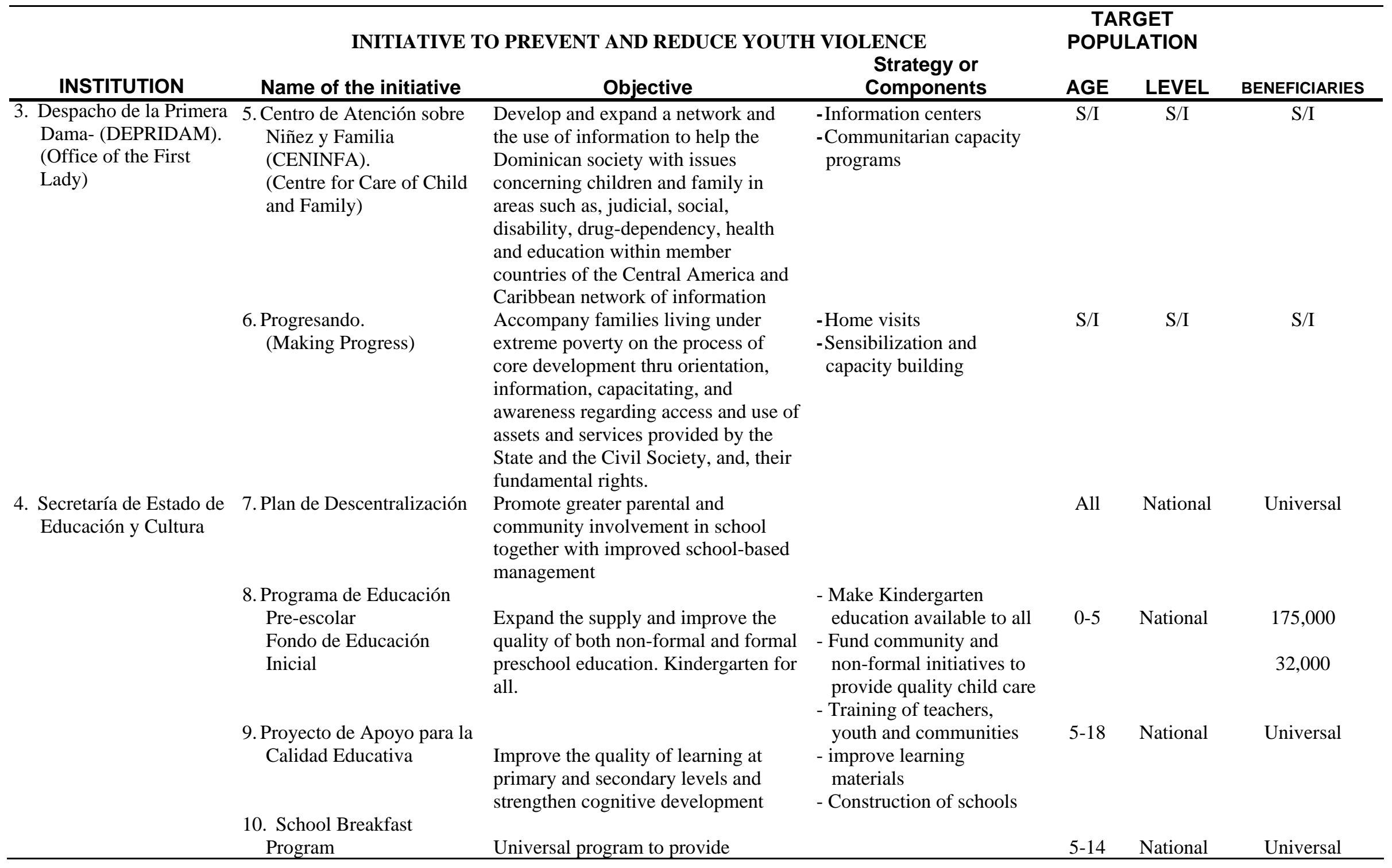




\begin{tabular}{|c|c|c|c|c|c|c|}
\hline \multirow[b]{2}{*}{ INSTITUTION } & \multicolumn{3}{|c|}{ INITIATIVE TO PREVENT AND REDUCE YOUTH VIOLENCE } & \multicolumn{2}{|c|}{$\begin{array}{c}\text { TARGET } \\
\text { POPULATION }\end{array}$} & \multirow[b]{2}{*}{ BENEFICIARIES } \\
\hline & Name of the initiative & Objective & $\begin{array}{c}\text { Strategy or } \\
\text { Components }\end{array}$ & AGE & LEVEL & \\
\hline \multirow{7}{*}{$\begin{array}{l}\text { 5. Secretaría de la } \\
\text { Presidencia }\end{array}$} & & breakfast to all children up to grade 8 & & & & \\
\hline & $\begin{array}{l}\text { 11. Prevención y Riesgo de } \\
\text { uso de droga }\end{array}$ & $\begin{array}{l}\text { Raise awareness among students of } \\
\text { the importance of keeping healthy and } \\
\text { how to avoid risky behavior and } \\
\text { substances }\end{array}$ & $\begin{array}{l}\text { - Individual counseling } \\
\text { - Parent counseling } \\
\text { - Conflict mediation } \\
\text { - Development of } \\
\text { education programs on } \\
\text { risk behaviors }\end{array}$ & $6-18$ & Regional & 100,000 \\
\hline & $\begin{array}{l}\text { 12. Proyecto Multigrado } \\
\text { Innovado. }\end{array}$ & $\begin{array}{l}\text { Increase coverage of primary } \\
\text { education in rural areas. }\end{array}$ & & $5-14$ & Rural & 100,000 \\
\hline & $\begin{array}{l}\text { 13. Prevención de riesgo } \\
\text { psicosociales }\end{array}$ & $\begin{array}{l}\text { Reduce violence and target education } \\
\text { support to children at risk }\end{array}$ & $\begin{array}{l}\text { - System of psychosocial } \\
\text { risk prevention at } \\
\text { individual level } \\
\text { - Teacher, student, parent } \\
\text { training }\end{array}$ & $5-18$ & National & Universal \\
\hline & $\begin{array}{l}\text { 14. SOLIDARIDAD: } \\
\text { Incentivo a la Asistencia } \\
\text { Escolar }\end{array}$ & $\begin{array}{l}\text { Conditional Cash Tranfers to poor } \\
\text { families to keep their children in } \\
\text { school }\end{array}$ & & $6-16$ & National & 214,000 \\
\hline & $\begin{array}{l}\text { 15. SOLIDARIDAD: } \\
\text { Dominicanos con Nombre } \\
\text { y Apellido }\end{array}$ & $\begin{array}{l}\text { Promote and accompany individuals } \\
\text { in obtaining their birth certificates and } \\
\text { identity cards, enabling them and their } \\
\text { children to benefit from public } \\
\text { services (education, health, etc) }\end{array}$ & & All & National & 142,000 \\
\hline & $\begin{array}{l}\text { 16. SOLIDARIDAD: Comer } \\
\text { es Primero }\end{array}$ & $\begin{array}{l}\text { Conditional Cash Transfers to poor } \\
\text { families to cover basic food costs, } \\
\text { using debit cards in established food } \\
\text { vendors }\end{array}$ & & All & National & 770,000 \\
\hline
\end{tabular}




\begin{tabular}{|c|c|c|c|c|c|c|}
\hline \multirow[b]{2}{*}{ INSTITUTION } & \multicolumn{3}{|c|}{ INITIATIVE TO PREVENT AND REDUCE YOUTH VIOLENCE } & \multicolumn{2}{|c|}{$\begin{array}{c}\text { TARGET } \\
\text { POPULATION }\end{array}$} & \multirow[b]{2}{*}{ BENEFICIARIES } \\
\hline & Name of the initiative & Objective & $\begin{array}{l}\text { Strategy or } \\
\text { Components }\end{array}$ & AGE & LEVEL & \\
\hline $\begin{array}{l}\text { 6. Secretaría de Estado de } \\
\text { Deportes, Educación } \\
\text { Física y Recreación } \\
\text { (SEDEFIR). } \\
\text { (Ministry of Sports, } \\
\text { Physical Education and } \\
\text { Recreation) }\end{array}$ & $\begin{array}{l}\text { 17. Programa para atletas de } \\
\text { alto rendimientos } \\
\text { (PARHI). } \\
\text { (Program for high endurance } \\
\text { athletes) }\end{array}$ & $\begin{array}{l}\text { Promote development of national } \\
\text { athletes from all sectors of society. }\end{array}$ & $\begin{array}{l}\text { - Nutrition Program } \\
\text {-Programs for the core } \\
\text { capacity of athletes. } \\
\text {-Promoting participation }\end{array}$ & $15-29$ & Nacional & 800 \\
\hline \multirow[t]{2}{*}{$\begin{array}{l}\text { 7. Secretaría de Estado de } \\
\text { Interior y Policía } \\
\text { (SEIP). } \\
\text { Ministry of the Interior } \\
\text { and Police }\end{array}$} & $\begin{array}{l}\text { 18. Plan de Seguridad } \\
\text { Democrática. } \\
\text { Democratic Security Plan }\end{array}$ & $\begin{array}{l}\text { Reform of the national police and } \\
\text { guarantee the citizen's basic rights } \\
\text { thru coordinated actions between } \\
\text { education, public works and health, } \\
\text { neighborhood's organizations and } \\
\text { Dominican civil society. }\end{array}$ & $\begin{array}{l}\text {-Safe Neighborhood } \\
\text { (Barrios Seguros) - } \\
\text { Communitarian police } \\
\text { - Program for the } \\
\text { reinforcements of } \\
\text { National Police force }\end{array}$ & $\mathrm{S} / \mathrm{I}$ & S/I & S/I \\
\hline & $\begin{array}{l}\text { 19. Voluntariado de Garantía } \\
\text { de los Derechos de los } \\
\text { Ciudadanos. } \\
\text { Volunteering for the } \\
\text { Guaranty of the Citizens } \\
\text { Rights. }\end{array}$ & $\begin{array}{l}\text { Investigate and prosecute delictive } \\
\text { crimes that have been committed } \\
\text { presumably by youth. } \\
\text { Serve as a channel of communication } \\
\text { with Departments such as riots, } \\
\text { police, special, and dignitary } \\
\text { protection. }\end{array}$ & $\begin{array}{l}\text { - Police program } \\
\text { specialized in Children } \\
\text { and Youth. } \\
\text { - National Program of } \\
\text { Preventive police }\end{array}$ & $\mathrm{S} / \mathrm{I}$ & $\mathrm{S} / \mathrm{I}$ & S/I \\
\hline $\begin{array}{l}\text { 8. Secretaría de Estado de } \\
\text { la Juventud (SEJ). } \\
\text { Ministry of Youth }\end{array}$ & $\begin{array}{l}\text { 20. Programa Nacional e } \\
\text { Internacional de Becas. } \\
\text { National and International } \\
\text { Scholarship Program. }\end{array}$ & $\begin{array}{l}\text { Provide youth with the tools necessary } \\
\text { for their development in the computer } \\
\text { and information field. }\end{array}$ & $\begin{array}{l}\text {-Youth formation. } \\
\text {-Incentive for } \\
\text { participation. }\end{array}$ & $\mathrm{S} / \mathrm{I}$ & $\mathrm{S} / \mathrm{I}$ & $\mathrm{S} / \mathrm{I}$ \\
\hline $\begin{array}{l}\text { 8.Secretaría de Estado de } \\
\text { la Juventud (SEJ). } \\
\text { Ministry of Youth } \\
\text { (continuation) }\end{array}$ & $\begin{array}{l}\text { 21. Program for the reduction } \\
\text { of the Digital Gap. } \\
\text { Programa de Reducción de la } \\
\text { Brecha Digital. }\end{array}$ & $\begin{array}{l}\text { Promote the core development of } \\
\text { youth, peace of mind of the citizens, } \\
\text { education, sports and access to } \\
\text { information. }\end{array}$ & $\begin{array}{l}\text { - Promoting incentives for } \\
\text { youth } \\
\text {-Providing computers and } \\
\text { equipments. }\end{array}$ & $\mathrm{S} / \mathrm{I}$ & $\mathrm{S} / \mathrm{I}$ & $\mathrm{S} / \mathrm{I}$ \\
\hline
\end{tabular}




\begin{tabular}{|c|c|c|c|c|c|c|}
\hline \multirow{3}{*}{ INSTITUTION } & \multicolumn{3}{|c|}{ INITIATIVE TO PREVENT AND REDUCE YOUTH VIOLENCE } & \multirow{2}{*}{\multicolumn{2}{|c|}{$\begin{array}{c}\text { TARGET } \\
\text { POPULATION }\end{array}$}} & \multirow[b]{2}{*}{ BENEFICIARIES } \\
\hline & Name of the initiative & Objective & $\begin{array}{c}\text { Strategy or } \\
\text { Components }\end{array}$ & & LEVEL & \\
\hline & $\begin{array}{l}\text { 22. Mi Barrio Joven. } \\
\text { My Young Neighborhood }\end{array}$ & $\begin{array}{l}\text { Assists with the core development of } \\
\text { youth and support the Democratic } \\
\text { Safety Program being executed by the } \\
\text { Central Government in diverse sectors } \\
\text { of the country for the prevention and } \\
\text { prosecution of criminality and } \\
\text { delinquency. }\end{array}$ & $\begin{array}{l}\text {-Improvements to the } \\
\text { community and } \\
\text { restoration of youth } \\
\text { spaces. }\end{array}$ & $\mathrm{S} / \mathrm{I}$ & $\mathrm{S} / \mathrm{I}$ & $\mathrm{S} / \mathrm{I}$ \\
\hline \multirow[t]{2}{*}{$\begin{array}{l}\text { 9. Secretaría de Estado de } \\
\text { la Mujer (SEM). } \\
\text { Ministry of Women }\end{array}$} & $\begin{array}{l}\text { 23. Programa de Género. } \\
\text { Gender Program }\end{array}$ & $\begin{array}{l}\text { Promote gender equality among men } \\
\text { and women within their communities }\end{array}$ & $\begin{array}{l}\text { - Social education and } \\
\text { sensibilization } \\
\text {-Encouragement of } \\
\text { alliances } \\
\text {-Home visits }\end{array}$ & $\mathrm{S} / \mathrm{I}$ & S/I & $\mathrm{S} / \mathrm{I}$ \\
\hline & $\begin{array}{l}\text { 24. Programa contra la } \\
\text { violencia intrafamiliar. } \\
\text { Program against intra-family } \\
\text { violence }\end{array}$ & $\begin{array}{l}\text { Promote and support women's rights } \\
\text { while oriented to the elimination of } \\
\text { violence and the protection of victims. }\end{array}$ & $\begin{array}{l}\text {-Support to victims of } \\
\text { intra-family violence. }\end{array}$ & & & \\
\hline $\begin{array}{l}\text { 10. Secretaria de Estado de } \\
\text { Trabajo (SET). } \\
\text { Ministry of Labor }\end{array}$ & $\begin{array}{l}\text { 25. Programa Juventud y } \\
\text { Empleo. } \\
\text { Youth and Employment } \\
\text { Program }\end{array}$ & $\begin{array}{l}\text { Improve the employability of low } \\
\text { income youth population with no } \\
\text { secondary education, that have } \\
\text { deserted from the formal education } \\
\text { system. }\end{array}$ & $\begin{array}{l}\text {-Institutional strengthening } \\
\text {-Capacity building, } \\
\text { formation and labor and } \\
\text { humanitarian orientation } \\
\text { for youth. }\end{array}$ & $15-29$ & Nacional & $\begin{array}{l}\text { Masculino 12,387 } \\
\text { Femenino } 11,435\end{array}$ \\
\hline
\end{tabular}




\section{Annex 5.3}

\section{INVENTORY OF CIVIL SOCIETY INITIATIVES FOR YOUTH VIOLENCE PREVENTION IN THE DOMINICAN}

REPUBLIC.

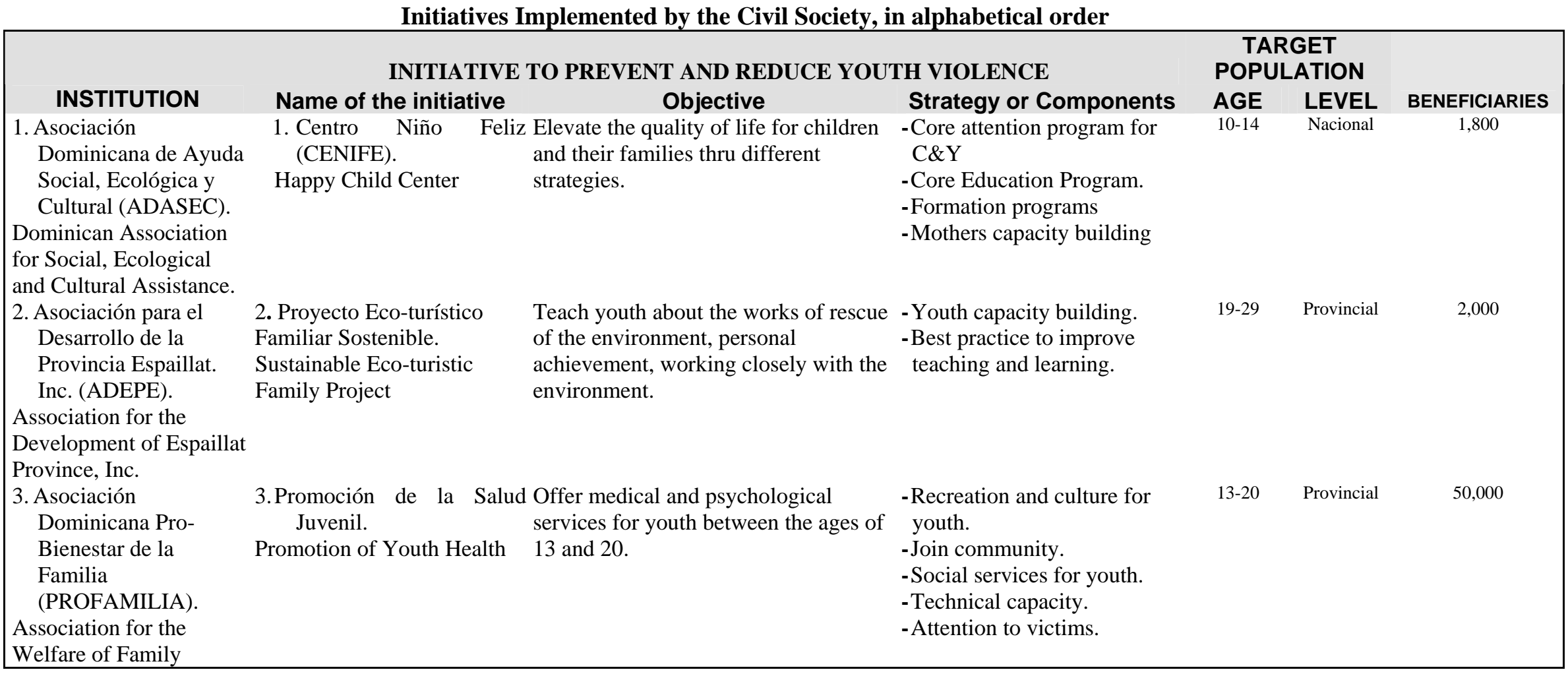




\begin{tabular}{|c|c|c|c|c|c|c|}
\hline \multirow[b]{2}{*}{ INSTITUTION } & \multicolumn{3}{|c|}{ INITIATIVE TO PREVENT AND REDUCE YOUTH VIOLENCE } & \multicolumn{2}{|c|}{$\begin{array}{c}\text { TARGET } \\
\text { POPULATION }\end{array}$} & \multirow[b]{2}{*}{ BENEFICIARIES } \\
\hline & Name of the initiative & Objective & Strategy or Components & AGE & LEVEL & \\
\hline \multirow[t]{3}{*}{$\begin{array}{l}\text { 4. Casa Abierta. } \\
\text { Open House }\end{array}$} & $\begin{array}{l}\text { 4. Prevención y atención } \\
\text { de riesgos psico-sociales } \\
\text { y sanitarios en Niños } \\
\text { Niñas y Adolescentes de } \\
\text { comunidades urbanos } \\
\text { marginales de la } \\
\text { República Dominicana. } \\
\text { Prevention and attention to } \\
\text { psico-social and sanitarian } \\
\text { hazards for children and } \\
\text { youth in urban marginal } \\
\text { areas in the Dominican } \\
\text { Republic. }\end{array}$ & $\begin{array}{l}\text { Develop acts of prevention to psycho- } \\
\text { social risks affecting infants and youth } \\
\text { living in low income communities in } \\
\text { the Dominican Republic }\end{array}$ & $\begin{array}{l}\text {-Community companionship } \\
\text {-Support of social conscience. } \\
\text {-Programas de formación. }\end{array}$ & $\mathrm{S} / \mathrm{I}$ & Provincial & $\mathrm{S} / \mathrm{I}$ \\
\hline & $\begin{array}{l}\text { 5. Prevención integral de } \\
\text { comunidades marginales } \\
\text { de la provincia de } \\
\text { Santiago de los } \\
\text { Caballeros. } \\
\text { Core prevention of } \\
\text { marginal communities } \\
\text { from the Santiago de los } \\
\text { Caballeros Province. }\end{array}$ & $\begin{array}{l}\text { Improve the quality of living for } \\
\text { vulnerable and marginal population } \\
\text { of the province. }\end{array}$ & & $\mathrm{S} / \mathrm{I}$ & Provincial & $\mathrm{S} / \mathrm{I}$ \\
\hline & $\begin{array}{l}\text { 6. Intervención sistémica } \\
\text { para Niños, Niñas y } \\
\text { Adolescentes de República } \\
\text { Dominicana. } \\
\text { Systemic intervention for } \\
\text { boys, girls and youth in the } \\
\text { Dominican Republic. }\end{array}$ & $\begin{array}{l}\text { Contribute to the human and social } \\
\text { development of C\&Y at risk and } \\
\text { substance consumers thru the } \\
\text { strengthening of intervention } \\
\text { strategies. }\end{array}$ & $\begin{array}{l}\text {-Development and } \\
\text { communitarian participation }\end{array}$ & $\mathrm{S} / \mathrm{I}$ & Provincial & $\mathrm{S} / \mathrm{I}$ \\
\hline
\end{tabular}




\begin{tabular}{|c|c|c|c|c|c|c|}
\hline \multirow[b]{2}{*}{ INSTITUTION } & \multicolumn{3}{|c|}{ INITIATIVE TO PREVENT AND REDUCE YOUTH VIOLENCE } & \multicolumn{2}{|c|}{$\begin{array}{c}\text { TARGET } \\
\text { POPULATION }\end{array}$} & \multirow[b]{2}{*}{ BENEFICIARIES } \\
\hline & Name of the initiative & Objective & Strategy or Components & AGE & LEVEL & \\
\hline $\begin{array}{l}\text { 5. Centro Cultural } \\
\text { Póveda } \\
\text { Poveda Cultural Center. }\end{array}$ & $\begin{array}{l}\text { 7. Conversatorios } \\
\text { periódicos y análisis de la } \\
\text { realidad de la violencia } \\
\text { juvenil. } \\
\text { Periodic forums and analysis } \\
\text { of the reality of youth } \\
\text { violence. }\end{array}$ & $\begin{array}{l}\text { Contribute in an active manner to the } \\
\text { formulation and evaluation of social } \\
\text { policies to overcome violence. }\end{array}$ & $\begin{array}{l}\text {-Individual therapy. } \\
\text {-Encouragement of } \\
\text { participation. }\end{array}$ & $15-18$ & Provincial & 800 \\
\hline & $\begin{array}{l}\text { 8. Foros juveniles } \\
\text { Interbarriales para la } \\
\text { prevención de la } \\
\text { violencia. } \\
\text { Youth inter-neighborhood } \\
\text { forums for violence } \\
\text { prevention. }\end{array}$ & $\begin{array}{l}\text { Support spaces of reflection and } \\
\text { participatory creation of alternatives } \\
\text { to the violence phenomenon. }\end{array}$ & $\begin{array}{l}\text {-Support groups for domestic } \\
\text { violence. }\end{array}$ & $19-24$ & Provincial & 800 \\
\hline & $\begin{array}{l}\text { 9. Estudio sobre la } \\
\text { violencia en barrios } \\
\text { empobrecidos de la ciudad } \\
\text { de Santo Domingo. } \\
\text { Study on violence in poor } \\
\text { neighborhoods of the city of } \\
\text { Santo Domingo }\end{array}$ & $\begin{array}{l}\text { Investigate main causes of domestic } \\
\text { violence in poor neighborhoods of } \\
\text { Santo Domingo. }\end{array}$ & $\begin{array}{l}\text {-Social Fluctuation } \\
\text {-Promoción de valores. }\end{array}$ & $15-29$ & Provincial & 800 \\
\hline $\begin{array}{l}\text { 6. Centro de Apoyo } \\
\text { Aquelarre (CEAPA). } \\
\text { Aquelarre Support } \\
\text { Center }\end{array}$ & $\begin{array}{l}\text { 10. Prevención y atención a } \\
\text { la violencia sexual y } \\
\text { doméstica. } \\
\text { Prevention and attention to } \\
\text { domestic and sexual violence }\end{array}$ & $\begin{array}{l}\text { Prevent and offer psychological and } \\
\text { emotional attention for program } \\
\text { participants. }\end{array}$ & $\begin{array}{l}\text {-Senzibilization and capacity } \\
\text { building } \\
\text { - Individual and group therapy }\end{array}$ & $10-29$ & Provincial & 100 \\
\hline $\begin{array}{l}\text { 7. Colectiva Mujer y } \\
\text { Salud. }\end{array}$ & $\begin{array}{l}\text { 11. Derechos Humanos de } \\
\text { las mujeres, en particular } \\
\text { los Derechos Sexuales y } \\
\text { los Derechos } \\
\text { Reproductivos. } \\
\text { Women Human Rights, }\end{array}$ & $\begin{array}{l}\text { Develop actions together with youth } \\
\text { regarding youth violence and its } \\
\text { implications }\end{array}$ & $\begin{array}{l}\text { - Support health services } \\
\text {-Social Fluctuation }\end{array}$ & $10-29$ & Provincial & $\mathrm{S} / \mathrm{I}$ \\
\hline
\end{tabular}




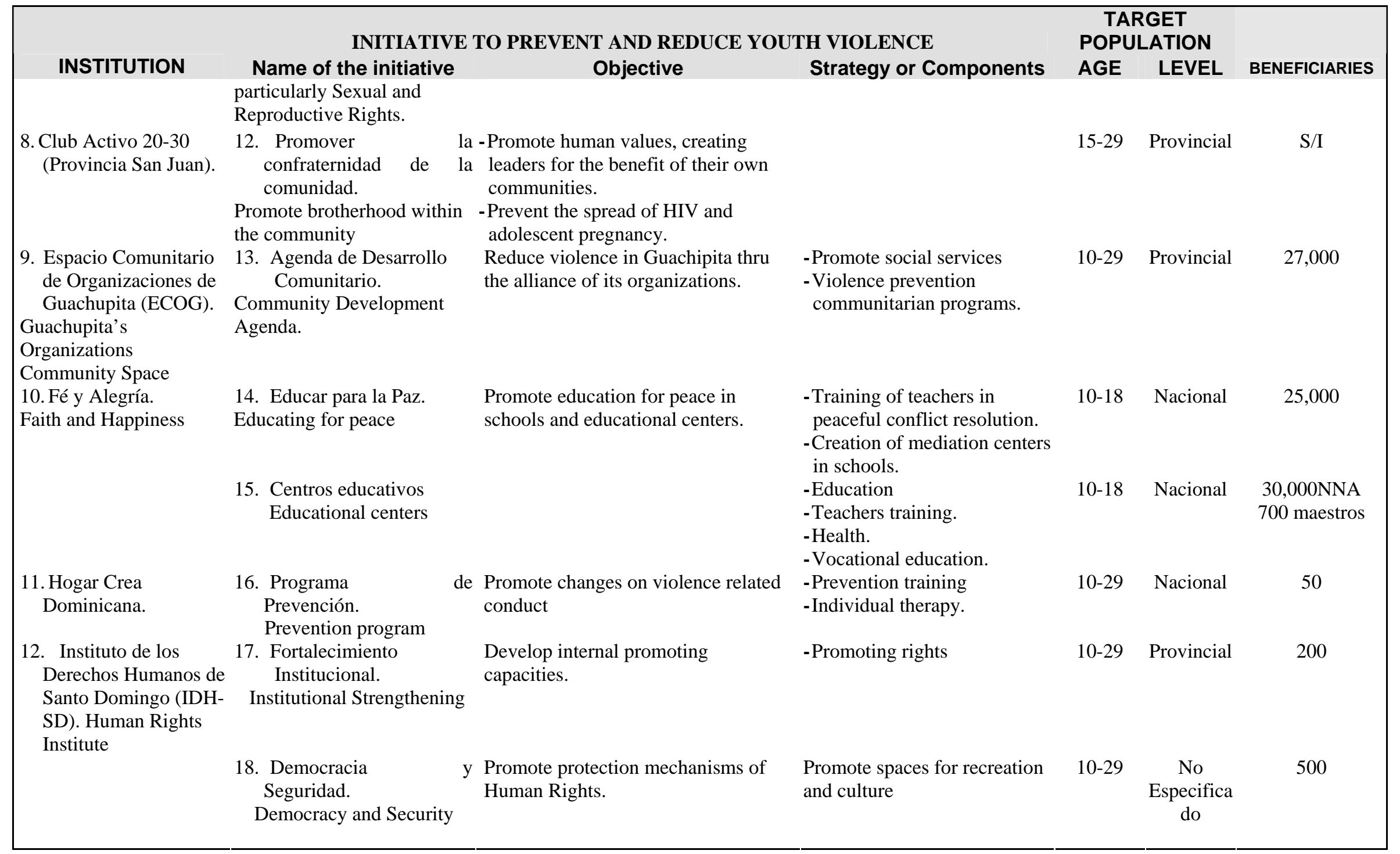




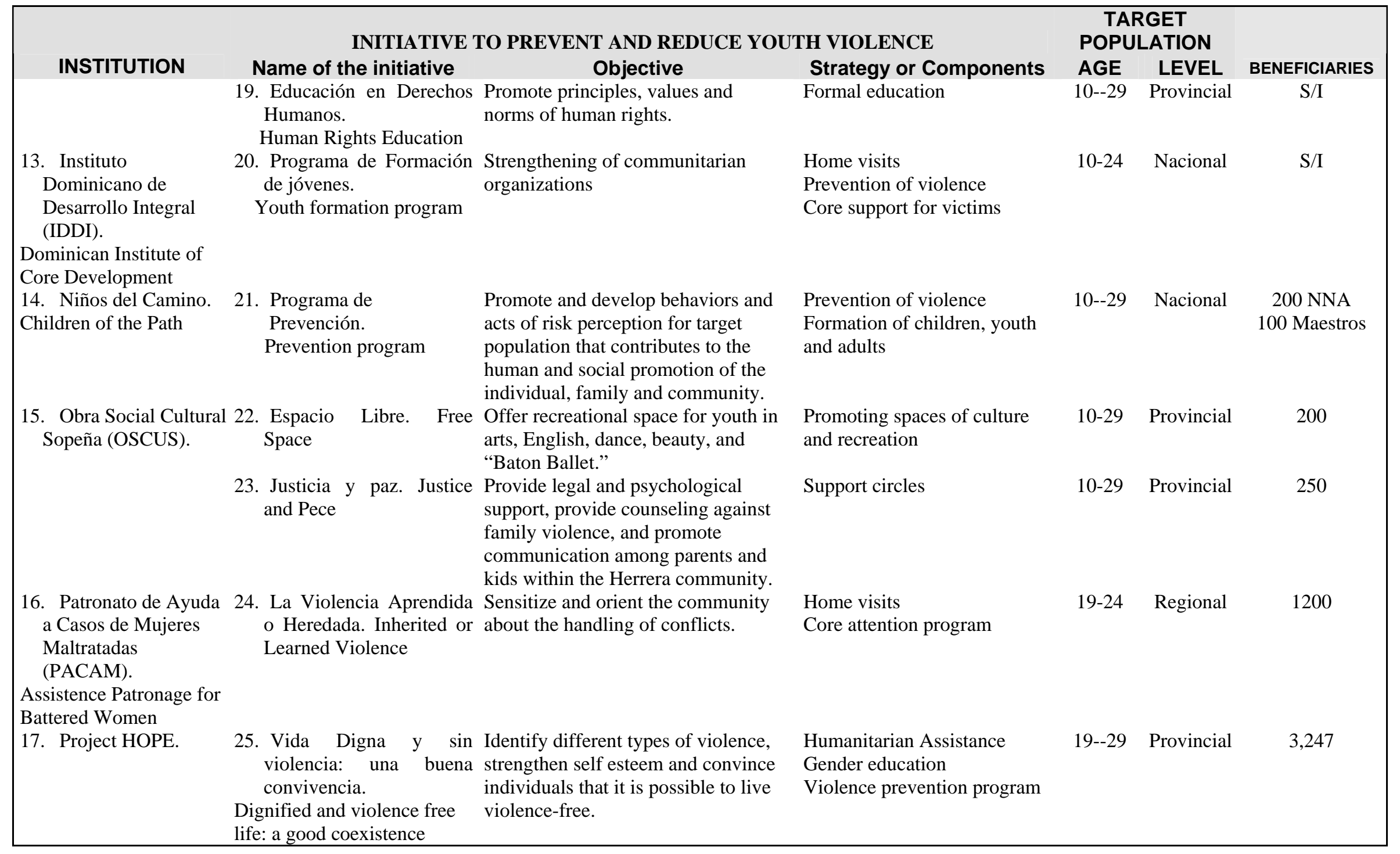




\begin{tabular}{|c|c|c|c|c|c|}
\hline \multirow[b]{2}{*}{ INSTITUTION } & \multicolumn{2}{|c|}{ INITIATIVE TO PREVENT AND REDUCE YOUTH VIOLENCE } & \multicolumn{2}{|c|}{$\begin{array}{c}\text { TARGET } \\
\text { POPULATION }\end{array}$} & \multirow[b]{2}{*}{ BENEFICIARIES } \\
\hline & Name of the initiative $\quad$ Objective & Strategy or Components & AGE & LEVEL & \\
\hline $\begin{array}{l}\text { 18. Red de Muchachos } \\
\text { y Muchachas con Don } \\
\text { Bosco. Network of } \\
\text { boys and girls with } \\
\text { Don Bosco }\end{array}$ & $\begin{array}{l}\text { 26. Proyecto Aprendices Training and educating children in the } \\
\begin{array}{ll}\text { con Don Bosco. } & \text { Salesiano preventive system. Love, } \\
\text { Apprentices with Don Bosco } & \text { race and faith and as participants of } \\
\text { Project } & \text { their own development. }\end{array}\end{array}$ & $\begin{array}{l}\text { Vocational training } \\
\text { Home visits } \\
\text { Promoting sports and culture } \\
\text { Formation programs }\end{array}$ & $7-15$ & Provincial & 180 \\
\hline $\begin{array}{l}\text { 19. Unión de Juntas de } \\
\text { Vecinos del Municipio } \\
\text { de Moca, Inc. }\end{array}$ & $\begin{array}{ll}\begin{array}{l}\text { 27. Apoyo, Ayuda } \\
\text { Defensa a la Juventud. }\end{array} & \begin{array}{l}\text { Face in a serious, responsible and } \\
\text { energetic manner, the number one } \\
\text { enemy of humanity and prime cause }\end{array} \\
\text { Support, Assistance and } & \begin{array}{l}\text { ef youth violence: "Drug-traffic." } \\
\text { Defense of Youth }\end{array}\end{array}$ & Family counseling & $\mathrm{S} / \mathrm{I}$ & Provincial & 1000 \\
\hline
\end{tabular}


Annex 6.1. Criminal deportations to Jamaica by year, offense, and sending country

\begin{tabular}{|l|l|l|l|}
\hline \multicolumn{1}{|l|}{2001} & & \\
\hline & USA & Canada & U.K. \\
\hline Drugs & 773 & 50 & 159 \\
\hline Firearms and violent crime 238 & 36 & 24 \\
\hline Robbery, burglary, larceny 100 & 17 & 3 \\
\hline Fraud and immigration & 245 & 85 & 446 \\
\hline Other & 54 & 15 & 133 \\
\hline
\end{tabular}

\begin{tabular}{|l|l|l|l|}
\hline & 2002 & & \\
\hline & USA & Canada & U.K. \\
\hline Drugs & 911 & 42 & 294 \\
\hline Firearms and violent crime 294 & 15 & 26 \\
\hline Robbery, burglary, larceny92 & 10 & 12 \\
\hline Fraud and immigration & 238 & 73 & 1092 \\
\hline Other & 32 & 1 & 37 \\
\hline
\end{tabular}

\begin{tabular}{|l|l|l|l|}
\hline & 2003 & & \\
\hline & USA & Canada & U.K. \\
\hline Drugs & 923 & 38 & 629 \\
\hline Firearms and violent crime 267 & 28 & 40 \\
\hline Robbery, burglary, larceny 100 & 11 & 10 \\
\hline Fraud and immigration & 323 & 86 & 1257 \\
\hline Other & 58 & 4 & 46 \\
\hline
\end{tabular}

\begin{tabular}{|l|l|l|l|}
\hline & 2004 & & \\
\hline & USA & Canada & U.K. \\
\hline Drugs & 984 & 39 & 864 \\
\hline Firearms and violent crime 334 & 27 & 37 \\
\hline Robbery, burglary, larceny 120 & 9 & 11 \\
\hline Fraud and immigration & 366 & 120 & 1054 \\
\hline Other & 58 & 4 & 46 \\
\hline
\end{tabular}

